\title{
Global value chains and world trade
}

Prospects and challenges for Latin America

RENÉ A. HERNÁNDEZ JORGE MARIO MARTÍNEZ-PIVA NANNO MULDER Editors

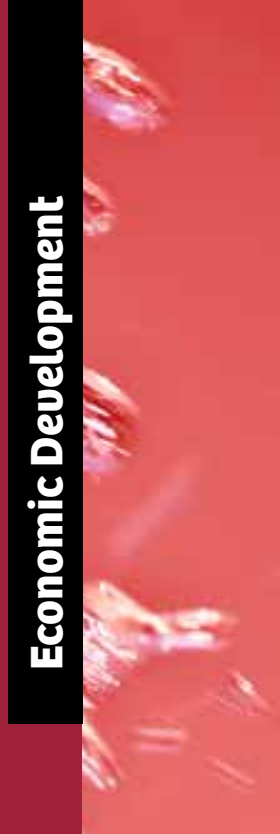




\section{Global value chains and world trade \\ Prospects and challenges for Latin America}

René A. Hernández

Jorge Mario Martínez-Piva

Nanno Mulder

Editors
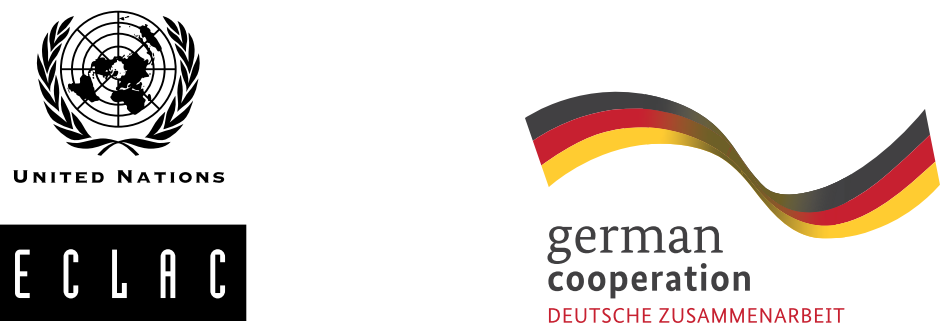

Economic Commission for Latin America and the Caribbean (ECLAC) Santiago, Chile, August 2014 
ECLAC Books

127

Alicia Bárcena

Executive Secretary

Antonio Prado

Deputy Executive Secretary

Osvaldo Rosales

Chief, International Trade and Integration Division

Ricardo Pérez

Chief, Publications and Web Services Division

This book was edited by René A. Hernández, Jorge Mario Martínez-Piva and Nanno Mulder of the Economic Commission for Latin America and the Caribbean (ECLAC). It contains a selection of original papers presented at the international conference "Latin America's Prospects for Upgrading in Global Value Chains", held on 14-15 March 2012 at Colegio de Mexico, Mexico City. The conference was jointly organized by four international organizations -ECLAC, the Inter-American Development Bank (IDB), the Organization for Economic Cooperation and Development (OECD) and the World Bank) in partnership with Colegio de México.

This book was made possible thanks to financial assistance kindly provided by the Federal Ministry for Economic Cooperation and Development (BMZ) of Germany. The views expressed in this book are those of the authors and do not necessarily coincide with those of the United Nations, its Member States or the sponsoring institutions.

The boundaries and names shown on the maps included in this publication do not imply official endorsement or acceptance by the United Nations.

\section{Cover design: Ximena Ulibarri}

United Nations publication

ISBN 978-92-1-221124-4

eISBN 978-92-1-056932-3

LC/G.2617-P

Sales No. E.14.II.G.17

Copyright (C) United Nations, 2014

All rights reserved

Printed at United Nations, Santiago, Chile

This publication should be cited as: René A. Hernández, Jorge Mario Martínez and Nanno Mulder, "Global value chains and world trade: Prospects and challenges for Latin America", ECLAC Books, No. 127 (LC/G.2617-P), Santiago, Chile, Economic Commission for Latin America and the Caribbean (ECLAC), 2014.

Applications for the right to reproduce this work are welcomed and should be sent to the Secretary of the Publications Board, United Nations Headquarters, New York, N.Y. 10017, United States. Member States and the governmental institutions may reproduce this work without prior authorization, but are requested to mention the source and inform the United Nations of such reproduction. 


\section{Contents}

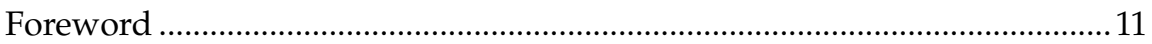

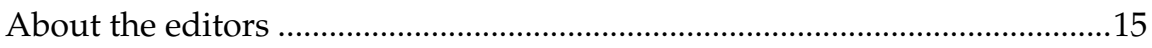

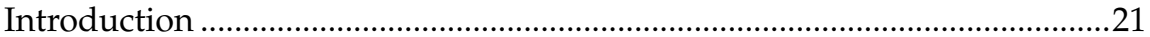

Chapter I

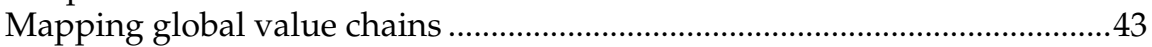

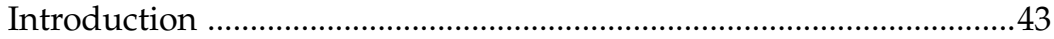

A. The rise of global value chains ………….....................................45

1. A brief history of global value chains .........................................45

2. The main drivers of the phenomenon.......................................46

3. How far will the fragmentation of production go?..................47

4. Industries, business functions or tasks? ....................................48

B. Data and methodology .................................................................48

1. New data available to study GVCs: the OECD

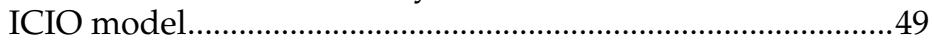

2. Measuring the importance of GVCs: country and industry indicators....................................................................50

3. The distance to final demand: what is the position of a country in the value chain? ..............................................54

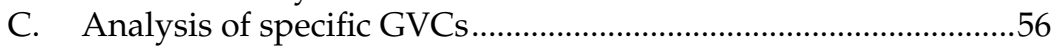

1. Case study 1: agriculture and food products..........................56

2. Case study 2: motor vehicles .....................................................61

3. Case study 3: electronics (office, accounting and computing machinery) ...............................................................64

4. Case study 4: business services ................................................67 
D. Concluding remarks: closing the gap between policies and the reality of business

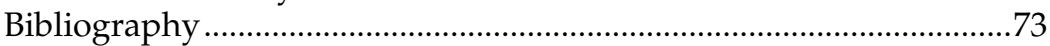

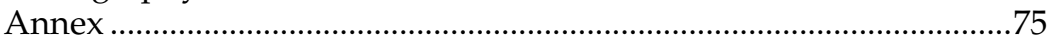

Chapter II

Global value chains in Latin America: A development perspective

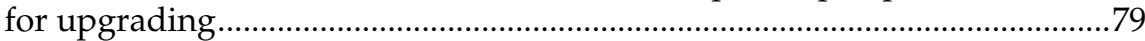

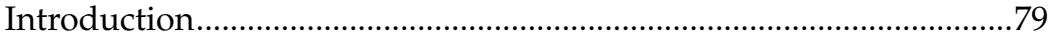

A. The global value chains framework: a tool for driving economic development

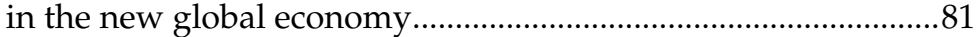

1. What is value chain analysis?...................................................81

2. What is the role of value chain analysis in economic development?

B. Latin America's participation and opportunities in global value chains

1. How Latin American countries participate in GVCs..............85

2. How Latin American countries can leverage local endowments to upgrade in global value chains.

C. Skills for upgrading in global value chains: workforce development and national innovation systems

1. Finishing schools in India and Latin America ........................96

2. The Chilean Public-Private Strategic Council for the Offshore Services Sector

3. The aerospace industry in Querétaro, Mexico ..........................98

4. Costa Rica's offshore services talent-development pipeline.

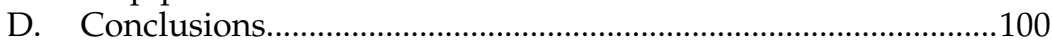

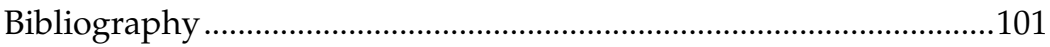

Chapter III

Access to finance in value chains: New evidence from

Latin America

Introduction

A. How can inter-firm linkages in value chains facilitate access to financing?

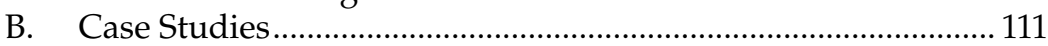

1. The agrifood industry in Argentina ...................................... 111

2. The furniture value chains in the Serra Gaucha cluster, Brazil.

3. The information and communication technology (ICT) sector in Costa Rica

C. Summary of empirical findings ....................................................128

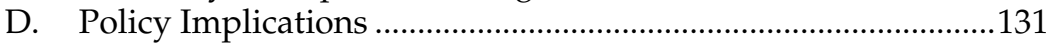

Bibliography. 


\section{Chapter IV}

Inclusive value chain interventions in the high-value agrifood sector in Latin America

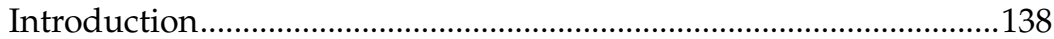

A. Inclusion of small and medium-sized producers in high-value agriculture chains.....

1. Changing governance patterns in high-value agrifood industries: challenges and opportunities for small producers.

B. Model for sustainable inclusion of small and mediumsized producers in the value chain: a holistic approach.

1. Competitiveness.

2. The four pillars model

3. Sustainability of small producer inclusion in the value chain

C. Selected IDB Multilateral Investment Fund projects: best practices and lessons learned.

1. Case 1. Supporting the competitiveness of Central American coffee producers (Costa Rica, El Salvador, Guatemala, Honduras and Nicaragua).

2. Case 2. Strengthening the competitiveness of the stevia value chain (Paraguay)

3. Case 3. Conversion to organic cacao cultivation (Peru) 154

4. Case 4. Strengthening the competitiveness of organic fruit and vegetable producers in the Peruvian Andes

5. Case 5. Improving the competitiveness of micro and small rural apiculturists (Nicaragua and Honduras)

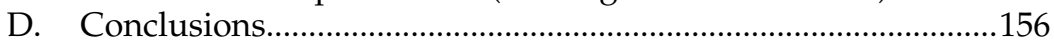

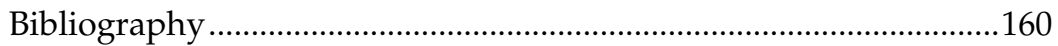

Chapter V

Economic integration and value chains case study: Dairy products in Central America.

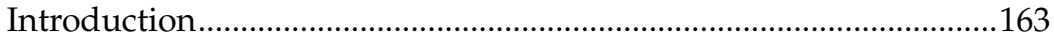

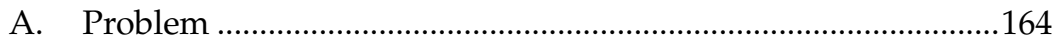

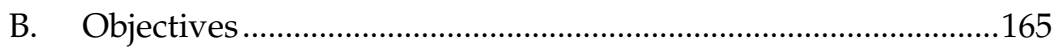

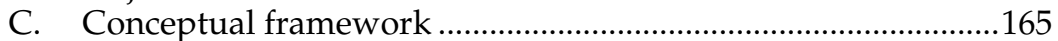

1. Economic integration and international trade.......................165

2. Foreign direct investment and economic integration.............166

3. Value chain analysis and governance ...................................168

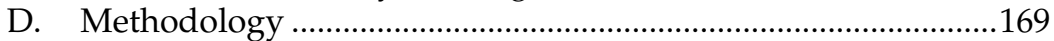

E. The dairy sector in Central America: an overview .....................170

1. Nicaragua's dairy value chain .............................................173

2. El Salvador's dairy value chain ...........................................174

3. Costa Rica's dairy value chain ................................................175

4. Panama's dairy value chain ..................................................176 
F. Economic integration through regional value chains.................178

1. Vertical Integration and Economic Integration......................178

2. FDI and integration of the Central American dairy industry.

G. Final Remarks

Bibliography.

Chapter VI

Value chain development for cocoa smallholders in Ecuador

A. The value chain approach to smallholder development in Ecuador adopted by the German Agency for

International Cooperation (GIZ)

B. The selection of value chains for promotion.

C. Value chain analysis of a speciality product — the case of "fine aromatic cocoa".

1. Product and market characteristics .........................................190

2. Value chain characteristics

3. Primary cocoa producers: characteristics and social aspects

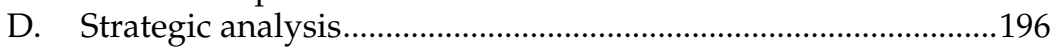

1. Development objective and strategy for fine aromatic cocoa

2. Value chain problems, needs and opportunities ..................197

E. Value chain development activities...............................................198

F. Impact and lessons learned ..........................................................201

1. Impacts of value chain promotion.........................................201

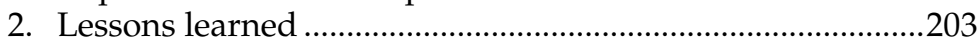

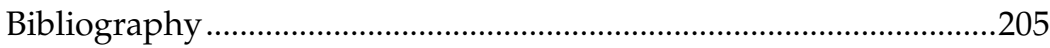

Chapter VII

Brazilian production sharing and implications for production

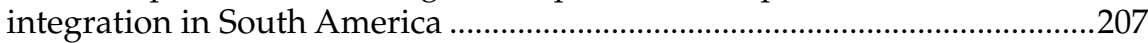

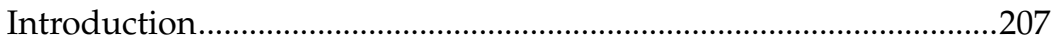

A. The state of theories and findings ...............................................209

B. Measuring production sharing ……………..................................213

C. Trade and production sharing ....................................................216

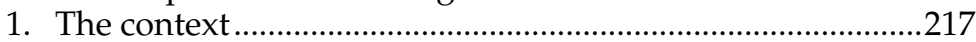

2. Trade in parts and components...............................................218

3. Trade in final manufacturing products ..................................221

D. Magnitude of production sharing in Brazil ................................227

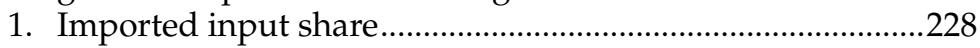

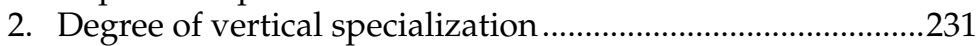

3. Advantages in assembly operations.......................................235

4. Results and policy implications .............................................238

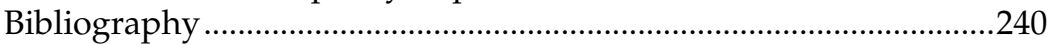

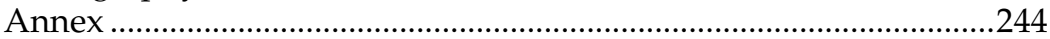




\section{Chapter VIII}

Value chains in Colombian exports to the European Union:

How inclusive are they?

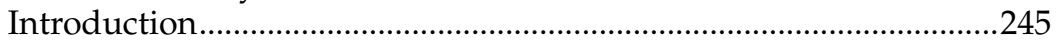

A. Exports and value chains.............................................................246

1. Backward linkages of the export sector to the

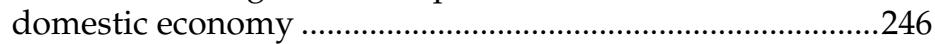

2. Domestic value chains related to exports to the European Union

3. Direct and indirect employment in sectors exporting to the European Union .

B. Background to the Association Agreement between

Colombia and the European Union ..........................................259

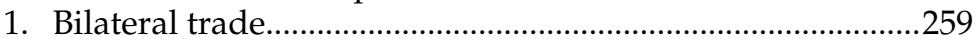

2. Outcomes of the Association Agreement ..............................262

3. Survey of previous studies ......................................................264

C. Modelling the effects of the Association Agreement

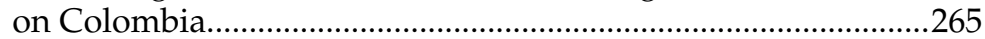

1. Computable general equilibrium model ................................265

2. Micro simulation methodology ................................................267

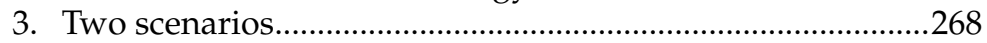

D. Macroeconomic and social outcomes of the Association Agreement with the European Union...........................................269

1. Macroeconomic outcomes ………………….........................269

2. Effects on international trade .................................................270

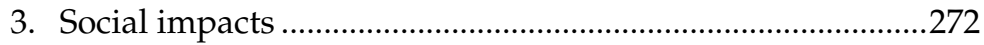

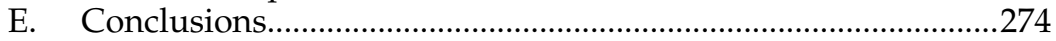

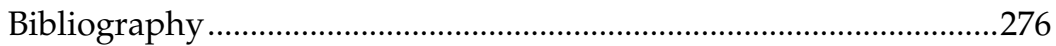

\section{Tables}

II.1 Latin America (selected countries): economic and industry indicators for the offshore services industry, 2008

III.1 Chain governance indicators .............................................................. 110

III.2 Summary of financial instruments and guarantees observed in Argentine agrifood value chains.

III.3 Main sources of finance for sampled furniture firms in Serra Gaucha

III.4 Summary of financial instruments and guarantees observed in furniture value chains (Serra Gaucha, Brazil).

III.5 Inter-firm linkages and financing in the ICT sector in Costa Rica.

III.6 Relationships between chain governance and inter-firm linkages in accessing finance for three case studies

IV.1 Selected competitiveness bottlenecks and measures for overcoming them 
IV.2 Overview of the Multilateral Investment Fund projects under consideration

V.1 Yearly average exports and imports of dairy products in Central America, 1994-2011 .............................................................171

V.2 Main characteristics of the dairy industry in Central America ............172

V.3 Countries' position in terms of world dairy production ..................173

VI.1 GIZ product and market evaluation matrix for promoting value chains, November 2002

VI.2 Ecuador: basic data on export cocoa, May 2004.

VI.3 Ecuador: sources of income of the members of the KALLARI Association, located in the Sumaco Biosphere Reserve

VI.4 Ecuador: strengths, weaknesses, opportunities and threats of the aromatic cocoa chain

VI.5 Ecuador: farmer-buyer contracts in the fine aromatic cocoa value chain.

VI.6 Summary of the strategy for improving the fine aromatic

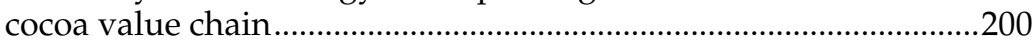

VI.7 Results (impact) model designed by GIZ to promote value chains, including monitoring indicators, 2003

VI.8 Impacts on the competitiveness of the KALLARI value chain, 2006-2011

VI.9 Impacts of the promotion of the special cacao value chain, at the level of small cacao farmers, in selected cases..........................203

VII.1 Brazil: top import and export countries in 2008...............................218

VII.2 Brazil: imports of parts and components, 2008 ……..........................219

VII.3 Brazil: exports of parts and components, 2008..................................220

VII.4 Finished products and parts and components in the electronics industry

VII.5 Finished products and parts and components in the automotive and aircraft industries.....................................................224

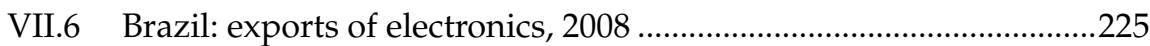

VII.7 Brazil: automotive/aircraft exports, 2008 ........................................225

VII.8 Average imported input share in finished products, 1975-1995..........229

VII.9 Coefficient of imported inputs in industrial sectors, 2005 ................229

VII.10 Vertical specialization in the manufacturing sector in Brazil..........232

VII.11 Revealed comparative advantage ......................................................236

VII.12 Revealed comparative advantages in Brazil: parts and components, electronics, automobiles and aircraft ..........................236

VII.A.1 Vertical specialization in Brazil...........................................................24

VIII.1 Sectors with stronger and weaker backward linkages, 2005 .............247

VIII.2 Ranking of products with significant backward linkages, 2005...........248

VIII.3 Colombia: export sectors to the European Union with strongest backward linkages, 2005.

VIII.4 Employment requirements per US\$ 1 million of production in sectors which export predominantly to the European Union, 2005. 
VIII.5 Output, exports and total and export-related production and employment, 2005.

VIII.6 Total employment in sectors linked to exports to the

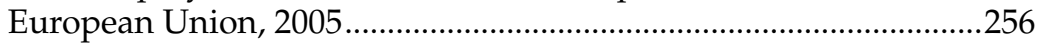

VIII.7 Direct and indirect exports employment by destination market, 2005.

VIII.8 European Union: tariffs applied to imports from Colombia, February 2012

VIII.9 Tariff protection structure at the product group level, baseline of the Global Trade Analysis Project (GTAP) ......................263

VIII.10 Estimation results on the probability of employment.......................268

VIII.11 Colombia: outcomes of simulations of an association agreement with the European Union ....

VIII.12 Colombia: impact of scenarios 1 and 2 on international trade by broad sector

VIII.13 Employment by industry in Colombia: persons employed, level of qualification and employment content of production, 2010

VIII.14 Colombia: microsimulation results

\section{Figures}

I.1 GVC participation index in OECD countries, 2009 ............................51

I.2 GVC participation index for selected non-OECD economies, 2009

I.3 Average length of GVCs across all industries .....................................53

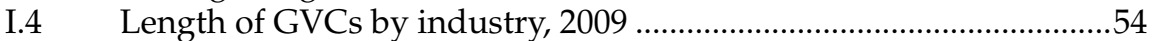

I.5 Distance to final demand, selected economies, 1995 and 2009..............55

I.6 Length index for the agriculture value chain, by country, 2009 .............58

I.7 Length index for the food product value chain, by country, 2009

I.8 Participation and distance to final demand in the agriculture value chain, by country, 2009

I.9 Participation and distance to final demand in the food products chain, by country, 2009.

I.10 Import content of exports by country of origin in the motor vehicle industry, 2009.

I.11 Length index of value chains in the motor vehicle industry, by country, 2009

I.12 Participation and distance to final demand in the motor vehicle industry, by country, 2009 .

I.13 Length index in the electronics value chain,

by country, 2009

I.14 Participation and distance to final demand in the electronics value chain, by country, 2009 .

I.15 Trade in business services, as a share of total trade in services, 2000-2008 
I.16 Length index of computer services value chains, by country, 2009

I.17 Length index in the value chain of other business services, by country, 2009

I.18 Participation and distance to final demand in the computer services value chain, by country, 2009 .

I.19 Participation and distance to final demand in the value chain of other business services, by country, 2009

II.1 Costa Rica and Mexico: medical exports by product category, 1998-2011

IV.1 Example of a high-value agriculture value chain ...............................140

VI.1 Total cocoa exports, 2004-2011 ...........................................................202

VII.1 Vertical specialization in manufacturing in Brazil, 1995, 2000 and 2005

VIII.1 Participation of sectors in export value and employment embodied in exports by trading partner, 2005

VIII.2 Participation of sectors in export value and employment embodied in exports to the European Union, 2005 .258

VIII.3 Colombia and the European Union: composition of export basket by product and destination market, 2010

\section{Boxes}

III.1 Loan guarantee associations in Argentina 114

III.2 Cases in which the help of a large firm enabled access to finance........126

VI.1 Definition of a value chain according to ValueLinks..........................186

\section{Diagrams}

II.1 Nicaragua: curve of value added stages in the global apparel value chain

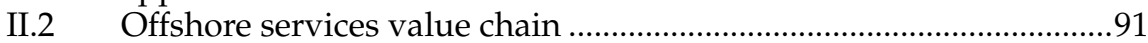

V.1 Nicaragua's dairy value chain .......................................................174

V.2 The dairy value chain in El Salvador................................................175

V.3 Dairy value chain in Costa Rica........................................................176

V.4 Structure of the dairy value chain in Panama ...................................177

VI.1 Overview of the ValueLinks Methodology........................................187

VI.2 Ecuador: map of the conventional cocoa value chain .......................194

VI.3 Ecuador: map of the speciality cocoa value chain ..............................194

VIII.1 Backward linkages of the coffee sector, 2005 .....................................254

\section{Maps}

I.1 The Nutella global value chain

VI.1 Intervention areas of the GIZ-Programme for sustainable management of natural resources in Ecuador. 


\section{Foreword}

Over the past two decades, the geographical disintegration of production processes has been a salient feature of globalization. The fragmentation of the Fordist vertically integrated mode of production has allowed the global dispersion of value added activities in a value chain or production network. This trend has led to a steep rise in the global trade of intermediate goods and opened up new opportunities for developing countries to participate in these networks.

The global value chain (GVC) framework shows how a sector participates in the sequence of activities required to bring a product or service from its initial conception to production and sales. The related literature analyses which activities and technologies are kept within a firm as its core competencies and which activities will be outsourced to other firms at home or abroad, emphasizing 'cross-border' linkages between firms in global production and distribution systems.

The global reorganization of production into different segments of the value chain has profound implications for Latin America and the Caribbean. Each segment within the value chain uses different combinations of production factors, has different opportunities to create value added and backward linkages, and offers different opportunities for the development of specific technological capabilities. The GVC framework can also identify hierarchical or power-based relations within the chain, which in turn determine the geographical location of production segments. 
The analysis of how Latin American and Caribbean economies participate in different segments of GVCs is at the heart of the current work agenda of the Economic Commission for Latin America and the Caribbean (ECLAC), which focuses on how structural change and productivity gains can promote economic development with equality. Structural change requires the reallocation of resources to segments of the value chain with higher value added content and more technology or knowledge-intensity. In short, structural change requires value chain upgrading.

Moreover, recent research at ECLAC underscores the need for innovation to improve productivity. This volume builds on the relevant literature and suggests that the movement of firms to higher value added activities in GVCs requires them to step up their innovation efforts and develop new products and processes. Success in improving market shares and value added will depend, however, on which firms innovate most. Hence, innovation is a necessary but insufficient condition for increasing value added and market shares.

This volume contains a selection of empirical and analytical contributions, presented originally at the international conference "Latin America's Prospects for Upgrading in Global Value Chains" held on 14-15 March 2012 at Colegio de Mexico, Mexico City. The conference was jointly organized by four international organizations (ECLAC, the Inter-American Development Bank (IADB), the Organization for Economic Cooperation and Development (OECD) and the World Bank) in partnership with Colegio de México. The main purpose of the conference was to take stock of and expand the range of empirical analyses on the participation and upgrading of Latin American firms in global value chains, including policies that promote this goal. The conference included a keynote address by Gary Gereffi, followed by 13 presentations on theoretical and empirical research from all participating organizations and associated academics. It also included a panel on policy, led by ministers of trade, trade negotiators and policymakers from the region.

The authors in this volume analyse how the Latin American and Caribbean region benefits from increasing vertical specialization and explore the extent to which the region can achieve technological upgrading through the increase in technological capabilities for the development of new products or processes or engagement in more knowledge-intensive activities. The main conclusion is that the participation of the region in 
world trade depends largely on its position and pattern of governance within GVCs. Moreover, the evidence suggests that since the 2008 economic crisis, the participation of Latin America and the Caribbean in global production networks has increased. We trust that this volume will provide valuable insights into the dynamics of the region's upgrading and participation in GCVs and the necessary policies to promote this goal, which centre on the need to strengthen technological capabilities, learning, innovation and knowledge diffusion.

\author{
Alicia Bárcena \\ Executive Secretary \\ Economic Commission for \\ Latin America and the Caribbean
}

(ECLAC) 



\section{About the editors}

The editors of this volume, René A. Hernández, Jorge Mario Martínez-Piva and Nanno Mulder are distinguished scholars and researchers affiliated to the United Nations Economic Commission for Latin America and the Caribbean (ECLAC). Eight chapters have been selected for this volume plus a foreword. To our knowledge, this volume will be the first one in English on global value chains (GVC) and global production networks (GPN) with emphasis on Latin America, covering analytical, empirical and policy issues and affording insight into the challenges and opportunities presented by GVC and GPN in a globalizing world.

\section{About the contributors (in alphabetical order)}

Penny Bamber is an Independent Research Associate with the Center on Globalization, Governance \& Competitiveness at Duke University. From Zimbabwe, she holds a B.A. in International Relations from the University of Pennsylvania, where she was a Benjamin Franklin scholar, and a Masters degree in Public Policy from the University of Chile. She also holds a Diploma in Public Policy from the Harris School at the University of Chicago. Penny has been a member of the CGGC research team since the beginning of 2009, with a research focus on economic development and competitiveness in Latin America, workforce development, offshore services and agrifood value chains.

Sebastián Castresana is research assistant with the Division of International Trade and Integration, in the United Nations Economic 
Commission for Latin America and the Caribbean (ECLAC) in Santiago, where he has worked since 2011. His research topics are global value chains, general equilibrium models and microsimulations. He worked from 2007 to 2010 at the Centre of International Economy of the Ministry of Foreign Affairs and Worship in Argentina. He is an economist from the Universidad de Belgrano, Argentina.

Koen De Backer is a Senior Economist with the OECD Directorate for Science, Technology and Industry (STI). His work focuses on the links between globalization and STI in a broad sense, and their direct effects on government policy, global value chains, trade in value added, R\&D internationalization and open innovation. He holds a PhD from the K.U. Leuven and a Master of Business Administration degree from K.U. Leuven/University of California at Irvine. Previously he held postdoctoral positions in Barcelona and Leuven, was professor at the Vlerick Leuven Gent Management School and acted as adviser to the Minister of Economic Affairs in Belgium (Flanders).

José Elias Durán is currently Economic Affairs Officer at the Division of International Trade and Integration of the United Nations Economic Commission for Latin America and the Caribbean (ECLAC). Formerly, he served in the Investment and Corporate Strategies Unit of the Commission's Division of Production, Productivity and Management. He holds degrees in law and economics from Vicente Rocafuerte University and Guayaquil University (both in Ecuador) and a PhD in economics from Barcelona University (Spain). He has served as an associate professor at the Catholic University Raúl Silva Henriquez in Chile and as a visiting fellow of the ECLAC/UNCTAD Joint Unit of FDI and Transnational Corporations. His current research themes are regional integration, trade patterns, regional and global value chains, general equilibrium models and FTAs assessment.

Karina Fernandez-Stark is a Senior Research Analyst at the Duke University Center on Globalization, Governance \& Competitiveness (CGGC). At CGGC she has led several research projects related to economic development and competitiveness. She has consulted for ECLAC, IDB, OECD, UNCTAD and the World Bank, among others. She has published numerous reports and articles on industrial upgrading and social and economic development. Karina developed a Spanish-language manual on global value chains for economic development researchers in Latin America and has facilitated global value chains workshops in Latin America and Africa. She holds a Master's degree on International Development Policy from Duke University.

Gary Gereffi is Professor of Sociology and Director of the Center on Globalization, Governance, \& Competitiveness at Duke University (www. cggc.duke.edu/). He received his B.A. degree from the University of Notre 
Dame and his Ph.D. degree from Yale University. Gereffi has published numerous books and articles, including: The New Offshoring of Jobs and Global Development (International Institute of Labour Studies, 2006); Global Value Chains in a Postcrisis World: A Development Perspective (The World Bank, 2010); and Shifting End Markets and Upgrading Prospects in Global Value Chains (special issue of International Journal of Technological Learning, Innovation and Development, 2011). He has recently completed a threeyear project on economic and social upgrading in global value chains (www.capturingthegains.org), financed primarily by the Department for International Development of the United Kingdom.

René A. Hernández has been Economic Affairs Officer of the Latin American and Caribbean Institute for Economic and Social Planning (ILPES), United Nations Economic Commission for Latin America and the Caribbean (ECLAC) since 1989. His current research interests include the areas of international economics, global value chains, economic development and industrial economics. He has lectured widely at universities in Europe, Latin America and the United States. He is an economist by training and completed his post-graduate studies in Economics at Vanderbilt University, United States, and the University of Warwick, United Kingdom.

Marco Kamiya is Regional Principal Executive at the Division of Public Policy and Competitiveness at the Development Bank of Latin America $(\mathrm{CAF})$, where he leads the initiatives for local productive development, global value chains and innovation in the region. He worked on private-sector development and competitiveness at the Inter-American Development Bank in Washington D.C. and, previously was Project Director with International Development Banks at PADECO Co., Ltd. in Japan. Kamiya has worked extensively in Asia and Latin America. He studied economics in Lima and Tokyo, and International Development at the John F. Kennedy School of Government at Harvard University.

Sonia Lehmann is currently a project management and organization adviser to the ProCamBIO programme in COMO Consulting. Previously, she was an expert on private sector cooperation and market access at the office of the German Agency for International Cooperation (GIZ) in Ecuador. She specializes in the promotion of value chains, product development, strategies for market access and public-private cooperation. She studied Business Administration at San Francisco University in Quito.

Jorge Mario Martínez-Piva is Chief of the Industry and Trade Unit at the subregional headquarters of the Economic Commission for Latin America and the Caribbean (ECLAC) in Mexico. He has worked on international trade and regional integration, including recent work on international production chains and FDI matters. Mr. Martínez-Piva 
obtained a Law degree at the University of Costa Rica, a master's degree in Economics at the Universidad Nacional (Costa Rica) and his doctorate in Economics at the Autonomous University of Madrid (Spain). His academic experience includes lectures and research at universities such as Universidad Nacional (Costa Rica), Autonomous University of Madrid (Spain), Florida International University, University of Puerto Rico and University of Turin.

Sébastien Miroudot is Senior Trade Policy Analyst in the Trade in Services Division of the OECD Trade and Agriculture Directorate. He holds a PhD from the Paris Institute of Political Studies in international economics. Before joining OECD, he was research assistant at Groupe $\mathrm{d}^{\prime}$ Economie Mondiale and he taught in the Master's degree programme at the Paris Institute. His research interests include trade in services, trade and investment and trade flows within global value chains. He is currently working at OECD on the measurement of trade in value added terms and the construction of a services trade restrictiveness index. He has published several articles and contributed several chapters to various journals and books dealing with trade policy issues.

Nanno Mulder is an Economic Affairs Officer at the Division of International Trade and Integration of the United Nations Economic Commission for Latin America and the Caribbean (ECLAC) in Santiago, where he has worked since 2006. His current research themes are global value chains, trade in services and productivity. He worked from 2002 to 2005 at the Economics Department of OECD and from 1996 to 2002 at a French research centre on international economics (CEPII). He holds an $\mathrm{MA}$ and PhD from the University of Groningen in the Netherlands. He is a co-founding member and the current President of the Latin American Network on Research in Services (www.redlas.net).

Lizbeth Navas-Alemán is a Research Associate at the Institute of Development Studies (Brighton, United Kingdom). A socioeconomist with broad experience in the field of international development, she carries out academic research and post-graduate teaching, training and consultancy on private-sector development, global value chains and industrial upgrading in Latin America, Asia and Europe. She is currently participating in the coordination of a large research programme, funded by the Department for International Development of the United Kingdom, on the developmental role of businesses from the BRICS (Brazil, Russia, India, China and South Africa) in Africa.

Carlo Pietrobelli is Lead Economist at the Inter-American Development Bank (IDB), where he is in charge of designing and managing programmes to promote innovation and private sector development in Latin America and the Caribbean. He is also actively involved in policy advice to 
Governments in the region. His recent activities include: cluster and value chain programmes, the impact evaluation of such programmes, support to competitiveness and innovation councils, programmes for local economic development, and programmes and institutions to support small and medium-sized enterprises. He holds a PhD in Economics from the University of Oxford and has been a regular advisor to international organizations such as the European Commission, the World Bank, the International Fund for Agricultural Development (IFAD), the United Nations Industrial Development Organization (UNIDO), the United Nations Conference on Trade and Development (UNCTAD), ECLAC, the Development Bank of Latin America (CAF), and OECD.

Andreas Springer-Heinze is a Senior Planning Officer at GIZ head office in Eschborn, Germany, where he covers topics of rural economic and value chain development. Andreas works as a short-term adviser and senior trainer in Latin America, South and South-East Asia and in SubSaharan Africa. He is the editor and main author of the GIZ ValueLinks methodology on value chain promotion and President of the International ValueLinks Association.

Guillermo Zúñiga-Arias holds a PhD in Economics with emphasis on value chain analysis from Wageningen University. He is currently working at the Inter-American Institute for Cooperation on Agriculture (IICA) as a Specialist in Policies and Institutional Modernization at the Center for Strategic Analysis for Agriculture (CAESPA); and previously worked as a consultant at the ECLAC subregional headquarters in Mexico and at the Inter-American Development Bank among other agencies. He has also worked at Universidad Nacional in Costa Rica focusing on the analysis of the relationship between small producers and market integration. He has been working in several Latin American countries and participated in projects based in the Netherlands with counterparts in Africa and Asia. 



\section{Introduction}

Over the last few decades, two fundamental changes have transformed the face of global production and world trade. The first is the increasingly integrated nature of world markets, which can be explained to a large extent by trade liberalization, regional integration agreements (RIAs), agglomeration and location economies, falling transportation and transaction costs and rapid technological advances, especially in information and communication technologies. The second is the "disintegration" of the production process, in particular the increasing presence of intermediate goods in global trade, which essentially entails the fragmentation of the Fordist vertically-integrated model of production and allows for the strategic global dispersion of different value added activities in value chains or global production networks.

The analysis encompassing all activities needed to bring a product or service from conception and design, through the intermediary phases of production, marketing, to culminate in delivery to the end consumers has been termed variously as outsourcing, global value chains (Kaplinsky, 2000), global commodity chains (Gereffi and Korzeniewicz, 1994), the disintegration of production (Feenstra, 1998), value networks, vertical specialization (Hummels and others, 1998) global production sharing (Ng and Yeats, 1999; Yeats, 2001) and global supply chains (Baldwin, 2012).

The global value chain (GVC) model sheds light on how an industry or sector participates in the sequence of activities required to bring a product or service through the entire process of production, including delivery and after-sales services (Kaplinsky, 2000). The main insights of 
the related literature lie in ascertaining which activities and technologies will be kept by the firm as its core competencies and which activities will be outsourced to other firms, emphasizing cross-border linkages between firms in global production and distribution systems.

Based on an analysis of the global organization of production, Gereffi and Korzeniewicz (1994) developed the global commodity chain framework, which distinguishes between producer-driven and buyerdriven chains. The former are coordinated by the main producers in the chain, which generally control crucial activities such as research and development (R\&D), design, the organization of production and technological know-how. The power within the chain flows vertically down from headquarters or the flagship firm to its subsidiaries or suppliers. In the latter, the governing role is played by a buyer, commonly a large wholesaler or distributor of branded products, which defines specifications and marketing strategies for products and outsources manufacturing and other activities to independent firms. Based on this conceptualization, Gereffi, Humphrey and Sturgeon (2005) established a typology from empirical observation that identifies five basic types of value chain governance: market, modular, relational, captive and hierarchy. This typology provided the basic insights to develop an operational theory of global value chains and enabled the identification of the three key determinants of value chain governance, namely the complexity of transactions, the codifiability of information and the capability of suppliers.

Participation in different segments of the value chain has profound and significant implications for developing countries in Latin America and the Caribbean. The activities within each segment use production factors (capital, technological knowledge and labour) with differing degrees of intensity and hence their potential for building up backward linkages varies. As mentioned above, the GVC framework is also helpful for identifying hierarchical or power-based relations within the chain, which have a direct effect on the global organization of the industry and on the geographical location of economic activities (Padilla-Pérez and Hernández, 2010).

The concept of global production networks (GPN) is complemented by that of GVCs. In the literature, GPNs are usually related to a flagship firm whereas GVCs are related to a specific product or service. This implies that a company-specific GPN can participate in a variety of GVCs. Conversely, a GVC can also comprise two or more production networks (Memedovic, 2004). Moreover, increasing international competition, economic liberalization and the dissemination of information technologies have encouraged the development of inter-organizational networks, 
grouped around a product and linking firms, buyers and suppliers in the context of the global economy (Gereffi and Korzeniewicz, 1994). In this sense, GPNs are associated with the decoupling of product development and manufacturing owing to the increasing separation of product design and development (carried out by specialized brand-name firms or original equipment manufacturers) from physical production (organized by contract manufacturing firms and other suppliers) (Ernst and Lüthje, 2003).

GPNs encompass both intra-firm and inter-firm transactions and different forms of coordination. They link multinational corporations with their own subsidiaries and with affiliates, joint ventures, subcontractors, suppliers, service providers and partners in strategic alliances. In so doing, they gain access to resources and capabilities and also to specific markets (Ernst and Kim, 2001). Analysis of GPNs is useful for identifying power relations or hierarchies, which have direct repercussions on the industry's global organization and on developing countries, particularly in respect of the activities outsourced to the countries participating in the global value chain. Flagship firms focus on the core capability areas that are perceived as essential to the formation of their existing competitive advantage, especially product innovation, marketing and other activities related to brand development. Once flagship companies have "deverticalized", they employ specialized suppliers to provide all non-core functions (Sturgeon, 2002). The characteristics of GPNs may vary greatly across industrial sectors and even within sectors.

The GVC literature has mainly focused on empirical analyses and case studies, in particular on investigating how different types of governance determine different types of upgrading at the firm level (Morrison, Pietrobelli and Rabellotti, 2006; Humphrey and Schmitz, 2002). The literature also recognizes four types of upgrading that can be adopted at the firm level: (i) product upgrading, namely the development and marketing of a product with improved performance characteristics, which can be defined in terms of increased unit values; (ii) process upgrading, namely the development and implementation of new or significantly more efficient production processes or delivery methods by introducing superior technology; (iii) functional upgrading, namely engaging in new and superior activities in the value chain, for instance a firm moving from components manufacturing to product design; and (iv) inter-sectoral upgrading, namely moving to new productive activities or sectors, using the knowledge, skills and technological capabilities acquired previously. For instance, knowledge acquired in manufacturing electronic goods may be used in other sectors such as aeronautics (Pietrobelli and Rabellotti, 2007). Technological upgrading, on the other hand, is understood here as using more advanced technological capabilities to develop new products or processes or to engage in 
more knowledge-intensive activities. Thus, upgrading can be construed as innovating to increase value added (Humphrey and Schmitz, 2002; Kaplinsky, 2000; Porter, 1990) or moving to higher value-added activities in global supply chains (Gereffi and Korzeniewicz, 1994). Undoubtedly, the capacity to innovate equates to the ability to increase value added and develop new products and processes. But this book argues that innovation may not be sufficient in itself, and should be placed in a relative context: a firm's innovation efforts must be compared with those of its competitors. If the rate of innovation of a firm is below that of its competitors this may result in declining value added and market share. Therefore, upgrading in the sense of innovation to increase value added (and unit value) is a necessary condition, but is not sufficient in isolation, insofar as it requires increasing both value added and market share (Kaplinsky and Readman, 2001).

The selection of articles in this book represents a variety of empirical and analytical contributions, which suggest that the participation of Latin America and the Caribbean in world trade is largely dependent on the position occupied and the pattern of governance within GVCs, as well as on endogenous efforts to deliberately create or strengthen technological capabilities, learning trajectories, innovation and the dissemination of knowledge. The share of Latin America and the Caribbean in global demand and in global production networks has increased in the aftermath of the 2008 economic crisis. However, it is not clear how Latin America and the Caribbean has benefited from increasing vertical specialization and to what extent it has achieved technological upgrading - the enhancement of technological capabilities for developing new products or processes- or has been able to engage in more knowledge-intensive activities. Upgrading equates to innovation aimed at increasing value added or market share, or participating in the production of knowledge-intensive goods and services or in GVCs with more dynamic internal and external demand.

Scarce evidence is available for the period since the global economic crisis in 2008 on the participation of Latin America and the Caribbean in GVCs and the main drivers of that participation. How has the spread of information and communication technologies in the region facilitated participation in GVCs? What country-specific evidence is available on how improved logistics, financial services and specific business services in Latin America and the Caribbean have promoted integration or upgrading in value chains? How has the recent signing of free trade agreements between Latin America and the Caribbean States and countries in northern and eastern Asia contributed to the formation of GVCs? To what extent do small and medium-sized enterprises (SMEs) participate in GVCs? What mechanisms for learning and for obtaining productive and technological feedback operate in different types of GVCs? Have national and local innovation systems in the region contributed 
to learning and innovation in GVCs? What role is played by policies to influence these processes? Is there any evidence to help explain why regional GVCs and trade integration processes tend to include more SMEs and less developed countries or territories than value chains involving firms from outside the region?

To address some of these questions and to promote dialogue among researchers, policymakers and other stakeholders, four international organizations - the United Nations Economic Commission for Latin America and the Caribbean (ECLAC), the Inter-American Development Bank (IDB), the Organization for Economic Co-operation and Development (OECD) and the World Bank - in partnership with the Colegio de México, organized a joint conference on "Latin America's Prospects for Upgrading in Global Value Chains" on 14-15 March 2012 in Mexico City. The aim was to take stock of and expand the range of empirical analyses on the participation and upgrading of Latin American firms in global value chains, including policies to promote this goal. During the conference, 13 original papers were presented with theoretical and empirical research from all participating organizations and associated academics. It also included a policy panel comprising ministers of trade, trade negotiators and policymakers from across the region.

This book contains a selection of the papers presented at the conference, drafted by prominent scholars and renowned academics. The book analyses the participation of Latin America and the Caribbean in GVCs, the main drivers of that participation and the challenges and opportunities associated with upgrading. It shows that GVCs and GPNs increasingly dominate international trade and production patterns in Latin America and the Caribbean, with variable outcomes in terms of economic growth, employment creation, competitiveness, regional development, vertical specialization and structural transformation.

Chapter I, by Koen de Backer and Sébastien Miroudot, aims to provide evidence on the position of countries within international production networks by using a set of indicators applied to a new database and by presenting case studies on four broad industries. The authors introduce their analysis with a review of the literature on GVCs, the main drivers and the limits to the international fragmentation of production, as well as the change in the unit of analysis from industry to business functions and tasks.

The aggregate analysis presented in this chapter is done using a new database developed by the OECD in collaboration with the World Trade Organization (WTO). This database estimates trade flows in value-added terms by linking input-output tables from 57 countries and a "rest of the world" table, covering 95\% of world output. Flows of intermediate inputs 
across countries and industries come from the bilateral trade database by industry and end-use category. The database registers all value-added transactions between industries and countries for 37 industries for five benchmark years (1995, 2000, 2005, 2008 and 2009).

The database is used together with three indicators to assess the importance, depth and length of global value chains, as well as the specific position of countries in these production networks:

- The GVC participation index, which assesses a country's participation in vertically fragmented production processes. It is measured by the percentage of gross exports and indicates the share of foreign inputs (backward participation) and domestically produced inputs used in third countries' exports (forward participation). Results show that OECD and nonOECD economies show similar rates of participation in GVCs. Large economies, such as Brazil or India, have a lower share of inputs in their vertical trade exports than small economies, such as Singapore or Chinese Taipei.

- The number of production stages index, which shows the extension of global value chains and identifies the domestic and international parts of the value chain. Results indicate an increase in the average length of value chains between 1995 and 2008. Since the domestic portion of value chains has remained almost the same length, the increase can be attributed to the extension of the international part of value chains. The five industries with the highest index of fragmentation are: television and communication equipment; motor vehicles; base metals; textiles, leather and footwear; and electrical machinery. On average, service industries have shorter value chains.

- The distance to final demand index, which demonstrates how far upstream countries are in the value chain. It shows how many stages of production are left before the goods or services produced by this industry reach final consumers. Results show that successful emerging economies have become more specialized in intermediate inputs and generally moved further upstream. This can be seen in particular in Asia (in the case of China, Malaysia, the Philippines and Singapore), as well as in the Americas (Chile).

This chapter also provides a more detailed assessment of global value chains in four broad industries:

- Agriculture and food products: with aggregate data on the length of chains, participation in them and distance to final 
demand, together with a case study of the product Nutella, the authors show that food products are globally produced in value chains involving both developing and developed countries. The data show that neither developing nor developed economies are confined to specific roles. For example, both Sweden and China can be found very far upstream in agriculture value chains and, conversely, both Viet Nam and Germany can be relatively far downstream in food product value chains.

- Motor vehicles: GVCs are a very prominent feature of the motor vehicles industry and are particularly noteworthy for their length. The regional organization of the production process is evident from the source country of imported intermediates. Analysis shows that intraregional sourcing within the three main regional blocks is important in the motor vehicles industry. European Union member States source the majority of their intermediates from other European countries, while the signatories of the North American Free Trade Agreement (NAFTA) primarily source from among their NAFTA partners. In Asia the sourcing of intermediates largely from within the region has led to a considerable degree of regional integration.

- Electronics is probably the industry where GVCs are the most pervasive, as illustrated by the large number of case studies on individual electronic products. The international character of electronics GVCs is reflected in the significant number of international stages involved in the manufacturing of electronic products. Electronics GVCs tend to consist of many firms across different countries, from large multinationals to SMEs. Contract manufacturers assemble products for lead firms and have limited market power despite the fact that they are typically large and often have operations in different countries. Most lead firms in the electronics industry are located in developed economies.

- Business services: both developing and developed countries have a high participation in business services GVCs. There is no clear pattern showing that either developed or developing countries are confined to specific segments of the value chain. Computer services incorporate more foreign inputs than other business services, but production fragmentation is evident with respect to all such services, especially in small, open economies. The distance to final demand tends to be high for business service producers, which is not surprising since most business services, such as R\&D activities, consulting, and market intelligence, are provided at the beginning of the value chain. 
The chapter concludes with some policy considerations. A better understanding of the role of each economy in global production networks is needed for multiple policy areas, such as trade, employment, national competitiveness and growth and innovation and development. Once the position and participation of countries in the GVC have been identified, the next step is to understand what determines this position and participation and what policies will have a positive or negative impact on the gains expected from GVCs.

Chapter II, by Karina Fernandez-Stark, Penny Bamber and Gary Gereffi, presents a fresh overview of the GVC framework, building on previous work from the same authors and presenting new insights such as the development of the workforce and the building of endogenous capabilities for upgrading. The first section provides a set of theoretical tools to explain how these chains operate and this helps to identify challenges and opportunities offered by global industries. The fragmentation of the production of goods and services across multiple firms and countries has provided an opportunity for developing countries to integrate into the global economy.

Since value chains are generally dynamic and firms can enter into, or move between, different stages of the chain in order to gain higher returns from their participation, the Latin American countries that have entered a variety of GVCs are faced with the challenge and the opportunity of "upgrading" their participation.

The authors give specific examples to illustrate the participation of Latin American countries in GVCs in a variety of industries, including both traditional sectors and new export-oriented industries. Much of this growth has been driven by the establishment of new export-oriented sectors, often supported by foreign direct investment taking advantage of labour availability and cost, strategic locations and other specific comparative advantages in sectors that include fruit and vegetables in Honduras, apparel in Nicaragua, medical device manufacturing in Baja California, Mexico, and Costa Rica and offshore services in several countries. These new sectors have provided considerable benefits in terms of employment, entry into high-tech fields and even upgrading into high-value products and activities in these developing countries. However, the region abounds with experience in more traditional sectors, such as natural resources and the extractive industries, which also offer substantial opportunities for adding value. Countries can leverage their endowment in natural resources and the related expertise to develop sophisticated services for export. The computerized traceability system used in the cattle industry in Uruguay, Chilean mining engineering services exports and environmental services in Costa Rica are 
examples of how countries can take advantage of their natural-resource endowments to upgrade.

The selected examples discussed in this chapter demonstrate the region's capacity to engage in both traditional and non-traditional export markets. The region now faces the challenge of upgrading into higher value-added segments of these chains and increasing the benefits gained from their participation. In particular, sectors where nations can leverage their natural-resource endowments to export sophisticated products and services represent significant opportunities for Latin American countries to drive upgrading. This upgrading requires a well-trained workforce to provide world-class products and services, and thus must be supported by a strong focus on human capital development. Therefore, for Latin American countries, it is not only a matter of whether to participate in the global economy, but how to do so gainfully, taking advantage of the dynamic nature of value chains, entering and moving between different stages of the chain in order to gain higher returns.

Chapter III, by Lizbeth Navas-Alemán, Carlo Pietrobelli and Marco Kamiya, analyses the impact of inter-firm linkages and interactions with large firms on the access of SMEs to finance in Latin America. They first review the literature on finance, which highlights linkages with large firms in value chains as a possible way of opening up access to credit. Another stream of literature on value chains emphasizes issues of coordination and governance of those linkages and their effects on industrial upgrading, with little mention of the financial implications for SMEs. Evidence on inter-firm finance is mainly limited to case studies in the agricultural sector, which provides examples of different inter-firm financing mechanisms.

A comparison between the different sources and instruments of finance used by SMEs is made using original enterprise-level data in three different sectors and in three different Latin American countries. Those three case studies illustrate a number of financial mechanisms, namely trade credit, factoring, and loan guarantees. Having strong linkages with well-known large firms gives SMEs greater access to finance. However, the evidence also suggests that strong third-party intervention is needed if they wish to use these mechanisms.

From the first case study on the Argentine agrifood industry it is clear that value chain governance matters for SME finance. In the poultry and milk industries, the perishable character of inputs has a major influence on a lead firm's competitiveness (buyers in this case). These chains tend, therefore, to be governed in a quasi-hierarchical fashion. In the three Argentine value chains considered (dairy, poultry, and food processing), linkages to large firms provide enhanced access 
to finance. Lead firms may restrict the options of SMEs as regards suppliers and the supplies themselves, although this does not occur in every case. Most Argentine agrifood SMEs recognize that having large and well-known clients facilitates access to commercial credit. However, interviews with financial institutions suggest that, while this factor is important for the assessment of an application by an SME for finance, it is not the dominant factor.

The second case study is on SMEs producing furniture in the Serra Gaúcha region in Brazil. This non-perishable product business tends to operate in value chains characterized by market-based forward linkages. For example, SMEs have more freedom to seek finance and clients, but usually do not benefit from a large buyer's guarantee for their loans. Although furniture SMEs may have market-based linkages with most of their buyers, they experience a quasi-hierarchy in backward linkages to their input suppliers, mainly large particle board suppliers. Trade credit from these suppliers is welcome but usually comes with conditions, from design suggestions (which are difficult to refuse) to minimum purchases, which are often too large for the smallest firms, thus forcing them to choose distributors that charge a premium for selling smaller amounts of material. Large department stores in Brazil push prices down but do not provide finance to SMEs. These buyers actually demand finance from their producers, thus squeezing them from both ends.

The third case study is on the ICT sector in Costa Rica. In this industry, inter-firm linkages and intra-firm finance are scarce. There are some isolated cases in which linkages with a larger firm have enabled an $\mathrm{SME}$ to access finance. Few firms have experience of lending (or providing guarantees) through vertical inter-firm linkages. The technology used in this industry is characterized by project-based work, which is not mass-produced; it is rare that solutions tailored to suit one customer can be repeated exactly for others. A certain amount of customer-product specificity makes it hard to generate value from intermediate work in progress (as manufacturing firms can do with their intermediate inputs or raw materials) or to provide physical collateral to secure finance (as agricultural and manufacturing firms do).

These examples show that self-financing remains the first and most common source for both short-term finance and working capital across all three case studies. For medium- and long-term finance (for infrastructure, machines, and innovation projects, for example), results are mixed: some SMEs apply for public funding first and self-financing as a second choice, whereas others will choose self-financing first. Clearly, regardless of the type of industry (traditional or knowledge-based, tightly governed or 
loosely coordinated), SMEs in Latin America find it difficult to overcome obstacles to additional finance even when they are part of a value chain. The role of large firms in enhancing the access of an SME to finance appears to depend on the way in which the chain is governed, which is in turn affected by the industry context that frames relationships with suppliers and customers. In industries such as dairy and poultry, where governance between buyers and SMEs tends to be quasi-hierarchical, the chain leader can play the role of guarantor and facilitate access to finance. In industries where chain governance is looser or market-based (such as furniture and information and communications technology), the role of large clients is limited to informing financial institutions of the reliability of applicants for financing.

Policies providing incentives to increase the role of large firms as direct financiers or guarantors for SMEs should take account of the type of governance in chains between large firms and SMEs across industries and countries. Certain other policy recommendations can also be made. Firstly, one difficulty of SME financing is the complexity of banking applications and procedures. This suggests that there is a need for programmes to facilitate SME applications, including technical assistance on finance to reduce obstacles related to banking procedures. Secondly, another obstacle to obtaining a loan is the lack of guarantees. There is thus a need to strengthen and improve the existing guarantee systems. Examples from Argentina and Brazil include the creation of preapproved credit lines and offering a rolling credit limit, lower interest rates or tax incentives to encourage large firms to provide guarantees to SMEs. Finally, third parties such as donors and business associations play a role in facilitating inter-firm finance and encouraging large firms to provide guarantees to SMEs. However, evidence from the case studies suggests that government policies may need to support this role by providing the right incentives and remedying possible coordination errors.

In chapter IV, Penny Bamber and Karina Fernandez-Stark use the global value chain methodology to analyse and evaluate value chain linkage initiatives in Latin America designed to help small producers join high-value agriculture value chains. A holistic model is proposed for work to address the common constraints faced by producers wishing to compete in national and international markets, namely access to markets, access to training, access to finance and coordination and collaborationbuilding. Several findings are useful for future linkage initiatives: a market approach which considers these producers as productive agents is essential to success; the "small and medium-sized producers" category is heterogeneous, with different levels of development and needs; initiatives that simultaneously address all major constraints tend to be 
more successful than those that solve constraints individually; and an exit strategy must be incorporated at the design stage of the project to ensure sustainability.

This chapter also discusses how small- and medium-sized producers are embedded in high-value national, regional and international agriculture value chains. These sectors are believed to have a major influence on poverty alleviation in rural areas of developing countries due to their potential to increase incomes and create employment (Weinberger and Lumpkin, 2007). However, the majority of smallholders in developing countries face a series of constraints that often limits their ability to participate competitively in these chains, and there has been considerable concern that these producers are being denied important opportunities for growth. Over the past decade, numerous projects have therefore been carried out across the developing world to help drive rural development (Jaffee, Henson and Diaz Rios, 2011). However, despite the substantial resources that have been allocated to these initiatives, there has been limited systematic analysis of their impact (Humphrey and Navas-Alemán, 2010).

This chapter seeks to understand how more effective measures can be planned to ensure the sustainable inclusion of these producers in value chains. Based on extensive primary and secondary research, major constraints on the competitiveness of these actors, and thus on their sustainable entry into chains, are identified and a holistic model to overcome these constraints is proposed. This model includes four main pillars: access to markets, access to training, access to finance and support in developing collaborative and coordinated horizontal and vertical linkages. This model is then used to analyse the design and implementation of five value chain linkage projects in Latin America funded by the IDB Multilateral Investment Fund (MIF).

Four lessons for future programmes and projects are drawn from this analysis. Firstly, a proactive market approach to the initiative is essential. This includes assessing the appropriateness of the crops selected for the small producers by identifying the potential role they would play in the value chain and comparing their relative competitiveness with that of larger producers in the absence of constraints; examining the commercial viability of the product; reviewing the requirements of the market; and developing an exit strategy to ensure that the producers can continue to compete sustainably once project resources are withdrawn. Secondly, not all small and medium-sized producers are the same. This is a heterogeneous group with a wide range of socioeconomic backgrounds and levels of educational attainment, and whose experience differs significantly, both in terms of cultivation and commercialization. This has 
important implications for project design, specifically in terms of the length of the work required and the content of training programmes, which must be customized to meet their specific needs. This requires flexibility in how the project is carried out. Thirdly, a holistic approach that improves access to markets, training and finance, emphasizes horizontal and vertical coordination and collaboration in the value chain and incorporates an exit strategy is more likely to achieve successful, sustainable inclusion. Finally, effective implementation is needed to ensure success: the executing agency must have local experience and expertise and be in a position to quickly generate trust between the producers and other actors in the chain. The organization must be prepared to coordinate and leverage potential synergies with other actors to maximize the use made of scarce resources and prevent parallel or counter-productive initiatives.

In chapter V, Jorge Mario Martínez-Piva and Guillermo Zúñiga-Arias analyse the creation of regional value chains (RVCs) within the Central American market. The chapter provides evidence of the relationship between regional integration and the emergence of RVCs, and gives recommendations on how to promote economic integration through RVCs linking small developing economies. In addition, this chapter contributes to analysis of the impact of vertical integration on economic integration and of the impact of trade and foreign direct investment (FDI) on different types of economic integration within Central American countries.

The first section establishes a conceptual framework based on the interplay between three economic categories: (i) economic integration and international trade, (ii) FDI and economic integration, and (iii) value chains and governance. In the first category, regional economic integration shapes global patterns of investment, production and trade. Thus the formation of production networks depends on regional integration systems, as they facilitate trade, FDI and the movement of people. In the second, economic integration and FDI flows are mutually reinforcing and both processes increase preferences for local production within the area. Therefore economic integration increases the location advantages of the markets inside the trading bloc, and firms from outside may exploit opportunities for servicing these markets through local production by means of FDI. Finally, in the third category the authors explain how the development outcomes of RVCs are strongly dependent on their governance patterns.

The case study presented in this chapter focuses on the dairy sector in Central America to analyse how regional integration has facilitated the creation of RVCs. The analysis underlines the importance of small businesses in the region's dairy sector and the coordination mechanisms and power balances among different actors in the value chain. The methodology was based on field work undertaken in El Salvador, 
Nicaragua, Costa Rica and Panama and on statistical data sets to describe the process of economic integration and how value chain players interact.

In the results section the authors present an overview of the dairy sector in Central America, at the regional and national levels. The analysis concludes that the way in which dairy products are distributed underlines the increasing importance of regional trade for this kind of product due to regional differences in costs and productivity, as well as related services such as logistics, marketing, packaging and innovation. Regional trade, which is facilitated by the process of regional integration, has led to the creation of RVCs. For instance, intraregional trade in the dairy sector has benefited from intraregional FDI, which has bolstered the firms' strategy of creating production lines based on regional value chains. These regional production chains have benefited from productivity and price differences between countries, but they face significant governance disparities owing to differences in rules between countries and in the distribution of power among producers.

Finally, the authors propose a set of policy recommendations, highlighting the limited number of studies on the economic integration of small developing economies that focus on regional value chains as a result of the integration process. The case studies in this chapter underline the importance of rules for the development of institutional arrangements within value chains. Countries with stronger institutions are better disposed towards agents in these chains than those operating within weaker institutional frameworks. This facilitates the creation of strong players that tend to govern the regional value chains. Lastly, the chapter concludes that vertical integration and FDI are an integral part of the construction of regional value chains in Central America. And while regional value chains have benefited from regional integration processes (better customs arrangements, tariff reductions and business facilitation), at the same time the integration process has been reinforced by the regional integration of private sector production.

In chapter VI, Sonia Lehmann and Andreas Springer-Heinze describe the stages of development of a project implemented in Ecuador by the German Agency for International Cooperation (GIZ by its German acronym), which was conducted in the framework of a bilateral cooperation programme on sustainable natural resources management (GESOREN) aimed at protecting the natural resource base by increasing the income of poor rural families.

This chapter aims to show how GIZ applied a value chain approach to rural development using its ValueLinks methodology, through a manual and a training course designed on the basis of experiences with economic and rural development in many countries. Specifically, it illustrates the 
conceptual and methodological elements of this methodology in the fine aromatic cocoa value chain in Ecuador.

The authors relate that the decision to promote the fine aromatic cocoa (or cacao nacional) value chain was made on the basis of four main criteria: (i) the use made of the available natural resources within the areas in which GIZ operated; (ii) the productive potential, which represented a competitive advantage for smallholders; (iii) the beneficiary families exhibiting a minimal degree of organization; and (iv) the fact that markets for fine aromatic cocoa have demonstrated positive and stable growth, with sufficiently high prices to cover the production costs of smallholders.

Once fine aromatic cocoa had been selected for promotion, GIZ collected additional information and quantitative data in order to clarify target markets and to set a baseline. As a first step, the authors characterized this specific type of cocoa in Ecuador as a unique specialty in the market segment of fine aromatic cocoa, highly valued by producers making highcocoa-content chocolate with specification of variety and origin. Then, the main characteristics of the specialty market and the specificities of its value chain structure were explained. Finally, the features, including the social characteristics, of primary cocoa producers were considered, as the key factor in Ecuadorian cocoa production.

Taking into account the historical importance of cocoa to the Ecuadorian economy, the government set itself the specific objective of revitalizing aromatic cocoa production by forming a consultative council of private associations and public agencies and designing a national programme to promote the value chain with the consent of all participating actors. On the basis of a general agreement in the cocoa industry to cultivate fine aromatic cocoa signed with the aid of GIZ, the project carried out development activities in cocoa production areas. It became clear from discussions in the different cocoa-producing provinces that the fine aromatic cocoa value chain had to be promoted by introducing business models that would link farmers directly to buyers of high-quality cocoa. Several studies and meetings with stakeholders and (potential) business partners were necessary to conduct an in-depth situation analysis of small cocoa producers and their relationship with market partners. This was summarized in a SWOT (strengths, weaknesses, opportunities and threats) analysis in order to identify the changes that needed to be made in the value chain to enhance competitiveness.

In light of the results of the strategic analysis, diverse actions were taken to resolve the issues identified along the value chain. The main element in the development of the fine aromatic cocoa value chain in Ecuador was the establishment of business linkages between farmer groups organized in cooperatives on the one hand and buyer companies 
on the other. GIZ, together with various supporting players, ran a series of projects at the micro level intended to give rise to concrete initiatives to provide individual companies with access to markets, thereby improving the competitiveness of the whole chain. At the same time, an upgrading strategy was followed which entailed the development of activities with higher value added in the chain, as well as new and better public services and adequate policies to support the sector. For this, GIZ helped open spaces for coordination and consensus-building among public and private stakeholders. This gave rise not only to a policy that was reflected in planning documents, but also to a sector in which participants could coherently express a joint vision of the value chain and operate according to a common forward-looking strategy.

In the last section the authors present the outcome of these efforts to promote the value chain and the lessons learned. Firstly, a results-based model is used to show that at least a part of the additional value added generated by the value chain has remained with the smallholders. The results yielded from the model are supplemented by a series of quantitative and qualitative indicators for periodic monitoring of changes along the value chain. The impact evaluation carried out is also complemented by case studies, which confirm that smallholders participating in the GIZ programme have remained integrated into the value chain and show that the scope of their commercial relationships has expanded. Secondly, the lessons learned from the experiences of GIZ in Ecuador are presented as recommendations and inputs for similar processes to support other regions or other products.

In chapter VII, Marco Kamiya provides an analytical framework for production sharing in Brazil and draws policy implications for productive integration in South America. This chapter first discusses previous empirical work assessing production sharing, reviews studies done on Brazil and describes the data available. Secondly, it examines trade in parts and components in the manufacturing industry, focusing on the electronics, automotive and aircraft industries. Thirdly it applies methodologies to ascertain the magnitude and direction of Brazilian-led production sharing using input-output matrix tables and trade statistics. Fourthly, it presents results and policy implications.

The chapter starts by putting the internationalization of production into context as one of the main features of the global economy since the early 1990s, propelled by the globalization of finance, better communications technologies and more efficient transport logistics. The chapter also elaborates on the evolution of production from an intrafirm activity to a cross-border process with the involvement of various companies and countries. It argues that this has been particularly visible 
in East Asia and China in the last two decades, turning that region into one of the main hubs for global outsourcing and production networks in electronics, vehicles and machinery industries for Japanese, European and American companies.

This chapter also presents an analysis of GPNs, one of the main characteristics of globalization. GPNs have developed as a result of an overall lowering of transportation costs, advances in information and communications technologies and improved infrastructure, which have reduced transaction costs worldwide, therefore allowing companies to arbitrage production and processes across countries and regions to margins allowed by distance over costs. According to Krugman (1995), four distinct new aspects of modern world trade have emerged: the rise of intra-trade, or trade in similar products between countries, the emergence of super-trader countries with high trade ratios in respect of their GDP, large-scale exports of manufactured goods from low-wage to high-wage nations and the "slicing of the value chain". The last point is a remarkable development and represents good news for developing countries, since it makes it possible to be part of global value chains by deciding which processes to implement to produce which components, and progressively becoming a leader in a given segment by enhancing capacities through closer proximity to a given process, thus accelerating industrial upgrading and development.

The chapter posits that value chains in all manufacturing sectors have been sliced up to differing extents, but that vertical specialization is most prominent in the automotive and electronics industries. The industrial organization of the automotive industry comprises a network of suppliers dispersed among regional and worldwide producers, with leading companies from the United States, Japan and Europe. Similarly, the electronics industry comprises assemblers which manufacture goods by bringing together complex and simple components, most of which are stand-alone products. Both the automotive and the electronics industries are composed of parts and components prone to being divided according to production time frames and physical stages. As developing countries progress, they will continue to embed themselves in vertically specialized global value chains in East Asia and China, Latin America and Africa at a pace mainly determined by their national strategies and their firms' competitiveness.

The main aim of this chapter is to ascertain to what extent Brazil is involved in production-sharing or value chain activities and how Brazilian companies are strengthening their position overseas, with multinational corporations competing in cutting-edge technology and product sectors, such as Embraer in the aircraft industry, Embrapa in agribusiness, 
Marco Polo in the transport vehicles sector, and dozens of other major global players. However, the existence of Brazilian multinationals does not necessarily equate to greater integration into global production networks. The chapter seeks to examine the existence and magnitude of Brazil's production networks in South America and their contribution to industrialization and development. In addition, the chapter explores the emergence of Brazilian multinationals. The ascent of competitive regional and global Latin American firms, not only from Brazil, but also from Mexico and other larger countries in the region paves the way for productive integration and cooperation.

In chapter VIII the authors Sebastián Castresana, José Elias Durán and Nanno Mulder assess the inclusive character of value chains in Colombian exports to the European Union, together with the likely effects of the association agreement between the two parties. This chapter starts with an evaluation of the degree of backward linkages in export sectors in the economy using three criteria: the strength of those linkages, measured by purchases of inputs from other sectors, their share in total exports and the depth of the value chain, using the diversification of inputs purchases as a proxy. When expressed in an input-output table, this analysis shows that out of 61 export sectors, 28 have above-average levels of domestic linkages, representing $47 \%$ of total exports in 2005. Examples include agricultural products (coffee, meat, fish, sugar, including brown sugar, cacao, chocolate, and skin and leather products), manufactures (chemicals, metallurgical products, textiles and transport equipment) and services (air transport).

A similar analysis of exports to the European Union shows that 7 out of the top 10 products have above-average levels of backward linkages: coffee (representing $21 \%$ of exports to the European Union), base metals $(12 \%)$, meat and fish $(2 \%)$, leather and footwear $(1 \%)$, textiles and clothing and non-metallic mineral products. The authors also describe the inclusive nature of these export value chains directed at the European Union. They conclude that the coffee chain seems the most inclusive, as the majority of producers - 500,000 families - are members of the National Federation of Coffee Growers (FNC), which guarantees a fair price for coffee and provides many social services to its members. In contrast, the coal sector has the weakest backward linkages.

Another aspect of the inclusivity of value chains is the capacity of export sectors to generate employment. In $2005,12.7 \%$ of total employment (2 million jobs) was directly or indirectly related to exports. The proportion of export-related employment in the goods-producing sector is much higher (35.3\%). Employment linked to exports can be divided into two categories: direct employment (jobs in firms that directly export) and indirect employment (workers in upstream industries that supply 
inputs to these firms). In 2005, indirect employment was 20\% higher than direct employment, meaning that every single worker in the export sector generated 1.2 indirect jobs. The coffee products sector creates not only most export-linked employment, but also the most indirect employment (almost 25 indirect jobs for each direct job).

In comparison with other destination markets, exports to the European Union are the most employment-intensive. This can be explained by the concentration of such exports in sectors with high employment requirements per dollar of output. Employment-related exports to the European Union account for $24 \%$ of total embodied employment in exports, even though this destination accounted for only $15 \%$ of the total value of exports in 2005. Exports to the European Union also create proportionally more indirect jobs (two for each direct job), which is double the indirect-todirect employment ratio of exports to the United States.

The final part of this chapter evaluates the possible economic and social impacts of the association agreement with the EU signed in 2012, using the Global Trade Analysis Project multi-sector and multi-product computable general equilibrium model. Two scenarios were defined for this purpose: the first includes only the association agreement with the European Union and the second takes into account the association agreement with the European Union and the free trade agreement with the United States. In both cases Colombia's sensitivities in respect of agricultural products (dairy products, cereals, wheat and rice) and textiles and clothing were taken into account. The simulation assumes that Peru and the Central American countries have also implemented free trade agreements with both partners. Computable general equilibrium model data are complemented with a microsimulations model to estimate the effects of the trade agreements on poverty and income distribution.

The most positive outcomes are produced in scenario 2 , which is also the most realistic since both parties have approved the agreement. Colombian GDP would increase by $1.3 \%$, exports would grow by $5.3 \%$, and private consumption, investment and government expenditure would also rise. The microsimulations undertaken in the model also show that the free-trade agreements with the European Union and the United States would both have favourable social outcomes, reducing unemployment by 2.1 percentage points and poverty by 1.7 percentage points. Moreover, both agreements would slightly reduce inequality, as indicated by a fall in the GINI coefficient.

One major challenge is to increase exports in sectors with strong domestic backward linkages and high employment requirements (especially indirect employment). Examples of such sectors include light manufactures, including vegetable oil, food, drinks and tobacco, textiles, clothing and footwear. 


\section{Bibliography}

Baldwin, R. (2012), "Global supply chains: why they emerged, why they matter, and where they are going", CTEI Working Papers, No. 2012-13, Geneva, The Graduate Institute, Centre for Trade and Economic Integration.

Ernst, D. and L. Kim (2001), "Global production networks, knowledge diffusion, and local capability formation: a conceptual framework", paper presented at the Nelson and Winter Conference in Aalborg, Denmark.

Ernst, D. and B. Lüthje (2003), "Global production networks, innovation, and work: why chip and system design in the IT industry are moving to Asia", Economics Study Area Working Papers, No. 63, Hawaii, East-West Center.

Feenstra, R.C. (1998), "Integration of trade and disintegration of production in the global economy", Journal of Economic Perspectives, vol. 12, No. 4, Nashville, Tennessee, American Economic Association.

Gereffi, G. and M. Korzeniewicz (eds.) (1994), Commodity Chains and Global Capitalism, Westport, Praeger Publishers.

Gereffi, G., J. Humphrey and T. Sturgeon (2005), "The governance of global value chains", Review of International Political Economy, vol. 12, No. 1, Taylor \& Francis.

Giuliani, E., C. Pietrobelli and R. Rabellotti (2005), "Upgrading in global value chains: lessons from Latin American clusters", World Development, vol. 33, No. 4, Amsterdam, Elsevier.

Hummels, David, Dana Rapoport and Kei-Mu Yi (1998), Vertical Specialization and the Changing Nature of World Trade, Federal Reserve Bank of New York, Economic Policy Review, June.

Humphrey, J. and L. Navas-Alemán (2010), Value Chains, Donor Interventions and Poverty Reduction: A Review of Donor Practice, Brighton, Institute of Development Studies.

Humphrey, J. and H. Schmitz (2004), "Governance in global value chains", Local Enterprises in the Global Economy, H. Schmitz (ed.), Cheltenham, Edward Elgar Publishing.

(2002), "How does insertion in global value chains affect upgrading in industrial clusters?", Regional Studies, vol. 36, No. 9, Taylor \& Francis.

Jaffee, S., S. Henson and L. Diaz Rios (2011), Making the Grade: Smallholder Farmers, Emerging Standards, and Development Assistance Programs in Africa, Washington, D.C., World Bank [online] http://siteresources.worldbank.org/INTARD/ Resources/Making_the_Grade_ePDF2.pdf.

Kaplinsky, R. (2000), "Globalisation and unequalisation: what can be learned from value chain analysis?", Journal of Development Studies, vol. 37, No. 2, Taylor \& Francis.

Kaplinsky, R. and J. Readman (2001), Integrating SMEs in Global Value Chains, Towards Partnership for Development, Vienna, United Nations Industrial Development Organization (UNIDO).

Krugman, P. (1995), "Growing world trade: causes and consequences", Brookings Papers on Economic Activity, vol. 1995, No.1, 25th Anniversary Issue, Washington, D.C., Brookings Institution Press.

Memedovic, O. (2004), "Inserting local industries into global value chains and global production networks: opportunities and challenges for upgrading", Working Papers, Vienna, United Nations Industrial Development Organization (UNIDO). 
Morrison, A., C. Pietrobelli and R. Rabellotti (2006), "Global value chains and technological capabilities: a framework to study industrial innovation in developing countries", CESPRI Working Paper, No. 192, Milano, Universitá Luigi Bocconi.

Ng, F. and A. Yeats (1999), "Production sharing in East Asia: who does what for whom, and why?", Policy Research Working Paper, No. 2197, Washington, D.C., World Bank.

Padilla-Pérez, R. and R. Hernández (2010), “Upgrading and competitiveness within the export manufacturing industry in Central America, Mexico, and the Dominican Republic", Latin American Business Review, vol. 11, No. 1, Taylor \& Francis.

Pietrobelli, C. and R. Rabellotti (2007), Upgrading to Compete. Global Value Chains, SMEs and Clusters in Latin America, Cambridge, Harvard University Press.

Porter, M. (1990), The Competitive Advantage of Nations, London, MacMillan.

Sturgeon, T. (2002), "Modular production networks: a new American model of industrial organisation", Industrial and Corporate Change, vol. 11, No. 3, Oxford University Press.

The Yearbook of World Electronics Data 2002/2003 (2002), Surrey, United Kingdom, Reed Electronics Research.

UNIDO (United Nations Industrial Development Organization) (2004), Inserting Local Industries into Global Value Chains and Global Production Networks, Vienna, United Nations.

Weinberger, K. and T.A. Lumpkin (2007), "Diversification into horticulture and poverty reduction: a research agenda", World Development, vol. 35, No. 8, Amsterdam, Elsevier.

Yeats, A. (2001), "Just how big is global production sharing?", Fragmentation: New Production Patterns in the World, S. Arndt and H. Kierzkowski (eds.), Oxford, Oxford University Press. 



\section{Chapter I \\ Mapping global value chains ${ }^{1}$}

Koen De Backer

Sébastien Miroudot ${ }^{2}$

\section{Introduction}

World trade and production are increasingly structured around what are known as "global value chains" (GVCs). ${ }^{3}$ A value chain can be defined simply as the "full range of activities that firms and workers do to bring a product from its conception to its end use and beyond" (Gereffi and Fernandez-Stark, 2011). Typically, a value chain includes the following

This is a shortened version of the OECD document originally published under the title: De Backer, K. and S. Miroudot (2013), "Mapping Global Value Chains", OECD Trade Policy Papers, No. 159, OECD Publishing, http://dx.doi.org/10.1787/5k3v1trgnbr4-en. The names used in the original OECD publication for certain countries and territories have been modified to conform with the practice of the United Nations Economic Commission for Latin America and the Caribbean (ECLAC).

2 The authors would like to thank Thibault Fally, of the University of Colorado Boulder, and Benno Ferrarini, of the Asian Development Bank, for their comments on an earlier draft. The paper benefited from its presentation and discussion at the conference on Latin America's prospects for upgrading in GVCs (Mexico City, March 2012), organized jointly by the Economic Commission for Latin America and the Caribbean (ECLAC), the Organisation for Economic Cooperation and Development (OECD), the Inter-American Development Bank (IDB) and the World Bank; at the final WIOD (World Input-Output Database) conference entitled "Causes and Consequences of Globalization" (Groningen, The Netherlands, April 2012); and at meetings of the OECD Working Party of the Trade Committee and the OECD Working Party on the Globalisation of Industry in Paris.

3 See Gereffi and Fernandez-Stark (2011) for an overview of global value chain analysis. 
activities: design, production, marketing, distribution and support to the final consumer. These activities can be performed within the same firm or divided among different firms. The fact that they are increasingly spread over several countries explains why the value chain is regarded as "global".

The concept of GVC was introduced in the early 2000s and has been useful for capturing several characteristics of the world economy:

- The increasing fragmentation of production across countries. GVCs link geographically dispersed activities into a single industry and give insights into the shifting patterns of trade and production. For policymakers, GVCs are useful for apprehending the interconnectedness of economies. In particular, GVCs emphasize how export competitiveness relies on the sourcing of efficient inputs, as well as access to final producers and consumers abroad.

- The specialization of countries in tasks and business functions rather than in specific products. Whereas most policies still assume that goods and services are produced domestically and compete with "foreign" products, the reality is that most goods and an increasing number of services are "made in the world" and that countries compete for economic roles within the value chain. The concept of GVCs is thus important for closing the gap between policy and the reality of business.

- The role of networks, global buyers and global suppliers. Global value chain analysis gives insights into economic governance and helps to identify firms and actors that control and coordinate activities in production networks. Understanding governance structures is important for policymaking, in particular for assessing how policies can have an impact on firms and the location of activities.

For all these reasons, there is a need to better understand how GVCs work and to provide new data and analysis to policymakers in the field of trade, industry and innovation. This chapter takes stock of the growing body of research on GVCs and develops a series of indicators and case studies, based on newly available data. Because policies are determined at the level of countries and for industries broadly defined, the report focuses on aggregate data and country indicators.

Against this backdrop, this chapter is organized as follows: section A provides a brief description of the rise of global value chains while section B discusses the data used in the empirical analysis, as well as the methodology, and includes some stylized facts on the importance of GVCs; section C introduces four case studies, three in the manufacturing 
sector (agriculture and food products, electronics and motor vehicles) and one in the services industry (business services); and section D presents concluding remarks.

\section{A. The rise of global value chains}

\section{A brief history of global value chains}

The concept of the global value chain can be traced back to the end of the 1970s with some work on the "commodity chain" (Bair, 2005). The basic idea was to trace all the sets of inputs and transformations that lead to an "ultimate consumable" and to describe a linked set of processes that culminate in this item (Hopkins and Wallerstein, 1977). The concept of "global commodity chain" was later introduced in the work of Gary Gereffi (1994), describing for example the apparel commodity chain, from raw materials (such as cotton, wool or synthetic fibres) to final products (garments). In the 2000s, there was a shift in terminology from "global commodity chain" to "global value chain", with the latter emerging from the analysis of trade and industrial organization as a value added chain in the international business literature (Porter, 1985). The concept of value chain is not really different from the commodity chain but it is more ambitious inasmuch as it tries to capture the determinants of the organization of global industries (Bair, 2005). Gereffi, Humphrey and Sturgeon (2005) provide a theoretical framework for value chain analysis and describe different types of global value chain governance.

An important distinction emphasized in the literature is between "producer-driven" and "buyerdriven" chains. Producer-driven GVCs are found in high-tech sectors such as the semi-conductor or the pharmaceuticals industry. Because these industries rely on technology and research and development $(R \& D)$, lead firms are placed upstream and control the design of products as well as most of the assembly, which is fragmented across different countries. In buyer-driven chains, retailers and branded marketers control the production, which can be totally outsourced, the focus being on marketing and sales. GVCs with lower needs for capital and relying on fewer skilled workers are generally organized this way, as illustrated by the apparel commodity chain (Gereffi, 1994).

A third and more recent strand of research places the emphasis on the concept of "network" rather than "chain" (Coe and Hess, 2007). This metaphor shift highlights the complexity of the interactions among global producers: "economic processes must be conceptualized in terms of a complex circuitry with a multiplicity of linkages and feedback loops rather 
than just 'simple' circuits or, even worse, linear flows" (Hudson, 2004). In this chapter, the focus is more on "global value chains", describing countries' position and participation in global production, rather than relying on network analysis.

\section{The main drivers of the phenomenon}

The outsourcing of activities and the fragmentation of production are not new. The trade economist Bertil Ohlin noted as early as 1933 that, "As a matter of fact, production is in many cases divided not into two stages - raw materials and finished goods- but into many". There are examples of global value chains before the 1980s. But what is undoubtedly new is the scale of the phenomenon and the way in which technological change has allowed a fragmentation of production in the past two decades that was not possible before.

The main reason why firms can fragment their production is that trade costs have decreased significantly. Trade costs include the whole range of costs that companies face between the factory or office where the good or service is produced and the final consumer. In the case of goods, trade costs include land transport and port costs, freight and insurance costs, tariffs and duties, and costs associated with nontariff measures; they may also be extended to include mark-ups from importers, wholesalers and retailers. In the case of services, transport costs are replaced with communication costs (although services can also be provided by natural persons that have to travel to the country where the consumer is located) and trade barriers are non-tariff measures. Other important costs relating to global value chains are co-ordination costs as geographically dispersed activities have to be managed in a consistent way.

Transport and communication costs have decreased thanks primarily to technological advances such as the container or the Internet. Progress has been made all along the logistics chain, ensuring the smooth flow of goods and services in a co-ordinated and inexpensive way. Lower trade costs are, however, not limited to technological change. Other important drivers were trade and investment liberalization and regulatory reforms in key transport and infrastructure sectors. Policies have played an important role in improving efficiency and have contributed, just as much as advances in transport and communication technologies, to the fragmentation of production.

Lastly, beyond technological change and regulatory reforms, it is also on the demand side that the world economy has radically changed in the last decades. The emergence of Asia and the high growth rates in 
new emerging economies have increased the size of world demand and boosted international trade. Asia is not just the factory of the world; there are also new consumers that can afford a broader range of products. As a consequence, trade in final goods and services has increased as much as trade in intermediates.

\section{How far will the fragmentation of production go?}

The level of fragmentation of production can be explained by the technical characteristics of products and the costs incurred when the production is split between different locations. Not all products can have their production sliced up in multiple stages. Services, for example, are less prone to vertical specialization when face-to-face contact between the provider and the consumer is required. Moreover, as described by Jones and Kierzkowski (2001), the level of fragmentation depends on a trade-off between lower production costs and higher transactions/co-ordination costs. By locating stages of production in countries where production costs are lower, firms decrease the marginal cost of production but they incur higher fixed and variable costs that correspond to all the services links needed to maintain the production in several locations. There is therefore an optimal level of fragmentation that depends on the level of trade and transaction costs.

This optimal level of fragmentation implies that we should not expect global value chains to expand continuously. Following the financial crisis, the consolidation of some value chains has been observed. Increasingly difficult access to trade finance, coupled with higher transactions costs due to uncertainties in the supply of some inputs, has caused the disruption of some value chains. Likewise, following the disruptions of GVCs in the aftermath of the 2011 tsunami in Tokohoku (Japan), some companies, in particular in the automotive and electronics industries, have made their value chains significantly shorter and less complex.

Companies continuously redefine their strategies and their boundaries. A model of production which is successful at some point is not guaranteed to be successful in the future. Some GVCs also rely on differences in the cost of labour and capital between countries, which are constantly changing. For example, as China grows more prosperous, wages rise and some production is already being offshored to other countries, while China develops new activities requiring workers with higher skills. Trade and production patterns will continue to change and policymakers should consequently be ready to make adjustments. 


\section{Industries, business functions or tasks?}

An important implication of the new GVC paradigm is the need to look beyond industries to understand trade and production patterns. Industries are still relevant for economic analysis but trade tends to be more intraindustry and the reallocation of resources following trade and investment liberalization is also an intra-industry reallocation (Melitz, 2003). If the division of labour no longer follows industries, the question is: what is the relevant unit?

The GVC literature insists on business functions, which are the activities along the supply chain, such as R\&D, procurement, operations, marketing or customer services. Countries tend to specialize in specific business functions rather than specific industries, such as the assembly operations for China or business services for India. The idea behind GVCs is also that the product and firm strategies define the global value chain, involving several "industries". Some services industries, such as financial services or transport services, will be part of almost all value chains. Extractive and raw material industries are also likely to be at the beginning of most manufacturing GVCs. The value chain follows specific commodities and services and encompasses several industries. This is also why specialization is no longer in industries but in specific functions in the value chain.

The trade literature has also introduced a smaller unit of specialization based on specific workers' activities: the tasks they perform. Tasks can be outsourced and their offshoring becomes "trade in tasks" (Grossman and Rossi-Hansberg, 2006). However, according to Lanz, Nordas and Miroudot (2011), there is no clear evidence that the fragmentation of production occurs at the task level. Firms generally prefer "multi-tasked" workers and "Toyotism" rather than "Fordism" remains the dominant production model. This being said, bundles of tasks could explain the specialization of countries in the value chain, bringing the "trade in tasks" paradigm close to the "business functions" described in the GVC literature. What is clear is that, as highlighted by Grossman and Rossi-Hansberg, it is "not wine for cloth anymore" and policymakers have to think beyond industries when looking at trade and industrial policies.

\section{B. Data and methodology}

Global value chains challenge the way statistics on trade and output are collected. There is a growing awareness that current statistics can give the wrong picture (Maurer and Degain, 2010). Trade statistics in 
particular are collected in gross terms and record several times the value of intermediate inputs traded along the value chain. As a consequence, the country of the final producer appears as capturing most of the value of goods and services traded, while the role of countries providing inputs upstream is overlooked. Bilateral trade statistics and output measures at the national level make it difficult to visualize the "chain" or the production network.

\section{New data available to study GVCs: the OECD ICIO model}

The Organisation for Economic Cooperation and Development (OECD), in co-operation with WTO, has built a new database of trade flow in value-added terms based on a global model of international production and trade networks. ${ }^{4}$ The Inter-Country Input-Output (ICIO) model links internationally input-output tables from 58 countries (one of these countries being the "rest of the world") and accounts for more than $95 \%$ of world output. Flows of intermediate inputs across countries and industries come from the Bilateral Trade Database by Industry and End-Use Category (BTDIxE) also developed in the course of this project. ${ }^{5}$

The OECD ICIO model allows the analysis of GVCs from a truly global perspective detailing all transactions between industries and countries for 37 industries. In contrast, previous research often used input-output data for a limited or even single country, hence offering only a partial picture of the GVC reality. Five years are available: 1995, 2000, 2005, 2008 and 2009. As 2009 was the year of the financial crisis and "trade collapse", indicators are quite different from previous years. This is why 2008 was added to the model (thus offering some insight into the impact of the crisis on GVCs).

There are several assumptions behind the construction of an ICIO model and gaps persist in the data collected by the OECD. One should be aware that such a model can only provide rough estimates of bilateral trade flows across industries and of the contribution of each economy to global production. At the level of aggregation where the results are presented, the margin of error remains low. But the more specific the results in terms of countries and industries, the more cautious the reader should be about the accuracy of the data reported.

See http:/ /oe.cd/tiva for more information on the TiVA database.

The BTDIxE database is described in Zhu, Yamano and Cimper (2011) and covers trade in goods. Earlier work on trade in intermediate goods and services includes Miroudot, Lanz and Ragoussis (2009). 


\section{Measuring the importance of GVCs: country and industry indicators}

This section provides a non-technical description of the indicators; readers interested in the technical details are referred to annex 1 , which includes further information on the methodology. Results are presented on the importance, depth and length of global value chains, as well as the specific position of countries in these production networks.

\section{(a) Participation in GVCs: what is the share of exports involved in a vertically fragmented production process?}

The first question that comes to mind when thinking about GVCs is to what extent countries are involved in a vertically fragmented production. One way to measure it - and historically the first indicator calculated in the literature- is to measure the vertical specialization (VS) share, which can be understood as the import content of exports. This indicator measures the value of imported inputs in the overall exports of a country (the remainder being the domestic content of exports). ${ }^{6}$ However, the VS share only looks at the importance of upstream foreign suppliers in the value chain. As a country also participates in GVCs by being a supplier of inputs used in third countries for further exports, the literature has also introduced the 'VS1' share, which is the percentage of exported goods and services used by other countries as imported inputs in the production of their exports (Hummels, Ishii and Yi, 2001). The VS and VS1 shares may be combined to obtain a comprehensive assessment of the participation of a country in GVCs, both as a user of foreign inputs (upstream links, i.e. backward participation) and as a supplier of intermediate goods and services used in other countries' exports (downstream links, i.e. forward participation). Such an indicator is proposed by Koopman and others (2010).

The participation index at the country level is represented in figure I.1 for OECD countries. The index is expressed as a percentage of gross exports and indicates the share of foreign inputs (backward participation) and domestically produced inputs used in third countries' exports (forward participation). As domestically produced inputs may incorporate some of the foreign inputs, there is an overlap and potentially some double counting (the indicator is not based on value-added trade) ${ }^{7}$.

6 The VS share was first introduced by Hummels, Ishii and Yi (2001) and may be calculated on the basis of national input-output tables. See De Backer and Yamano (2007) and Miroudot and Ragoussis (2009) for previous OECD reports in which the vertical specialization share is calculated.

7 Likewise, some foreign inputs may incorporate domestic value added exported at an earlier stage of the value chain. 
Small open economies such as Luxembourg, the Czech Republic and the Slovak Republic source more inputs from abroad in GVCs than large countries, such as the United States of America or Japan (where, owing to the size of the economy, a larger share of the value chain is domestic (see below)). The participation index, however, is less correlated with the size of countries than the import content of exports, since it also looks forward at the use of inputs in third countries. For example, the foreign content of United States exports is about $15 \%$ while United States participation in GVCs rises to $40 \%$ when the use of United States intermediates in other countries' exports is taken into account.

\section{Figure l.1}

GVC participation index in OECD countries, 2009

(Foreign inputs (backward participation) and domestically-produced inputs used in third countries' exports (forward participation), as a percentage of gross exports)

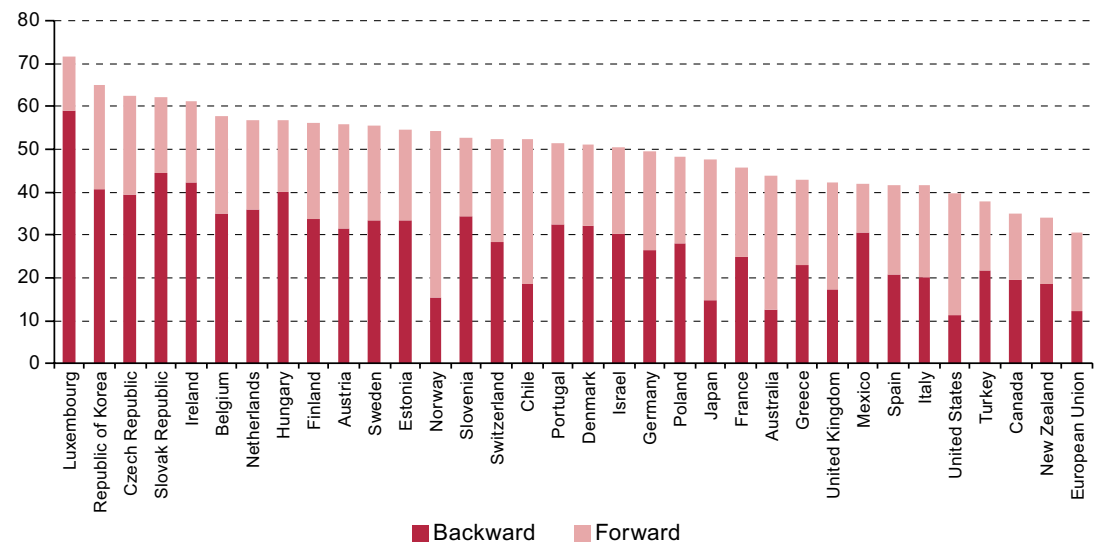

Source: Authors' calculations on the basis of the OECD ICIO model, May 2013.

A comparison of OECD and non-OECD economies (see figure I.2) shows that the participation in GVCs is of a similar magnitude in the two groups of countries. Large economies, such as Brazil or India, have a lower share of exports made of inputs taking part in vertical trade, as opposed to small economies, such as Singapore or Taiwan Province of China. But figure I.2 only includes emerging economies; the participation in GVCs would be lower for least developed countries (LDCs) if data were available to include them in the global input-output model. 


\section{Figure I.2}

GVC participation index for selected non-OECD economies, 2009

(Foreign inputs (backward participation) and domestically-produced inputs used in third countries' exports (forward participation), as a percentage of gross exports)

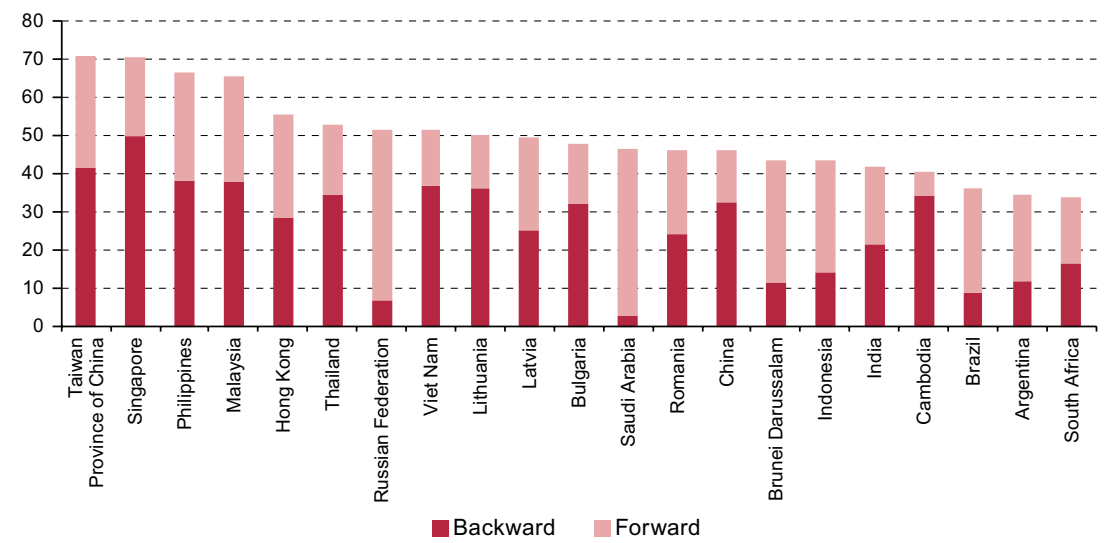

Source: Authors' calculations on the basis of the OECD ICIO model, May 2013.

(b) The length of GVCs: how many production stages in the GVC?

While the imported foreign inputs in countries' own exports and the domestically-produced intermediates used in third-countries' exports give an idea of the importance of vertical specialization, they do not indicate how "long" value chains are, i.e. how many production stages are involved. For example, a high VS share could correspond to the use of expensive raw materials in a very simple value chain, while conversely a high VS1 share could be added in one go at the final stage of the production process. This is why an indication of the "length" of GVCs would be useful and complementary.

In the literature, the length of GVCs has been assessed through the "average propagation length" (APL), an indicator emerging from inputoutput analysis (Dietzenbacher and Romero, 2007). In this section we refer to a simpler index, introduced more recently in the trade literature (Fally, 2012; Antràs and others, 2012). The index takes the value of 1 if there is a single production stage in the final industry and its value increases when inputs from the same industry or other industries are used, with a weighted average of the length of the production involved in these sectors (see annex 1 for the calculation).

Information available on foreign and domestic inputs makes it possible to identify the domestic and international parts of the value chain. Figure I.3 below shows the average length for all industries. The value of the index can be interpreted as the actual number of production 
stages if it is based on plant-level information. When calculated at the aggregate level, the value is only an index but still reflects the length of the value chain.

Figure I.3

Average length of GVCs across all industries ${ }^{a}$

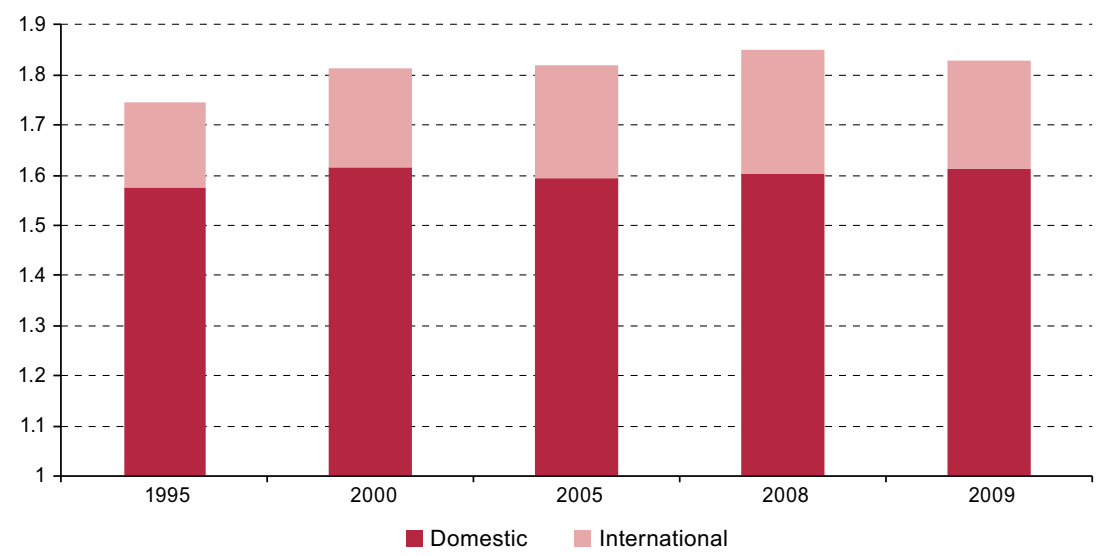

Source: Authors' calculations on the basis of the OECD ICIO model, May 2013.

a The value of the index is 1 when no intermediate inputs are used to produce a final good or service.

Figure I.3 highlights the increase in the average length of value chains between 1995 and 2008. The domestic length has remained almost unchanged; the international part of the value chain accounts for all of the increase. With the financial crisis and trade collapse in 2009, there has been a decrease in the length of GVCs. Again the international part is the driver of the observed change with even a slight increase in the domestic length in 2009, confirming that some companies have switched back to domestic suppliers owing to the lack of availability of trade finance and risks associated with international suppliers. Figure I.3 is consistent with the "optimal level of fragmentation" previously mentioned. Firms may have explored outsourcing strategies with various degrees of success and some of them have abandoned such strategies. However, the financial crisis of 2008-2009 is very recent and it is too early to determine whether this consolidation of GVCs is cyclical or whether it corresponds to a structural change. Further reductions in trade and transaction costs in the future could lead to higher levels of fragmentation.

More variation in the length of value chains is observed at the industry level (see figure I.4). The five industries with the highest index of fragmentation are: television and communication equipment, motor vehicles, basic metals, textiles, leather and footwear and electrical 
machinery. Services industries have on average shorter value chains but some services industries such as construction, hotels and restaurants, research and development or transport and storage are also found to have relatively long value chains. Education and real estate activities are among the few services sectors that do not involve any significant fragmentation of production.

Figure I.4

Length of GVCs by industry, $2009^{\text {a }}$

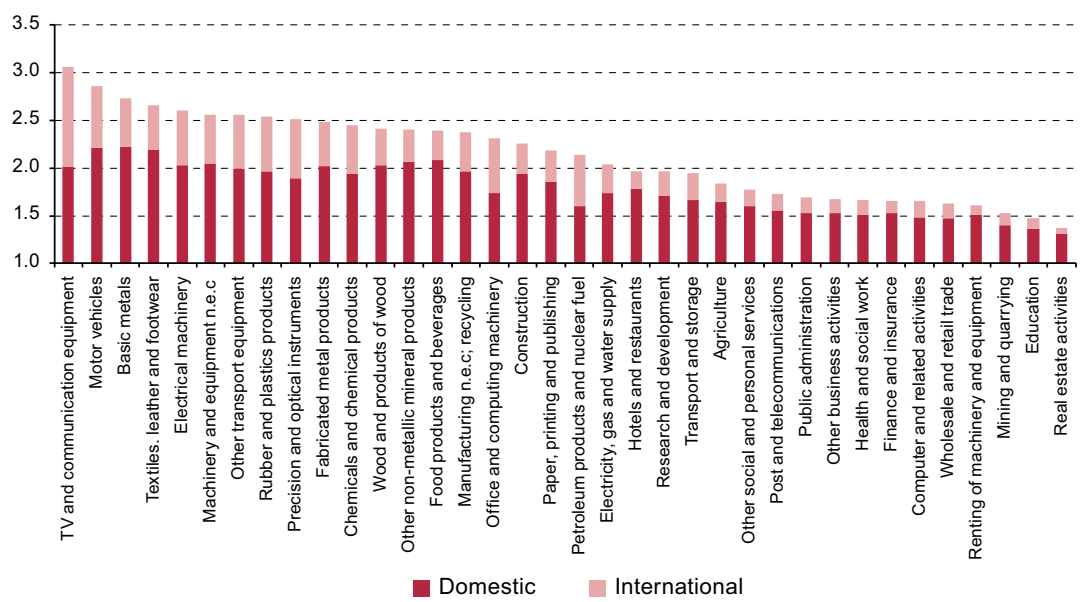

Source: Authors' calculations on the basis of the OECD ICIO model, May 2013.

a The value of the index is 1 when no intermediate inputs are used to produce a final good or service.

\section{The distance to final demand: what is the position of a country in the value chain?}

Once the depth and length of particular GVCs have been assessed, the important question is where countries are located in the value chain. A country may be upstream or downstream, depending on its specialization. Countries upstream produce the raw materials or intangibles involved at the beginning of the production process (e.g., research, design), while countries downstream carry out the assembly of processed products or specialize in customer services.

Fally (2012) and Antràs and others (2012) have introduced a measure of "upstreamness", which may be referred to as the "distance to final demand". Starting from one industry in a given country, the index measures the number of stages of production that are left before the goods or services produced by this industry reach final consumers. This is again a calculation based on the inter-country input-output framework 
that was used to derive the previous GVC indicators. The average value by country (over all industries) is presented in figure I.5 for selected OECD countries and non-OECD economies. As regards the change in the value of the index between 1995 and 2008, figure I.5 includes only those economies where the value has increased by more than $8 \%$ in order to show the most significant changes. An increase in "upstreamness" means that these economies are now more specialized in the production of inputs at the beginning of the value chain. The increase in the index is high for economies such as China, Taiwan Province of China, Hong Kong (China), Malaysia, the Philippines, Singapore or Thailand. Interestingly, however, European Union countries such as Austria, Germany, Ireland or Luxembourg have also significantly increased their upstreamness. In Latin America, Chile is the country with the highest increase in the distance to final demand.

There are only a few countries where the distance to final demand has decreased (for example, Cambodia, Romania, the Slovak Republic and Slovenia, (see figure I.5). These countries tend to specialize in goods and services further downstream. The fact that, on average, most countries move upstream is consistent with the overall increase in the length of GVCs and the outsourcing phenomenon. When the production of some inputs is outsourced, their value added is moved backward to the industries supplying intermediate inputs and the distance to final demand increases.

Figure I.5

Distance to final demand, selected economies, 1995 and 2009 a

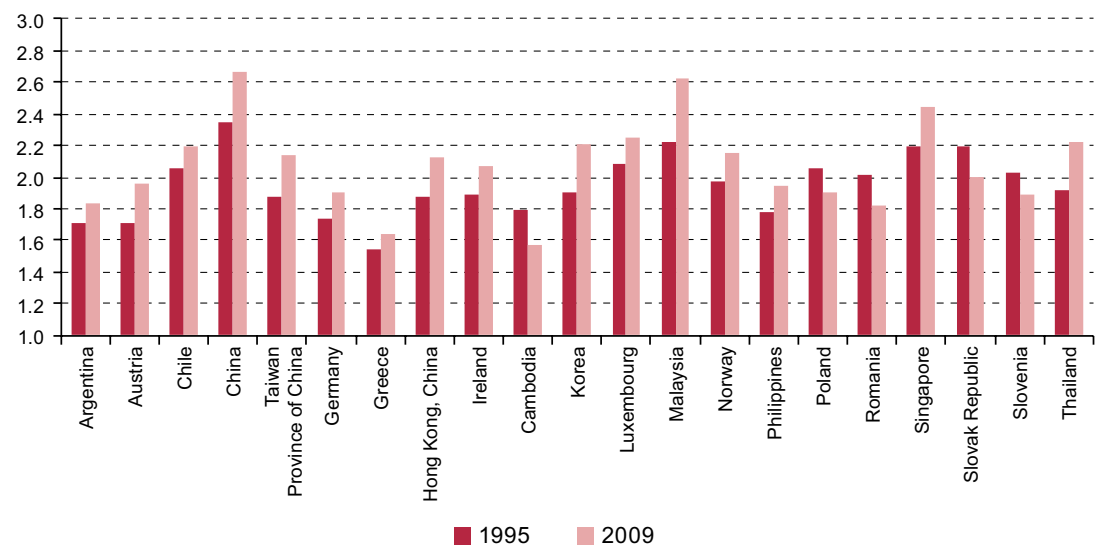

Source: Authors' calculations on the basis of the OECD ICIO model, May 2013. The countries represented are those where the distance to final demand increased or decreased by more than $7 \%$ between 1995 and 2009.

a The value of the index is 1 when all goods and services produced are directly purchased by final consumers. 
The indicators presented above are further used in the analysis of specific GVCs in the next section. They illustrate the use of aggregate country and industry indicators to inform the policy debate. From the data presented so far, we can emphasize the following stylized facts:

- Even at the aggregate level, empirical data on trade and output confirm the fragmentation of production and the emergence of global value chains. Recent indicators introduced in the literature give a better understanding of the depth of the phenomenon. On average more than half of the value of exports is made up of products traded in the context of global value chains.

- Global value chains are not limited to Asia; all economies show a comparable level of participation in GVCs but with differences between large economies that rely less on international trade and production and small open economies more integrated in global production networks.

- Successful emerging economies have become more specialized in intermediate inputs and generally increased their "upstreamness". This can be seen in Asia, but also in Latin America (in particular with Chile).

\section{Analysis of specific GVCs}

\section{Case study 1: agriculture and food products}

Global value chain analysis is not limited to manufacturing industries; it also applies to services (see below) or agriculture. In the latter case, the GVC perspective links agriculture to downstream activities in what can be called the "agrifood business". This is why the following analysis covers both agriculture and the food and beverage industry.

The agrifood industry is increasingly structured around global value chains led by food processors and retailers. Supermarkets, for example, work with both importers and exporters and seek to control how products are grown and harvested. They wish to ensure that quality and food safety standards are met all along the chain and this requires vertical coordination. In all countries, consumers have changed their consumption patterns and demand food quality and safety (Reardon and Timmer, 2007). At the same time, FDI and trade liberalization have given new opportunities for firms to reorganize their value chain. A relatively small number of companies now organize the global supply of food and link small producers in developed or developing countries to consumers all over the world (Gereffi and Lee, 2009). 
At the product level, map I.1 represents the Nutella global value chain. Nutella is a famous hazelnut and cocoa spread sold in more than 100 countries. ${ }^{8}$ About 350,000 tons of Nutella are produced each year. Nutella is representative of agrifood value chains. The food processing company Ferrero International SA is headquartered in Luxembourg and currently has ten factories producing Nutella: five are located in the European Union, one in Russia, one in Turkey, one in North America, one in South America and one in Australia. Some inputs are mainly locally supplied, for example the packaging or some of the ingredients like skimmed milk. There are however ingredients that are globally supplied: hazelnuts come mainly from Turkey, palm oil from Malaysia, Papua New Guinea and Brazil, cocoa mainly from Côte d'Ivoire, Ghana, Nigeria and Ecuador, sugar mainly from Europe and the vanilla flavour from the United States and Europe. Nutella is then sold around the world through sales offices (which are more numerous than the few represented in map I.1).

The Nutella global value chain

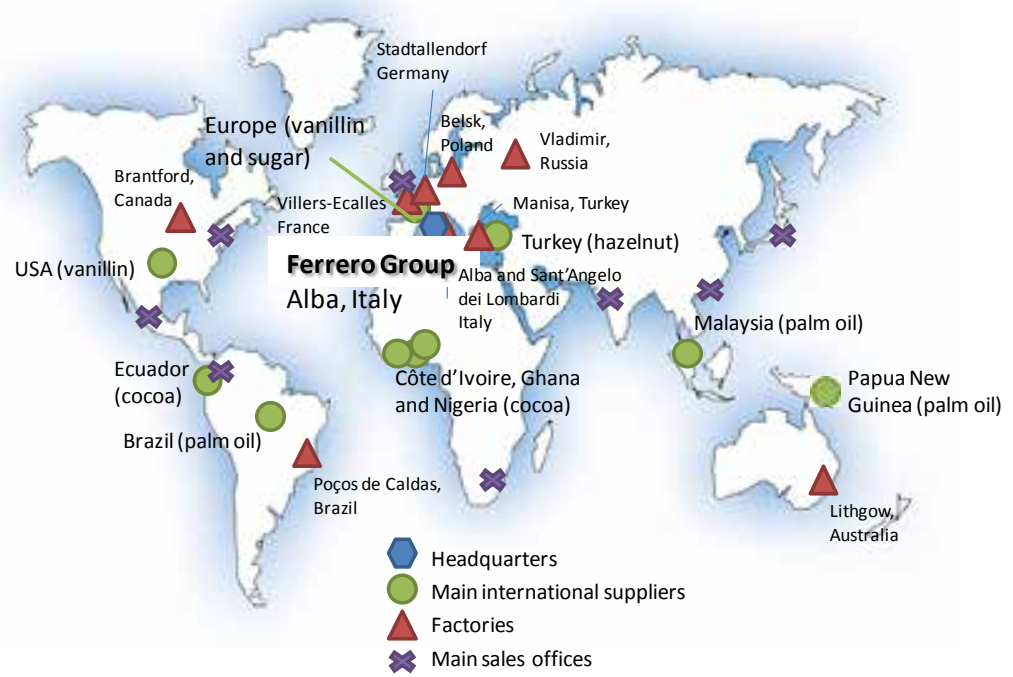

Source: Organisation for Economic Cooperation and Development (OECD), Mapping Global Value Chains, Paris, 2012 [online]http://www.oecd-ilibrary.org/trade/mapping-global-value-chains_ $5 \mathrm{k} 3 \mathrm{v} 1$ trgnbr4-en.

$8 \quad$ Nutella ${ }^{\circledR}$ is a registered trademark used for a spread containing cocoa and other ingredients and owned by Ferrero S.p.A. (Piazzale Pietro Ferrero). 
The location of production is close to final markets where Nutella is in high demand (Europe, North America, South America and Oceania). There is no factory in central and east Asia so far because the product is less popular (another Ferrero delicacy, the Ferrero Rocher is however more popular in Asia). In agrifood business value chains, there are more developing and emerging economies involved, as can be seen with countries in Latin America and Africa in the case of Nutella.

Figures I.6 and I.7 show that agriculture and food products value chains are relatively long. When they involve breeding animals for instance, there are many agricultural inputs upstream to produce all the food consumed and then further processing downstream and longer retailing chains when products are delivered for example to hotels or restaurants. Fally (2012) finds that in the United States economy, meat packing plants and sausages and other prepared meat products have the longest value chains.

Both agriculture and food products have value chains that are quite international, in particular in the case of small economies such as Luxembourg or Singapore. East Asian economies such as Viet Nam or Cambodia also have highly international value chains. China has a different profile for agriculture and food products than in other GVCs. Most of the intermediate inputs used by the country in the different production stages are domestic.

Figure I.6

Length index for the agriculture value chain, by country, $2009^{\text {a }}$

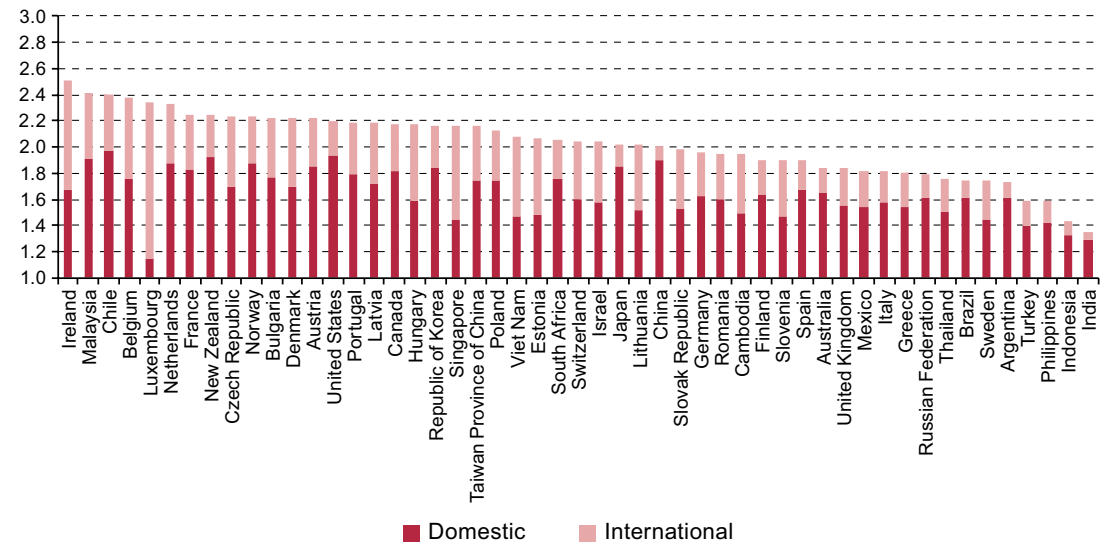

Source: Authors' calculations on the basis of the OECD ICIO model, May 2013.

a The value of the index is 1 when no intermediate inputs are used to produce a final good or service. 
Figure I.7

Length index for the food product value chain, by country, $2009^{a}$

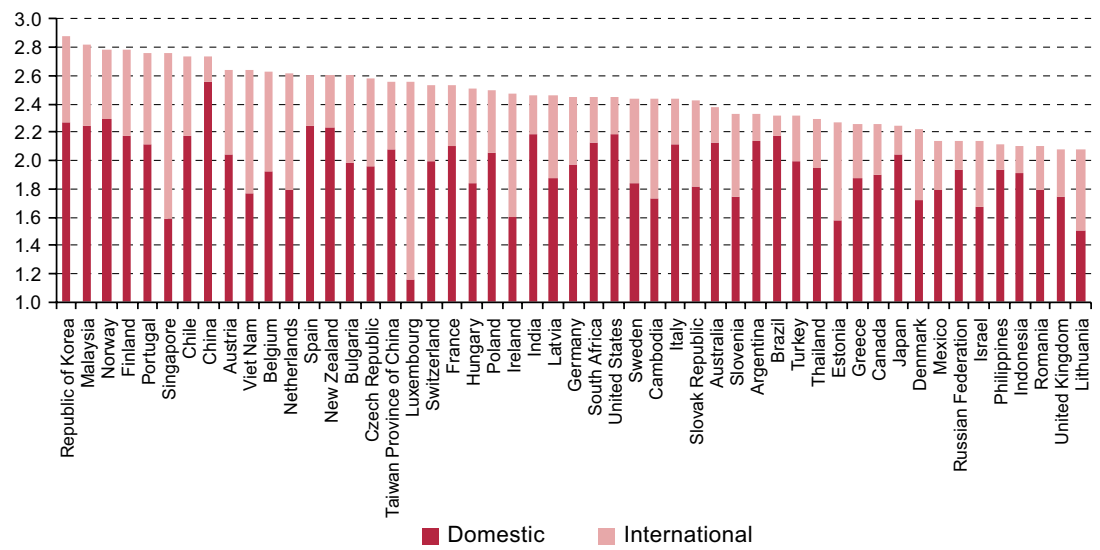

Source: Authors' calculations on the basis of the OECD ICIO model, May 2013.

a The value of the index is 1 when no intermediate inputs are used to produce a final good or service.

In terms of participation, Cambodia, Viet Nam and Brazil are the three economies where the agriculture global value chain represents the highest percentage of exports (see figure I.8). Brazil is positioned more upstream in the value chain than Viet Nam and Cambodia. China is the country with the highest index of upstreamness, while India has one of the lowest. Agriculture represents a similar share of exports for the two economies, but their role in the agriculture value chain is very different. India produces mainly products going to final consumers after few production stages while China is involved in much longer agriculture GVCs, producing mainly inputs used in the agricultural activities of other countries.

Viet Nam, New Zealand and the Netherlands are the three countries with the deepest involvement in the food products and beverages value chain (see figure I.9). Malaysia and China have a clear specialization in inputs high upstream, while Cambodia, Mexico and Lithuania are the countries the most downstream, processing imported food and agricultural products. Figures I.8 and I.9 illustrate the marked differences across countries in patterns of specialization. Moreover, there is no correlation between the participation index and the distance to final demand. Leading exporters of agricultural and food products are found both upstream and downstream in the value chain. 
Figure I.8

Participation and distance to final demand in the agriculture

value chain, by country, 2009

(Percentages and distance indexes)

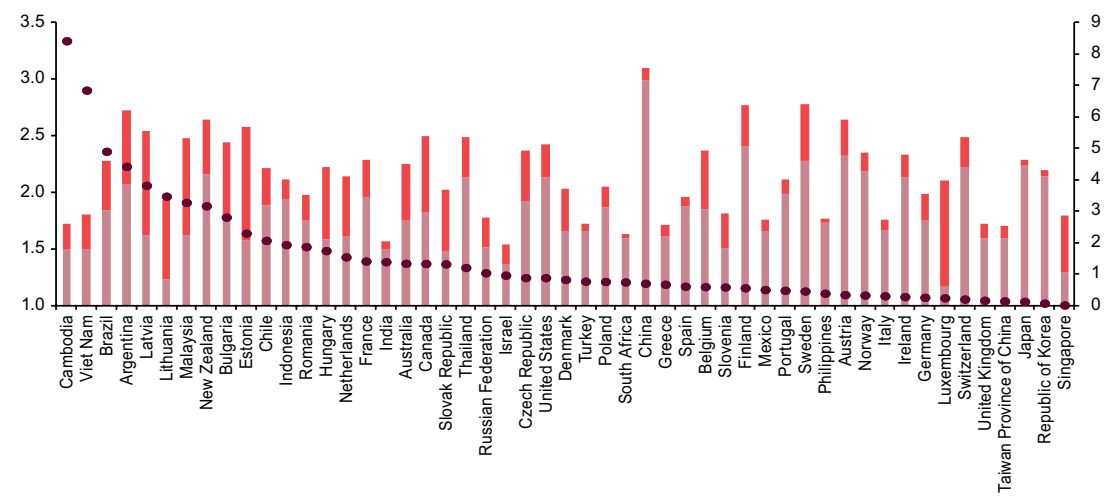

Distance to final demand (domestic) Distance to final demand (international) • Participation (right axis)

Source: Authors' calculations on the basis of the OECD ICIO model, May 2013.

Figure I.9

Participation and distance to final demand in the food

products chain, by country, 2009

(Percentages and distance indexes)

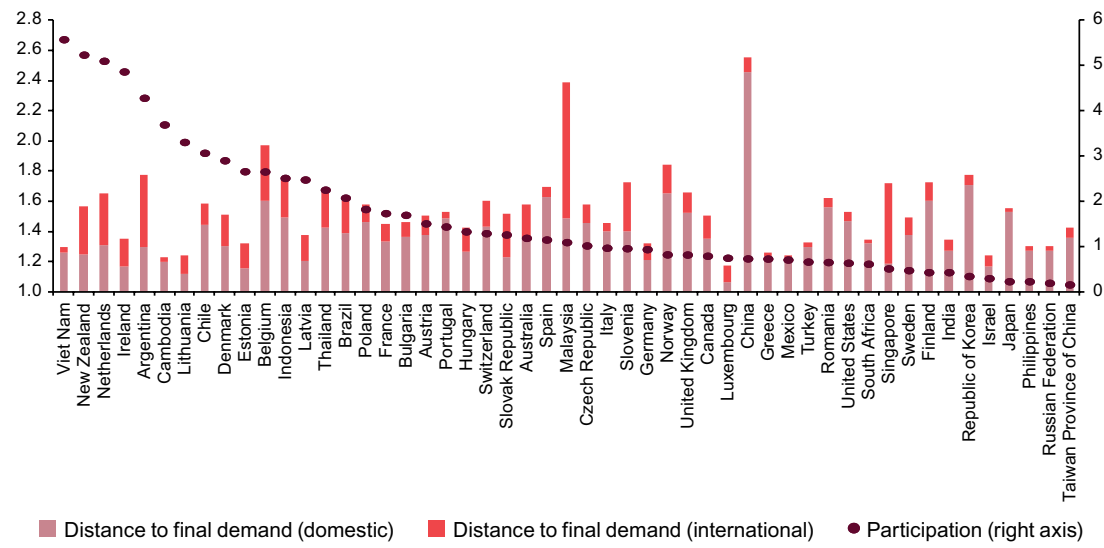

Source: Authors' calculations on the basis of the OECD ICIO model, May 2013.

Aggregate data on the length, participation and distance to final demand confirm what could be highlighted with the Nutella case study. Food products are produced globally in value chains involving both developing and developed countries. The data do not indicate that developing or developed economies are confined to specific roles. 
For example, both Sweden and China can be found high upstream in agriculture value chains and conversely, both Viet Nam and Germany are quite downstream in the food products value chain. As exemplified by the Nutella supply chain, being close to final consumers and to specific input suppliers matters for the agrifood industry and the same activities may be located in developed and emerging markets.

\section{Case study 2: motor vehicles ${ }^{9}$}

The motor vehicle industry 'is one where the unbundling of production has already been taking place for decades; outsourcing or offshoring by companies has pushed the international fragmentation of production quite far in this industry. The value chain of motor vehicles is largely organized through a hierarchical structure, with the large automotive manufacturers positioned at the top of the pyramid as lead firms responsible for design, branding, and final assembly. One level down, first-tier suppliers produce complete subsystems by cooperating with a large network of lower-tier suppliers and subcontractors. Close relationships have developed especially between car assemblers and first-tier suppliers as the latter have taken up a larger role in the whole production process, including design. These suppliers have increasingly developed into global suppliers since lead firms increasingly demand that their largest suppliers have a global presence and system design capabilities as a precondition to being considered as a source for a complex part or subsystem (Sturgeon and Florida, 2004).

Notwithstanding the global activities of lead firms and first-tier suppliers, regional production is still very important in the motor vehicles industry. High transportation costs make intercontinental shipping very costly especially in downstream activities, e.g. complete cars or subsystems. In addition, political pressure may also motivate lead firms to locate production close to end markets; the high cost and visibility of automotive products can create the risk of a political backlash if imported vehicles become too large a share of total vehicles sold. This in turn creates pressure for supplier co-location within regional production systems for operational reasons, such as just-in-time production, design collaboration and the support of globally produced vehicle platforms (Van Biesebroeck and Sturgeon, 2010). As a result, the supplier network in the motor vehicle industry consists of a large number of suppliers,

It should be noted that data availability and quality are not the same across all countries, particularly at a more disaggregated industry level; the results in this paper should be interpreted accordingly with some caution. Continuing effort is put in improving the underlying OECD ICIO model which will result in better estimates in the future. 
some of them entirely local suppliers (typically lower-tier suppliers), others global suppliers with a local presence (top-tier suppliers).

The regional organization of the production process is clearly demonstrated when distinguishing the source country of imported intermediates (see figure I.10). It becomes clear that intra-regional sourcing within the three main regional blocks is important in the motor vehicle industry. European Union member states source the majority of their intermediates from other European countries, while partners of the North American Free Trade Agreement (NAFTA) source mainly from within the NAFTA area. Also in Asia, a clear regional integration has developed through the sourcing of intermediates largely from within the region.

Figure I.10

Import content of exports by country of origin in the motor vehicle industry, 2009

(Percentages)

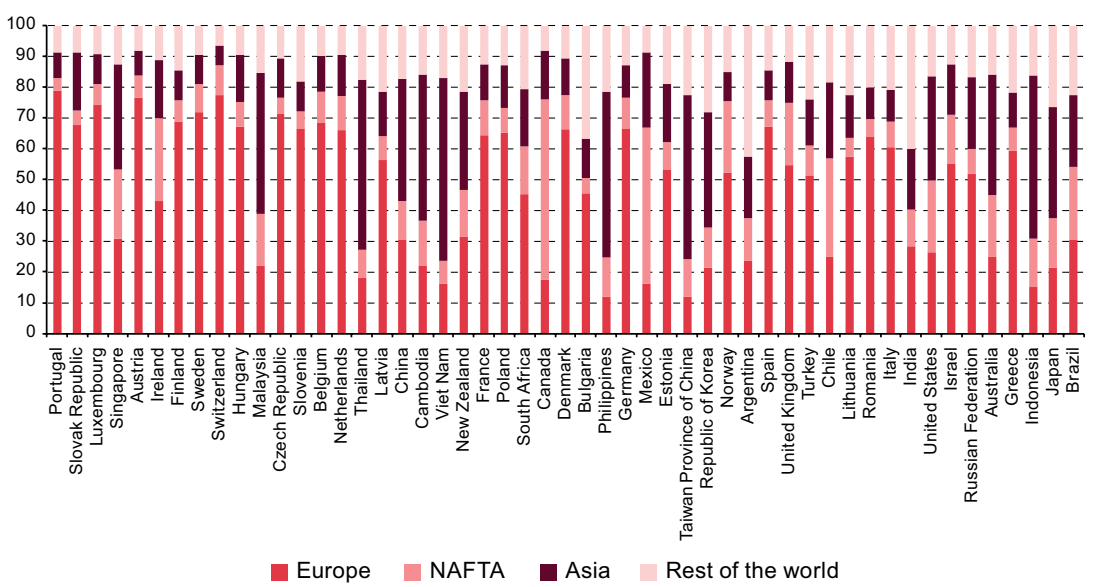

Source: Authors' calculations on the basis of the OECD ICIO model, May 2013.

GVCs are very prominent in the motor vehicles industry, which is reflected in the index of the length of GVCs across all industries (see figure I.4 in previous section). Except for a couple of countries, the index of the 'number of production stages' is above 2.5 (it should be recalled that the index for a final industry without production stages equals 1), illustrating the importance of vertical linkages between the motor vehicles industry and other industries. A significant part of these stages are located abroad, underlining the international (albeit regional rather than truly global) character of these motor vehicle chains. Smaller countries display on average more international production stages, illustrating the fact 
that these countries depend more on (directly and indirectly) imported intermediates (see figure I.11). Countries such as the Republic of Korea, China and Japan display larger production stages at home, reflecting very well the domestic organizational structure of the motor vehicle industry in these countries.

Figure I.11

Length index of value chains in the motor vehicle industry, by country, 2009

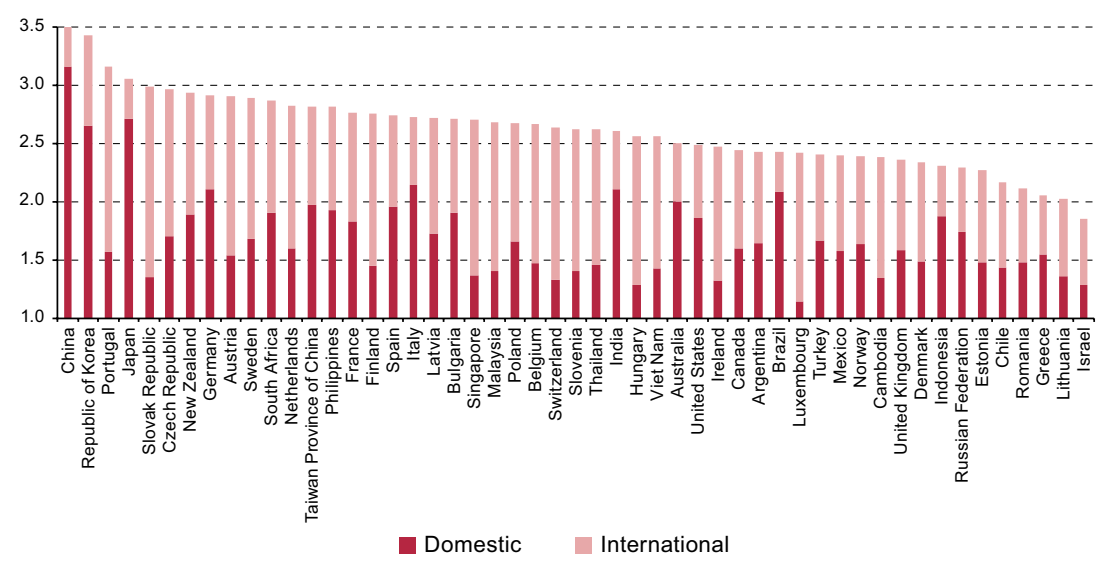

Source: Authors' calculations on the basis of the OECD ICIO model, May 2013.

The participation of countries in motor vehicle GVCs seems to be strongly driven by the importance of imported intermediates (see figure I.10 above on the import content of exports). Figure I.12 shows high participation indices especially for smaller (Eastern European) economies with large car assembly activities: the Slovak Republic, Hungary, the Czech Republic and Poland. In countries like Mexico, maquiladoras undertake large-scale car manufacturing activities based on intermediate products imported from abroad.

Germany also shows a relatively high participation in the car industry, reflecting its large car assembly activities as well as its production of intermediates, which are then exported to other countries. The same observation also applies to Japan and the United States; both countries have major assembly activities but also produce large numbers of intermediates, which are then exported for assembly in other countries. 
Figure I.12

Participation and distance to final demand in the motor

vehicle industry, by country, 2009

(Percentages and distance indexes)

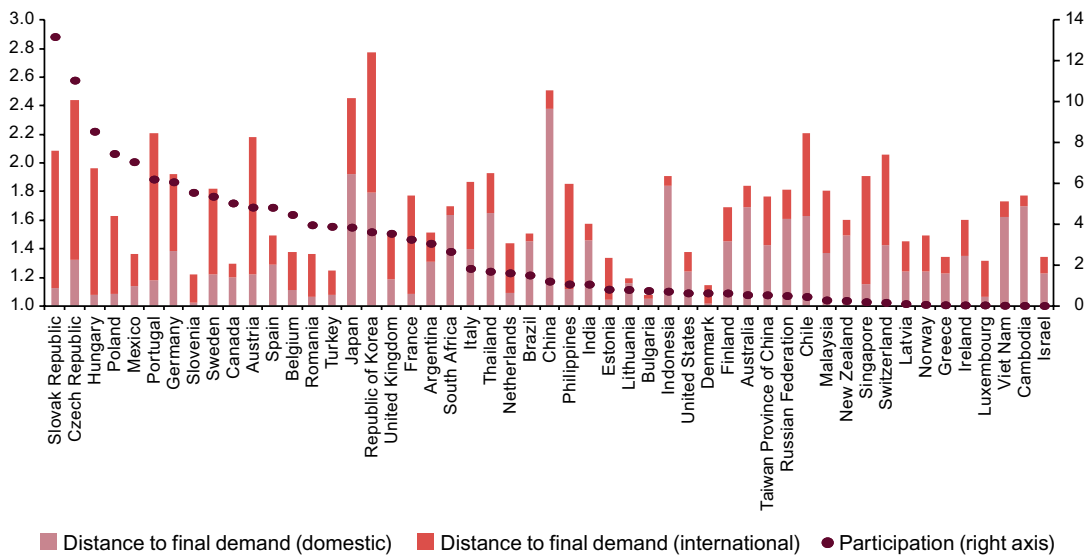

Source: Authors' calculations on the basis of the OECD ICIO model, December 2012.

Countries with a high distance-to-final-demand index, such as the Slovak Republic, Hungary or the Czech Republic in Europe, have companies that are on average located at the higher levels in the supplier networks of automotive industry, meaning that the intermediates that they produce are exported to other countries and included there in more downstream production activities (high international distance to final demand). At the other end, closer to end markets, a country like Mexico is specialized in the assembly of cars for the local market as well as for export to other Latin American and NAFTA countries, hence, its high participation rate and low distance-to-final-demand index.

\section{Case study 3: electronics (office, accounting and computing machinery)}

Electronics is probably the industry where GVCs are the most pervasive as illustrated by the large number of case studies for individual electronic products (Apple's iPod, iPhone, iPad; Nokia's phones, etc.). ${ }^{10}$ An important reason for the high value chain character of the electronics industry is the high modularity of its products. Standardization, codification and computerization allow for a large interoperability of parts and components, which in turn allows for the fragmentation of the

10 Apple's iPod ${ }^{\circledR}$, iPhone ${ }^{\circledR}$ and iPad $\AA$ are trademarks of Apple Inc., registered in the United States and other countries. Nokia is a registered trademark of Nokia Corporation. 
production process across different stages. Product design, logistics and different parts of the production process are often executed by different firms in the value chain.

Value chains in the electronics industry are increasingly global since high modularity enables activities to be undertaken across large distances if transportation costs are low. Most electronic products are characterized by high value-weight ratios, resulting in the rapid (often via air transport) and rather inexpensive delivery of intermediate and final electronic products across the globe. The coordination between the different production stages across different countries is largely done via the Internet, allowing for a smooth sharing and monitoring of information.

The international character of electronics GVCs is reflected in the significant number of international stages involved in the manufacturing of electronic products. On average, around two thirds of the total length index of office, computing and accounting industry concerns international as well as domestic sourcing of intermediates (see figure I.13); results for other electronic industries are similar. Electronic manufacturers source a large number of inputs from suppliers abroad.

Figure I.13

Length index in the electronics value chain, by country, 2009

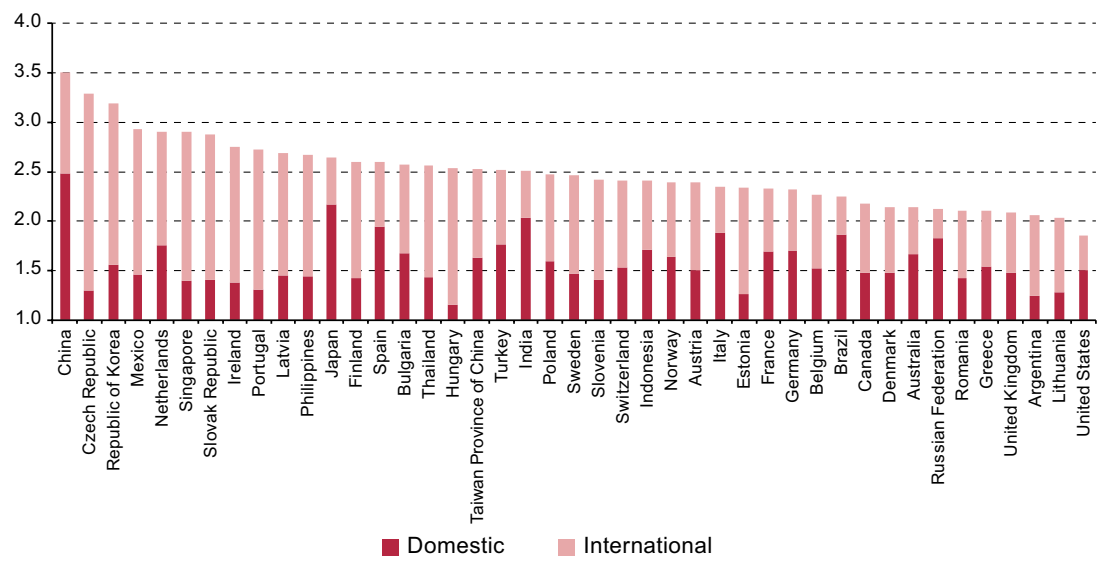

Source: Authors' calculations on the basis of the OECD ICIO model, May 2013.

The electronics GVC consists of a very large number of firms across different countries, from large transnationals to small and mediumsized enterprises (SMEs). Sturgeon and Kawakami (2010) distinguish 
between lead firms and contract manufacturers in discussing the most important actors within the electronics GVC. Lead firms are the firms that carry brands and sell branded products to final customers; these firms have typically a lot of market power over suppliers more upstream in the electronics GVC because of technological leaderships and large investments in brand development. In some segments of the electronics industry such as personal computers (PCs) or mobile phones, these lead firms have grown to platform leaders, as their technology is incorporated in the products of other companies (examples are Intel and Apple).

Contract manufacturers assemble products for lead firms, have limited market power, although they are typically large, and often have operations in different countries (comparable to the first-tier suppliers in the automotive industry). The actual activities undertaken by contract manufacturers differ across companies; original equipment manufacturers (OEMs) provide only production services while original design manufacturers (ODMs) undertake production as well as design activities. Contract manufacturers are working with smaller suppliers although the supplying pyramid in electronics is less developed than in the automotive industry.

Most lead firms in the electronics industry are located in developed economies, especially Europe, Japan and the United States; the Republic of Korea joined this group recently (Sturgeon and Kawakami, 2010). Emerging economies are more represented in the category of contract manufacturers; some companies like Acer and Huawei have successfully moved up the value chain from OEM over ODM to true original brand manufacturers (OBM), while others like computer manufacturers from Taiwan Province of China have failed to do so.

In terms of participation in office, accounting and computing GVCs, the participation of smaller countries is considerable: the Czech Republic, Hungary, Ireland, the Slovak Republic and others import a large variety of inputs from abroad for assembly into (final) products (see figure I.14). Larger countries such as China, Mexico and Thailand act as contract manufacturers using processing imports and exports. The higher participation of countries like Finland and Japan is driven more by their exports of high value intermediates, often to the contract manufacturing countries. 
Figure I.14

Participation and distance to final demand in the electronics

value chain, by country, 2009

(Percentages and distance indexes)

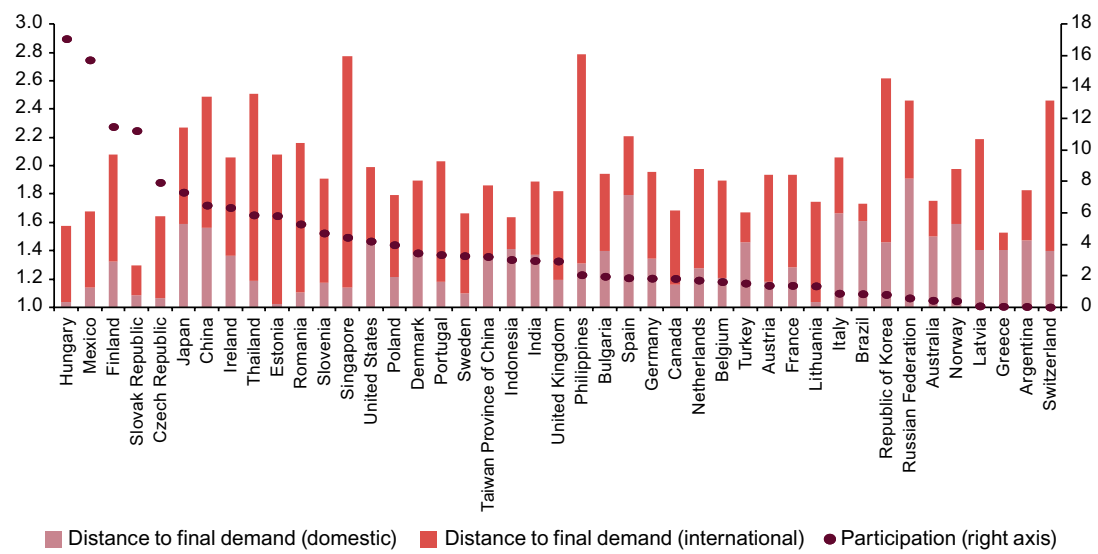

Source: Authors' calculations on the basis of the OECD ICIO model, May 2013.

\section{Case study 4: business services}

In section $B$, there was some evidence that GVCs play a smaller role in the production of services. A large part of the services sector is made up of small domestic companies that provide services directly to domestic consumers with very limited (foreign) inputs. But it would be wrong to assume that this is the case for all services industries. The fragmentation of production takes place in the services sector as well and a good example is the business services sector.

As firms have redefined their boundaries and focused on their core competencies, an increasing number of business services previously supplied within companies have been outsourced and offshored. The share of business services in international trade has steadily increased over the last 15 years. Computer services, legal, accounting, management consulting and public relations services, as well as miscellaneous business, professional and technical services represent a higher share of total trade in services today than 10 years ago (see figure I.15). Business services are an integral part of the global value chain and to some extent what ties it together.

As described by Gereffi and Fernandez-Stark (2010), business services may be horizontal, i.e. provided across all industries, or industry-specific. Horizontal activities include services that are needed by any type of company: information technology services (e.g. software research and development, IT consulting), knowledge process 
outsourcing (KPO) services (e.g. market intelligence or legal services), and business process outsourcing (BPO) services (e.g. accounting, human resource management or supply chain management). Vertical activities are services that are part of a specific value chain in the manufacturing sector (e.g. clinical trials in the pharmaceuticals value chain) or in another services industry (e.g. private equity research or risk management analysis in the banking and insurance industries). Human capital (the education of the people providing the services) accounts for many of the differences in the value of business services. High value-added activities, such as KPO services, are provided by highly educated people, while routine BPO activities (such as recruitment or data management) are carried out by employees with lower degrees.

Figure I.15

Trade in business services, as a share of total trade in services, 2000-2008 (Percentages)

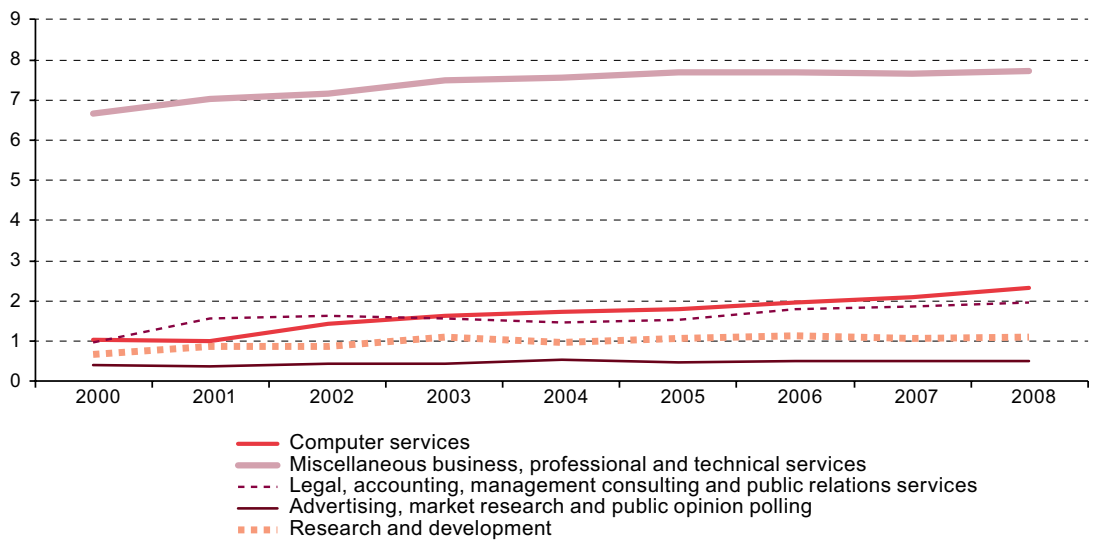

Source: Authors' calculations on the basis of data from the Organisation for Economic and Cooperation and Development (OECD), Statistical Office of the European Communities (EUROSTAT) and United Nations.

The market for business services is concentrated in high-income countries where most firms operate and in particular have their headquarters' activities. But the industry has become global with the offshoring of some of these services to developing economies where the skills and talents can be found at a lower cost. The model of lead firms in the industry is the "global delivery model" (Sako, 2009). Firms create a network of support offices in the countries where their customers are located. Specialized delivery centres are then located in lower cost countries, such as India or the Philippines. All activities are coordinated from the headquarters. This "spider-type" network ensures close contact with clients while achieving economies of scale. 
Services trade statistics are unfortunately not detailed enough to capture bilateral flows of specific business services. Available data and the indicators presented above provide an insight into the role of specific countries in the business services value chain for two segments: "computer and related activities" and "other business services". The first category covers most of the information technology outsourcing (ITO), software and infrastructure services, while the second corresponds to all the rest of the horizontal activities (KPO, BPO) and includes some of the industry-specific services (but not all of them; for example, banking, financial services and insurance are in part of financial services in our classification).

Computer services incorporate more foreign inputs than other business services, but overall there is also a fragmentation of production in the case of these service activities, especially in small open economies. Value chains can be quite long in the industry (see figures I.16 and I.17) with indices above 2, similar to what can be observed in manufacturing value chains. The value chain in business services involves upstream knowledge and information management (e.g. training and research). Consultative and advice activities are in the middle of the chain and the client relationship management at the end (Sako, 2009). There are also horizontal supporting activities, such as human resource management, accounting and information technology (IT). For economies on the left of figure I.17, some of these activities are outsourced and offshored, while for economies on the right, offshoring is more limited. But the fragmentation can be domestic through domestic outsourcing.

Figure I.16

Length index of computer services value chains, by country, 2009

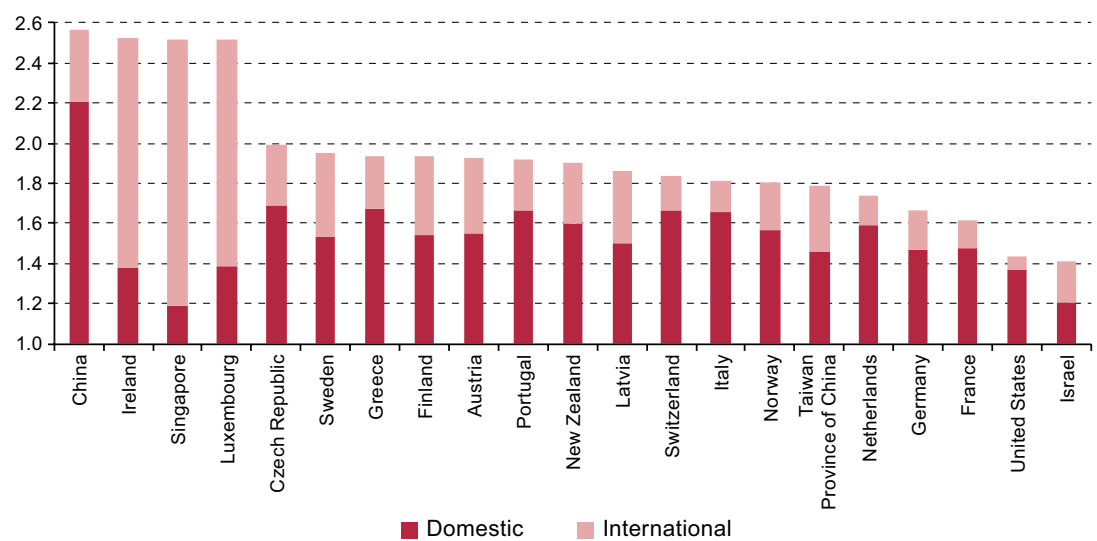

Source: Authors' calculations on the basis of the OECD ICIO model, May 2013. Data for computer services are only available for selected economies. 
Figure I.17

Length index in the value chain of other business services, by country, 2009

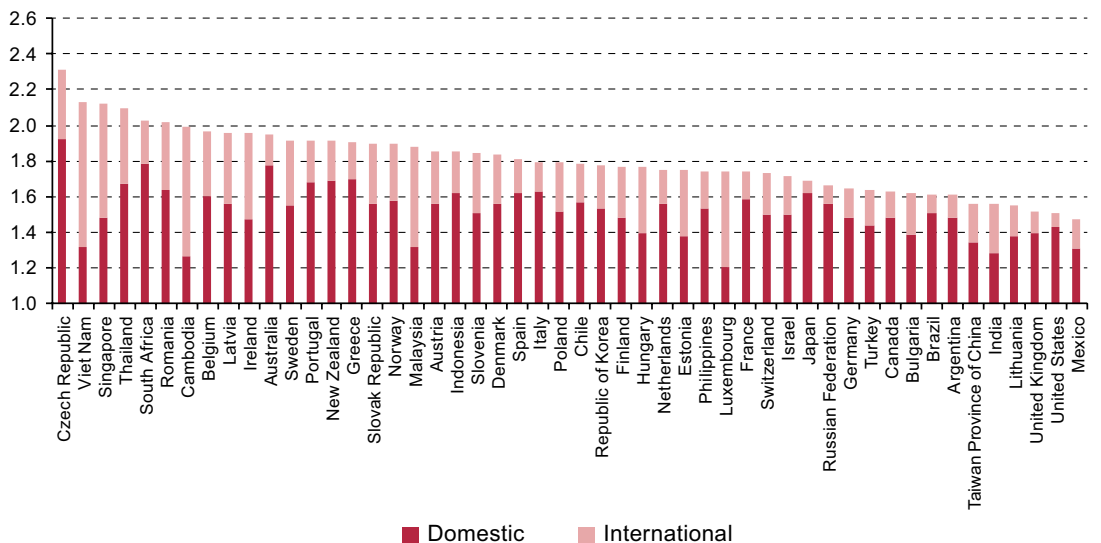

Source: Authors' calculations on the basis of the OECD ICIO model, May 2013.

Computer services represent a high share of GVC exports in Ireland, Israel, ${ }^{11}$ Luxembourg, Finland and Sweden (see figure I.18). There are differences across these economies in terms of position in the value chain. Israel, one of the main exporters for this type of services, is positioned more downstream. The service provided by Israeli companies tends to be directed more at the final producers at the end of the value chain. Singapore is another important exporter and is positioned upstream. Upstream activities in the value chain are IT services that companies need when they research and design new products or find solutions for their customers. The value of these IT services then "trickles down" all along the manufacturing and other services value chains, which accounts for the higher distance to final demand.

With respect to other business services (see figure I.19), there are differences across economies but overall, the distance to final demand tends to be high, which is not surprising since most business services are provided at the beginning of the value chain: research and development activities, consulting, market intelligence, etc. The participation in GVCs is high for Belgium, India and the United Kingdom. Belgium and the United Kingdom tend to specialize in services upstream, while India is on the contrary more downstream, indicating a specialization more oriented towards customer business services.

Note on the use of data for Israel: The statistical data for Israel are supplied by and under the responsibility of the relevant Israeli authorities. The use of such data by the OECD is without prejudice to the status of the Golan Heights, East Jerusalem and Israeli settlements in the West Bank under the terms of international law. 
Figure l.18

Participation and distance to final demand in the computer

services value chain, by country, 2009

(Percentages and distance indexes)

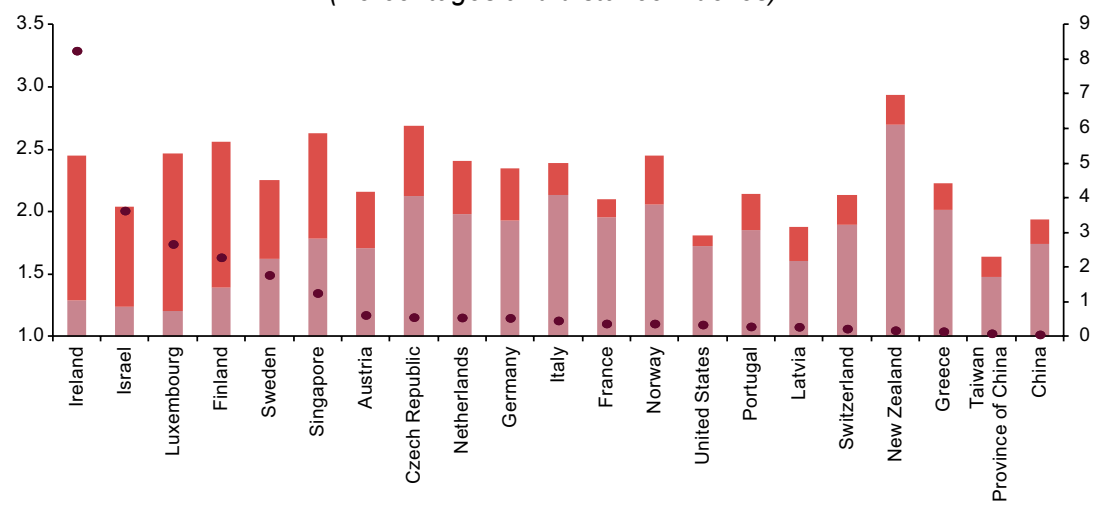

Distance to final demand (domestic) Distance to final demand (international) Participation (right axis)

Source: Authors' calculations on the basis of the OECD ICIO model, May 2013. Data for computer services are only available for selected economies.

Figure I.19

Participation and distance to final demand in the value chain of other business services, by country, 2009

(Percentages and distance indexes)

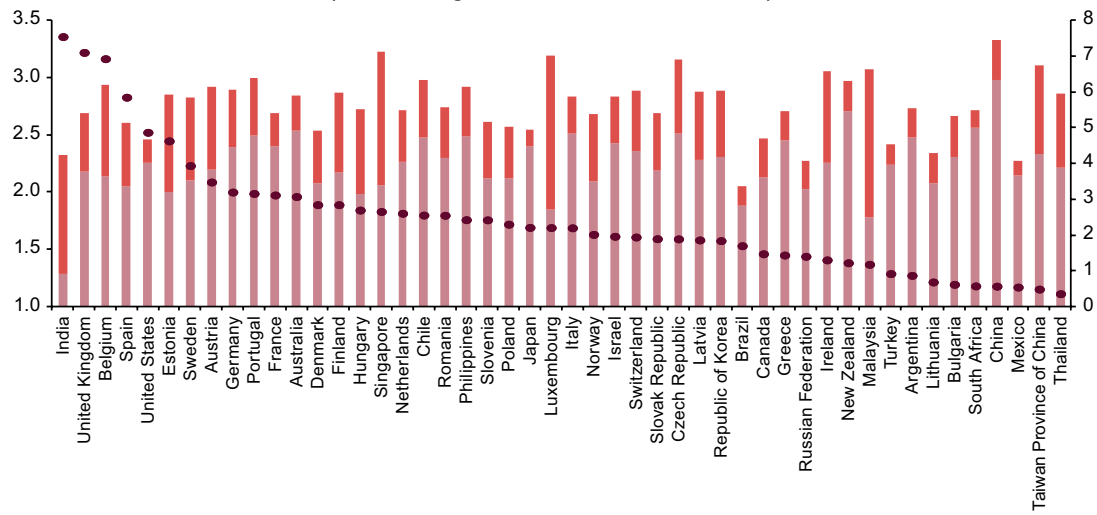

Distance to final demand (domestic) — Distance to final demand (international) $\quad$ Participation (right axis)

Source: Authors' calculations on the basis of the OECD ICIO model, May 2013.

As was observed with the agriculture and food products value chain, both developing and developed countries can be found among countries with a high participation in business services GVCs. There is also no clear pattern that developed and developing countries are confined to specific segments of the value chain. The specialization in horizontal activities or more industryspecific business services, as suggested by Gereffi and Fernandez-Stark (2010), is more likely to explain differences across GVC indicators. 


\section{Concluding remarks: closing the gap between policies and the reality of business}

The increasing importance of GVCs during the past two decades has significantly reshaped the global economy. Hence GVCs can be expected to generate substantial impacts on national economies. The size and direction of these effects are, however, not yet fully understood, since the empirical evidence on GVCs remains limited and largely falls short of capturing their impact on national economies. The last years have witnessed a growing number of case studies on the globally integrated value chain at the product level, but of course these analyses only depict the situation for a specific product.

More aggregate evidence has also been developed in order to get a more comprehensive picture of GVCs. The OECD, in cooperation with the WTO, has developed a large project on the measurement of trade in value added terms. Inter-country input-output tables and a full matrix of bilateral trade flows are used to determine the trade in value-added data. Since these data capture the domestic value that countries are adding to goods and services, the results will give a better picture of the integration and position of countries in GVCs.

Policymakers everywhere are looking for more and better policy evidence to examine the position of countries within international production networks. This chapter has developed a number of indicators that help policymakers assess the role of their country in these GVCs. A better characterization of the role of each economy in global production networks is necessary for several policy areas, including trade policy, trade and employment, national competitiveness and growth, innovation and development. There are also global systemic risks associated with global value chains. The interconnectedness between economies exposes the latter to the eventuality of macro-economic shocks transmitted along the value chains.

This report has introduced new data that can be used in the above areas. The policy implications of global value chains are explored with more details in OECD (2013) and a series of reports recently released. ${ }^{12}$ Once the position and participation of countries in the GVC have been identified, the next step is to understand what determines this position and participation and what policies have or are likely to have a positive or negative impact on the gains expected from GVCs. GVC analysis can enable policymakers to close the gap between policies and the reality of business and provide them with more efficient tools for designing and implementing policies that support inclusive growth.

12 See United States International Trade Commission (USITC, 2011), Foreign Affairs and International Trade Canada (2011) and National Board of Trade (2012) for recent government reports dealing with the policy implications of GVCs. 


\section{Bibliography}

Antràs, P. and others (2012), "Measuring the upstreamness of production and trade flows", American Economic Review, vol. 102, No. 3, Nashville, Tennessee, American Economic Association.

Bair, J. (2005), "Global capitalism and commodity chains: looking back, going forward", Competition \& Change, vol. 9, No. 2.

Center on Globalization, Governance \& Competitiveness (2011), "North Carolina in the Global Economy" [online] www.soc.duke.edu/NC_GlobalEconomy/ index.shtml.

Coe, N.M. and M. Hess (2007), "Global production networks: debates and challenges", paper prepared for the GPERG Workshop, Manchester, University of Manchester.

De Backer, K. and N. Yamano (2007), "The measurement of globalisation using international input-output tables", OECD Science, Technology and Industry Working Papers, No. 2007/8, Paris, OECD Publishing.

Dietzenbacher, E. and I. Romero (2007), "Production chains in an interregional framework: identification by means of average propagations lengths", International Regional Science Review, vol. 30, No. 4, SAGE Publications.

Fally, T. (2012), "Production Staging: Measurement and Facts", Boulder, Colorado, University of Colorado Boulder, May.

Foreign Affairs and International Trade Canada (2011), Global Value Chains: Impacts and Implications. Trade Policy Research 2011, A. Sydor (editor), Minister of Public Works and Government Services Canada.

Gereffi, G. (1994), "The organization of buyer-driven global commodity chains: how U.S. retailers shape overseas production networks", Commodity Chains and Global Capitalism, G. Gereffi and M. Korzeniewicz (eds.), Westport, Praeger Publishers.

Gereffi, G. and K. Fernandez-Stark (2011), Global Value Chain Analysis: A Primer, Center on Globalization, Governance \& Competitiveness (CGGC), Durham, North Carolina, Duke University.

(2010), "The offshore services value chain: developing countries and the crisis", Global Value Chains in a Postcrisis World. A Development Perspective, O. Cattaneo, G. Gereffi and C. Staritz (eds.),Washington, D.C., World Bank.

Gereffi, G., J. Humphrey and T. Sturgeon (2005), "The governance of global value chains", Review of International Political Economy, vol. 12, No. 1, Taylor \& Francis.

Gereffi, G. and J. Lee (2009), "A global value chain approach to food safety and quality standards", paper prepared for the Global Health Diplomacy for Chronic Disease Prevention Working Paper Series, February.

Grossman, G. and E. Rossi-Hansberg (2006), "The rise of offshoring: it is not wine for cloth any more", The New Economic Geography: Effects and Policy Implications, Federal Reserve Bank of Kansas City, August.

Hopkins, T. and I. Wallerstein (1977), "Patterns of development of the modern world-system", Review, vol. 1, No. 2, Research Foundation of SUNY.

Hudson, R. (2004), "Conceptualizing economies and their geographies: spaces, flows and circuits", Progress in Human Geography, vol. 28, No. 4, SAGE Publications.

Hummels, D., J. Ishii and K.-M. Yi (2001), "The nature and growth of vertical specialization in world trade", Journal of International Economics, vol. 54, No. 1, Amsterdam, Elsevier. 
Jones, R. and H. Kierzkowski (2001), "A framework for fragmentation", Fragmentation: New Production Patterns in the World Economy, S. Arndt and $\mathrm{H}$. Kierzkowski (eds.), New York, Oxford University Press.

Koopman, R. and others (2010), "Give credit to where credit is due: tracing value added in global production chains", NBER Working Papers, No. 16426, Cambridge, Massachusetts, National Bureau of Economic Research, September.

Lanz, R., H. Nordas and S. Miroudot (2011), "Trade in tasks", OECD Trade Policy Working Papers, No. 117, Paris, OECD Publishing.

Maurer, A. and C. Degain (2010), "Globalization and trade flows: what you see is not what you get!", Staff Working Paper, No. ERSD -2010-12, Geneva, World Trade Organization.

Melitz, M.J. (2003), "The impact of trade on intra-industry reallocations and aggregate industry productivity", Econometrica, vol. 71, No. 6, New York, The Econometric Society.

Miroudot, S., R. Lanz and A. Ragoussis (2009), "Trade in intermediate goods and services", OECD Trade Policy Papers, No. 93, Paris, OECD Publishing.

Miroudot, S. and A. Ragoussis (2009), "Vertical trade, trade costs and FDI", OECD Trade Policy Papers, No. 89, Paris, OECD Publishing.

National Board of Trade (2012), "Business reality and trade policy - closing the gap", Stockholm.

OECD (Organisation for Economic Cooperation and Development) (2013), Interconnected Economies: Benefiting from Global Value Chains, Paris, OECD Publishing.

Porter, M. (1985), Competitive Advantage: Creating and Sustaining Superior Performance, New York, The Free Press.

Reardon, T. and C. Timmer (2007), "Transformation of markets for agricultural output in developing countries since 1950: how has thinking changed?", Handbook of Agricultural Economics, vol. 3, R.E. Evenson and P. Pingali (eds.), Amsterdam, Elsevier.

Sako, M. (2009), "Global strategies in the legal services marketplace: institutional impacts on value chain dynamics" [online] http://www.sbs.ox.ac.uk/ideasimpact/novakdrucecentre/research/working-papers/global-strategies-legalservices-marketplace-institutional-impacts-value-chain-dynamics.

Sturgeon, T.J. and R. Florida (2004), "Globalisation, deverticalisation and employment in the motor vehicle industry", Locating Global Advantage: Industry Dynamics in a Globalising Economy, M. Kenny (ed.), Palo Alto, Stanford University Press.

Sturgeon, T. and M. Kawakami (2010), "Global value chains in the electronics industry: was the crisis a window of opportunity for developing countries?", Global Value Chains in a Postcrisis World, O. Cattaneo, G. Gereffi and C. Staritz (eds.),Washington, D.C., World Bank.

USITC (United States International Trade Commission) (2011), "The Economic Effects of Significant U.S. Import Restraints. Seventh Update 2011. Special Topic: Global Supply Chains", Investigation, No. 332-325, Washington, D.C., August.

Van Biesebroeck, J. and T.J. Sturgeon (2010), "Effects of the 2008-09 crisis on the automotive industry in developing countries: a global value chain perspective", Global Value Chains in a Postcrisis World, O. Cattaneo, G. Gereffi and C. Staritz (eds.), Washington, D.C., World Bank.

Zhu, S., N. Yamano and A. Cimper (2011), "Compilation of Bilateral Trade Database by Industry and End-Use Category", OECD Science, Technology and Industry Working Papers, No. 2011/06, Paris, OECD Publishing. 


\section{Annex}

\section{Global value chain indicators}

The global value chain indicators presented in the chapter are based on the May 2013 release of the OECD Inter-Country Input-Output model. The model consists of five global input-output matrices estimated for the years 1995, 2000, 2005, 2008 and 2009. Based on national input-output tables harmonized by the OECD, the model covers 58 economies (34 OECD and 23 non-OECD economies plus the "rest of the world") and 37 industries.

The national input-output tables on which the model is built are those developed by the OECD in the STAN I/O database. They are linked internationally with trade flows decomposed by end-use. The Bilateral Trade Database by Industry and End Use (BTDIxE) covers goods and relies on the Broad Economic Categories (BEC) classification to identify consumption, intermediate and capital goods. ${ }^{13}$ Data on services are based on official statistics but are complemented with estimates (using gravity modelling and optimization techniques) to fill the gaps and decompose trade flows by end-use.

The inter-country input-output matrix is organized as shown in the diagram below:

\begin{tabular}{|c|c|c|c|c|c|}
\hline & \multicolumn{3}{|c|}{ Interindustry transactions } & \multirow{2}{*}{$\begin{array}{c}\text { Total } \\
\text { intermediate }\end{array}$} & \multirow{2}{*}{$\begin{array}{l}\text { Components of final demand } \\
\text { Country } 1 \text { Country } 2 \ldots\end{array}$} \\
\hline & \begin{tabular}{|l|} 
Country 1 Country 1 Country 1 \\
Industry 1 Industry $2 \ldots$
\end{tabular} & $\begin{array}{l}\text { Country } 2 \text { Country } 2 \text { Count } \\
\text { Industry } 1 \text { Industry } 2 \ldots\end{array}$ & & & \\
\hline $\begin{array}{l}\text { Country } 1 \text { Industry } 1 \\
\text { Country } 1 \text { Industry } 2 \\
\text { Country } 1 \ldots\end{array}$ & Use of domestic inputs & Use of foreign inputs & $\ldots$ & & \\
\hline 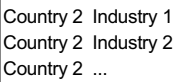 & Use of foreign inputs & Use of domestic inputs & $\ldots$ & & \\
\hline $\begin{array}{ll}\cdots & \ldots \\
\cdots & \ldots \\
\cdots & \ldots\end{array}$ & . & . & & & \\
\hline $\begin{array}{l}\text { Value-added } \\
\text { Gross output }\end{array}$ & & & & & \\
\hline
\end{tabular}

Source: Authors' representation of the OECD ICIO model, May 2013.

The model covers the following 58 economies:

- All OECD countries: Australia, Austria, Belgium, Canada, Chile, Czech Republic, Denmark, Estonia, Finland, France, Germany, Greece,Hungary, Iceland, Ireland, Israel, Italy,Japan, Luxembourg, Mexico, Netherlands, New Zealand, Norway, Poland, Portugal, Republic of Korea, Slovak Republic, Slovenia, Spain, Sweden, Switzerland, Turkey, United Kingdom and United States.

13 An extended version of the BEC classification has been developed to deal with specific goods that are not clearly for consumption, intermediate or capital use. See Zhu Yamano and Cimper (2011). 
- Selected non-OECD economies: Argentina, Brazil, Brunei Darussalam, Bulgaria, China, Taiwan Province of China, Cyprus, Hong Kong-China, India, Indonesia, Latvia, Lithuania, Malaysia, Malta, Philippines, Romania, Russian Federation, Saudi Arabia, Singapore, South Africa, Thailand and Viet Nam.

- "Rest of the world" (to account for all other economies not included, representing less than $5 \%$ of world output).

The 37 sectors included are defined on the basis of the ISIC Rev. 3 classification and harmonized across countries. See http://www.oecd.org/ dataoecd/48/9/42163998.zip for more details on the aggregation and specific country notes. It should be noted that data availability and quality are not the same across all countries, particularly at a more disaggregated industry level; accordingly, the results given in this paper should be interpreted with some caution. Efforts are continuing to improve the underlying OECD ICIO model, which will result in better estimates in the future.

\begin{tabular}{|c|c|c|}
\hline No & 37 Sectors & ISIC Rev. 3 \\
\hline 1 & Agriculture, hunting, forestry and fishing & $1+2+5$ \\
\hline 2 & Mining and quarrying & $10-14$ \\
\hline 3 & Food products, beverages and tobacco & $15+16$ \\
\hline 4 & Textiles, textile products, leather and footwear & $17+18+19$ \\
\hline 5 & Wood and products of wood and cork & 20 \\
\hline 6 & Pulp, paper, paper products, printing and publishing & $21+22$ \\
\hline 7 & Coke, refined petroleum products and nuclear fuel & 23 \\
\hline 8 & Chemicals & 24 \\
\hline 9 & Rubber and plastic products & 25 \\
\hline 10 & Other non-metallic mineral products & 26 \\
\hline 11 & Basic metals & 27 \\
\hline 12 & Fabricated metal products, except machinery and equipment & 28 \\
\hline 13 & Machinery and equipment, n.e.c. & 29 \\
\hline 14 & Office, accounting and computing machinery & 30 \\
\hline 15 & Electrical machinery and apparatus, n.e.c. & 31 \\
\hline 16 & Radio, television and communication equipment & 32 \\
\hline 17 & Medical, precision and optical instruments & 33 \\
\hline 18 & Motor vehicles, trailers and semi-trailers & 34 \\
\hline 19 & Other transport equipment & 35 \\
\hline 20 & Manufacturing n.e.c., recycling (include furniture) & $36-37$ \\
\hline 21 & Utility & $40-41$ \\
\hline 22 & Construction & 45 \\
\hline 23 & Wholesale and retail trade; repairs & $50-52$ \\
\hline 24 & Hotels and restaurants & 55 \\
\hline 25 & Transport and storage & $60-63$ \\
\hline 26 & Post and telecommunications & 64 \\
\hline 27 & Finance and insurance & $65-67$ \\
\hline 28 & Real state activities & 70 \\
\hline 29 & Renting of machinery and equipment & 71 \\
\hline 30 & Computer and related activities & 72 \\
\hline 31 & Research and development & 73 \\
\hline 32 & Other business activities & 74 \\
\hline 33 & Public admin. and defence; compulsory and security & 75 \\
\hline 34 & Education & 80 \\
\hline 35 & Health and social work & 85 \\
\hline 36 & Other community, social and personal services & $90-93$ \\
\hline 37 & Private households with employed persons & $95-99$ \\
\hline
\end{tabular}




\section{Length of GVCs}

The index of the number of production stages is proposed by Fally (2012) and calculated for the United States economy with a single country input-output matrix. Using our inter-country, inter-industry framework, we calculate our index of the length of GVCs as:

$$
N=u \cdot(I-A)^{-1}
$$

where $N$ is a column vector with the indices for all countries $i$ and industries $k, u$ is a column unit vector, I is an identity matrix and $\mathrm{A}$ is the matrix of technical coefficients in the ICIO. $(I-A)^{-1}$ is the Leontief inverse and the index is similar to the calculation of backward linkages in the input-output literature. In the ICIO matrix, we have the values of all inputs used by one industry in a given country. In addition, we can distinguish between domestic inputs and foreign inputs, by calculating the index in the country and industry dimension. This is how we decompose the index according to domestic production stages and foreign production stages.

\section{Distance to final demand}

The distance to final demand is the second indicator suggested by Fally (2012) and calculated in a similar way:

$$
D=u \cdot(I-G)^{-1}
$$

where is a column vector with the indices for all countries $i$ and industries $k, u$ is a column unit vector, $I$ is the identity matrix and $G$ a matrix of output coefficients, with $(I-G)^{-1}$ being known as the output inverse or Ghosh inverse in the input-output literature. The index is similar to the calculation of forward linkages in the context of an ICIO. See also Antràs and others (2012) for a similar index of a country's "upstreamness" in the value chain.

\section{Participation in GVCs}

This index is based on Koopman and others (2010). The starting point is the decomposition of gross exports into value-added shares by source country. The following matrix is calculated:

$$
V B E=V .(I-A)^{-1} \cdot E
$$

where $\mathrm{V}$ is the diagonal of a vector with value-added shares in each country and industry, $B=(I-A)^{-1}$ is the Leontief inverse and $\mathrm{E}$ is the diagonal of a vector of gross exports. 
When adding values in the columns of the VBE matrix (without the contribution of domestic industries), one obtains the contribution of foreign industries to exports (the import content of exports), which divided by gross exports in each country gives a vector of VS shares, as defined by Hummels, Ishii and Yi (2001). Summing over rows (and omitting domestic industries), we have the contribution of domestically produced intermediates to exports in third countries. Divided by gross exports for each country, this calculation provides the VS1 shares defined by Hummels, Ishii and Yi (2001).

The GVC participation index simply adds the VS and VS1 shares for country $i$ and industry $k$ and can be expressed as:

$$
P_{i k}=\frac{V S_{i k}}{E_{i}}+\frac{V S 1_{i k}}{E_{i}}
$$

where $V S_{i k}$ is an element of the vector obtained by summing the columns of the VBE matrix (without domestic industries), corresponding to the import content of exports in country $i$ and industry $k$, and $V S 1_{i k}$ is an element of the vector obtained when summing the rows of the VBE matrix (without domestic industries) and corresponding to exports of domestically-produced intermediates used in third countries' exports. VS and VS1 are values that are divided by gross exports in country $i, E_{i^{\prime}}$ in order to express the participation index as a share of gross exports. 


\title{
Chapter II \\ Global value chains in Latin America: A development perspective for upgrading
}

\author{
Karina Fernandez-Stark \\ Penny Bamber \\ Gary Gereffi
}

\section{Introduction}

This chapter presents an overview of the global value chains (GVC) framework, highlighting the benefits of applying this methodology for the future competitiveness and economic development of Latin America and the Caribbean. Examples are presented of the region's progress to date in using this methodology to engage in a wide variety of global industries. Countries in the region participating in value chains have generally been confined to lower value segments of traditional sectors such as agriculture, manufacturing and extractive industries. As firms continue to globalize their production networks, Latin America is well positioned to leverage its experience in these sectors to move beyond basic production activities and add greater value in its export sectors. Upgrading into higher value segments in these global chains depends to a large extent on the quality and availability of human capital. The final section gives examples of workforce development strategies and innovation systems across the region that can drive this upgrading. 
Global value chains (GVCs) are increasingly shaping international trade, with major repercussions for employment and gross domestic product (GDP) in developing countries around the world. The fragmentation of the production of goods and services across multiple firms and countries has provided an opportunity for developing countries to integrate into the global economy. Latin America has entered a variety of these GVCs, participating not only in low value added segments providing raw materials, but also in new non-traditional sectors such as aerospace, medical device manufacturing and offshore services. The region's insertion into these chains has provided employment opportunities and has led to transfers of technology and upgrading into higher value services. In addition, there are emerging success stories of upgrading into high-value services in traditional sectors by helping countries leverage their expertise while reducing their dependence on primary products.

This introductory chapter offers a brief overview of the GVC framework. Understanding how these chains operate and breaking them down into their numerous segments and sectors is essential to identifying the challenges and taking advantage of the opportunities offered by global industries. Indeed, the GVC framework is increasingly being used by international development agencies to help new actors enter these chains, while those already operating within such chains are using the framework to uncover new opportunities to add value and increase the gains from their contributions to these global sectors. However, the long-term competitiveness of Latin American countries is contingent on a well-prepared workforce that can adapt to the challenges presented by the dynamic nature of these GVCs. While there continue to be mismatches between the supply of talent from universities and demand from the private sector, complex and innovative systems have emerged in several Latin American countries to help them upgrade in global value chains.

The chapter is structured into three sections. Section A presents an overview of the GVC framework and how it has been used to date to help developing countries enter sectors of the global economy. This is followed in section B by a discussion of several examples of how Latin American countries are participating in both traditional and non-traditional sectors, highlighting important opportunities for upgrading in the natural resource sector. Section $C$ provides examples of how innovation systems in the region have responded to the need for a qualified workforce to drive competitiveness in these chains. Section D concludes. 


\section{A. The global value chains framework: a tool for driving economic development in the new global economy}

The global economy is increasingly structured around GVCs, which account for an ever larger share of international trade, global GDP and employment. These chains have become prominent in sectors ranging from agriculture and electronics to business services and tourism. In 2009, it was estimated that intermediate goods and services accounted for approximately $56 \%$ and $73 \%$ of total trade, respectively. ${ }^{1}$ GVCs link firms, workers and consumers around the world through complex production and supply networks spanning multiple countries. This reorganization of international trade has created diverse opportunities for developing countries to integrate into the global economy. By providing access to developed-country markets, participation in GVCs enables emerging economies to add value to their local industries. Insertion into GVCs alone, however, does not necessarily translate into positive gains from trade. In order to benefit from participating in these global sectors, developing countries must be able to sustain and upgrade their competitiveness over time, mainstream trade into their broader national economic development agenda, build internal capacity and generate more and better jobs to reduce unemployment and poverty. Thus, it is not only a matter of whether to participate in the global economy, but how to do so gainfully.

\section{What is value chain analysis?}

The value chains framework helps explain how industries are organized by examining the structure and dynamics of the different actors involved. The value chain describes the full range of activities that firms and workers perform to bring a product from the design stage through to consumption and beyond. This includes both tangible and intangible value-adding activities, such as research and development, design, production, distribution, marketing and support to the final consumer. These activities can be carried out by a single firm or divided among different firms. In the context of globalization, these activities are increasingly being carried out in inter-firm networks on a global scale. Chain governance, that is, the nature of the relationships between the diverse actors in different countries within these chains, plays an

These figures are based on Miroudot and others (2009), using input-output tables to analyse trade between the countries of the Organization for Economic Cooperation and Development (OECD) and their main developing-country trading partners. This figure likely underestimates the share of trade that is engaged in GVCs because limited data are available on trade in intermediate goods between developing countries within GVCs. 
important role in determining firms' access to key markets. Generally, owing to their relative market power, lead firms based in key markets control the generation and distribution of knowledge and resources and determine which firms can participate in the chain (Gereffi, 1994; Humphrey and Schmitz, 2002).

Value chain analysis examines the labour inputs, technologies, standards, regulations, products, processes and markets in specific industries and locations in order to provide a holistic view of these global industries (Gereffi and Fernandez-Stark, 2011). The factors are examined from four perspectives: (1) the input-output structure, which describes the process of transforming raw materials into final products; (2) geographical distribution, which identifies the firms and countries participating in the chain; (3) the governance structure, which explains how access to and upgrading in the value chain is controlled; and (4) the local institutional context of the countries in which the value chain is embedded (Gereffi, 1994, 1995 and 1999). The input-output structure, geographical distribution and governance structure provide a top-down perspective of how these chains are structured and how they operate at a global level. Local conditions, such as economic and political stability, industrial policies, infrastructure, the ease of doing business, human capital and coordination and collaboration among industry stakeholders, influence how firms based in a specific country compete within the chain (Fernandez-Stark, Bamberand Gereffi, 2010a, 2010c and 2012b).

Value chains are generally dynamic and firms can join, or move between, different links of the chain in order to gain higher returns on their participation. This movement is referred to as "upgrading" (Gereffi, 2005) and is a central element in value chain analysis. Traditionally, a firm could upgrade its participation in a production model in four distinct ways: (1) product upgrading, namely the shift into the production of a higher value product; (2) process upgrading, namely improving the efficiency of production systems, for example, by incorporating more sophisticated technology; (3) functional upgrading, namely moving into higher value stages in the chain that require additional skills; and (4) chain or intersectoral upgrading, namely entry into a new value chain by leveraging the knowledge and skills acquired in the current chain (Humphrey and Schmitz, 2004). In addition to these four strands, two additional types of upgrading can be identified: (1) entry into a value chain by a new actor (Fernandez-Stark, Bamber and Gereffi, 2011); and (2) end-market upgrading, which can include moving into more sophisticated markets that require compliance with new, more rigorous standards or into larger markets that call for production on a larger scale and price accessibility. 
Early use of GVC methodology focused principally on economic and competitiveness issues, but more recently social and environmental dimensions have also been incorporated. GVC research is now exploring new topics such as labour regulation issues, workforce development, the greening of value chains and gender. Today, GVC analysis is one of the preferred methodologies for examination of global industries, international trade dynamics and how vulnerable economic actors engage in chains (Barrientos, Gereffi and Rossi, 2011; Gereffi and Lee, 2012).

\section{What is the role of value chain analysis in economic development?}

GVC analysis is also increasingly being adopted by the economic development community, and almost all international development agencies have devised a GVC strategy (Henriksen and others, 2010; Humphrey and Navas-Alemán, 2010; Stamm and von Drachenfels, 2011). In this field, the GVC framework is used in efforts to achieve two key objectives: to embed new actors in chains and to improve the position of actors already in chains.

In the first case, the framework is applied to understand how to embed new economic actors in regional and global value chains at both the country and firm levels. New actors typically include developing countries that have not yet engaged in global industries and various types of firms, including small and medium-sized companies, which often lag behind larger organizations in joining chains. Specifically, the methodology is used to identify key opportunities within the chain for new actors and the major constraints inhibiting their participation. The Aid for Trade initiative led by the Organization for Economic Cooperation and Development (OECD) and World Trade Organization (WTO), which accounts for approximately one third of all sector-allocable official development assistance flows to developing countries (OECD/WTO, 2011), for example, is employing GVC analysis to understand and overcome the barriers to these emerging economies' participation in global trade (Bamber, Fernandez-Stark and Gereffi, forthcoming). Similarly, major development agencies, including the Department for International Development (United Kingdom), the German Agency for International Cooperation, the United States Agency for International Development (USAID) and the United Nations Industrial Development Organization (UNIDO), have adopted the GVC methodology to devise initiatives to help small and medium-sized firms from developing countries upgrade in these chains, add value to their production and allow them to make the most of their participation (Barrientos, Gereffi and Rossi, 2011; Fernandez- 
Stark, Bamber and Gereffi, 2012a; Humphrey and Navas-Alemán, 2010; Meyer-Stamer and Waltring, 2006; UNIDO, 2009; USAID, 2012).

The framework is also used to provide insights for countries that already participate in global industries on how to upgrade within these chains by identifying opportunities to add value to products and services for export, finding niche sectors in which to compete, and devising strategies to maximize gains in terms of fostering goodquality employment and the use of domestic components in exports. By breaking down the industry into its key segments, GVC analysis helps countries identify the specific activities in the chain currently performed by their firms, as well as potential opportunities for these firms in the future (Gereffi and Fernandez-Stark, 2011). This analysis can also provide insightful findings to guide policymakers. The governments of Chile and Costa Rica have used the GVC methodology to shape policy to promote upgrading in strategic industries with high growth potential. Chile's economic development agency CORFO has applied this framework to drive upgrading in the offshore services industry. The framework allowed the country to better understand the industry at the global level, to identify Chile's position in the value chain and to pursue industry opportunities aligned with the country's capabilities. Similarly, the Costa Rican Foreign Trade Ministry recently used this framework to analyse four selected industries of growing importance for the country: medical devices, electronics, aerospace and offshore services. The objective was to examine the changing dynamics of these industries at the global level, identify Costa Rica's position in these chains and highlight potential opportunities for the country to perform more competitively and move up the value chains.

\section{B. Latin America's participation and opportunities in global value chains}

Latin American countries have entered GVCs in a variety of industries, from high-value agriculture to aerospace and business services outsourcing (Casalet and others, 2011; Fernandez-Stark, Bamber and Gereffi, 2012a and 2013b; Giuliani, Pietrobelli and Rabellotti, 2005; Pietrobelli and Rabellotti, 2005). Much of this growth has been driven by the establishment of new export-oriented sectors, often supported by foreign direct investment (FDI) with a view to taking advantage of labour availability and cost, strategic locations and other specific comparative advantages. This section provides four short examples to illustrate how Latin American countries have thus far participated in these global industries: Honduras in fruit and vegetables, Nicaragua in apparel, 
the state of Baja California in Mexico and Costa Rica in medical device manufacturing and several countries in offshore services. These new sectors have brought considerable benefits to these developing countries in terms of employment, entry into high-tech fields and even upgrading into high-value products and activities. However, Latin American participation in global chains should not be considered exclusively within the realm of new export-oriented industries dependent on foreign firms and technology. The region abounds with experience in more traditional sectors such as natural resources and the extractive industries. This domestic experience can be leveraged to export high value services to other countries operating in the chain. Three short case studies presented in the second part of this section illustrate how capitalizing on this experience has facilitated value chain upgrading in primary product sectors in Chile, Costa Rica and Uruguay.

\section{How Latin American countries participate in GVCs}

\section{(a) Nicaragua in the global apparel manufacturing value chain ${ }^{2}$}

The value of exports from the Nicaraguan apparel industry totalled approximately US\$ 530 million in 2008, accounting for one fifth of the country's reported exports that year (UN COMTRADE, 2012). Nicaragua mainly participates in the low-value cut-make-trim stage of the apparel value chain (see diagram II.1). Leveraging the country's competitive wage advantage (Portocarrero Lacayo, 2010), the industry employed more than 51,300 people in 2010 (ILO/IFC, 2010). ${ }^{3}$ In 2009, 89\% of Nicaraguan apparel exports were to the United States. The country is still considered a small regional supplier, but since 2004 it has steadily gained market share in the United States in certain segments, such as woven trousers and cotton shirts, as a result of its preferential trade status through exceptions to the Dominican Republic-Central American Free Trade Agreement (Gereffi and Bair, 2013). Apparel manufacturers in Nicaragua focus on trousers, mainly denim jeans and twill trousers, and T-shirts.

The industry consists of a large proportion of foreign-owned firms and very few locally owned companies. Firms from Republic of Korea and the United States dominate the sector, with the remainder coming from El Salvador, Honduras, Mexico and Taiwan Province of China. A significant proportion of these firms are part of larger global or regional networks. This structure allows global firms to provide full-package services for their clients by leveraging the interactions of their multi-country operations,

See Gereffi and Bair (2013).

The industry reached a peak in employment in 2007 , with 88,700 employees. However, pressure from the economic crisis forced layoffs and closures during 2008 and 2009. 
particularly in Central America. Knitwear firms sell to buyers such as Walmart, Target and Ralph Lauren. Woven apparel firms tend to have a more regional focus, with operations in neighbouring countries such as Guatemala, Honduras and Mexico. Leading buyers in the sector include Levi Strauss, Cintas and Kohl's.

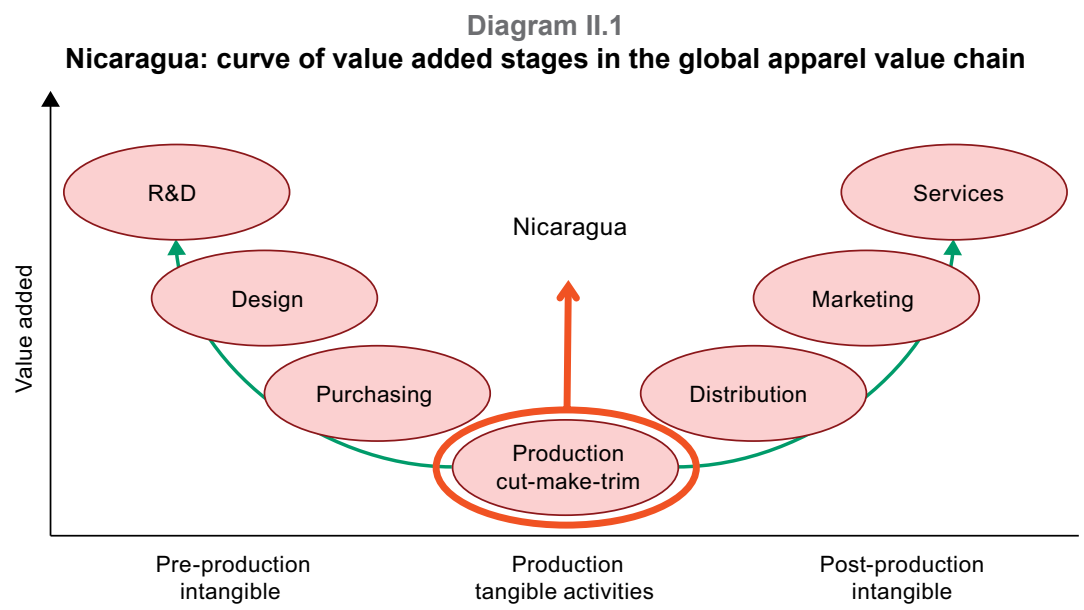

Source: Prepared by the authors, on the basis of S. Frederick, "Development and Application of a Value Chain Research Approach to Understand and Evaluate Internal and External Factors and Relationships Affecting Economic Competitiveness in the Textile Value Chain", doctoral thesis, Raleigh, North Carolina State University, 2010.

Between 2005 and 2010, the volume of Nicaragua's apparel exports grew by $8.6 \%$, yet Nicaragua has had limited success in moving up the apparel value chain and mainly offers production services. The country's apparel exporters have not achieved significant product upgrading either, as the value of exports increased by only $4.5 \%$ (PRONicaragua, 2010). Rather, this period was characterized by an increase in the production of T-shirts and knitwear, which are low value added products. Prior to the economic crisis, the value of Nicaragua's exports had risen on the back of a boost in exports of higher value woven trousers, but the economic slowdown in the United States in 2009 caused exports to fall back to their 2006 levels. Nicaragua remains vulnerable in terms of economic upgrading because its apparel exports remain dependent on United States trade policy (specifically the tariff preference level (TPL) exception offered to Nicaragua that allows it to import textiles from East Asia). However, the country has shown advances in social upgrading, attributable in large part to the efforts of the tripartite National Free Trade Zones Commission to reconcile the interests of workers, the private sector and the government. The country also joined the Better Work programme established by the International Labour Organization (ILO) in partnership with the International Finance Corporation (IFC) (Gereffi and Bair, 2013). 


\section{(b) Mexico and Costa Rica in the global medical device manufacturing value chain}

In the Americas, Baja California (Mexico), Costa Rica, Puerto Rico and the Dominican Republic - all strategically located close to the United States - are home to major export-oriented medical device clusters. There are around 67 medical device firms operating in Baja California, 67 in Costa Rica and more than 30 firms in Puerto Rico (MPO, 2011; Producen, 2007). Several of the top 10 global firms, including Johnson and Johnson, Cardinal Health, Baxter, B. Braun Melsungen and Hospira, have also established production facilities in the Dominican Republic. Exports from these countries include both lower and higher value product categories and are primarily destined for the United States. Brazil also plays a significant role in the manufacture of medical devices, but the bulk of multinational firms in the country, including Baxter and GE Healthcare, are more focused on producing for the domestic market than driving export growth.

\section{(c) Baja California, Mexico}

The medical device sector in Baja California has built up over the past 25 years. During this time, medical device manufacturers, primarily from the United States, have established operations in the region to take advantage of low-cost opportunities for labour-intensive processes in very close proximity to the Californian medical device clusters (Producen, 2007). ${ }^{4}$ The maquila import-export regime and Mexico's accession to the North American Free Trade Agreement have also been important drivers of the sector. Despite Mexico's large internal demand for medical devices, this is an export-oriented industry. In 2005, $95 \%$ of medical devices produced in the region were covered by the preferential tax regime for assembly operations and, in 2011, $92 \%$ of production was exported. By 2012, the 67 plants operating in the medical device sector employed approximately 42,000 people.

The plants in the region focus principally on manufacturing and assembly and little progress has been made towards upgrading to research and development beyond some process engineering at the manufacturing level (Carillo, 2009). Products made in the region are predominantly disposables, such as surgical bandages, catheters, and drug delivery systems and surgical instruments. These are mature products; that is, they have been on the market for a considerable time and safeguarding intellectual property is thus less of a concern (Producen, 2007). Exports from these plants account for over $50 \%$ of Mexico's total medical device exports (PROMEXICO, 2011).

In 2007, 28 of the plants operating in Baja California had corporate offices or operations in southern California (Producen, 2007). 


\section{(d) Costa Rica}

The Costa Rican medical device industry is relatively young: the first device company to establish operations in the country did so in 1985. The most significant growth in the number and variety of firms and the value of their key products took place between 2009 and 2012. In 2012, approximately 50 firms were participating in the medical device supply chain in Costa Rica, with an additional 16 companies providing packaging and support services. Over half $(60 \%)$ of these firms were from the United States and less than 30\% were Costa Rican. The remaining firms came from five countries: one each from Colombia, Germany, Ireland, Japan and Puerto Rico. Companies in the sector are concentrated in the production segments of the value chain, with $70 \%$ of them manufacturing components or assembling final goods.

A small number of original equipment manufacturing firms perform additional manufacturing research and development with a view to improving the production process (sustaining engineering) and establishing production processes for new products (process development) to be launched directly from Costa Rica. Costa Rican-owned firms are principally active in the labelling and packaging segments of the value chain and in support services. There has been a general increase in the complexity of products manufactured in Costa Rica since 2005, with the country shifting from mainly disposable products, such as intravenous catheters, to more sophisticated products, such as bovine heart valves. In addition, there has been an increase in the number of highly regulated life-supporting or lifesustaining devices produced in the country, indicating a growing confidence in the ability of Costa Rican plants to follow strict regulatory protocols.

Figure II.1 illustrates Costa Rica and Mexico's respective product exports in the medical device sector. Products range in value from disposables, such as simple plastic catheter tubing to surgical instruments to therapeutic products, such as heart valves and orthopaedic implants, and to high value, single-purchase capital equipment items such as magnetic resonance imaging equipment.

Baja California and Costa Rica are positioned in similar stages of the medical device value chain, that is, in the components production and assembly segments. These stages leverage the lower cost workforce relative to their principal market, the United States. However, while the two countries continue to operate in lower value segments of this value chain, they have both engaged in product upgrading since entering the medical device manufacturing GVC: Costa Rica has expanded from disposables into both surgical instruments and therapeutic products, such as heart valves, and Mexico has concentrated more on surgical instruments with a steady supply of medical electronic capital equipment 
since 2005 (see diagram II.2). In industries in which a developing country has limited experience, product upgrading can be a more feasible way of increasing value added trade than functional upgrading. Functional upgrading requires significant investment in skills development and training of human capital, often at the postgraduate and doctoral level (Gereffi, Fernandez-Stark and Psilos, 2011).

Figure II.1

Costa Rica and Mexico: medical exports by product category, 1998-2011

(Millions of dollars)

A. Costa Rica
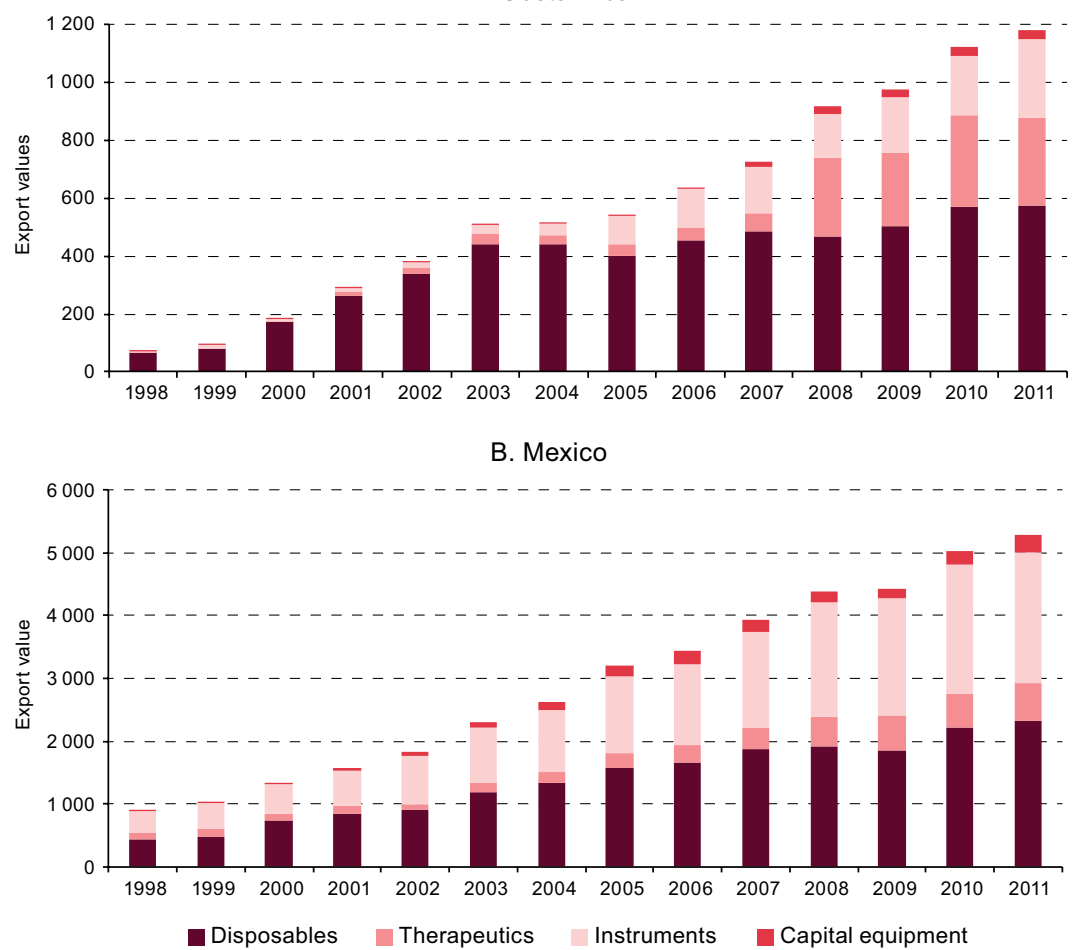

Source:P. Bamber and G. Gereffi, "Costa Rica in the Medical Devices Global Value Chain: Opportunities for Upgrading”. Durham, North Carolina, Center on Globalization, Governance and Competitiveness, Duke University, 2013.

Note: This figure is intended to illustrate export composition in the sector and not relative exports. The scale differs on the two figures.

Baja California and Costa Rica are positioned in similar stages of the medical device value chain, that is, in the components production and assembly segments. These stages leverage the lower cost workforce relative to their principal market, the United States. However, while the two countries continue to operate in lower value segments of this value 
chain, they have both engaged in product upgrading since entering the medical device manufacturing GVC: Costa Rica has expanded from disposables into both surgical instruments and therapeutic products, such as heart valves, and Mexico has concentrated more on surgical instruments with a steady supply of medical electronic capital equipment since 2005 (see diagram II.2). In industries in which a developing country has limited experience, product upgrading can be a more feasible way of increasing value added trade than functional upgrading. Functional upgrading requires significant investment in skills development and training of human capital, often at the postgraduate and doctoral level (Gereffi, Fernandez-Stark and Psilos, 2011).

\section{(e) Offshore services in selected Latin American countries}

While a relative latecomer to the industry, Latin America emerged as a key region in the provision of offshore services in the early 2000s due to its geographical location and cheap labour costs. The growth of this sector was further supported by the industrial policies of numerous countries in the region, extensive new telecommunications infrastructure and the availability of qualified human capital. By 2011, the region had become an important participant in the offshore services trade, exporting services to countries all around the globe (Fernandez-Stark, Bamber and Gereffi, 2013b). According to the 2009 AT Kearney Global Services Location Index, eight Latin American countries, including Argentina, Brazil, Chile, Costa Rica and Mexico, were among the top 50 most competitive international locations for offshoring services (AT Kearney, 2009). Other countries such as Colombia, Guatemala, Peru and Uruguay have been identified as important "countries to watch" (Gartner, 2009). In 2010 the information technology outsourcing (ITO) industry in Latin America was worth US\$ 8 billion, compared with US\$ 5 billion in Eastern Europe, despite its having entered the industry almost a decade later (Tucci, 2011). This growth was driven to a large degree by FDI projects established on the continent to serve mainly Spain and the Hispanic communities in the United States.

Latin American countries participate in the offshore services industry in a heterogeneous manner, with each nation specializing in its area of competitive advantage, though, generally speaking, the services they provide are considered to be lower value (see table II.1), for example, the Dominican Republic, Guatemala and El Salvador concentrate on call centre activities. Certain other countries have, however, upgraded into higher sections of the chain. Costa Rica, for example, has developed a strong presence in the $\mathrm{BPO}$ services segment, but has also upgraded into knowledge process outsourcing (KPO) and research and development (R\&D) activities. Uruguay focuses on information technology (IT) activities, Mexico has a well-diversified portfolio of offshore services, while the majority of the services exported by Chile are in the KPO sector. 

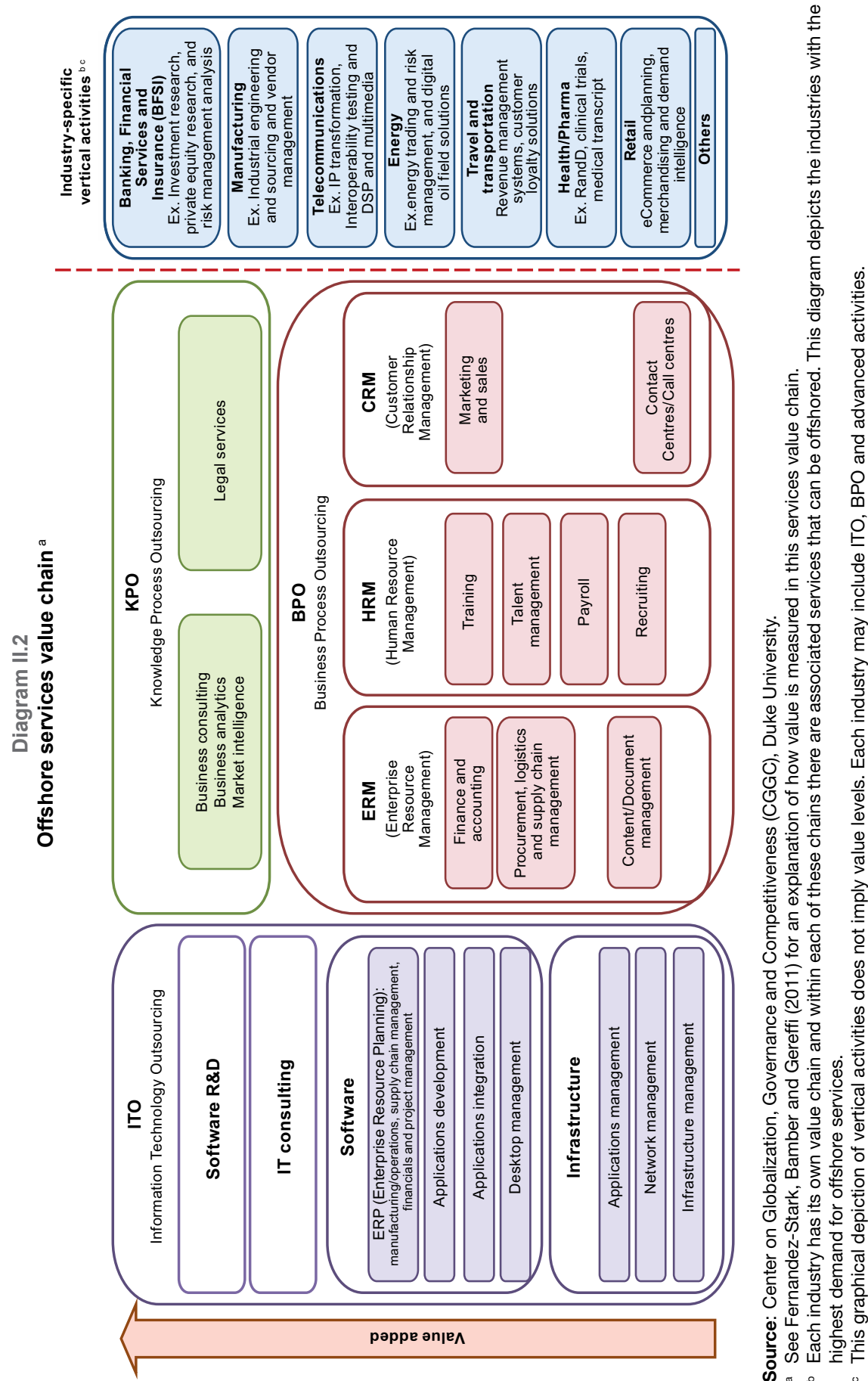
Table II.1

Latin America (selected countries): economic and industry indicators for the offshore services industry, 2008

\begin{tabular}{|c|c|c|c|c|c|c|c|}
\hline & Chile & $\begin{array}{l}\text { Costa } \\
\text { Rica }\end{array}$ & $\begin{array}{l}\text { Dominican } \\
\text { Republic }\end{array}$ & $\begin{array}{c}\text { El } \\
\text { Salvador }\end{array}$ & Guatemala & Mexico & Uruguay \\
\hline $\begin{array}{l}\text { Offshore services } \\
\text { revenue } \\
\text { (billions of dollars) }\end{array}$ & 0.86 & $1.39^{a}$ & $\ldots$ & $\ldots$ & $\ldots$ & 5 & $0.786^{b}$ \\
\hline $\begin{array}{l}\text { Offshore services } \\
\text { as a percentage } \\
\text { of GDP }\end{array}$ & 0.5 & 4.6 & $\ldots$ & $\ldots$ & $\ldots$ & 0.45 & 2.6 \\
\hline $\begin{array}{l}\text { Labour force in } \\
\text { offshore services }\end{array}$ & 20000 & $33170^{a}$ & 22000 & 6800 & 6500 & $\ldots$ & $20000^{b}$ \\
\hline $\begin{array}{l}\text { Offshore services } \\
\text { labour force as a } \\
\text { percentage of total } \\
\text { labour force }\end{array}$ & 0.28 & 1.30 & 0.50 & 0.24 & 0.17 & $\ldots$ & 1.25 \\
\hline $\begin{array}{l}\text { Year of entry into } \\
\text { industry }\end{array}$ & $\begin{array}{l}2000- \\
2002\end{array}$ & $\begin{array}{l}\text { Late } \\
\text { 1990s-early } \\
\text { 2000s }\end{array}$ & $\begin{array}{l}2000- \\
2002\end{array}$ & $\begin{array}{l}2004- \\
2005\end{array}$ & $\begin{array}{l}2005- \\
2006\end{array}$ & $\begin{array}{l}\text { Late } \\
\text { 1990s-early } \\
\text { 2000s }\end{array}$ & $\begin{array}{l}\text { Early } \\
2000 \text { s }\end{array}$ \\
\hline Entry point & $\begin{array}{l}\text { IT and } \\
\text { call } \\
\text { centre }\end{array}$ & BPO & $\begin{array}{l}\text { Call } \\
\text { centre }\end{array}$ & $\begin{array}{l}\text { Call } \\
\text { centre }\end{array}$ & $\begin{array}{l}\text { Call } \\
\text { centre }\end{array}$ & $\begin{array}{l}\text { IT and } \\
\text { BPO }\end{array}$ & IT \\
\hline $\begin{array}{l}\text { Highest value } \\
\text { activity }\end{array}$ & $\begin{array}{l}\text { High IT, } \\
\text { KPO } \\
\text { R\&D }\end{array}$ & $\begin{array}{l}\mathrm{KPO} \\
\text { and } \\
\mathrm{R} \& \mathrm{D}\end{array}$ & $\begin{array}{l}\text { BPO } \\
\text { and } \\
\text { F\&A }\end{array}$ & $\begin{array}{l}\text { Contact } \\
\text { centre }\end{array}$ & $\begin{array}{l}\text { BPO } \\
\text { and } \\
\text { F\&A }\end{array}$ & KPO & KPO \\
\hline
\end{tabular}

Source: Prepared by the authors, on the basis of Business Processing Association of the Philippines (BPAP), Offshoring and Outsourcing Philippines: Roadmap 2010, 2007 [online] http://www.bpap. org/bpap/publications/bpap_roadmap.pdf; The Economist Intelligence Unit, "Country Profile 2008 - Chile", 2008 [online] http://www.eiu.com/site_info.asp?info_name=ps_country_profiles \&entry1=psNav\&page=noads; IDC Latin America, "La industria de servicios globales en Chile. Estudio cluster de servicios globales", Santiago, Chile, Production Promotion Corporation (CORFO), 2009; Ministry of Education of Chile, "Titulados Pre-grado, Post-grado y Post-Títulos, años 1998-2007", Santiago, Chile, 2009; NASSCOM, "Indian IT-BPO Industry Factsheet", 2009; UNESCO Institute for Statistics, "UIS Statistics in Brief. Education (all levels) Profile -Philippines", 2010 [online] http://stats.uis.unesco.org/unesco/TableViewer/document.aspx?Reportld=121\&IF _ Language $=$ eng\&BR_Country $=6080 \& B R \_$Region $=40515$; Coalition for Development Initiatives (CINDE), "Offshore Services Data Industry", 2012; Nearshore Americas, "Guatemala City Executive Video Forum", 2010 [online] http://www.nearshoreamericas.com/the-premiere-of-thenearshore-video-executive-forum/.

Note: BPO, business process outsourcing; F\&A, finance and accounting; IT, information technology; $\mathrm{KPO}$, knowledge process outsourcing; R\&D, research and development.

a Data for 2011.

b Data for 2010.

\section{How Latin American countries can leverage local endowments to upgrade in global value chains}

The region has not been particularly proactive in leveraging its long trajectory in traditional sectors, such as mining, forestry, and agriculture, to participate in higher value sectors of international trade. Despite significant natural resource endowments, many Latin American countries continue to be confined to the lower segments of numerous 
primary product value chains and thus do not add much value at the domestic level. Continued high commodity prices, owing in large part to China's strong demand for raw materials, ${ }^{5}$ have provided no incentives to upgrade. These industries nonetheless offer considerable opportunities for adding value. Countries can leverage their wealth in natural resources and the related expertise to develop sophisticated, higher value services for export, as shown in the three examples presented below: the development of a computerized traceability system for the cattle industry in Uruguay, Chilean mining engineering service exports and environmental services in Costa Rica.

\section{(a) Creating knowledge: a traceability system for the cattle industry in Uruguay}

With over 12 million head of cattle in the country, cows outnumber people by four to one in Uruguay, whose main export is beef. In 2010, Uruguay exported US\$ 1.1 billion in beef products (COMTRADE, 2012). The global beef industry, however, is extremely vulnerable to health and food safety problems. Uruguay has not been immune to these difficulties: a 2000 outbreak of foot-and-mouth disease led to a multi-year ban on exports to the European Union, the United States and numerous other countries including Chile, Israel and the Republic of Korea. In order to mitigate the impact on key export revenues, Uruguay embarked on the development of a sophisticated bovine traceability system to allow the country to quickly and efficiently track the source of and contain potential problems and maintain consumer and regulatory confidence in its products.

The livestock traceability system was developed through a collaborative multi-stakeholder initiative bringing together producers, local governments, transport staff, the private sector, IT companies and the central government (particularly the Ministry of Agriculture). Today, it is the only system in the world with real-time monitoring of $100 \%$ of the national cattle herd. A chip implanted in each cow's ear at birth allows the system to keep centralized and accurate information regarding the animal, from birth through to sales and distribution points. Approximately 2.5 million new animals are registered each year (Crescionini, 2012; SONDA, 2012; World Bank, 2012). Uruguay has a great opportunity to capitalize on its knowledge and experience by exporting these services to other countries that face similar issues. Indeed, Colombia has already begun to roll out this information system for its cattle herd. This means that Uruguay can participate in different segments of the cattle value chain. In addition to continued beef exports,

According to the Economic Commission for Latin America and the Caribbean (ECLAC), over the past 10 years China's share in the region's exports has risen from $1 \%$ to $7 \%$ (Bárcena and Rosales, 2010). 
Uruguay now has the potential to export advanced services not only for the beef industry, but for the wider livestock sector. As the industry must meet increasingly strict global food safety standards, this represents a tremendous competitive advantage for Uruguay.

\section{(b) Leveraging success in mining for offshore services in engineering ${ }^{6}$}

With significant reserves of copper and other metals, mining is a major industry in Chile. By 2010, the country had successfully translated its experience in the field into an important source of services revenue, emerging as one of the leading global centres of mining engineering services (Fernandez-Stark, Bamber and Gereffi, 2010b). As international mining companies moved to Chile to tap the country's tremendous mineral wealth, their large global engineering partners also began to set up operations in the country to support them (Arze, 2009; Sanchez and Boolan, 2009). These firms, including Hatch, Fluor, SNC-Lavalin, Bechtel, SKM-Minmetals and Ara Worley Parsons, established a significant presence in Chile in the 1990s (Arze, 2009). These companies started out by providing lower value design drawings for Chilean mining operations, but by the end of the 2000s five of these firms had established global centres of excellence for the copper industry in Chile. These centres serve as the lead offices for the development of all copper projects around the globe. Together, the firms employed over 3,500 engineers at the height of the copper boom in 2008 (Fernandez-Stark, Bamber and Gereffi, 2010b) and engineering service exports related to mining alone totalled an estimated US\$ 275.3 million. At the time, this was the largest offshore service export sector in Chile, accounting for one third of service exports (IDC Latin America, 2009).

The government has placed significant emphasis on supporting the export of Chilean engineering services and has sponsored a variety of projects in this area. It was also able to leverage dramatic events such as the February 2010 earthquake - the fifth most powerful earthquake on record, in which just 10 buildings were severely damaged- and the rescue of 33 miners who were trapped 700 metres underground to promote and demonstrate the quality of local engineers (ABS-CBN News, 2010). The government has also invested close to US\$ 1 million on a branding and promotional initiative for Chilean engineering services in Canada (Au, 2011). Continuing to support Chile's position as a market leader in mining engineering exports will be important in the long term as natural reserves dwindle.

${ }_{6} \quad$ See Fernandez-Stark, Bamber and Gereffi (2013b). 


\section{(c) Environmental services offshoring: an opportunity for Costa Rica}

Costa Rica is recognized worldwide for its unique approach to environmental protection and is a leader in the field among developing and developed countries alike. As a result of conservation incentives put in place in the 1980s, today tropical forest covers more than half of the country. Illegal logging has decreased from $82 \%$ to $15 \%$ in the past 20 years and farmers are paid to manage and protect their natural surroundings (Conservation International, 2012). This know-how has, however, thus far been used principally in support of domestic priorities; experts work for national non-governmental organizations and foundations, and the country has not yet seized the opportunity of finding a commercial use for the significant expertise it has built over many years. As climate change gains in prominence on the global development agenda, there is significant demand for services in these areas. The global environmental services and technology market is estimated to be worth US\$ 782 billion (OEEI, 2012).

Owing to its critical mass of qualified human capital sustaining this market niche (Chassot, 2012; Rodríguez, 2012), Costa Rica is in an excellent position to export high-demand environmental services, including natural resources management, environmental impact studies, assessments of threatened and endangered species and protected areas and environmental education and training. More than 18 other countries, including China, have consulted Costa Rica on their conservation policies (Conservation International, 2012). As with many developing countries, however, limited knowledge of potential markets and undeveloped entrepreneurship skills undermine the potential for translating these consulting opportunities into profitable service exports (Chassot, 2012). Promoting this industry will require support to help local firms internationalize, on one hand, and to convince foreign environmental firms to use the country as platform for the export of services, on the other. Linkages between these two types of firms will be critical for the development of this niche activity that is in great demand at the global level.

\section{Skills for upgrading in global value chains: workforce development and national innovation systems}

As shown in the previous sections, the global fragmentation of GVCs presents multiple opportunities for countries in Latin America to drive economic growth and add value to their industries. At the same time, however, intense international competition threatens to push many actors out of GVCs. Developing countries, including those in Latin America, can 
no longer compete on the basis of cheap labour and natural resources alone - to upgrade they must enhance their capabilities or specialize in particular market segments. Skills and workforce development have been identified as essential elements for upgrading in GVCs (Gereffi, Fernandez-Stark and Psilos, 2011). Countries must therefore align their skills development policies with international labour requirements to maintain and upgrade their positions within GVCs.

Owing to their constantly changing sources of demand, GVCs require individuals who can continuously update and improve their skills rapidly and effectively. Yet, in developing countries, traditional workforce development systems often fail to provide the skills required by global industries. Greater coherence must therefore be sought between the skills imparted by education and training and the capabilities required by the private sector (Fernandez-Stark, Bamber and Gereffi, 2010b; Gereffi, Fernandez-Stark and Psilos, 2011; Wadhwa and others, 2008). Despite this mismatch, developing countries are nonetheless adding value to their sectors. As a result, complex local innovation systems have emerged in developing countries to support skills upgrading, encompassing a broad range of stakeholders both within and beyond the chain. These stakeholders include private firms, public and private institutions in education, governments, non-governmental organizations, industry associations and international donors. However, these local arrangements are reactive policies designed to fill skills gaps, and few coordinated efforts have been made to proactively improve the effectiveness of skills upgrading at the national level.

The four Latin American workforce development systems described below emerged to help firms enter, or upgrade within, GVCs. These case studies illustrate the involvement of a variety of stakeholders and underscore the importance of collaboration and coordination between actors in value chains in moving up the value chain. The examples include the finishing school project implemented by the Inter-American Development Bank (IDB) in several countries in the region, the Chilean Public-Private Strategic Council for Offshore Services, workforce development initiatives led by the local government in collaboration with industry to develop the aeronautic cluster in Querétaro, Mexico, and the human capital development model adopted in Costa Rica to serve the business services sector in the country.

\section{Finishing schools in India and Latin America}

Finishing schools show promise as a tool for narrowing the gap between the human capital needs of GVCs and the skills supplied by national education systems. The finishing school model has been tested in 
India and the Philippines, and was recently applied in Latin America with the support of the IDB. These schools help recent graduates and workers develop skills that are in high demand, thus making them more employable. By increasing workforce employability, finishing schools can, in turn, help a country improve its position in the value chain.

Finishing schools build on the fundamental skills acquired in academic institutions, filling in specific gaps in knowledge and soft skills. These gaps are determined on the basis of a comparison between the skill sets needed by a particular industry and the skills currently offered by the workforce. In India, the most effective finishing schools are those that collaborate with companies to identify the desired skill sets, and adapt training accordingly (Tholons, 2012). In the global services industry, the priorities often include technical IT skills, proficiency in English and soft skills that focus on interpersonal relations, confidence and presentation skills. Programmes at finishing schools to train workers for careers in IT services can run from five weeks to one year (Tholons, 2012, p. 14). These schools often target young people who have recently graduated from high school or university, but they can also play a role in retraining adult workers (IDB, 2012).

Public-private partnerships are central to creating effective financing and governance mechanisms to support finishing school programmes in developing countries. Although finishing schools in India may be run by either the government or a private institution, in Latin America there is increasing recognition that collaborative policies and institutions provide the most effective support to finishing school initiatives. The IDB replicated the public-private partnership models developed in India in its first pilot projects in Uruguay and Colombia. The pilot finishing schools project in Colombia is a partnership between Fundación Universitaria Empresarial (a private, non-profit higher education institution) and the Colombian Ministry for Trade, Industry and Tourism. This project will train 40 software professionals over 6 months, combining classroombased training and an internship at one of the 26 companies participating in the project. The public-private model offers two key advantages: firstly such partnerships create opportunities for co-financing, reducing the cost burden borne by any one sector and, secondly, the content of the programmes is determined by the employers themselves, ensuring that the skills developed match industry needs (IDB, 2012). Thus, the finishingschool model recognizes the role of all stakeholders, the State, academia and industry in shaping the capabilities of the labour pool towards delivering information technology and business process outsourcing services (Tholons, 2012, p. 14). 


\section{The Chilean Public-Private Strategic Council for the Offshore Services Sector}

In 2007, the Chilean Committee of Ministries for Innovation created a public-private coalition for the offshore services industry with the goal of increasing the size of the industry fivefold in four years. The coalition is composed of 13 public and private institutions, including multinational corporations, domestic companies, industry associations, educational institutions, ministries and Chile's economic development agency CORFO. It is managed by CORFO and financed from the Chilean Innovation and Competitiveness Fund. Workforce development was defined as one of four strategic areas for action and is the sector that receives the most funding (the other areas were developing an international promotion strategy, improving infrastructure and the regulatory framework and developing domestic firms). Annual investment in this strategic plan was estimated at US\$ 27 million per year in 2008, 2009 and 2010, of which 83\% was earmarked for human capital development (Government of Chile, 2008). The majority of these funds were allocated to workforce development initiatives, illustrating the importance afforded to improving skills in the workforce in efforts to continue moving up in the value chain.

In addition, CORFO has funded several studies on the workforce requirements of the offshore services industry and on the readiness of the Chilean labour force to meet those demands (Fernandez-Stark, Bamber and Gereffi, 2010d; Mercer, 2008). One of the principal shortcomings identified in the Chilean labour force was a lack of workers fluent in English. In response, CORFO offered English-language scholarships for potential industry employees, with 3,000 such scholarships awarded between 2008 and 2010 (Gereffi, Fernandez-Stark and Psilos, 2011).

\section{The aerospace industry in Querétaro, Mexico ${ }^{7}$}

The aerospace industry in Querétaro has grown rapidly since Bombardier - one of the leading companies in the sector - set up in the area in 2006, marking Querétaro's entry into the aerospace GVC. The French group Safran and Spanish airframe manufacturer Aernnova quickly followed suit, establishing operations in 2007. Under the leadership of the Secretariat for Sustainable Development, Querétaro's aerospace cluster has since become one of the four leading clusters in Mexico. By 2012, there were over 30 foreign firms operating in the state, employing an estimated 6,000 staff, approximately $20 \%$ of the country's aerospace workforce. Mexico's exports in the sector had reached US $\$ 4.5$ billion by 2011, up from US $\$ 1.3$ billion in 2004 .

Information for this case study is based on the following sources: Ayala, 2009; Casalet and others, 2011; Case, 2012; Johnson, 2012; Secretariat of Economic Affairs, 2012; Sorbie, 2009;

The Business Year, 2012. 
Growth was supported by a clear commitment to the development of the industry by the state government. Among the most important manifestations of this was the creation in 2007 of the National Aeronautics University of Querétaro (UNAQ), which offered several technical programmes developed as part of public-private initiatives and launched the first aerospace engineering programme in the country. State investment in UNAQ totalled US\$ 21 million in 2009. In addition to recruiting teaching staff from both Canada and Spain, UNAQ drew teachers from aerospace firms working in the region. By 2012, there were 488 technical and professional students at UNAQ. The contribution made by UNAQ to human capital development in the state came in addition to an already strong engineering training base. In $2009,41 \%$ of all undergraduate degrees were awarded in engineering, while $65 \%$ of the master's degree programmes available in the state were in engineering fields (Casalet and others, 2011). Additionally, in 2007 an aircraft maintenance programme was established in Querétaro by the National Mexican Technical Training Institute, which sees 90 technicians graduate each year. This has stoked the ongoing development of the state's aircraft maintenance and repair sector and helped attract large investments, including the 2012 deal between Delta and Aeroméxico to establish a US\$ 50 million maintenance, repair and overhaul facility in Querétaro with seven production lines to serve both airlines.

\section{Costa Rica's offshore services talent-development pipeline}

Costa Rica is one of Latin America's leading exporters of business services to the wider world (Fernandez-Stark, Bamber and Gereffi, 2013a). Growing competition for the country's human capital in the offshore services sector has led to the development of several public- and private-sector initiatives to expand the available workforce to sustain the country's competitiveness in the chain.

The approach taken by the private sector is increasingly focused on developing a talent pipeline for generating human capital with a view to upgrading into higher segments of GVCs. Firms in the sector recruit highschool students to join the workforce in basic technical positions. Vocational training is provided to help them fulfil their entry-level functions. They are then actively encouraged to pursue further education, with time off for study and, in some cases, even the reimbursement of tuition fees for those studying towards university degrees. As these individuals progress in their education, they are given opportunities to move up to higher value services in the company. Firms work proactively with universities to design curricula to ensure that their long-term needs are met. 
Concurrently, Costa Rica's Ministry of Public Education has established bilingual public high schools with a focus on the call centre sector to meet strong demand for staff fluent in English in the offshore services industry, thus ensuring an ongoing supply of entry-level graduates for the industry. Finally, in 2008, the government launched Costa Rica Multilingüe, a not-for-profit organization focused on improving communication skills for greater personal and professional development. ${ }^{8}$ Central to the organization's strategy is the National English Plan, which aims to ensure that all students graduating from high school have an intermediate or advanced level of proficiency in English by 2017.

This multi-stakeholder approach is helping both to bolster the country's immediate competitiveness and to facilitate longer-term upgrading in the offshore services GVC. This provides technical talent for the sector in the short term and also ensures long-term career development for individuals.

\section{Conclusions}

Over the past three decades, Latin American countries have come to participate in GVCs in a variety of industries in the agriculture, manufacturing and service sectors. The examples highlighted in this chapter demonstrate the region's capacity to engage in both traditional and non-traditional exports, including high-tech sectors such as aerospace, medical device equipment and advanced business services. The region now faces the challenge of upgrading into higher value added segments of these chains and reaping greater benefits from its participation. In particular, sectors where nations can leverage their natural-resource endowments to export sophisticated products and services represent significant opportunities for Latin American countries to drive upgrading. This upgrading requires a well-trained workforce to provide world-class products and services, and must therefore be supported by a strong focus on human capital development.

As Latin America becomes a more important player in international trade, it is time to analyse a new set of issues to determine how countries in the region can maximize the potential gains to be made from engaging in the global economy. Central to these issues is how countries can gainfully participate in GVCs by involving local firms, assimilating new knowledge and improving employment conditions, and how this participation can be enhanced by regional and national policies that simultaneously foster economic, social and environmental development. The organization was established by decree to ensure its sustainability over time,
regardless of the political party in power. 


\section{Bibliography}

ABS-CBN News (2010), "Financial BPO Sets Up Shop in Philippines" [online] http: / / www.abs-cbnnews.com/business / 02 /17/10/financial-bpo-setsshop-philippines.

Antràs, P. and others (2012), "Measuring the upstreamness of production and trade flows", American Economic Review, vol. 102, No. 3, Nashville, Tennessee, American Economic Association.

Arze, E. (2009), "Chile Interview Series: Ara Worley Parsons S.A. Personal Communication with K. Fernandez-Stark and G. Gereffi", 27 January.

AT Kearney (2009), "Geography of Offshoring is Shifting" [online] http:// www.atkearney.com/index.php/News-media/geography-of-offshoring-isshifting.html.

Au, R. (2011), "Personal communication with K. Fernandez-Stark", December.

Ayala, H. (2009), "Querétaro: Crece aeropuerto", Diario de Querétaro, 11 September [online] http:/ / www.oem.com.mx/laprensa/notas/n1320992.htm.

Bamber, P. and G. Gereffi (2013), "Costa Rica in the Medical Devices Global Value Chain: Opportunities for Upgrading", Durham, North Carolina, Center on Globalization, Governance \& Competitiveness, Duke University.

Bamber, P., K. Fernandez-Stark and G. Gereffi (forthcoming), "Developing Countries in Regional and Global Value Chains", Paris, Organization for Economic Cooperation and Developement.

Bárcena, A. and O. Rosales (2010), The People's Republic of China and Latin America and the Caribbean: Towards a Strategic Relationship (LC/L.3224-P), Santiago, Chile, Economic Commission for Latin America and the Caribbean (ECLAC) [online] http://www.eclac.org/publicaciones/xml/1/39521/china_latin_america_ caribbean_strategic_relationship_906.pdf.

Barrientos, S., G. Gereffi and A. Rossi (2011), "Economic and social upgrading in global production networks: a new paradigm for a changing world", International Labour Review, vol. 150, No. 3-4, Wiley.

BPAP (Business Processing Association of the Philippines) (2007), Offshoring and Outsourcing Philippines: Roadmap 2010 [online] http://www.bpap.org/bpap/ publications/bpap_roadmap.pdf.

Carillo, Jorge (2009), "Developing the US-Mexico border region for a prosperous and secure relationship: innovative companies and policies for innovation on the US-Mexico border", Houston, James Baker III Institute for Public Policy of Rice University.

Casalet, M. and others (2011), "Evolución y complejidad en el desarrollo de encadenamientos productivos en México. Los desafíos de la construcción del cluster aeroespacial en Querétaro" (LC/W.411), Santiago, Chile, Economic Commission for Latin America and the Caribbean (ECLAC).

Case, B. (2012), "Delta Repair Center with Aeromexico to boost aerospace hub", Bloomberg [online] http://www.bloomberg.com/news/2012-08-31/deltaaeromexico-to-build-repair-center-in-central-mexico.html.

Chassot, O. (2012), "Servicios medioambientales", personal communication with K. Fernandez-Stark", 2 November.

CINDE (Coalition for Development Initiatives) (2012), "Offshore Services Data Industry". 
Conservation International (2012), "Costa Rica" [online] http:/ /www.conservation. org/where/north_america/costarica/Pages/costarica.aspx.

Crescionini, E. (2012), "Sistema de trazabilidad bovina en Uruguay", Ministry of Cattle, Agriculture and Fisheries [online] http://www.imaginar.org/taller/ agrotic/eduardo_crescioni_ministerio_agricultura_uruguay.pdf.

Fally, T. (2012), "Production Staging: Measurement and Facts", Boulder, Colorado, University of Colorado Boulder, May.

Fernandez-Stark, K., P. Bamber and G. Gereffi (2013a), "Costa Rica in the Offshore Services Global Value Chain: Opportunities for Upgrading", Durham, North Carolina, Center on Globalization, Governance \& Competitivenes, Duke University.

(2013b), "Regional competitiveness in the Latin America offshore services value chain", The Oxford Handbook of Offshoring and Global Employment, D. Bardhan, D. Jaffee and C. Kroll (eds.), Oxford, Oxford University Press.

(2012a), "Inclusion of Small- and Medium-Sized Producers in High-Value Agro-Food Value Chains", Durham, North Carolina, Center on Globalization, Governance \& Competitiveness, Duke University.

(2012b), "Upgrading in Global Value Chains: Adressing the Skills Challenge in Developing Countries", Durham, North Carolina, Center on Globalization, Governance \& Competitiveness, Duke University.

(2011), "The offshore services value chain: upgrading trajectories in developing countries", International Journal of Technological Learning, Innovation and Development, vol. 4, No. 1.

(2010a), "The Chilean Offshore Services Industry: A Global Value Chain Approach".

(2010b), "Engineering Services in the Americas", Durham, North Carolina, Center on Globalization, Governance \& Competitiveness, Duke University [online] http://www.cggc.duke.edu/pdfs/CGGC-IDB_CORFO_Engineering_ Services_in_the_Americas_July_1_2010.pdf.

(2010c), "The Offshore Services Industry: Upgrading Through Workforce Development", Durham, North Carolina, Center on Globalization, Governance \& Competitiveness.

(2010d), "Workforce Development in Chile's Offshore Services Industry", Durham, North Carolina, Center on Globalization, Governance \& Competitiveness, Duke University [online] http://www.cggc.duke.edu/ pdfs/CGGC-CORFO_Workforce_Development_in_Chiles_Offshore_Services_ Value_Chain_March_15_2010.pdf.

Fernandez-Stark, K. and S. Frederick (2011), “The apparel global value chain: economic upgrading and workforce development", Skills for Upgrading: Workforce Development and Global Value Chains in Developing Countries, G. Gereffi, K. Fernandez-Stark and P. Psilos (eds.), Durham, North Carolina, Center on Globalization, Governance \& Competitiveness, Duke University.

Frederick, S. (2010), “Development and Application of a Value Chain Research Approach to Understand and Evaluate Internal and External Factors and Relationships Affecting Economic Competitiveness in the Textile Value Chain", Raleigh, North Carolina, North Carolina State University, unpublished. 
Gartner (2009), “Gartner Outsourcing \& Vendor Management Summit 2009. Post Event Brief", Las Vegas, 4-6 May [online] http:/ / www.gartner.com/imagesrv/ summits/docs/na/outsourcing/std12_2009_post_event_trip_report.pdf.

Gereffi, G. (2005), "Export-oriented Growth and Industrial Upgrading: Lessons from the Mexican Apparel Case", 31 de enero.

(1999), "International trade and industrial upgrading in the apparel commodity chain", Journal of International Economics, vol.48, No. 1, Amsterdam, Elsevier. (1995), "Global production systems and third world development", Global Change, Regional Response: The New International Context of Development, B. Stallings (ed.), Cambridge, Cambridge University Press.

(1994), "The organization of buyer-driven global commodity chains: how U.S. retailers shape overseas production networks", Commodity Chains and Global Capitalism, G. Gereffi and M. Korzeniewicz (eds.), Westport, Praeger Publishers.

Gereffi, G. and J. Bair (2013), "Better work in Central America: assessing the opportunities for upgrading in Nicaragua's apparel sector", Towards Better Work: Understanding Labor in Apparel Global Value Chains, A. Rossi, A. Luinstra and J. Pickles (eds.), Geneva, International Labor Organization.

Gereffi, G. and K. Fernandez-Stark (2011), Global Value Chain Analysis: A Primer, Durham, North Carolina, Center on Globalization, Governance \& Competitiveness (CGGC), Duke University [online] http://www.cggc.duke. edu/pdfs/2011-05-31_GVC_analysis_a_primer.pdf.

Gereffi, G., K. Fernandez-Stark and P. Psilos (2011), Skills for Upgrading: Workforce Development and Global Value Chains in Developing Countries, Durham, North Carolina, Center on Globalization, Governance \& Competitiveness, Duke University.

Gereffi, G. and J. Lee (2012), "Why the world suddenly cares about global supply chains", Journal of Supply Chain Management, vol. 48, No. 3, Wiley.

Giuliani, E., C. Pietrobelli and R. Rabellotti (2005), "Upgrading in global value chains: lessons from Latin American clusters", World Development, vol. 33, No. 4, Amsterdam, Elsevier.

Government of Chile (2008), Consultoría para el diseño de programas y agendas estratégicas del cluster offshoring y servicios financieros, para la División de Innovación de la Subsecretaría de Economía, Fomento y Reconstrucción (R.A. Exenta No. 1000), Santiago, Chile, Ministry of Economic Affairs.

Henriksen, L. and others (2010), Agro-Food Value Chain Interventions in Asia: A Review and Analysis of Case Studies, Vienna, United Nations Industrial Development Organization (UNIDO).

Hummels, D., J. Ishii and K.-M. Yi (2001), "The nature and growth of vertical specialization in world trade", Journal of International Economics, vol. 54, No. 1, Amsterdam, Elsevier.

Humphrey, J. and L. Navas-Alemán (2010), Value Chains, Donor Interventions and Poverty Reduction: A Review of Donor Practice, Brighton, Institute of Development Studies.

Humphrey, J. and H. Schmitz (2004), "Chain governance and upgrading: taking stock", Local Enterprises in the Global Economy: Issues of Governance and Upgrading, H. Schmitz (ed.), Cheltenham, Edward Elgar Publishing. (2002), "How does insertion in global value chains affect upgrading in industrial clusters?", Regional Studies, vol. 36, No. 9, Taylor \& Francis. 
IDB (Inter-American Development Bank) (2012), "What is the Inter-America Development Bank Doing About BPO Labor in Latin America?" [online] http://www.nearshoreamericas.com/interamerica-development-bank-bpolabor-latin-america/.

IDC Latin America (2009), "La industria de servicios globales en Chile. Estudio cluster de servicios globales", Santiago, Chile, Production Promotion Corporation (CORFO).

ILO/IFC (International Labour Organization/International Finance Corporation) (2010), "Better Work", vol. 2010.

Johnson, T. (2012), "Mexico takes flight as hub for aerospace industry", McClatchy Newspapers, 18 July [online] http://www.mcclatchydc.com/2012/07/18/ 156657 / mexico-takes-flight-as-hub-for.html.

Koopman, R. and others (2010), "Give credit to where credit is due: tracing value added in global production chains", NBER Working Papers, No. 16426, Cambridge, Massachusetts, National Bureau of Economic Research, September.

Mercer (2008), "Comparative Salary Study about Professionals and Technicians in Latin America, US and India in IT, BPO and KPO Functions (Finance and Biotech)", August.

Meyer-Stamer, J. and F. Waltring (2006), "Value Chain Analysis and 'Making Markets Work for the Poor' (M4P): Poverty Reduction Through Value Chain Promotion", Eschborn, German Agency for Technical Cooperation (GTZ).

Ministry of Economic Affairs of Chile (2009), Política Nacional de Innovación para la Competitividad, Santiago, Chile.

Ministry of Education of Chile (2009), "Titulados Pre-grado, Post-grado y PostTítulos, años 1998-2007", Santiago, Chile.

Miroudot, Sébastien, Rainer Lanz and Alexandros Ragoussis (2009), "Trade in Intermediate Goods and Services", OECD Trade Policy Working Paper, No 93 [online] http:/ / www1.oecd.org/trade/its/44056524.pdf.

MPO (Medical Product Outsourcing) (2011), "Puerto Rico Ups the Ante to Attract Medtech manufacturers and Suppliers" [online] http://www.mpo-mag. com/contents /view_breaking-news/2011-10-12/puerto-rico-ups-the-ante-toattract-medtech-m/.

NASSCOM (2009), “Indian IT-BPO Industry Factsheet”.

Nearshore Americas (2010), "Guatemala City Executive Video Forum" [online] http:/ / www.nearshoreamericas.com/the-premiere-of-the-nearshore-videoexecutive-forum/.

OECD/WTO (Organization for Economic Cooperation and Development/World Trade Organization) (2011), Aid for Trade At a Glance 2011: Showing Results, July [online] http:/ / dx.doi.org/10.1787/9789264117471-en.

OEEI (Office of Energy and Environmental Industries) (2012), "Industry Facts" [online] http://web.ita.doc.gov/ete/eteinfo.nsf/068f3801d047f26e8525688300 6ffa54/4878b7e2fc08ac6d85256883006c452c?OpenDocument.

Pietrobelli, C. and R. Rabellotti (2005), Mejora de la competitividad en clusters y cadenas productivas en América Latina: El papel de las políticas, Washington, D.C., InterAmerican Development Bank [online] http://econegociosagricolas.com/ena/ files/Mejora_de_la_competitividad_en_clusters_-_BID_2005.pdf. 
Portocarrero Lacayo, A.V. (2010), El sector textil y confección y el desarrollo sostenible en Nicaragua, Geneva, International Centre for Trade and Sustainable Development, January.

Producen (2007), “Actualización del programa para el desarrollo del cluster de productos médicos de las californias", Tijuana, October.

PROMEXICO (2011), "In Search of Medical Innovation" [online] http://negocios. promexico.gob.mx/english/11-2011/art01.html.

PRONicaragua (2010), "Investment Opportunities Textiles and Apparel: PRONicaragua" [online] http://www.pronicaragua.org/index.php?option= com_content\&view=article\&id=35\&Itemid=98\&lang=en.

Rodríguez, C.M. (2012), "Servicios medioambientales", personal communication with K. Fernandez-Stark, 22 August.

Sanchez, J. and H. Boolan (2009), "Chile Interview Series: Bechtel S.A. Personal communication with K. Fernandez-Stark and G. Gereffi", 29 January.

Secretariat of Economic Affairs (2012), El sector aeronaútico en México, Mexico City.

SONDA (2012), “Un sistema de trazabilidad para el ganado bovino de Uruguay que asegura calidad sanitaria" [online] http:/ / www.sonda.com/caso/10/.

Sorbie, B. (2009), "Queretaro Prepares for Massive Aerospace Growth" [online] http:/ / www.flightglobal.com/news/articles/queretaro-prepares-for-massiveaerospace-growth-325253/.

Stamm, A. and C. von Drachenfels (2011), "Value Chain Development: Approaches and Activities by Seven UN Agencies and Opportunities for Interagency Cooperation", Geneva, International Labor Organization [online] http:/ / www. ilo.org/empent/Publications/WCMS_170848/lang--en/index.htm.

The Business Year (2012), "Sonic boom" [online] http:/ / www.thebusinessyear.com/ publication/article/12/942/mexico-2012/sonic-boom.

The Economist Intelligence Unit (2008), "Country Profile 2008 - Chile" [online] http://www.eiu.com/site_info.asp?info_name=ps_country_profiles\&entry1= psNav\&page $=$ noads.

Tholons (2012), "Outsourcing \& National Development in Latin America" [online] http: / / www.google.com/url?sa=t\&rct=j\&q=\&esrc=s\&source=web\&cd=1\&cad =rja\&ved=0CD0QFjAA\&url=http $\% 3 \mathrm{~A} \% 2 \mathrm{~F} \% 2 \mathrm{Fwww}$.tholons.com $\% 2 \mathrm{Fnl} \_p d f \% 2$ FTholons_Whitepaper_Tholons_Outsourcing_and_National_Development_ Whitepaper_February_2012.pdf\&ei=eAi5UK3pIJSw8ATChoHYCQ\&usg=AFQ jCNGzetmK9aZXhHIKjKXOk7ROE9Y_Gw\&sig2=n4Rj-utYcgJ5bCnpMUo8Fw.

Tucci, M. (2011), The Future of Latin America's IT Services Sector, Tholons.

UN COMTRADE (United Nations Commodity Trade Statistics Database) (2012) [online] comtrade.un.org.

UNESCO Institute for Statistics (2010), “UIS Statistics in Brief. Education (all levels) Profile - Philippines" [online] http://stats.uis.unesco.org/unesco/ TableViewer / document.aspx?ReportId=121\&IF_Language $=$ eng \&BR_ Country=6080\&BR_Region $=40515$.

UNIDO (United Nations Industrial Development Organization) (2009), "AgroValue Chain Analysis and Development", Vienna [online] http://www.unido. org/fileadmin/user_media/Publications /Pub_free/Agro_value_chain_ analysis_and_development.pdf. 
USAID (United States Agency for International Development) (2012), "Microenterprise Development" [online] http://www.usaid.gov/our_work/ economic_growth_and_trade/micro/index.html.

Wadhwa, Vivek, Una Kim De Vitton and Gary Gereffi (2008), "How the disciple became the guru: is it time for the U.S. to learn workforce development from former discipline India?", The Oxford Handbook of Offshoring and Global Employment, Ashok Bardhan, Dwight M. Jaffee and Cynthia A. Kroll (eds.).

World Bank (2012), "Proyecto de recuperación de emergencia ante la fiebre aftosa" [online] http://web.worldbank.org/WBSITE/EXTERNAL/BANCOMUNDIAL/ NEWSSPANISH/0,,contentMDK:22912662 pagePK:64257043 piPK:437376 t heSitePK:1074568,00.html.

Zhu, S., N. Yamano and A. Cimper (2011), "Compilation of bilateral trade database by industry and end-use category", OECD Science, Technology and Industry Working Papers, No. 2011/06, Paris, OECD Publishing. 


\title{
Chapter III \\ Access to finance in value chains: New evidence from Latin America
}

\author{
Lizbeth Navas-Alemán \\ Carlo Pietrobelli \\ Marco Kamiya
}

\section{Introduction ${ }^{1}$}

The literature on financing for small and medium-sized enterprises (SMEs) highlights linkages with large firms in value chains as a possible way of enhancing access to credit. However, much of the literature on value chains emphasizes issues of coordination and governance of those linkages, along with their effects on industrial upgrading, with little mention of the financial implications for SMEs. This paper seeks to fill this gap by looking for evidence of the impact of inter-firm linkages and specifically

The authors wish to thank Juan O'Farrell, Carlos Alvarado-Quesada, Eduardo TrejosLalli and Anabel Marin for their valuable contributions to the case studies. They are also grateful to the entrepreneurs, finance institutions and technical service providers for participating in our interviews and generously sharing their time, data, and experiences. Local counterparts (MOVERGS in Brazil, CENIT in Argentina and CAMTIC in Costa Rica) provided key contacts, information, and context throughout the research process. The authors would also like to thank John Humphrey for comments and Hannes Bahrenburg for research assistance, and two anonymous reviewers for their comments. The opinions expressed in this chapter are those of the authors and do not necessarily reflect the views of their institutions. 
interactions with large firms on access by SMEs to financing. Original enterprise-level data in three different Latin American and Caribbean sectors and countries (agro-industry in Argentina, furniture in Brazil, and information and communications technologies in Costa Rica) are used to compare the different sources and instruments of finance used by SMEs. A distinction is made between arm's length financial mechanisms, based on "hard data" and relationship finance, based on "soft data". The findings suggest that chain governance matters for the type of role large firms can play in enhancing access by SMEs to financing. Policies should take into account the type of chain governance between large firms and SMEs across industries and countries when providing incentives to increase the role of large firms as direct financiers or guarantee providers for SMEs.

Upgrading value chain linkages to enhance competiveness is the overriding objective of firms and supporting governments. However access to finance remains one of the critical obstacles to economic development and growth, especially for small and medium-sized enterprises (SMEs) in developing countries. Nichter and Goldmark (2009) point to the constraints posed by lack of credit at start-up and subsequently for investment and upgrading, and Beck and Demirgüç-Kunt (2008) argue that this credit constraint is especially binding on the growth of SMEs.

Financial system lenders look for two conditions when lending money. The first one is some idea of whether the borrower is likely to be able to repay. The second is some form of collateral so that the money lent is protected even in case of default and the borrower has a strong incentive to pay back the loan. Both conditions are more easily provided by large firms: more information is available about them, and they have more assets to offer as collateral.

SMEs have none of these advantages. It is more difficult and expensive for banks to assess the risk profile of potential SME borrowers, and these borrowers are less able to provide the collateral that banks would demand. Arguably, many SMEs are creditworthy since they grow over time and become large firms themselves, but the formal banking system is not well-structured for distinguishing between high and low risks relating to SME credit provision.

In the present world of open international markets, SMEs rely increasingly on larger firms for their access to markets, and larger firms find it convenient and profitable to outsource and fragment their activities into a chain of many functions, which are carried out by many different actors and in different locations (UNCTAD, 2011; Pietrobelli and Rabellotti, 2007). Networks of firms with dense inter-firm linkages, such as the vertical linkages prevailing in value chains, have become increasingly common forms of industrial organization. Do the linkages built into value 
chains facilitate SME access to credit? Could they play a facilitating role of this kind and under what circumstances? This article analyses these issues in Argentina, Brazil and Costa Rica and finds that cooperation as shown by inter-firm linkages leads to access to finance through different channels. Firms should exploit these opportunities and governments support these efforts.

\section{A. How can inter-firm linkages in value chains facilitate access to financing?}

In value chains, financial flows may be facilitated through two mechanisms: (i) the large firm offers direct financing to SMEs (e.g. trade finance or materials and machinery acquisitions); (ii) the link to a large firm strengthens the capacity of the SME to obtain credit, either because of the reputational effect of working for a larger company, or because this link provides future cash flow and orders, or because the large firm may be prepared to offer guarantees. Moreover, access to finance may improve in firm networks due to: (i) reputation effects, which are important and increase the cost of default to an SME (this could be viewed as a kind of collateral); and (ii) the easier diffusion of information in firms' networks, which would reduce the information asymmetry relating to the financial situation of a local SME.

The present study seeks to explore whether inter-firm linkages in value chains can improve access to financing for SMEs. We find evidence of their existence across different industries in Latin America, often eased by the presence of a third party, and highlight some opportunities for public policies. ${ }^{2}$ The paper presents findings from three case studies based on primary data collected during November and December 2010 on 41 firms from the Argentine agro-industry, Brazilian furniture, and Costa Rican IT sectors, supplemented by more than 20 interviews with key informants (banks, SME finance experts, business associations and consultants), as well as secondary sources.

In terms of whether and how linkages with larger firms improve SME access to finance, different forms of inter-firm institutional arrangements (including value chain governance, see table III.1) are explored to determine which would be most likely to influence SME financing and possible ways of promoting them. In particular, this study looks for evidence of:

A detailed review of the available literature on SME finance in developing countries, with a particular emphasis on inter-firm financing, is presented in Navas-Alemán, Pietrobelli and Kamiya (2012). 
- Large firms providing supplier or buyer credit to SMEs

- SMEs that obtain financing conditional upon their linkage to large firms

- Loan guarantees provided by other firms to benefit SMEs

- SMEs that use different financial instruments involving interfirm linkages

- Intervention by third parties to promote SME finance that exploits the presence of inter-firm linkages

Table III.1

Chain governance indicators

\begin{tabular}{|c|c|c|}
\hline $\begin{array}{l}\text { Type of chain } \\
\text { governance }\end{array}$ & Explanation & Indicators \\
\hline Market & $\begin{array}{l}\text { - Arm's length relations } \\
\text { between firms } \\
\text { - No governance }\end{array}$ & $\begin{array}{l}\text { - Low buyer concentration and low producer } \\
\text { concentration } \\
\text { - No buyer or market dependency } \\
\text { - Buyer not involved in product definition } \\
\text { - Repeat transactions are possible, but } \\
\text { information flows are limited } \\
\text { - No technical assistance }\end{array}$ \\
\hline Network & $\begin{array}{l}\text { - Coordination of activities } \\
\text { between firms, but mutual } \\
\text { interdependence } \\
\text { - Typical of strategic alliances } \\
\text { and division of competences } \\
\text { between firms }\end{array}$ & $\begin{array}{l}\text { - No buyer or producer dependency } \\
\text { (producer may have various buyers, but if } \\
\text { only a few, the buyer is likely to have few } \\
\text { producers) } \\
\text { - Few exit options on either side } \\
\text { - No asymmetry in knowledge (producer's } \\
\text { knowledge is valuable to buyer and hard to } \\
\text { substitute, and vice versa) }\end{array}$ \\
\hline Quasi-hierarchy & $\begin{array}{l}\text { - Producer is subordinate to } \\
\text { one or a few buyers } \\
\text { - Strong power asymmetries } \\
\text { and long-term relationships } \\
\text { - One firm exerts a high } \\
\text { degree of control over } \\
\text { other firms even if they are } \\
\text { formally independent of } \\
\text { each other }\end{array}$ & $\begin{array}{l}\text { - High buyer dependency (main buyer takes } \\
\text { more than } 30 \% \text { of producer's output) } \\
\text { - High buyer concentration } \\
\text { - Buyer sets production parameters for } \\
\text { the producer } \\
\text { - Few direct sales from producer to buyer. } \\
\text { Intermediaries keep producers away from } \\
\text { final markets. } \\
\text { - Producer's performance is tightly audited/ } \\
\text { monitored by buyer } \\
\text { - Producer's exit options are more restricted } \\
\text { than buyer's } \\
\text { - Buyer provides technical assistance } \\
\text { - Information asymmetry (buyer knows more } \\
\text { about producer's costs and capabilities } \\
\text { than producer knows about buyer's) } \\
\text { - "Antagonistic cooperation" } \\
\text { - Buyer's competence in essential chain } \\
\text { activities is higher than producer's }\end{array}$ \\
\hline
\end{tabular}

Source: L. Navas-Alemán, "The impact of operating in multiple value chains for upgrading: the case of the Brazilian furniture and footwear industries", World Development, vol. 39, No. 8, Amsterdam, Elsevier, 2011, adapted from J. Humphrey and H. Schmitz (2000) 
In order to gather examples from a range of industries, three different types of industry with different models of engagement with larger firms are analysed: (i) processing of agricultural produce (dairy production) in Buenos Aires, Argentina; (ii) traditional manufacturing (furniture) in Serra Gaucha, State of Rio Grande do Sul, Brazil; and (iii) knowledge-intensive products and services (information technology (IT) and software) in San Jose, Costa Rica.

In sum, three main aspects may be highlighted from the literature review. First, evidence from experience with arm's length and relationshipbased inter-firm financing is very scarce and tends to focus on the agricultural sector.

Second, complex financing arrangements involving inter-firm linkages have not emerged organically, but generally have been initiated by a third-party facilitator. Firms in value chains apparently are not aware of innovative lending technologies and/or are mistrustful of other firms to the extent that only a third party would be able to foster the trust needed for financial transactions to take place.

Third, despite the lack of empirical research on the relationship between value chain governance and types of financing arrangements, some theoretical expectations may be proposed. Thus, in value chains headed by strong lead firms, relationship-based mechanisms involving more than two actors yield much potential for SMEs. The literature suggests that a lead firm may facilitate access to finance through multiple means, including reverse factoring, trade credit, and loan financing/loan guarantees.

The present study innovates by explicitly testing some of these expectations derived from previously separate branches of the literature with case-based evidence from Latin America.

\section{B. Case Studies}

\section{The agrifood industry in Argentina ${ }^{3}$}

The study of the agrifood industry in Argentina focuses mainly on two sectors: dairy cattle and broiler chickens. In these sectors, processing companies source inputs from small farms that specialize in very specific segments of production, e.g. fattening broiler chickens. The foodprocessing sector - mainly flour-based products such as biscuits, pasta and cereals- has also been studied (see table III.2).

This section summarizes evidence from a case study conducted by Juan O'Farrell and Anabel Marin (CENIT), based on the authors' questionnaire. 
In dairy and poultry production, processors outsource to independent farmers, but they also coordinate and supervise the farmers closely for a number of reasons. First, processors may wish to drive improved production processes along the chain. Scientific approaches to feeding and rearing may require the provision of special food and expert guidance on management of farm units. Second, in order to increase the value chain's overall efficiency, processors promote improved quality, productivity, and consistency in these feeder units. Third, the reliability of supply is crucial to the efficiency of processing plants that run continuously (Lawrence and others, 1997).

Consequently, processors depend upon maintaining a reliable group of input providers who can produce the required volumes and make the investments necessary for improving production. Processors, therefore, are motivated to invest in improving supplier capacity and struggle to reap the benefits of these investments. Thus, through value chain financing, processors both support their suppliers and tie them into their supply networks. This tying-in of suppliers is a characteristic of quasi-hierarchical forms of value chain governance (see table III.1).

In the case of the dairy industry, one of the value chains analysed in this study is led by La Serenísima (LS), the largest dairy company in Argentina. The company has 5,000 employees and annual sales of 2.3 million Argentine pesos. In 1999 the company founded a loan guarantee association (LGA), designed explicitly "to strengthen its value chain." This LGA now has 1,046 participant partners (all LS suppliers), who represent around one third of its total suppliers: almost $65 \%$ of them are dairy farms, $27 \%$ are firms involved in transport, and 8\% supply ambulance and medical services. ${ }^{4}$

This LGA provides commercial and financial guarantees and financial and technical assistance. It started by obtaining credit lines with financial institutions and offering them to its suppliers. To encourage the creation of LGAs, the Government of Argentina has provided tax exemptions to large firms, whereby those firms are guarantors and SMEs benefit from the guarantees. However, according to senior LS managers, "the key is not the tax break but to improve the quantity and quality of the raw materials purchased by the company" (Authors' interview with the LS LGA, December 2010).

The Argentine economic crisis of 2001 had a severe impact on the dairy industry, and the 2002 devaluation of the currency did nothing to reactivate the sector, which is oriented towards the domestic market. In this context, LS designed a programme to increase its suppliers' productivity, including providing technical and management assistance, financing input acquisition, and offering financial assistance for liability restructuring. The LGA supported this programme by offering guarantees to participant

Information for this section comes from an interview with the president of La Serenísima's LGA and an unpublished report from the company: "LS LGA History Report." 
partners, resulting in a notable increase in volume and range of services. While in 2002 the LGA provided 743 guarantees for a total of US\$ 1.8 million, in 2009 it provided 1,345 guarantees for a total of US\$ 5.5 million.

Because it knows much more about the firms to which it lends, and has the implicit collateral of suppliers' loss of contracts should default occur, the LS LGA operates as a communication channel, giving its lead company an advantage over specialist finance providers. Its staff is "directly and continuously" connected with agricultural engineers who "have in-depth knowledge of the farms" and who regularly produce reports on each farm's conditions. Overall, these practices improve information on a farmer's capacity to repay.

Some similar processes were observed in the poultry value chain in Argentina. Once again, this is a classic example of large firms strengthening their capacity to control and direct activities along the value chain by increasing the financial opportunities of their SME providers. Although large poultry firms have traditionally provided financial services to strategic suppliers, this function has been substantially strengthened through the activities of public and private LGAs.

Total production in the sector has increased from 764,000 tons in 2003 to 1,680,000 tons in 2010. The sector's expansion generated the need to increase the productive capacity of all firms within the value chain, from farms to transporters; for example, small farms, which especially suffer from limited access to credit, need financing for expansion in areas such as broiler growers and fattening units.

The Argentine poultry value chain follows a model known as the "global role model," also used in the United States and Brazil, which is characterized by strong vertical coordination in the value chain. Such vertical coordination occurs when a single firm, known as an integrator, exercises close control over all or most aspects of production from "farm to fork" (Leibler and others, 2008). The integrators contract out to farmers the raising of chicks and the fattening of chickens. Hence, farmers act as true service providers for the large firms governing the whole chain.

\section{(a) Access to sources of finance within value chains}

The dairy and poultry chains provide examples of facilitation of financing for suppliers by large firms through trade credit, input and machinery acquisitions, and short-term loans. However, indirect assistance through the provision of guarantees also deserves mention. Thus, linkages with large firms may both directly and indirectly make it easier for an SME to obtain financing.

Large firms facilitate SME financing on an individual basis by means of an agreement between the large firm and the SME, or between the firm and a financial institution, or through the creation of LGAs. In Argentina, 
LGAs have expanded significantly over the past ten years, especially in the agrifood sector (Llisterri and others, 2006). LGAs are thought to overcome credit market imperfections by allowing lenders to shift part of the loan recovery risk to the guarantor, the LGA (Camino and Cardone, 1999).

Overall, it has been observed that SMEs have much more access to finance through relationships with larger firms in the poultry and dairy chains than in other sectors of the food industry. This difference in chain governance and in SMEs access to financing can be explained by the nature of inputs the SMEs provide: flour and other ingredients can be stored for a long time, and lead firms in this sector do not fear their key input getting spoiled (as in the dairy sector), growing beyond the standard selling size (as in the poultry sector), or requiring strict traceability (as in both sectors).

\section{Box III.1}

\section{Loan guarantee associations in Argentina}

In Argentina many large firms are founding members of closed and semiclosed loan guarantee associations (LGAs), and contribute capital to give guarantees and sometimes direct financing to SMEs.

The strong private capital presence is a peculiar characteristic of Argentine LGAs which makes this system unique in the world. It was established under Law 24.467, which determines tax benefits for founding members of LGAs, with the aim of stimulating investment of private capital in the guarantee system. Hence, large firms now have a double incentive to engage in an LGA: a fiscal incentive (tax exemptions for capital contributions to the LGA constitution) and an incentive to improve the conditions of its small and medium-sized suppliers.

Because of the fiscal incentive, private actors actively participate in LGAs in Argentina: of the 20 LGAs that existed in 2007, 17 were totally privately owned (Llisterri and others, 2006). The presence of LGAs is especially strong in the agrifood industry, with 7 LGAs. Moreover, in Argentina, these associations rely essentially on large firms' investments, unlike many countries where LGAs depend on public guarantee funds (elsewhere in Latin America) or mixed systems that have strong state subsidies (e.g. Spain).

Argentine LGAs differ from guarantee systems elsewhere in Latin America where the tendency is to cater for a larger number of small enterprises that borrow relatively small amounts. In contrast, Argentine LGAs are directed at smaller numbers of SMEs that borrow larger amounts, mainly for working capital and capital equipment.

The evidence we have collected shows that in some sectors, e.g. dairy, poultry, stock-breeding, and wine, the participation of large enterprises is stronger through LGAs than through other guarantee systems. These value chains are structured so that a large leading firm (or cooperative) needs a critical input that is generally provided by SMEs. This feature gives the large firm stronger incentives to improve conditions for its SME suppliers.

Source: J. Llisterri and others, Sistemas de garantía de crédito en América Latina: Orientaciones operativas, Washington, D.C., Inter-American Development Bank, 2006; and M. Kulfas, "Las pymes argentinas en el escenario post convertibilidad. Políticas públicas, situación y perspectivas", Project Document, No. 4 (LC/W.272), Santiago, Chile, Economic Commission for Latin America and the Caribbean (ECLAC), 2008. 


\section{(b) Access to sources of finance outside value chains}

All the SME representatives interviewed maintained and there is ample evidence to corroborate their position - that their links with large firms enhance their creditworthiness. Having a large buyer with a stable demand is a clear advantage. Many also added that a positive "reputation effect" makes SMEs more attractive to financial institutions: supplying to a large firm is a good credential. However, many bank managers interviewed repeatedly stated that although they consider this effect important, it was not the main reason for the Argentine model's success.

Table III.2

Summary of financial instruments and guarantees observed in Argentine agrifood value chains

\begin{tabular}{|c|c|c|c|}
\hline Instruments & Dairy value chain & Poultry value chain & $\begin{array}{l}\text { Food processing } \\
\text { value chain }\end{array}$ \\
\hline \multicolumn{4}{|l|}{ Self-financing } \\
\hline Self-financing & $\begin{array}{l}\text { Frequently observed } \\
75 \% \text { of interviewees } \\
\text { declare that they finance } \\
\text { almost } 100 \% \text { with own } \\
\text { resources; } 50 \% \text { use } \\
\text { resources from another } \\
\text { agricultural business } \\
\text { they own. }\end{array}$ & Frequently observed & Frequently observed \\
\hline \multicolumn{4}{|c|}{ Inter-firm / arm's length finance } \\
\hline $\begin{array}{l}\text { Factoring or } \\
\text { reverse factoring }\end{array}$ & Not observed & Not observed & Not observed \\
\hline Leasing & $\begin{array}{l}\text { Occasionally } \\
\text { Transporters frequently; } \\
\text { farmers occasionally }\end{array}$ & $\begin{array}{l}\text { Occasionally } \\
\text { Particularly transporters } \\
\text { and distributors }\end{array}$ & Occasionally \\
\hline $\begin{array}{l}\text { Purchase order } \\
\text { finance }\end{array}$ & $\begin{array}{l}\text { Occasionally } \\
\text { Purchase agreements } \\
\text { between LS and } \\
\text { input and machinery } \\
\text { suppliers. Obtain better } \\
\text { financial terms. }\end{array}$ & Not observed & Not observed \\
\hline $\begin{array}{l}\text { Warehouse } \\
\text { receipt finance }\end{array}$ & Not observed & Not observed & Not observed \\
\hline \multicolumn{4}{|c|}{ Relationship finance } \\
\hline Trade credit & $\begin{array}{l}\text { Frequently } \\
\text { Capital advances from } \\
\text { producer to its suppliers, } \\
\text { later deducted from } \\
\text { product supply } \\
\text { Occasionally the LS } \\
\text { LGA buys inputs and } \\
\text { sells them to its partners } \\
\text { at better financial terms } \\
\text { than the market }\end{array}$ & $\begin{array}{l}\text { Frequently } \\
\text { A large firm (integrator) } \\
\text { buys equipment (e.g. } \\
\text { generator) and sells it } \\
\text { to farms. The price is } \\
\text { deducted from product } \\
\text { supply. Common } \\
\text { financing of smaller } \\
\text { amounts, e.g. fencing. } \\
\text { Smaller amounts than } \\
\text { dairy because inputs are } \\
\text { provided by the integrator. }\end{array}$ & Not observed \\
\hline
\end{tabular}


Table III.2 (concluded)

\begin{tabular}{|c|c|c|c|}
\hline Instruments & Dairy value chain & Poultry value chain & $\begin{array}{l}\text { Food processing } \\
\text { value chain }\end{array}$ \\
\hline $\begin{array}{l}\text { Deferred } \\
\text { payment checks } \\
\text { (discounted) }\end{array}$ & $\begin{array}{l}\text { Frequently observed } \\
\text { SMEs cash deferred } \\
\text { payment checks with } \\
\text { support provided by the } \\
\text { LS LGA. }\end{array}$ & $\begin{array}{l}\text { Occasionally observed } \\
\text { Thanks to LGAs, SMEs } \\
\text { can cash checks at } \\
\text { better discount rates }\end{array}$ & $\begin{array}{l}\text { Occasionally observed } \\
\text { Used by micro and } \\
\text { small firms. Some have } \\
\text { better interest rates with } \\
\text { support from a large firm } \\
\text { or LGA, and others lack } \\
\text { collateral and cash their } \\
\text { checks, using informal } \\
\text { financial entities }\end{array}$ \\
\hline \multicolumn{4}{|l|}{ Other } \\
\hline Angel investors & Not observed & Not observed & Not observed \\
\hline \multicolumn{4}{|l|}{ External financing } \\
\hline $\begin{array}{l}\text { Commercial } \\
\text { bank }\end{array}$ & $\begin{array}{l}\text { Frequently observed } \\
\text { SMEs use credit cards, } \\
\text { leasing, regular loans, } \\
\text { and overdrafts. }\end{array}$ & $\begin{array}{l}\text { Frequently observed } \\
\text { Regular loans and } \\
\text { leasing }\end{array}$ & $\begin{array}{l}\text { Occasionally observed } \\
\text { Interviewed SMEs } \\
\text { were mostly } 100 \% \text { self- } \\
\text { financed }\end{array}$ \\
\hline Micro credit & Not observed & Not observed & Not observed \\
\hline Public bank & $\begin{array}{l}\text { Frequently observed } \\
\text { Subsidized loans }\end{array}$ & $\begin{array}{l}\text { Frequently observed } \\
\text { Subsidized loans }\end{array}$ & Not observed \\
\hline \multicolumn{4}{|l|}{ Other } \\
\hline $\begin{array}{l}\text { Buyer/supplier } \\
\text { technical } \\
\text { assistance }\end{array}$ & $\begin{array}{l}\text { Frequently observed } \\
\text { The producer offered } \\
\text { financial assistance for } \\
\text { liabilities restructuring } \\
\text { after the } 2001 \text { crisis. } \\
\text { The LS LGA provides } \\
\text { assistance on financial } \\
\text { management }\end{array}$ & $\begin{array}{l}\text { Frequently observed } \\
\text { Large firms provide } \\
\text { veterinary and } \\
\text { maintenance assistance } \\
\text { to farms, especially at } \\
\text { initial stages }\end{array}$ & Not observed \\
\hline
\end{tabular}

Source: Prepared by the author on the basis of survey interviews, December 2010.

\section{The furniture value chains in the Serra Gaucha cluster, Brazil ${ }^{5}$}

The Brazilian furniture industry is the largest in Latin America, with production exceeding US\$ 8 billion (of which US\$ 968 million are exports); the industry comprises almost 17,000 firms spread all over the country (ABIMOVEL, 2010). The industry is clustered in various locations, and this study focuses on value chains in the Serra Gaucha cluster in Rio Grande do Sul, Brazil's southernmost state. This is one of the most successful furniture clusters in Brazil, the country's largest producer and second largest exporter in this field, and the leader in technological attainment (Gorini, 1998; Roese, 2003; MOVERGS, 2010). Serra Gaucha producers are mostly SMEs that make all types of furniture for domestic and foreign markets, mainly using particleboard (MOVERGS, 2010; Sindmóveis, 2010).

5 This section summarizes evidence from a case study conducted by Lizbeth Navas-Alemán. 
The furniture industry in Rio Grande do Sul emerged out of skills brought by Italian immigrants from Piedmont, Lombardy, and Veneto in the second half of the 19th century. Until the 1940s, most furniture production took place in small, mostly informal, carpentry establishments; but the 1950s and 1960s saw the establishment of formal firms, some of which still operate, with registered employees and mass production technologies (Lunelli, 2010).

In the 1970s, an expanding domestic market caused fast growth in the Serra Gaucha furniture cluster. The local market's absorption capacity was so high that firms did not target export markets until the 1980s. At that point, the Brazilian economy's hyperinflation and slow growth made many firms look outside for alternative outlets or agents to facilitate marketing. This process accelerated during the 1990s, when the Brazilian economy opened up. These trends induced a remarkable "modernization process" of Brazil's furniture sector (Vargas and Alievi, 2000), which was particularly marked among the Serra Gaucha's leading producers, who invested heavily in acquiring machinery and technology. These investments were often self-financed but also financed by the increasing subsidized credit offered by Brazilian government banks (e.g. Banco do Brasil, Caixa Federal, and Banrisul). The majority of micro and small enterprises, however, remained technologically backward (Gorini, 1998).

The intensive export trend that started in the late 1990s reached its peak by the mid-2000s; at that point, several value chains emerged, selling to domestic, Latin American, United States and European markets. Manufacturers often used their own designs and sometimes their own brands, making some Serra Gaucha furniture producers the lead firms of their own value chains (Navas-Alemán, 2006 and 2011). The strength of the Brazilian currency and the weakness of the United States dollar after 2005 made the growing Brazilian market more attractive to furniture firms, and this trend intensified during the 2008 financial crisis, when exporting to the weakened developed economies became riskier and less lucrative.

In 2010, most Serra Gaucha producers devoted a larger share of production to the fast-growing domestic market because of: (i) cheaper and more abundant consumer credit; (ii) cash-transfer programmes to low-income groups; (iii) the accelerated rate of economic growth in Brazil over the last decade; (iv) growth of the construction industry and the resulting demand for furniture; and (v) the skilled negotiation by business associations (e.g. MOVERGS), which have persuaded government entities of the need to include credit for furniture purchases in housing credit packages in social programmes managed by public banks, such as Minha Casa, Minha Vida (“My House, My Life”). 
Nevertheless, exports remain an important part of the Serra Gaucha business model: although volumes may be lower, the value added appears to be rising, particularly among the value chain's largest firms. ${ }^{6}$

\section{(a) Main sources of finance for furniture producers in Serra Gaucha}

Two strong values that have prevailed in Serra Gaucha are selfreliance and avoiding excessive debt. ${ }^{7}$ Therefore, Sierra Gaucha's most common sources of finance are self-finance and relationship finance. The latter consists generally of networks composed of family and friends and trade credit from other firms). Arm's length finance in the form of public bank loans and commercial loans were also mentioned (see table III.3).

Table III.3

Main sources of finance for sampled furniture firms in Serra Gaucha

\begin{tabular}{lccccc}
\hline $\begin{array}{l}\text { Source of } \\
\text { finance }\end{array}$ & $\begin{array}{c}\text { Self-finance } \\
\text { from the } \\
\text { firm and its } \\
\text { partners }\end{array}$ & $\begin{array}{c}\text { Family and } \\
\text { friends } \\
\text { network }\end{array}$ & Public banks & $\begin{array}{c}\text { Commercial } \\
\text { banks }\end{array}$ & Other firms \\
\hline $\begin{array}{l}\text { Percentage of } \\
\text { sample firms } \\
\text { using this } \\
\text { source }\end{array}$ & 88 & 88 & 100 & 50 & 77 \\
\hline
\end{tabular}

Source: Prepared by the authors.

Self-finance essentially took two forms: (i) using a firm's profits as working capital or investments, and (ii) selling a company's assets (even buildings) to solve financial difficulties and pay debts. Among the oldest (and probably more traditional) firms in the sample, selling assets to other local entrepreneurs was preferable to taking out loans with interest. Younger firms (those founded in the early 1990s or headed by younger entrepreneurs) were more open to using loans to finance longterm investment, preferring public banks with lower interest rates. Selling assets also brings a further complication: increased tax burdens. ${ }^{8}$

6 Firms such as Todeschini, Florense, Dell Anno, SCA, Marelli, and Bontempo have their own shops in foreign markets in Latin America, the United States, Europe and Africa, selling their own brand of furniture (MOVERGS, 2010)

7 Previous studies have attributed this reluctance to incur debt to the values of the Italian immigrants in the cluster, such as the desire to keep collective investments in local industries and to avoid losing assets that are part of what the local, tight-knit community perceives as its collective resources (Roese, 2003; Lunelli, 2010).

$8 \mathrm{PZ}$, one of the SMEs in the sample, survived two processes of bankruptcy protection (concordata), which were apparently caused by commercial debts, paid with the sale of assets, but then incurred a high tax penalty from the State. Interest rates on tax obligations are high and this adds to problems when a firm is trying to deal with creditors (Interview with PZ, December 2010). 
When considering preferences beyond self-finance, two important distinctions emerged: short-term versus long-term finance and SMEs versus larger firms. Results were mixed despite the expectation that we would see clear preferences for public loans for long-term investment and commercial banking or self-finance for short-term financing.

Some interviewees responded that "in an ideal world" they would prefer to use networks of family and friends (and self-finance) for shortterm lending and public finance for long-term lending. Public banks were preferred because of lower interest rates and advantageous repayment conditions. Some new financial products from banks such as Banco Nacional de Desenvolvimento Econômico e Social (National Bank for Economic and Social Development) (BNDES) have become increasingly attractive because they include working capital loans attached to longerterm investment loans, e.g. for building a new factory or purchase of a new machine. However, many of the small firms complained about public banks' difficult and lengthy application procedures.

In our interviews with bank officers and the Association of Furniture Industries of the State of Rio Grande do Sul (MOVERGS), we also found that many SMEs cannot ask public banks for loans because these banks only lend to SMEs that can prove that their taxes are up to date and that no lawsuits are pending against them in any court. Since many SMEs in the Serra Gaucha do not declare $100 \%$ of operations to the authorities, it becomes impossible for them to access those funds. Commercial banks, which have fewer requirements, grant the loan more readily but also ask for hard information and documents as collateral (e.g. property titles or accounts receivable from well-known clients); and they charge high interest rates. These factors create the distorted financial patterns we observe in the Serra Gaucha: use by SMEs of their own funds and those of family and friends to finance expansion plans and resort to very expensive credit from commercial banks for working capital and other short-term lending. ${ }^{9}$ Lastly, a large majority of firms confirmed that they receive at least 60 days of trade credit (with an interest rate between $2 \%$ and 3\% per month) from their main raw material suppliers. ${ }^{10}$

\section{(b) Access to sources of finance between firms within the value chains}

Trade credit between firms of any size is the most common form of intra-firm finance in the Serra Gaucha, especially credit granted by

Interview with a financial consultant in Bento Gonçalves, December 2010.

10 These results are confirmed by a much larger study supported by MOVERGS on 1,231

firms (Mattia and others, 2007). 
large suppliers of particleboard and veneers to furniture producers. A small number of multinational corporations of Chilean, Argentine, and Portuguese ownership, as well as two Brazilian suppliers, provide these essential materials for the industry; those suppliers wield enormous power to set prices and production parameters for Brazilian furniture producers, resulting in widespread complaints about the "dominance" exerted by particleboard suppliers (Navas-Alemán, 2006). Large producers can afford to buy materials without credit (" $a$ vista"), and they often obtain a $5 \%$ to $10 \%$ discount.

Particleboard suppliers limit credit to firms that are in financial difficulty, and they can even stop granting it altogether if there are doubts about the producer's ability to continue selling. Once an SME is regarded as successful in attracting buyers, particleboard companies trust that it will pay for materials bought on credit. Several firms mentioned that when faced with financial difficulty, they could borrow from their peers. Most such loans are granted on the basis of family or ethnic ties and in a spirit of solidarity and reciprocity.

There was only one mention of trade credit granted by buyers to producers, a "one-off" event during the 2008 financial crisis (field interview with KP, December 2010). Buyers rarely give producers any advance because of their own need to finance the customers expected to pay for furniture in instalments. Thus, an opportunity exists for many financial institutions to fulfil producers' demand for credit to provide working capital and purchase raw materials.

The mere mention of the word "factoring" raised negative reactions among sampled firms: they consider factoring with its high interest rates as a last resort; interviewees called the factors agiotistas (usurers), a term that implies an unfair, almost illegal, level of interest (at least 10\% per month). Factors also require sizable guarantees, so firms consider factoring only when they have lost all good credit and are in a desperate situation.

\section{(c) Access to sources of finance outside the value chain}

Borrowers pay higher interest rates to relatives and friends than those lenders to a commercial bank savings account $(0.5 \%$ per month), but the borrower pays less than a public bank would charge for a loan (1\% to $1.5 \%$ per month). Such loans are usually raised within ethnic groups, often Italian descendants who are also active in other businesses (e.g. wine makers or large agricultural producers might lend money to relatives in the furniture business). Capital injections that imply changes in a company's ownership are formally registered. 
For loans, documents are drawn to record the terms of repayment, but these documents are not formally registered before any official authority. Local reciprocity ties within the community ensure that their terms are largely respected, and social sanctions also create pressure: defaulting on such a loan risks financial ruin because the borrower would be mistrusted by the entire business community on which most finance is based.

Public banks charge lower interest rates than commercial banks ( $3 \%$ to $7 \%$ per month), but the former are usually slower and more bureaucratic. Medium-sized and large firms are likely to apply for loans from public banks such as Banco do Brasil or BNDES when planning expansion and investing in new equipment. Guarantees for such loans and for commercial loans are usually larger than the loan itself $(120 \%)$ and this expense clearly represents a barrier for smaller firms.

However, public banks, particularly BNDES, Caixa Federal and Banco do Brasil, offer many other credit lines and financial products to SMEs. An array of instruments is offered for leasing, working capital financing, and innovation finance (e.g. the BNDES Investment Support Programme (PSI), a credit line designed to encourage innovation among SMEs).

An instrument mentioned by most SMEs is the cartão BNDES, which works like a credit card with a low interest rate $(0.97 \%$ month) and can be used to pay for goods and services. The card is aimed at SMEs only, and encourages firms to recommend each other on the card's website (hosted by BNDES) in order to register and make transactions. The cartão BNDES is a popular way of financing working capital in the form of rolling credit (paid in up to 48 instalments), in line with the Brazilian tradition of buying and selling almost everything in instalments. ${ }^{11}$

Commercial bank loans and leasing are also very common among SMEs. Having a guarantee in the form of accounts receivable or predated checks from a large, well-known firm (e.g. Todeschini, Carraro or Multimóveis) makes it easier to obtain a loan but does not change the interest rate, which ranges between $2 \%$ and $6 \%$ per month.

11 Two interviewees mentioned also a special line of credit for the furniture sector created by BNDES a few years ago called REVITALIZA, which provided cheap finance for all types of firms. This programme was terminated in 2008, apparently because it was "unsustainable" (interview with KP and financial consultancy firm IF). Beneficiary firms in the sample said that financing was so cheap under the scheme ( $2 \%$ interest per year) that they were amazed it lasted so long. 
Table III.4

\section{Summary of financial instruments and guarantees observed in furniture} value chains (Serra Gaucha, Brazil)

\begin{tabular}{|c|c|}
\hline Instruments & Brazilian furniture chain \\
\hline \multicolumn{2}{|l|}{ Self-financing } \\
\hline Self-financing & $\begin{array}{l}\text { Frequently observed } \\
\text { The main form of financing in the sector, both for working capital } \\
\text { and expansion. }\end{array}$ \\
\hline \multicolumn{2}{|c|}{ Inter-firm / arm's length finance } \\
\hline $\begin{array}{l}\text { Factoring or } \\
\text { reverse factoring }\end{array}$ & $\begin{array}{l}\text { Not observed } \\
\text { Firms reported its existence but it is considered an instrument of last } \\
\text { resort due to high interest rates and substantial guarantees required. }\end{array}$ \\
\hline Leasing & $\begin{array}{l}\text { Frequently observed } \\
\text { Many public and commercial banks have developed leasing products for } \\
\text { SMEs (e.g. FINAME from BNDES). }\end{array}$ \\
\hline $\begin{array}{l}\text { Purchase order } \\
\text { finance }\end{array}$ & Not observed \\
\hline $\begin{array}{l}\text { Warehouse } \\
\text { receipts finance }\end{array}$ & Not observed \\
\hline \multicolumn{2}{|l|}{$\begin{array}{l}\text { Relationship } \\
\text { Finance }\end{array}$} \\
\hline Trade credit & $\begin{array}{l}\text { Frequently (granted by suppliers to their buyers) } \\
\text { Guarantees are usually not required when the buyer has a good credit } \\
\text { history and/or the two firms have been trading for some time. }\end{array}$ \\
\hline $\begin{array}{l}\text { Deferred } \\
\text { payment checks } \\
\text { (discounted) }\end{array}$ & $\begin{array}{l}\text { Frequently observed } \\
\text { One of the most common instruments used, along with accounts } \\
\text { receivable. Most commercial banks have provision for this. The guarantee } \\
\text { is the check itself, and those from well-known/large companies are } \\
\text { better received. }\end{array}$ \\
\hline \multicolumn{2}{|r|}{ 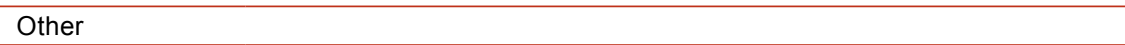 } \\
\hline Angel investors & $\begin{array}{l}\text { Occasionally observed } \\
\text { A "network of friends and family": it is rare for the investor to be from } \\
\text { outside the Serra Gaucha community. }\end{array}$ \\
\hline \multicolumn{2}{|l|}{ External financing } \\
\hline $\begin{array}{l}\text { Commercial bank } \\
\text { loans }\end{array}$ & \multirow{2}{*}{$\begin{array}{l}\text { Frequently observed } \\
\text { Properties usually required as guarantees. For short-term loans the } \\
\text { portfolio of accounts receivable is often used. Accounts receivable from } \\
\text { well-known/large firms are better received. }\end{array}$} \\
\hline Public bank loans & \\
\hline $\begin{array}{l}\text { Special } \\
\text { instruments for } \\
\text { SMEs (e.g. the } \\
\text { BNDES credit } \\
\text { card) }\end{array}$ & $\begin{array}{l}\text { Frequently observed } \\
\text { SMEs are defined as firms earning less than } 90 \text { million reais (as at August } \\
2012 \text {, about US } \$ 40 \text { million) per year. Guarantees include an immaculate } \\
\text { credit history, proof of tax payment, and no financial or environmental } \\
\text { lawsuits in their past. Other instruments from BNDES aimed at SMEs } \\
\text { such as PROGEREN (for working capital) and PSI (for innovation projects) } \\
\text { were mentioned. }\end{array}$ \\
\hline $\begin{array}{l}\text { Special } \\
\text { instruments for } \\
\text { the furniture } \\
\text { industry }\end{array}$ & $\begin{array}{l}\text { Occasionally observed } \\
\text { The use of "Construcard" was mentioned by one firm. It is a credit card funded } \\
\text { by the Caixa Federal Bank (a government bank), but aimed at allowing final } \\
\text { consumers to pay for construction materials and furniture in instalments. }\end{array}$ \\
\hline \multicolumn{2}{|l|}{ Other } \\
\hline Buyer/supplier TA & Not observed \\
\hline
\end{tabular}

Source: Prepared by the author on the basis of survey interviews, December 2010. 


\section{The information and communication technology (ICT) sector in Costa Rica ${ }^{12}$}

The expansion of information and communication technologies (ICT) in Costa Rica has its roots in a combination of public policies in the 1970s, especially those related to technology transfer and public education, health and infrastructure, and the emergence of dynamic businesses (Vargas, 2004). Awareness of the increasing economic relevance of ICTs led to the creation of computer sciences and computer engineering courses, first by the University of Costa Rica in 1973 and then by the Technological Institute of Costa Rica in 1976 (PROSIC,2007). In the 1980s, lower tariffs on hightechnology products made them more accessible and created opportunities for the development of custom software applications for local needs. This move, together with low labour costs and a considerable number of qualified graduates in computer sciences, generated the "first national entrepreneurs in the software industry aiming to satisfy the necessities of commerce, industry, law firms, among others" (PROSIC, 2007, p. 224).

In the 1990s, a number of local software firms were already producing for the national market and also exporting, especially to Central America (López and others, 2008) In the late 1990s, some auspicious conditions emerged that supported the growth of the software industry in Costa Rica: (i) Intel's 1996 decision to open a factory in Costa Rica; (ii) The advent of mass usage of the Internet; (iii) the "panic" linked to the year 2000, which increased local demand for software patches and applications; and (iv) increased competition from other Latin American software hubs, which spurred budding Costa Rican entrepreneurs to become more competitive (PROSIC, 2007, p. 225 and 234). However, the sector was not yet organized, no chamber or association represented producers, and there was anxiety about the potential shortage of qualified human resources to fulfil the growing industry's demands (IDB, 2004).

The "Intel factor" is of special relevance. By 2005, Intel had invested more than US\$ 770 million and created employment for 2,900 direct workers and approximately 2,000 indirect jobs (World Bank, 2006).

The establishment in Costa Rica of Intel and other ICT transnational corporations (TNCs), such as DSC Communications Corporation and Hewlett Packard, did not result from a government-led policy, but from the strategy of the Costa Rican Investment Promotion Agency (CINDE) ${ }^{13}$

12 This section summarizes evidence from a case study conducted by Carlos AlvaradoQuesada and Eduardo Trejos-Lalli on the basis of the authors' questionnaire.

13 CINDE is a private non-profit organization founded in 1982 and declared an institution of public interest by the Government in 1984. Its main goal is to attract foreign direct investment (FDI) into the country. 
to attract foreign direct investment (FDI). In the early 1990s, the country did not have a defined strategy for ICT, but the government adopted the CINDE policy, along with other policies for attracting FDI, after Intel's 1996 announcement (Rodriguez-Clare, 2001).

The presence of Intel and other large TNCs in the country has had positive effects on the country's FDI, GDP, exports, and employment. In 2004, FDI inflows reached US\$ 585 million, corresponding to 3.2\% of GDP (World Bank, 2006, p. 26).

Despite this success, FDI spillovers and linkages appear to have been limited. ${ }^{14}$ Ciarli and Giuliani (2005) reach a similar conclusion, pointing out the weakness of the backward linkages, which are mainly concentrated in low technology sectors.

In spite of the interest in buying inputs domestically from the many small and medium-sized TNCs that came to Costa Rica, encouraged by CINDE's promotion and the Intel example, many of these opportunities have not been exploited. One reason is limited access to credit due to high collateral requirements and steep interest rates (Cordero and Paus, 2008, p. 18).

To address this problem, in 2008 the Legislative Assembly of Costa Rica approved a law creating the System for Development Banking, ${ }^{15}$ which included a specialized strategy for granting SMEs guarantees and non-financial services, such as management training. The project involved public and private financial institutions, but so far, it has been ineffective, and the Legislative Assembly is already considering a new project to reform the system.

The strategy of attracting FDI into technology-intensive sectors has benefited the local software industry by giving visibility to the country, but the main obstacle is the limited pool of qualified human resources for whom both local and foreign firms compete (PROSIC, 2007).

In 1998, 15 local firms created the Chamber of Software Producers of Costa Rica (CAPROSOFT), a non-profit organization with the strategic goal of representing the country's software sector (CAMTIC, 2005b). This was a thoroughly private and firm-led initiative. In 1999, CAPROSOFT launched an initiative for a technical cooperation project granted by the

14 "Although TNC purchases of domestic goods and services have grown in absolute terms, they have declined in relative terms. Between 1997 and 2005, TNC expenditures on national goods and services nearly quadrupled, from US\$ 99 million to US\$ 368 million. In relative terms, however, the picture shows very little progress: as a share of imports, national expenditures were $13 \%$ in 1997 and 12\% in 2005; and as a share of exports they were $11 \%$ in 1997 and 10\% in 2005" (Cordero and Paus, 2008, p. 16).

15 "Sistema de Banca de Desarrollo, Ley 8634. Published by the Diario Oficial La Gaceta, No. 87, 7 May 2008. 
Inter-American Development Bank (IDB), called PROSOFTWARE, its main goal being to boost the competitiveness of the Costa Rican software sector. The project had a US\$ 2.5 million budget, with IDB contributing a US\$ 1.5-million grant, and the rest coming from three national organizations: CAPROSOFT, PROCOMER ${ }^{16}$ and FUNCENAT ${ }^{17}$.

Although the project's execution presented some problems (IDB, 2004), different sources describe the results from PROSOFTWARE as successful (Jenkins, 2006). This project triggered two major outcomes for the industry. First, it raised awareness that the national market, although significant, was limited in size and could not generate economies of scale for future growth, hence the need for an internationalization strategy (IDB, 2004, p. 59). Second, in 2003 CAPROSOFT proposed a Strategic Plan for the Software Industry, which recommended a process to "create a new organization with a wider formal constitution" to include local and foreign software firms, as well as producers of electronic components, telecommunication infrastructure services, call centres, and other firms offering technical support (Nicholson and Sahay, 2009, p. 11; PROSIC, 2007, p. 169).

Between 2004 and 2006, local production grew from US\$ 100 million to US\$ 121 million; exports from US\$ 70 million to US\$ 84 million; and employees from 4,500 to 6,600 (CAMTIC, 2005a; PROCOMER/ CAMTIC, 2006). Today, the software industry operates within an ICT cluster concentrated in the Central Valley of Costa Rica and $84 \%$ of its employees have higher education. Software produced primarily comprises Internet applications, but also includes software for business and process administration, banking, education, tourism, and health, along with custom-made applications (Ciravegna, 2008). The cluster is composed of an estimated 695 firms (PROCOMER/CAMTIC, 2006) operating in different value chains and divided into four categories:

- Software producers, ${ }^{18}$ who create and commercialize software applications and tools (250 firms estimated)

- Producers of components and hardware, who design, manufacture, assemble, and/or sell IT products (35 firms)

- Direct IT service providers, who provide training, technical support, consultancy, and other services in IT (350 firms)

- Other IT-related service providers, such as call centres (60 firms)

16 PROCOMER is the Costa Rican Export Promotion Agency a governmental agency which works jointly with the Ministry of Foreign Trade.

17 FUNCENAT is the Foundation of the Centre for High-Technology, an institution directed by the National Council of Rectors (CONARE). CONARE brings together the rectors of the four public universities and represents them in PROSOFTWARE.

18 The sample for this report was drawn from software producers only. 
Of the four sectors, software is the most diverse in terms of company size. The components sector is mostly made up of large multinational firms, with no SMEs. Even with better organization and a common strategy at hand, this sector faces serious challenges. First, the CINDE strategy forces both local software and technology multinationals to compete for the scarce qualified human resources (PROSIC, 2007, p. 177). Second, local software firms struggle to become suppliers for multinational firms, in the absence of proactive public policies to encourage such linkages. As Nicholson and Sahay point out, the sector is hampered by weak linkages between universities and the private sector, poor English-language skill, and technical staff with inadequate management capabilities (Nicholson and Sahay, 2008). Lastly, the software industry faces stiff financial and credit constraints.

\section{(a) Access to sources of finance within the value chain}

Costa Rica's software sector does not appear to support the idea that inter-firm linkages and especially linkages with larger firms substantially improve SME demand for and access to finance. However, our research shows a limited number of successful examples.

Most of the firms reported that they rely for funding on selffinancing, family resources, or angel investors. Only a minority of firms reported interacting with either the financial system or agents within the value chain.

\section{Box III.2}

\section{Cases in which the help of a large firm enabled access to finance}

Info Costa Rica S.A. was created in 1997 as a micro firm that provided web applications. Initially it financed its operations with its profits, but mounting competition in the form of a multi-user platform for video games, caused it to seek new sources of financing. In 2007 a foreign client associated with an angel investor became interested in the product, bought shares in the company, and provided US\$1 million in credit. Results included an increase in the software price. To date, Info Costa Rica S.A. still holds $33 \%$ of the shares of the business and is planning to expand sales to Latin America and Scandinavia.

Grupo Asesor is a software firm that develops software applications and provides ICT consultancy and training. In addition, Grupo Asesor is a supplier of British American Tobacco (BAT) in Costa Rica. BAC San José bank works with BAT, and it launched a special finance programme for the suppliers of its large client. In 2006, Grupo Asesor obtained access to a special line of trust credit with no collateral required due to the relationship with BAT.

Source: Prepared by the author, on the basis of survey interviews, December 2010. 
Few firms acknowledged using factoring to raise credit for contracts with larger firms (in particular, public sector entities). There is however, evidence (table III.5) of funding by angel investors operating in a network; in one case, this support has been partially strengthened by collaboration between IDB and the Costa Rican Chamber of Information and Communication Technologies (CAMTIC). ${ }^{19}$

Table III.5

\section{Inter-firm linkages and financing in the ICT sector in Costa Rica}

\begin{tabular}{|c|c|}
\hline Instruments & Costa Rican IT sector \\
\hline \multicolumn{2}{|l|}{ Self Financing } \\
\hline Self-financing & $\begin{array}{l}\text { Frequently observed } \\
\text { in SMEs, it is the leading source of finance. Many reported to be in the } \\
\text { process of seeking new sources of credit other than their own profits, } \\
\text { especially in order to expand, to venture into a new market, or to apply for } \\
\text { an international certification. }\end{array}$ \\
\hline Family finance & $\begin{array}{l}\text { Occasionally observed } \\
\text { (18\% of the sample firms, especially in SMEs), sometimes blended with } \\
\text { profits from the firm or funds from angel investors. }\end{array}$ \\
\hline \multicolumn{2}{|c|}{ Inter-firm / arm's length finance } \\
\hline Factoring & $\begin{array}{l}\text { Not observed in any interview } \\
\text { Firms are familiar with the instrument, but no evidence of its use. }\end{array}$ \\
\hline Reverse factoring & $\begin{array}{l}\text { Not observed in any interview } \\
\text { Qualitative evidence shows it is not a common instrument within the } \\
\text { business culture of the sector. }\end{array}$ \\
\hline Leasing & $\begin{array}{l}\text { Occasionally observed } \\
\text { ( } 9 \% \text { of the sample firms). Leasing was observed in a medium-sized firm } \\
\text { that works with software and finances its telecommunications hardware } \\
\text { suppliers. This firm uses its equipment as a guarantee for its financial } \\
\text { operations. }\end{array}$ \\
\hline $\begin{array}{l}\text { Purchase order } \\
\text { finance }\end{array}$ & $\begin{array}{l}\text { Occasionally observed } \\
\text { Even though this instrument was reportedly used in only one case, firms in } \\
\text { the local market that have a stable contract with larger firms - especially } \\
\text { public enterprises- mention this mechanism as an apparently viable } \\
\text { option. }\end{array}$ \\
\hline $\begin{array}{l}\text { Warehouse } \\
\text { receipt finance }\end{array}$ & $\begin{array}{l}\text { Not observed in any interview } \\
\text { This instrument is not easily applied to the industry. }\end{array}$ \\
\hline \multicolumn{2}{|c|}{ Relationship finance } \\
\hline Trade credit & Not observed \\
\hline $\begin{array}{l}\text { Deferred payment } \\
\text { checks }\end{array}$ & Not observed \\
\hline Other & \\
\hline
\end{tabular}

19 One component of the Link project developed by CAMTIC and IDB involved the establishment of a network of angel investors to support technological entrepreneurship and provide capital for the business. One example is the firm Fair Play Labs, which provides software services for videogames and graphic design. This firm reported that in 2007 it obtained a capital of US\$150,000 through an angel investor-not part of the value chain-who helped to finance its operations (survey interview, December 2010). 
Table III.5 (concluded)

\begin{tabular}{ll}
\hline Instruments & Costa Rican IT sector \\
\hline Angel investors & $\begin{array}{l}\text { Occasionally observed } \\
\text { One case was supported through a CAMTIC-IDB project. The angel } \\
\text { investor was part of an investor network. In the other case identified, the } \\
\text { angel investor was also a client (see box III.2) who decided to invest in the } \\
\text { firm and provide finance at a fixed interest rate. }\end{array}$ \\
\hline External Financing & \\
\hline Commercial bank & $\begin{array}{l}\text { Occasionally observed } \\
\text { Firms always reported to have used personal guarantees or property as } \\
\text { collateral, but in one case (see box III.2) linkages with a larger firm allowed } \\
\text { the use of credit history as a guarantee. Qualitative evidence suggests } \\
\text { that firms fear the bureaucracy associated with private and public banks. }\end{array}$ \\
\hline Micro-credit & Occasionally observed \\
\hline Public bank & Occasionally observed \\
\hline Other & \\
\hline Buyer/supplier TA & Not observed \\
\hline
\end{tabular}

Source: Prepared by the author, on the basis of survey interviews, December 2010.

Unlike other sectors, the software sector does not experience lending (or providing guarantees) through vertical inter-firm linkages as a common practice. The technology used in this industry is characterized by project-based work, which is not mass-produced; solutions can rarely be exactly repeated for different customers. A certain amount of customerproduct specificity makes it hard to generate value from intermediate work in progress (as manufacturing firms can do with their intermediate inputs or raw materials) or to provide physical collateral to secure finance (as agricultural and manufacturing firms do). An exception was observed in a leasing arrangement offered by a telecommunication company, against the value of physical telecom equipment.

\section{Summary of empirical findings}

This study has sought to explore whether linkages of SMEs to large firms in value chains enhance SME access to finance. Evidence on inter-firm finance, mainly based on case studies, is rather limited and refers mostly to the agricultural sector. However, the literature does offer some examples of different inter-firm financing mechanisms (factoring, leasing, reverse factoring, purchase order finance, warehouse receipt finance, trade credit, and loan guarantees). Most of these mechanisms require a relationship between the SME and a large firm, because the latter enjoys higher levels of creditworthiness with financial institutions and can provide collateral and guarantees. Furthermore, large firms may offer guarantees to ease SME access to finance in the case of reverse factoring, trade credit, and loan financing/loan guarantees. 
This study was designed to provide preliminary evidence of the presence of these inter-firm financing mechanisms. The three case studies described above illustrate a number of these mechanisms, namely trade credit, factoring, and loan guarantees. Having strong linkages with large, well-known firms is a positive advantage for SMEs seeking access to finance. However, our evidence also suggests that strong third-party intervention is needed for these mechanisms, particularly for warehouse receipt finance, factoring (and reverse factoring), purchase order finance, and loan guarantees. In the case of the Argentine agrifood industry, it is clear that value chain governance matters for SME finance. In the poultry and milk industries, proper handling of perishable inputs is vital for a lead firm's competitiveness (buyers in this case); therefore, we see a tendency for these chains to be governed in a quasi-hierarchical fashion. In the three Argentine value chains mentioned (dairy, poultry, and food processing), it is clear that linkages to large firms provide enhanced access to finance. For an SME, the downside of this strong hierarchical governance is that along with finance and purchasing, the lead firm reduces options for its suppliers, locking them into a relationship with few alternatives. Most Argentine agrifood SMEs are convinced that having large and well-known clients facilitates access to commercial credit. However, interviews with financial institutions suggest that while this factor is important during the assessment of an SME's application for finance, it is not the dominant factor.

SMEs whose products are non-perishable tend to operate in value chains characterized by market-based forward linkages; for example, the furniture producers of the Serra Gaucha may have more freedom to seek finance and clients, but usually do not benefit from a large buyer's guarantee for their loans.

Although the value chain literature tends to emphasize the role of buyers as chain leaders, they are not the sole determinants; lead firms in VCs can also supply key inputs for the production process, such as raw materials. Although furniture SMEs may have market-based linkages with most of their buyers, they experience quasi-hierarchy in the backward linkages to their input suppliers, mainly large particleboard suppliers. Trade credit from these suppliers is welcome but usually comes with conditions, from design "suggestions" (which are difficult to refuse) to minimum purchases-which are often too large for the smallest firms, forcing them to choose distributors that charge a premium for selling smaller amounts of material. Large department stores in Brazil push prices down but do not provide finance to SMEs. These buyers actually demand finance from their producers, thus squeezing them from both ends. 
The ICT sector in Costa Rica appears to be a type of industry where inter-firm linkages and intra-firm finance are scarce, if they exist at all. Some limited examples exist in which linkages with a larger firm have enabled an SME to access finance; however these examples only highlight a possibility, including the signalling effect of the creditworthiness of the SME.

\section{Table III.6}

\section{Relationships between chain governance and inter-firm linkages in accessing finance for three case studies}

\begin{tabular}{lll}
\hline Market & $\begin{array}{l}\text { Agro-industry } \\
\text { (Argentina) Furniture } \\
\text { (Brazil) }\end{array}$ & $\begin{array}{l}\text { - Little evidence of the role of inter-firm linkages } \\
\text { beyond the perception that larger firms or well-known } \\
\text { customers are a potential positive signalling mechanism } \\
\text { to third parties }\end{array}$ \\
\hline Network & ICT sector (Costa Rica) & $\begin{array}{l}\text { - Some evidence of the role of inter-firm linkages in } \\
\text { facilitating access to angel investors. Moreover, a } \\
\text { widespread perception that larger firms or well-known } \\
\text { customers are a potential signalling mechanism to } \\
\text { third parties }\end{array}$ \\
\hline $\begin{array}{l}\text { Quasi- } \\
\text { hierarchy/ } \\
\text { captive }\end{array}$ & $\begin{array}{l}\text { Dairy (Argentina) } \\
\text { Poultry (Argentina) } \\
\text { Furniture (Brazil): } \\
\text { where the lead firm } \\
\text { can be the oligopolistic } \\
\text { input supplier of } \\
\text { particleboard) }\end{array}$ & $\begin{array}{l}\text { - Clear role for lead firm (buyer) in facilitating access to } \\
\text { finance by acting as guarantor through trade credit and } \\
\text { loan financing/loan guarantees. }\end{array}$ \\
$\begin{array}{ll}\text { - Clear role for lead firm (input supplier) in providing } \\
\text { finance, as well as production and design parameters, } \\
\text { leading to an increased use of particleboard by local } \\
\text { furniture producers } \\
\text { - There are important signalling mechanisms to financial } \\
\text { institutions about external third parties derived from } \\
\text { inclusion/exclusion from the supply chain, and hence } \\
\text { about the supplier's capabilities and creditworthiness } \\
\text { - The role of the chain leader in reverse factoring was not } \\
\text { observed in the cases studied }\end{array}$ \\
\hline
\end{tabular}

Source: Author's analysis, on the basis of L. Navas-Alemán, "The impact of operating in multiple value chains for upgrading: the case of the Brazilian furniture and footwear industries", World Development, vol. 39, No. 8, Amsterdam, Elsevier, 2011, based on the chain governance typology of J. Humphrey and H. Schmitz, "How does insertion in global value chains affect upgrading in industrial clusters?", Regional Studies, vol. 36, No. 9, Taylor \& Francis, 2002 and Humphrey and Schmitz (2000).

Self-finance remains the first and most common source for both short-term finance and working capital across all three case studies. For medium- and long-term finance (e.g. infrastructure, machines, and innovation projects), results are mixed: some SMEs tend to apply for public funding first and self-finance as a second choice, whereas others will choose self-finance first. Clearly, regardless of the type of industry (traditional or knowledge-based, tightly governed or loosely coordinated), SMEs in Latin America, even when they are part of a value chain, find it difficult to overcome the obstacles to additional finance. 
The role of large firms in enhancing access to finance for an SME appears to depend on the type of chain governance, which in turn is affected by the industry context that frames relationships with suppliers and customers. ${ }^{20}$

In sum, based on our empirical evidence we argue that:

- In industries such as dairy and poultry, where chain governance tends to be quasi-hierarchical between buyers and SMEs, the chain leader can play the role of guarantor and facilitate access to finance.

- In industries where chain governance is looser or market-based (e.g. furniture and ICT), the role of large clients is limited to signalling reliability to financial institutions.

\section{Policy Implications}

Some conclusions from this study may be amenable to policy interventions.

First, as revealed in the interviews, one of the main problems faced by SMEs in seeking financing is the complexity of banking applications and procedures. Some firms interviewed pointed to "paperwork" as one of the obstacles to better financing. In this sense, the role of LGAs in Argentina as financial intermediaries or networks is instructional. Their role in activities such as information-gathering and assisting SMEs with applications helps bridge the gap between banks and SMEs. This example suggests a need for programmes to facilitate SME applications, including financial technical assistance to reduce obstacles relating to banking procedures.

Second, it is well known that a primary obstacle to obtaining a loan is the lack of guarantees. SMEs are often rejected by banks not because of the project they present, but because they lack collateral. The policy challenge here is to strengthen and improve the existing guarantee systems. Efforts of banks such as the BNDES and the Caixa Federal in Brazil provide some possible solutions (such as creating credit lines that are preapproved), have a rolling credit limit, can be paid in instalments, and apply lower interest rates. A key element of these lines is an acceptance of guarantees such as credit history and balance sheets to secure loans. These new products for SMEs require an excellent communication strategy to reach intended clients and a simple platform for usage. A good example is the BNDES

20 This conclusion is consistent with Gereffi, Humphrey and Sturgeon (2005) and Pietrobelli and Rabellotti (2011 and 2012). 
"credit card," 21 which SMEs can apply for through the bank's website and which enables them to forge business relationships with other registered firms (hence increasing trust) and to recommend trusted distributors to enrol in the platform.

In Argentina, the government provides tax incentives to encourage large firms to form LGAs that will give guarantees to SMEs. These incentives have resulted in large firms (chain governors) facilitating increased financial access to their suppliers (usually SMEs). However, this strategy is not without risks: when large firms create LGAs, there is a potential for financial speculation; and the actors must rely on a fiscal incentive for the guarantee system.

In addition, there is often a mismatch between receipt of payment for its products by an SME and the need to pay for its inputs. Such a mismatch increases costs that often appear to have been underestimated in the Argentine and Costa Rican cases. In Brazil, it is often offset by the generalized practice of offering trade credit to clients along the value chain, but it remains a problem. Financial instruments that would allow an SME to cash in its receivables faster would free resources that at present cannot be used until final payments are made. Receivables from well-known large firms are often better accepted as collateral, indicating a potential role for large firms in working with SMEs, which could be encouraged through appropriate programmes.

Lastly, the role of third parties such as donors, business associations and LGAs, in facilitating inter-firm finance and increasing large firms' provision of guarantees to SMEs cannot be overstated. However, the evidence from case studies suggests that government policies may need to support this role by providing the right incentives and remedying the coordination failures that are likely to emerge. Business associations such as MOVERGS and SINDMOVEIS in the Serra Gaucha and CAMTIC in the Costa Rican ICT sector have strong leverage and provide important support services to local firms. Their coordinating and bridging role can be very useful, opening the way to relevant inter-firm financing mechanisms.

${ }^{21}$ See [online] https://www.cartaobndes.gov.br/cartaobndes/ accessed 9 January 2011. 


\section{Bibliography}

ABIMOVEL (Associação Brasileira das Indústrias do Mobiliário) (2010), "Panorama do setor moveleiro, 2008-2009" [online] http:/ / www.abimovel.com.

Banerjee, A. and E. Duflo (2004), "Do firms want to borrow more? Testing credit constraints using a directed lending program", CEPR Discussion Papers, No. 4681 [online] http:/ /ideas.repec.org/p/cpr/ceprdp/4681.html.

Beck, T. and A. Demirgüç-Kunt (2008), "Access to finance: an unfinished agenda", World Bank Economic Review, vol. 22, No. 3, Oxford, Oxford University Press.

Camino, B. and R. Cardone (1999), "The valuation and cost of credit insurance schemes for SMEs: the role of the loan guarantee associations", International Small Business Journal, vol. 17, No. 4.

CAMTIC (Costa Rican Chamber of Information and Communication Technologies) (2005a), "Estado nacional del software 2005: Estadísticas sectoriales de Costa Rica", San Jose.

(2005b), "Costa Rica verde e inteligente: Estrategia nacional de tecnologías de información y comunicación", San Jose.

Ciarli, T. and E. Giuliani (2005), "Inversión extranjera y encadenamientos productivos en Costa Rica", Heterogeneidad estructural, asimetrías tecnológicas y crecimiento en América Latina, M. Cimoli (ed.), Santiago, Chile, Economic Commission for Latin America and the Caribbean (ECLAC)/Inter-American Development Bank (IDB).

CINDE (Costa Rican Investment Promotion Agency) (2008), “¿Por qué invertir en Costa Rica?" [online] http://www.cinde.org/index.php/ipor-que-invertir-encosta-rica.

Ciravegna, L. (2008), "Multinationals, technological development and the role of social ties: evidence from the Costa Rican ICT cluster", paper prepared for the SASE Annual Meeting.

Cordero, J. and E. Paus (2008), "Foreign investment and economic development in Costa Rica: the unrealized potential", Discussion Paper, No. 13, Working Group on Development and Environment in the Americas.

Demirgüc-Kunt, A. and V. Maksimovic (2001), “Firms as Financial Intermediaries: Evidence from Trade Credit Data", World Bank [online] http://ideas.repec. org/p/wbk/wbrwps/2696.html.

Gereffi, G., J. Humphrey and T. Sturgeon (2005), "The governance of global value chains", Review of International Political Economy, vol. 12, No. 1, Taylor \& Francis.

Giuliani, E., C. Pietrobelli and R. Rabellotti (2005), “Upgrading in global value chains: lessons from Latin American clusters", World Development, vol. 33, No. 4, Amsterdam, Elsevier.

Gorini, A. (1998), "Panorama do setor moveleiro no Brasil, com ênfase na competitividade externa a partir do desenvolvimento da cadeia industrial de produtos sólidos de madeira", Panorama Setorial, No. 8, Rio de Janeiro, Brazilian Development Bank (BNDES).

Humphrey, J. and L. Navas-Alemán (2010), “Value chains, donor interventions and poverty reduction: a review of donor practice", IDS Research Report, No. 63, Brighton, Institute of Development Studies.

Humphrey, J. and H. Schmitz (2002), "How does insertion in global value chains affect upgrading in industrial clusters?", Regional Studies, vol. 36, No. 9, Taylor \& Francis. 
(2000), "Governance and upgrading: Linking industrial cluster and global value chain research", IDS Working Paper, No. 120.

IDB (Inter-American Development Bank) (2004), Lecciones aprendidas en la promoción de mercados de servicios de desarrollo empresarial: Un análisis de la experiencia del Banco Interamericano de Desarrollo en el periodo 1995-2002, Washington D.C.

Jenkins, M. (2006), "Pro-Software: a government-industry-academia partnership that worked", Software Engineering Education and Training, 2004. Proceedings, IEEE Computer Society.

Kulfas, M. (2008), “Las pymes argentinas en el escenario post convertibilidad. Políticas públicas, situación y perspectivas", Project Document, No. 4 (LC/W.272), Santiago, Chile, Economic Commission for Latin America and the Caribbean (ECLAC).

Lawrence, J. and others (1997), "Vertical coordination in the US pork industry: status, motivations, and expectations", Agribusiness, vol. 13, No. 1.

Leibler, J., J. Otte and E. Silvergeld (2008), “Zoonotic disease risks and socioeconomic structure of industrial poultry production: review of the U.S. experience with contract growing", Research Reports RR, No. 08-06, John Hopkins Bloomberg School of Public Health.

Llisterri, J. and others (2006), Sistemas de garantía de crédito en América Latina: Orientaciones operativas, Washington, D.C., Inter-American Development Bank.

Lopez, L., S. Kundu and L. Ciravegna (2009), "Born global or born regional? Evidence from an exploratory study in the Costa Rican software industry", Journal of International Business Studies, vol. 2009, No. 40.

Lunelli, T. (2010), "Trajetoria do arranjo produtivo local de moveis de Bento Gonçalves", São Leopoldo, University of Vale do Rio Sinos, unpublished.

Martinez, S. (2002), "Vertical coordination of marketing systems: lessons from the poultry, egg and pork industries", Agricultural Economics Report, No. 807, Washington, D.C., Economics Research Service, United States Department of Agriculture.

Mattia, A. and others (2007), "Relatorio da pesquisa perfil da industria moveleira do Estado do Rio Grande do Sul", Bento Gonçalves, Nucleo de Pesquisa Aplicada da Região dos Vinhedos (NUPARVI), unpublished.

Morrison, A., C. Pietrobelli and R. Rabellotti (2008), "Global value chains and technological capabilities: a framework to study learning and innovation in developing countries", Oxford Development Studies, vol. 36, No. 1.

MOVERGS (Associação das Indústrias de Móveis do Estado do Rio Grande do Sul) (2010), "Dados do setor moveleiro" [online] http://www.movergs.com.br/ numeros-setor.

NAFIN (Nacional Financiera) (2011), “Crece cartera de crédito de Nafinsa y Bancomext en 20 y 15 por ciento, respectivamente, durante 2010" [online] http: / / www.nafin.com/portalnf/content/sobre-nafinsa/sala-de-prensa / boletin-01-11.html.

Navas-Alemán, L. (2011), "The impact of operating in multiple value chains for upgrading: the case of the Brazilian furniture and footwear industries", World Development, vol. 39, No. 8, Amsterdam, Elsevier.

(2006), "Opportunities and Obstacles for Industrial Upgrading of Brazilian Footwear and Furniture Firms: A Comparison of Global and National Value Chains", PhD thesis, Brighton, Institute of Development Studies, University of Sussex, unpublished. 
Navas-Alemán, L., C. Pietrobelli and M. Kamiya (2012), “Inter-firm linkages and finance in value chains", IDB Working Paper Series, No. IDB-WP-349, Washington, D.C., Inter-American Development Bank, September.

Nicholson, B. and S. Sahay (2008), "Human resource development policy in the context of software exports: case evidence from Costa Rica", Progress in Development Studies, vol. 8, No. 2, SAGE Publications.

Nichter, S. and L. Goldmark (2009), "Small firm growth in developing countries", World Development, vol. 37, No. 9, Ámsterdam, Elsevier.

Paus, E. (2007), Inversión extranjera, desarrollo y globalización: ¿Puede Costa Rica emular a Irlanda?, San Jose, Editorial UCR.

Pietrobelli, C. (2008), "Global value chains in the least developed countries of the world: threats and opportunities for local producers", International Journal of Technological Learning, Innovation and Development, vol. 1, No. 4, Inderscience Publishers.

Pietrobelli, C. and R. Rabellotti (2012), "Innovation Systems and Global Value Chains", Evidence-based Development Economics: Essays in Honour of Sanjaya Lall, C. Pietrobelli and R. Rasiah (eds.), Kuala Lumpur, University of Malaya Press. (2011), "Global value chains meet innovation systems. Are there learning opportunities for developing countries?", World Development, vol. 39, No. 7, Amsterdam, Elsevier.

(2007), Upgrading to Compete. Global Value Chains, Clusters and SMEs in Latin America, Cambridge, Massachusetts, Harvard University Press.

Pietrobelli, C. and F. Saliola (2008), "Power relationships along the value chain: multinational firms, global buyers and performance of local suppliers", Cambridge Journal of Economics, vol. 32, No. 6, Oxford University Press.

PROCOMER/CAMTIC (Costa Rica Export Promotion Agency/Costa Rican Chamber of Information and Communication Technologies) (2006), "Exportaciones deserviciosdeCostaRica" [online]www.eclac.org/mexico/noticias/paginas/4/ 31984/Sector_TIC_Costa_Rica_A._Mora.pdf.

PROSIC (Programme on the Information and Knowledge Society) (2007), Hacia la sociedad de la información y el conocimiento en Costa Rica: Informe 2007, San Jose, University of Costa Rica.

Rodríguez-Clare, A. (2001), “Costa Rica's development strategy based on human capital and technology: how it got there, the impact of Intel, and lessons for other countries", Human Development Occasional Papers (1992-2007), No. HDOCPA-2001-12, United Nations Development Programme (UNDP).

Roese, M. (2003), "Problemas globais, respostas locais: a indústria de móveis de madeira no Brasil à luz dos enfoques de cadeias produtivas e sistemas regionais de inovação", PhD thesis, São Paulo, State University at Campinas, unpublished.

Schmitz, H. (2006), "Learning and earning in global garment and footwear chains", European Journal of Development Research, vol. 18, No. 4, Palgrave Macmillan.

Sindmóveis (Sindicato das Indústrias do Mobiliário de Bento Gonçalves) (2010), "Dados do setor. Setor moveleiro no ano 2009" [online] http://www. sindmoveis.com.br/sindmoveis/dados-do-setor/.

Thorsten, B. and A. Demirgüc-Kunt (2008), "Access to finance: an unfinished agenda", The World Bank Economic Review, vol. 22, No. 3, Oxford, Oxford University Press. 
UNCTAD (United Nations Conference on Trade and Development) (2011), World Investment Report: Non-equity Modes of International Production and Development (UNCTAD/WIR/2011), Geneva, United Nations. United Nations publication, Sales No. E.11.II.D.2.

Vargas, L. (2004), "ICT Strategy in Costa Rica: the Case of the Costa Rican Software Industry", Heredia, Costa Rica, International Centre of Economic Policy for Sustainable Development.

Vargas, M. and R. Alievi (2000), "Competitividade, capacitação tecnológica e inovação no arranjo produtivo moveleiro da serra gaúcha", Brasilia, Institute of Applied Economic Research (IPEA), unpublished.

World Bank (2006), “The Impact of Intel in Costa Rica: Nine years after the decision to invest", Investing in Development Series, Washington, D.C. 


\section{Chapter IV \\ Inclusive value chain interventions in the high-value agrifood sector in Latin America}

Penny Bamber

Karina Fernandez-Stark

This chapter uses the global value chain methodology to analyse and evaluate value chain linkage initiatives in Latin America designed to help small producers join high-value agriculture value chains. ${ }^{1} \mathrm{~A}$ holistic model is proposed for work to address the common constraints faced by producers wishing to compete in national and international markets, namely access to markets, access to training, access to finance and coordination and collaboration-building. Several findings are useful for future linkage initiatives: a market approach which considers these producers as productive agents is essential to success; the "small and medium-sized producers" category is heterogeneous, with different levels of development and needs; initiatives that simultaneously address all major constraints tend to be more successful than those that tackle constraints individually; and an exit strategy must be incorporated at the design stage of the project to ensure sustainability.

This research project was funded by the Inter-American Development Bank (IDB) through its Multilateral Investment Fund. 


\section{Introduction}

This chapter discusses how small and medium-sized producers are embedded in high-value national, regional and international agriculture value chains. The agrifood sector can help alleviate poverty alleviation in rural areas of developing countries by increasing incomes and creating employment (Weinberger and Lumpkin, 2007). However, the majority of smallholders in developing countries face constraints that often limit their ability to participate competitively in these chains, and there has been considerable concern that these producers are being denied important opportunities for growth. Over the past decade, numerous projects have been carried out across the developing world to help drive rural development (Jaffee, Henson and Diaz Rios, 2011). However, despite the substantial resources that have been allocated to these initiatives, there has been limited systematic analysis of their impact (Humphrey and NavasAlemán, 2010).

This chapter seeks to contribute to the international development community's understanding of how more effective measures can be planned to ensure the sustainable inclusion of these producers in value chains. On the basis of extensive primary and secondary research, major constraints on the competitiveness of these actors, and thus on their sustainable entry into chains, are identified and a holistic model to overcome these constraints is proposed. This model includes four main pillars: access to markets, access to training, access to finance and support in developing collaborative and coordinated horizontal and vertical linkages. This model is then used to analyse the design and implementation of five value chain linkage projects in Latin America funded by the Multilateral Investment Fund of the Inter-American Development Bank (IDB).

Four key sets of lessons for future programmes were drawn from this analysis. First, a proactive market approach to the initiative is essential. This includes assessing the appropriateness of the crops selected for the small producers by identifying the potential role they would play in the value chain and comparing their relative competitiveness with that of larger producers in the absence of constraints; examining the commercial viability of the product; reviewing the requirements of the market; and developing an exit strategy to ensure that the producers can continue to compete sustainably once project resources are withdrawn. Second, not all small and medium-sized producers are the same: they make up a heterogeneous group from a wide range of socioeconomic backgrounds, with varying levels of educational attainment, and whose cultivation and commercialization experiences differ significantly. This has important implications for project design, specifically in terms of the length of the work required and the content of training programmes, which must be 
customized to meet their specific needs. This requires flexibility in how the project is carried out. Third, a holistic approach that improves access to markets, training and finance, and emphasizes horizontal and vertical coordination and collaboration in the value chain and incorporates an exit strategy is more likely to achieve successful, sustainable inclusion. Finally, effective implementation is needed to ensure success: the executing agency must have local experience and expertise and be in a position to quickly generate trust between the producers and other actors in the chain. The organization must be prepared to coordinate and leverage potential synergies with other actors to maximize the use made of scarce resources and prevent parallel or counter-productive initiatives.

In terms of the structure of the chapter, the first section summarizes how high-value agriculture chains have changed as governance patterns in the industry have evolved, and it discusses the challenges and opportunities for small producers within these increasingly complex market structures. The second section presents a model for sustainable inclusion designed to address the key constraints faced by these producers. This model was developed on the basis of a broad review of secondary literature, including project impact assessments, and on primary field research in the Dominican Republic, Honduras, Nicaragua, Paraguay and Peru. The third section applies this model to analyse the effectiveness of five interventions that were financed by the IDB Multilateral Investment Fund and to identify the principal lessons for developing future value chain linkage initiatives.

\section{A. Inclusion of small and medium-sized producers in high-value agriculture chains}

Over the past three decades, high-value agriculture markets have become more sophisticated, consolidated and regulated, making it increasingly difficult for smaller producers to participate. Determining how to effectively insert small and medium-sized producers into high-value agriculture markets requires a thorough understanding of how those markets work. The value chain methodology provides a useful tool to trace shifting production and consumption patterns, to link geographically dispersed activities and actors in the industry and to determine the roles they play in developed and developing countries alike. ${ }^{2}$

\section{What are high-value agriculture value chains?}

High-value agriculture or agrifood products are non-bulk agricultural commodities that require special handling, such as fresh

See chapter $\mathrm{X}$ for a detailed explanation of global value chain (GVC) analysis. 
fruits and vegetables, or are processed in one or more post-harvest stages, such as specialty coffee and honey, prior to reaching the end market. ${ }^{3}$ These products tend to be significantly more labour intensive than cereal crops and other traditional agriculture, largely because mechanization is complicated by the need to prevent damage to fragile produce (Joshi and others, 2004). Quality is a key factor in determining price and potential markets. These products are subject to a range of sanitary and phytosanitary regulations to ensure food safety and prevent the spread of disease affecting food security. High-value agricultural products thus typically net higher prices and generate significant income for the producer (Weinberger and Lumpkin, 2007). Figure IV.1 illustrates a typical high-value agriculture value chain.

Figure IV.1

Example of a high-value agriculture value chain

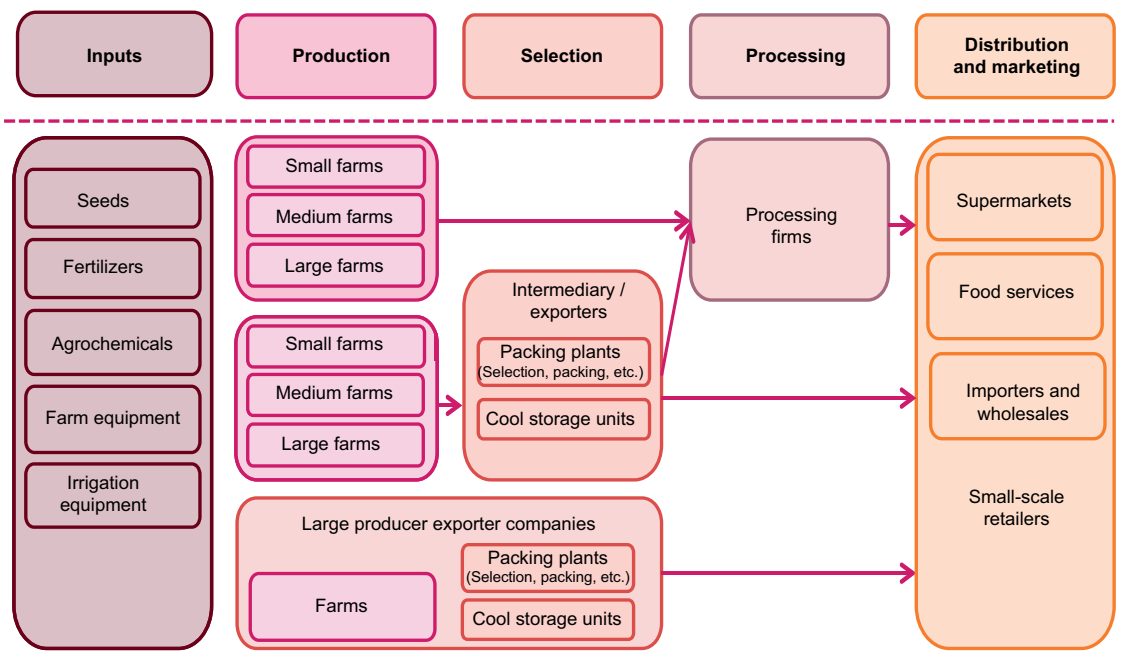

Source: Center on Globalization, Governance and Competitiveness, Duke University.

\section{Changing governance patterns in high-value agrifood industries: challenges and opportunities for small producers}

Traditionally, agrifood sectors included producers of all sizes that participated in spot markets, where the forces of supply and demand prevailed and the highest bidder purchased the available product. Individual farmers determined the varieties and quality of the crops grown and the production processes used. Today, however, particularly

\footnotetext{
The terms "high-value agriculture" and "high-value agrifoods" are used synonymously
} in the literature to refer to this broad range of non-traditional agricultural crops. 
for high-value, non-commodity products, this simple arrangement has been replaced by a highly complex agrifood system. Owing to rising global incomes, urbanization, and the liberalization and growth of international trade, traditional markets have been replaced with vertically coordinated, market linkage systems where local sourcing in both developed and developing countries has largely been replaced by centralized national, regional or international supply chains. In Western Europe, for example, just 85 buying desks source from 1.7 million farmers - a ratio of 1 to 20,000to supply over 30,000 supermarkets (Grievink, 2008). Strict standards must be met to gain access to these chains (Reardon and others, 2009; van der Meer, 2006); national and global lead firms now dictate how products are cultivated, harvested, transported, processed and stored through a series of public and private standards that producers, both large and small, around the world must satisfy in order to maintain their access to markets.

These changes have forced producers to upgrade in various ways, including by improving product varieties (product upgrading), introducing traceability and administrative measures and installing irrigation systems and greenhouses (process upgrading). These requirements can represent significant barriers to market access as compliance and upgrading typically demand considerable "financial, informational and network resources" (Lee, Gereffi and Beauvais, 2012), which make them prohibitive for many small and medium-sized producers. Resource constraints tend to be further compounded in developing countries by obstacles to competitiveness, including weak regulatory institutions, poorly designed and implemented sanitary and phyto-sanitary regulations, inadequate transportation, overly bureaucratic customs processes, inadequate power and water infrastructure, and the absence of important upstream value chain actors, such as equipment, seed and fertilizer suppliers and firms providing support services (Hazell and others, 2010; Markelova and others, 2009).

As a result of both resource constraints and country-level challenges, small and medium-sized producers are generally not well positioned to respond to changes in market structures and are thus marginalized (Dolan and Humphrey, 2004; Lee, Gereffi and Beauvais, 2012; Maertens and Swinnen, 2009). The dramatic decline in the number of small producers contributing to national and export vegetable markets in Kenya at the turn of the century is one frequently cited example of the impact of the changes to the governance structure of the global agrifood market (Dolan and Humphrey, 2004). This decline raised alarm regarding future smallholder participation in the sector (Neven and others, 2009), and led to numerous studies on the impact of changing conditions (Jaffee, Henson and Diaz Rios, 2011; Reardon and others, 2009).

These studies revealed, however, that smallholders continue to play a critical role in modern, high-value agrifood chains owing to a variety of 
reasons, including policy change and land ownership structures (Reardon and others, 2009; Weersink and Herath, 2009). There are a number of chain and country contexts in which it is more efficient to source from small and medium-sized producers than from modern mechanized agricultural operations, these include tea processing in Sri Lanka and vegetable production in Madagascar (Reardon and others, 2009). In particular, three important factors can help identify opportunities for small producers to play a role in the value chain: (1) labour-capital intensity ratio, whereby smallholders can compete when they have a comparative advantage over large producers owing to the labour intensity of crop production; (2) the product's susceptibility to disease and adverse weather can favour multiple smallholder production that involves the geographical separation of supply; and (3) the product's commercial viability, with smallholders being best suited to products with a strong existing market that is less prone to demand shocks. These factors are discussed in further detail below.

First, small producers have a comparative advantage over large producers with regard to certain crops that involve more labour-intensive cultivation methods. Some crops are significantly more labour-intensive than capital-intensive, often because the nature of the product prevents mechanized planting and harvesting, for example, coffee (Berrios, 2012), or requires constant monitoring for disease prevention, such as organic fruits and vegetables and stevia (Consorcio de Productores Orgánicos de Huánuco, 2012; Dávalos, 2012; Fernández Maldonado and Figueroa, 2012). While small producers may have higher capital costs, they generally have lower labour costs, potentially outweighing the economies of scale of larger producers. This differential can account for as much as $40 \%$ of production costs (van der Meer, 2006). When strict labour laws require costly social protection, such as paid vacation, health-care provision and pension contributions, unregulated family labour on smallholder plots becomes substantially more competitive.

Second, in addition to labour cost advantages, the product's vulnerability to disease and adverse weather conditions can be to the advantage of small producers. Diseases that spread rapidly and are difficult to contain can result in large producers losing their entire crop, potentially disrupting the supply chain. ${ }^{4}$ Geographically separating production into multiple plots can help minimize this risk, allowing diseased plants to be more easily contained, thus giving diverse smallholder production an advantage over large-scale production. One case in point is the cultivation

4 In agrifood value chains, producers are often contracted through an intermediary of some sort (often an exporter), who in turn has contracts with key buyers. If a large producer cannot supply the intermediary owing to adverse weather or disease, the intermediary may, in turn, be forced to breach its contract with the buyer. Given significant competition around the world for access to these chains, repeated failure to supply buyers with the contracted quantities can lead to exporters being excluded. 
of jalapeños in Honduras. A large exporter decided to shift from largescale production to a smallholder strategy because of both the labour required to harvest the jalapeños and the crop's susceptibility to disease, which had caused the exporter to lose a significant portion of previous harvests (Velásquez, 2011).

Third, owing to resource constraints and vulnerability to income fluctuations, smallholders are best suited to producing crops for markets in which there is existing, strong or growing demand for the product. New crops, with underdeveloped markets and unstable demand, generate significant uncertainty and can result in short-term shocks that vulnerable small producers are unable to withstand, leading to rapid exclusion from the chain. With fewer resources to cope with such unpredictability, smallholders should seek participation in existing chains, where possible (Humphrey and Navas-Alemán, 2010). Small producers face enough difficulties entering value chains without having to cope with the challenges associated with developing markets for new products. This was an important lesson learned by producer groups in Bali seeking to connect directly with consumers to market their organic rice. Already facing the challenges of improving the consistency and quality of production, and seeking ways to finance costly certification, they found that consumers were not knowledgeable about the product and tended to buy rice "based on the packaging". As demand for organic rice was still very limited, producers found themselves without a market (VECO/Cordaid/IIED, 2008).

\section{B. Model for sustainable inclusion of small and medium-sized producers in the value chain: a holistic approach}

While opportunities for smallholder production do exist within new market structures, such participation does not guarantee them access to national and global value chains. If it did, smallholders would gainfully cultivate the products they were best suited to producing, buyers would source from them and interventions would not be necessary. However, several market failures prevent this from happening, such as asymmetrical information and non-competitive markets. Small producers often require support from external actors in order to circumvent these market failures. On the basis of extensive primary and secondary research into smallholder participation in chains and the interventions facilitating their entry, we have identified the major constraints that limit the competitiveness of small and medium-sized producers. A four-pillar holistic model is thus proposed for overcoming these constraints through access to markets, access to training, access to finance and support in developing collaborative and coordinated horizontal and vertical linkages. 


\section{Competitiveness}

In order to participate in a value chain, actors need to be competitive. Small and medium-sized producers, however, usually face competitiveness bottlenecks that limit their potential involvement, including low productivity, poor product quality, lack of standards compliance, high transaction costs and limited scale. These competitiveness bottlenecks are difficult for smallholders to overcome since they face major constraints: lack of access to markets, lack of training (technical and entrepreneurial), lack of collaborative networks (among small producers and with chain stakeholders) and lack of finance. If these constraints can be attenuated, small and medium-sized producers have the opportunity to become more competitive and participate in national and international value chains in a sustainable manner.

Table IV.1 shows how different competitiveness challenges faced by small producers can be overcome when the constraints are removed. For example, productivity issues are usually related to: (1) lack of exposure to buyers and their requirements; (2) lack of technical and entrepreneurial skills; (3) lack of access to finance to pay for equipment, infrastructure or inputs; and (4) lack of information flows between producers and other members of the chain.

Table IV.1

Selected competitiveness bottlenecks and measures for overcoming them

\begin{tabular}{|c|c|c|c|c|}
\hline & Link to buyers & Training & Finance & Collaborative networks \\
\hline Productivity & $\begin{array}{l}\text { Potential access } \\
\text { to cutting-edge } \\
\text { technologies }\end{array}$ & $\begin{array}{l}\text { Production } \\
\text { and harvesting } \\
\text { techniques, } \\
\text { organization } \\
\text { of production, } \\
\text { maximization } \\
\text { of resources }\end{array}$ & $\begin{array}{l}\text { Equipment, } \\
\text { infrastructure, } \\
\text { improved inputs }\end{array}$ & $\begin{array}{l}\text { Information about adaptation } \\
\text { techniques, best practices, } \\
\text { new or better inputs, } \\
\text { lobbying power for access } \\
\text { to critical resources such as } \\
\text { water or electricity }\end{array}$ \\
\hline Quality & $\begin{array}{l}\text { Information about } \\
\text { specific quality } \\
\text { requirements }\end{array}$ & $\begin{array}{l}\text { Production } \\
\text { and harvesting } \\
\text { techniques }\end{array}$ & $\begin{array}{l}\text { Equipment, } \\
\text { infrastructure, } \\
\text { improved inputs }\end{array}$ & $\begin{array}{l}\text { Information about } \\
\text { adaptation techniques, good } \\
\text { agricultural practices }\end{array}$ \\
\hline $\begin{array}{l}\text { Standards } \\
\text { compliance } \\
\text { (including safe } \\
\text { production and } \\
\text { traceability) }\end{array}$ & $\begin{array}{l}\text { Information } \\
\text { on specific } \\
\text { standards } \\
\text { required }\end{array}$ & $\begin{array}{l}\text { Technical } \\
\text { training to meet } \\
\text { the standards, } \\
\text { entrepreneurial } \\
\text { skills }\end{array}$ & $\begin{array}{l}\text { Certification by } \\
\text { a third party }\end{array}$ & $\begin{array}{l}\text { Economies of scale to } \\
\text { reduce costs, access to } \\
\text { information regarding } \\
\text { different standards }\end{array}$ \\
\hline $\begin{array}{l}\text { Economies } \\
\text { of scale }\end{array}$ & Bargaining power & $\begin{array}{l}\text { Entrepreneurial } \\
\text { and soft skills } \\
\text { training to run a } \\
\text { cooperative }\end{array}$ & $\begin{array}{l}\text { Equipment, } \\
\text { infrastructure } \\
\text { and efficient } \\
\text { input flows }\end{array}$ & $\begin{array}{l}\text { Coordination and } \\
\text { collaboration critical to } \\
\text { achieving economies } \\
\text { of scale }\end{array}$ \\
\hline $\begin{array}{l}\text { Enforcement } \\
\text { of contracts } \\
\text { (Reduced costs) }\end{array}$ & $\begin{array}{l}\text { Understanding } \\
\text { of buyers' } \\
\text { commitment } \\
\text { to purchase }\end{array}$ & $\begin{array}{l}\text { Entrepreneurial } \\
\text { skills }\end{array}$ & $\begin{array}{l}\text { Cash flow } \\
\text { management }\end{array}$ & $\begin{array}{l}\text { Group pressure to avoid } \\
\text { moral hazard challenges }\end{array}$ \\
\hline
\end{tabular}

Source: Prepared by the authors. 


\section{The four pillars model}

The holistic model for intervention proposed in this section addresses each of these constraints to improve producers' competitiveness and sustain their value chain inclusion upon project completion. Measures are grouped under four pillars, corresponding to the key constraints: (1) access to markets; (2) access to training; (3) access to finance; and (4) collaboration and cooperation-building. This model is applicable to all beneficiaries, regardless of their level of development. Beneficiaries with lower capability levels may need longer interventions involving all four pillars, while those with established levels of expertise may need support in only one area, having already overcome the other constraints.

\section{Access to markets}

Tackling constraints on access to markets typically consists of overcoming tariff and non-tariff barriers such as import and export quotas, transportation and logistics challenges, and cumbersome customs procedures. This model, however, concentrates on producer-level links to potential markets, focusing specifically on value chain linkages between producers and buyers and how they can be established. Traditionally, spot markets in agrifood sectors called for no direct relationship between producers and buyers, with producers selling their harvest to the highest bidder. However, these sectors have been transformed and rigorous public and private standards have been introduced, obligating producers to comply with standards on specific product characteristics, production controls and traceability. The governance of the high-value agriculture sector now involves a much closer relationship, with buyers dictating exactly which product is produced and under what conditions. ${ }^{5}$

Owing to geographical, cultural and educational factors, among others, many small producers do not have the networks required to establish relationships with potential firms (Fernández Maldonado and Figueroa, 2012). Unorganized ${ }^{6}$ small producers do not generally participate in international trade fairs, have websites or generate publicity; they may not know that there is a potential market for their products or what requirements or standards buyers may have (Consorcio de Productores Orgánicos de Huánuco, 2012; Vargas and Plata, 2012). Buyers, particularly those located abroad in global markets, have no way of knowing about these potential producers, let alone establishing formal sourcing contracts with them or communicating product preferences or quality standards. An intervention is often required to overcome this lack of information.

Agricultural commodities, such as wheat, corn and sugar, continue to be sold through more traditional market structures.

6 "Unorganized" in this context literally means not organized into groups, such as producer cooperatives. 
The first stage of any intervention must therefore establish a link between producers and buyers. To achieve this, buyers or lead firms must be educated on the business potential of sourcing from small producers, and interactions must be facilitated until small producers are in a position to sustainably manage the relationship independently. Henson and others (2008) found that the most important role for implementing agencies in smallholder interventions in Africa was linking smallholders with the private sector. In a comparison of value chain interventions promoting the inclusion of small producers, Humphrey and NavasAlemán (2010) found that those focused on building producer-buyer linkages were more effective than those focused on improving the broader context of the chain. In domestic markets, a direct link between the producer and the final buyer can circumvent the need for intermediaries, allowing producers to generate maximum profits from their participation; meanwhile in global chains, this link is more likely to be built through an exporter intermediary.

While often criticized for taking advantage of small producers, an effective intermediary can fulfil a vital role, translating buyer needs for the small producer, facilitating a relationship where social, economic and language barriers may prevent direct interaction, and assisting with access to financing to obtain inputs and technical assistance (Humphrey and Navas-Alemán, 2010). Proximity with the final buyer also depends on the producer's level of development. Producers with a low level of expertise and organization require intermediaries to carry out certain activities, while well-organized producers with higher levels of expertise can bypass intermediaries and sell directly to the buyer.

\section{Access to training}

While many small producers may have worked in agriculture their entire lives, specific training is often required to improve productivity and product quality, introduce new technologies and plant varieties, and comply with food safety and other certification requirements that govern entry into national, regional and international value chains. Agrifood value chains today are very sophisticated and crops grown with traditional methods often do not meet the market requirements. Skills development in agrifood value chains has, however, been underestimated in the past and the focus on training at the commercial level has emerged only in recent years (Fernandez-Stark, Bamber and Gereffi, 2011). Rural education levels in many developing countries are low and technical assistance and education programmes run by the government are often understaffed and inadequately prepared to cater to the requirements of increasingly demanding buyers (Fernandez-Stark, Bamber and Gereffi, 2011). As many of these programmes are provided 
through the respective ministry of agriculture, there has been a tendency to focus on production, neglecting the entrepreneurial skills required for small producers to run independent, productive enterprises.

The training provided to producers to facilitate their inclusion in value chains must cover four main elements: awareness of the need for training; the technical aspects of production; business skills; and social skills. This approach provides the small producer with the necessary skill set to cultivate and commercialize products that meet the demands of their target market.

- Awareness-building: The first step is to explain the purpose of the training to the producers and convince them of the importance of adapting their traditional production methods (Bamber, 2012; Berrios, 2012; Ravello, 2012; Vargas and Plata, 2012).

- Technical training: Different crops require specific technical skills and this element is not intended to be exhaustive. Nonetheless, all technical training programmes should emphasize that good agricultural practices aligned with buyers' standards are a critical element for successful value chain entry (Fernandez-Stark, Bamber and Gereffi, 2011).

- Entrepreneurial training: The participation of smallholders in value chains hinges on producers seeing the farm as a firm and acquiring the relevant management skills. Modern agrifood value chains depend on consistency of supply and quality and are governed by strict contracts and planning procedures. In order to achieve their sustainable inclusion producers must understand and anticipate these procedures, manage their costs and cash flow, and negotiate with buyers. This calls for skills creation in relation to planning, efficient cost management, financial literacy and client management, as well as appropriate infrastructure and timely investments in equipment to improve quality and productivity.

- Social skills training: Skills relating to communication, leadership, conflict management, negotiation and teamwork are also often overlooked as interventions tend to overemphasize the technical aspects of training. Furthermore, it is difficult to measure whether such skills have been learned. However, soft skills have been shown to be essential for growth in value chains in a number of industries (Gereffi and others, 2011). Small producers, in particular, need these skills as they must work together in order to achieve economies of scale. 
In the light of the poor level of rural education in many developing countries, the methods used in training programmes must be carefully considered. In particular, a practical approach can be useful for many producers who do not keep written records and rely on memory and developing new routines. Effective training methods include on-site practical sessions with producers using real examples and visits to successful farms and demonstration plots (Berrios, 2012; Ravello, 2012; Vargas and Plata, 2012). One tool that can be used to improve farm management is a template that producers can complete to record farmrelated information, including labour, costs, time frames, estimated quantity of production and profits.

\section{Access to finance}

Entry into value chains requires investments in infrastructure, equipment and obtaining certifications. Small producers, however, often face liquidity and credit constraints and have no access to formal finance channels, limiting their potential to make the required investments. Credit for small producers in both low- and high-value agriculture is constrained for a number of reasons, including high risk, asymmetrical information, lack of guarantees, geographical dispersion in rural areas and unfavourable economic policies (World Bank, 2008). These credit constraints have been found to prevent small producers from making the necessary investments in irrigation systems, greenhouses or cold storage to achieve productivity improvements, develop unused portions of their land or upgrade into higher value products (Maertens, 2009), thereby limiting their potential to participate in coordinated value chains. Indeed, the lack of access to finance for irrigation systems alone can limit farmers' access to national or international value chains, where buyers require consistent quality and output (Chilavert, 2012; Miyata, Minot and $\mathrm{Hu}, 2009$ ).

Interventions can facilitate access to finance through various models. Frequently seen approaches include direct financing from buyers and the use of buyers contracts as collateral for obtaining bank loans. Direct financing from buyers includes schemes such as resourceprovision contracts whereby the buyer provides inputs such as seeds and fertilizer and other services on credit. In many cases, the buyer absorbs the financing cost for this model (Bamber, 2011 and 2012). Use of purchase contracts as collateral can also be seen in some credit markets, where banks accept procurement contracts that include technical assistance from buyers as sufficient collateral to access credit (Coon, Campion and Wenner, 2010; Maradiaga and Galo, 2011). However, interest rates and loan terms can be prohibitive. The executing agency, together with other more influential supporting funding institutions, should coordinate 
with the banking sector in order to create effective financial instruments tailored to meet smallholder needs and should ensure that producers have the financial literacy required to manage any loans they are awarded. In addition, owing to the significant costs involved for small producers, credit should be sought only for upgrading activities that will result in significant income increases so that producers can pay off their loans within a reasonable time frame.

\section{Coordination and collaboration-building}

Coordination and collaboration-building should occur at two levels. First, horizontal coordination among producers facilitates the formation of producer groups or associations, not only to achieve essential economies of scale but also to provide opportunities to add value to their products (upgrading). Second, vertical coordination and collaboration involves interactions with other chain actors to establish linkages, find synergies and share information in order to improve the performance of the chain as a whole.

\section{Horizontal coordination and collaboration}

Small and medium-sized producers must seek out economies of scale in order to compete in the market since alone they cannot produce large quantities of any crop. The transaction costs of dealing with individual producers are high and it is not cost-effective for the buyer to work with them on an individual basis (Kolk and van Tulder, 2006). ${ }^{7}$ It is therefore important for producers to work together, not only to produce the quantities required to access new markets, but also to facilitate access to cheaper inputs and certification, to exchange ideas on addressing common problems such as disease, to reduce information asymmetries in production, and to build social capital to empower producers to sell their products in more sophisticated markets (Markelova and others, 2009). Collective action can be an effective method of group monitoring that can reduce moral hazard by, for example, preventing side-selling, which can increase the costs associated with smallholders in buyers' sourcing strategies (Narrod and others, 2009).

Organization into collectives is a challenge for small and mediumsized producers because it often requires a considerable trade-off between immediate individual benefits and longer-term group advantages. The commitment of producers is critical to their successful engagement in an organized production group or cooperative. However, they often need the

A significant portion of the literature on small-scale farmers in agriculture has focused on the challenges of transaction costs. Pingali, Khwaja and Meijer (2005) provide a concise summary of the different factors that contribute to these transaction costs. 
encouragement and support of external actors to understand the pay-offs of collective action and establish themselves as formal, legal organizations (FECOPROD, 2012; Markelova and others, 2009). This support can range from basic team-building initiatives to help in completing the legal paperwork formally establishing the cooperative as a business (FECOPROD, 2012). External actors need to convey that the group is more than the sum of individual producers.

\section{Vertical coordination and collaboration}

Coordination and collaboration among stakeholders is critical for the performance and upgrading of value chains (Gereffi and others, 2011). Chain stakeholders include all actors that play a role in the development of the industry, including producers, input providers, intermediaries, buyers, industry associations, training institutions, industry service providers, finance institutions, government agencies dedicated to the development of the industry, export-promotion agencies and regulatory institutions. Promoting dialogue and public and private alliances has benefited smallholders, helped resolve information asymmetries and fostered industry advancement at the local and country levels. These alliances provide insight into the challenges and opportunities in the sector and can pave the way for the definition of a common industry development strategy and the formulation of supportive government regulation for industry competitiveness.

\section{Sustainability of small producer inclusion in the value chain}

The four pillars model enables producers to overcome the principal constraints on their entry into the value chain. However, it is important to consider the sustainability of that participation from an economic, social and environmental perspective. First, economic sustainability means that, when an intervention comes to an end, producers are able to operate as independent economic actors and access the resources they need in the market. Second, projects can help resolve social challenges, leading to improved housing, better education and job creation, but they can also generate problems. For example, inclusion in the value chain for small producers is often based on smallholder efficiency, which in many cases comes down to unpaid female labour on family plots (Bamber and Fernandez-Stark, 2013). Interventions should ensure that it does not exacerbate existing social problems or generate new ones. Finally, the expansion of global agriculture can take a significant toll on the environment and result in the degradation of natural resources. Interventions should consider how they can improve the producers' management of their environment. 


\section{Selected IDB Multilateral Investment Fund projects: best practices and lessons learned ${ }^{8}$}

This section applies the four pillars model to identify effective practices in five IDB Multilateral Investment Fund projects that focused on the inclusion of small and medium-sized producers in high-value agriculture value chains and to highlight lessons that can be useful for the development of future value chain linkage projects. The projects analysed involved the cultivation of a variety of crops and were implemented in different countries in Latin America by a range of actors, including industry associations, cooperatives and national and international nongovernmental organizations. These projects varied considerably in terms of funding, with amounts from US\$200,000 to over US\$ 3.5 million. The number of project beneficiaries ranged from 200 to 6,000, and the interventions covered different stages in the value chains.

\section{Table IV.2}

Overview of the Multilateral Investment Fund projects under consideration

\begin{tabular}{|c|c|c|c|c|c|c|c|}
\hline \multirow[b]{2}{*}{$\begin{array}{l}\text { Geographical } \\
\text { coverage }\end{array}$} & \multirow[b]{2}{*}{$\begin{array}{l}\text { Targeted } \\
\text { product }\end{array}$} & \multirow[b]{2}{*}{$\begin{array}{l}\text { Number of } \\
\text { beneficiaries }\end{array}$} & \multirow[b]{2}{*}{$\begin{array}{l}\text { Targeted } \\
\text { stage of the } \\
\text { value chain }\end{array}$} & \multirow[b]{2}{*}{$\begin{array}{l}\text { Executing } \\
\text { agency }\end{array}$} & \multicolumn{2}{|c|}{$\begin{array}{c}\text { Funding } \\
\text { (United States dollars) }\end{array}$} & \multirow{2}{*}{$\begin{array}{l}\text { Project } \\
\text { duration } \\
\text { and end } \\
\text { date }\end{array}$} \\
\hline & & & & & $\begin{array}{c}\text { Inter- } \\
\text { American } \\
\text { Development } \\
\text { Bank }\end{array}$ & Counterpart & \\
\hline $\begin{array}{l}\text { Central } \\
\text { America }\end{array}$ & Coffee & 6000 & Production & Technoserve & 3000000 & 1615450 & 54 months \\
\hline Paraguay & Stevia & 2500 & $\begin{array}{l}\text { Production, } \\
\text { R\&D }\end{array}$ & CAPASTE & 1269400 & 1364470 & $\begin{array}{l}36 \text { months, } \\
2012\end{array}$ \\
\hline Peru & $\begin{array}{l}\text { Organic } \\
\text { cacao }\end{array}$ & 200 & Production & $\begin{array}{l}\text { Naranjillo } \\
\text { Cooperative }\end{array}$ & $\begin{array}{l}100000 \\
(87307)\end{array}$ & $\begin{array}{r}67000 \\
(127000)\end{array}$ & $\begin{array}{l}27 \text { months, } \\
2008\end{array}$ \\
\hline Peru & $\begin{array}{l}\text { Organic } \\
\text { fruits and } \\
\text { vegetables }\end{array}$ & $\begin{array}{r}415 \\
(100 \\
\text { certified })\end{array}$ & $\begin{array}{l}\text { Production, } \\
\text { packing }\end{array}$ & $\begin{array}{l}\text { IDMA } \\
\text { (National } \\
\text { NGO) }\end{array}$ & 397990 & 264930 & $\begin{array}{l}33 \text { months, } \\
2011\end{array}$ \\
\hline $\begin{array}{l}\text { Nicaragua } \\
\text { and } \\
\text { Honduras }\end{array}$ & Honey & 542 & Production & $\begin{array}{l}\text { Swisscontact } \\
\text { (International } \\
\text { NGO) }\end{array}$ & 982026 & $\begin{array}{r}448700 \\
(+200000)\end{array}$ & $\begin{array}{l}36 \text { months, } \\
2012\end{array}$ \\
\hline
\end{tabular}

Source: Prepared by the authors on the basis of IDB project design and evaluation documents. 


\section{Case 1. Supporting the competitiveness of Central American coffee producers (Costa Rica, El Salvador, Guatemala, Honduras and Nicaragua)}

This initiative focused on improving the competitiveness of selected small and medium specialty ${ }^{9}$ coffee producers in five Central American countries (Costa Rica, El Salvador, Guatemala, Honduras and Nicaragua) following the international coffee crisis in the early 2000s. There were two key components: (1) technical assistance for the cultivation of high quality coffee; and (2) establishing links with foreign buyers. Producers were taught about the requirements of high quality coffee for global markets, the potential premiums paid for high quality coffee, and improved production practices to obtain that quality. The project provided administrative and technical support to help producers obtain the certifications required by foreign buyers. Different global buyers selected the beneficiaries' organizations to work with in the future, committing to purchase their coffee once they reached certain quality thresholds. This project also included an investment component to improve equipment and infrastructure. Each cooperative was required to match the funds provided for these investments. Originally the project included almost 3,000 beneficiaries organized in 10 cooperatives $(2$ cooperatives per country). These cooperatives varied widely in size, from 10 members to 2,400 members. Three thousand additional beneficiaries were incorporated into the project in the final year. The majority of the beneficiaries selected were experienced coffee growers.

From a sustainable value chain inclusion perspective, the project was quite effective. It selected a product for which there was rising global demand. The level of development of the beneficiaries was high, which meant that several of the constraints that typically face small and medium producers did not have to be addressed. This project thus focused on the two remaining pillars that were weak: access to markets and access to training in order to produce fine coffee. With the support of the executing agency, experienced coffee producers established business relationships with future buyers and aligned production with their specific requirements. Training in and adoption of good agricultural practices for the production of speciality coffee resulted in quality and productivity improvements, and the incorporation of environmentally friendly farming methods. These improvements translated into increased income and quality-of-life gains for the beneficiaries. In addition, the executing agency participated as a facilitator rather than inserting itself into the value chain, ensuring a sustainable exit strategy.

Specialty coffee refers to arabica coffee grown at over 1,200 metres above sea level. The climate at this altitude is particularly good for producing high quality coffee. 


\section{Case 2. Strengthening the competitiveness of the stevia value chain (Paraguay)}

This project focused on improving the competitiveness of the stevia value chain in Paraguay. Stevia is a plant native to Paraguay and is a natural sweetener. The project consisted of three key components: (1) increasing the quality and quantity of stevia production by small producers; (2) strengthening producer groups; and (3) fostering innovation and technology transfer to improve both plant variety quality and prospects for in-country value added processing. The central component of the project was the inclusion of new producers into the value chain under an outgrower model. Participating firms recruited and contracted new producers, provided them with specific inputs for production, training and technical assistance and guaranteed the purchase of their harvest. The project also organized and consolidated producer groups. The groups received legal advice regarding how to formalize their organizations and skills development to improve teamwork and collaboration.

Additionally, the project included awards for innovative projects and technology development: winning projects included a service-based initiative to empower producers to bypass intermediary brokers and connect directly with buyers in foreign markets, and a project to develop new stevia varieties with higher Rebaudioside- $\mathrm{A}^{10}$ content. The project took place at a time of considerable shifts in the world stevia market. In 2008, the Food and Drug Administration in the United States approved the Rebaudioside-A single molecule for human consumption; this was followed by Rebaudioside-A approval by the European Union in 2011. Many exporters, however, had expected the approval of a broader range of stevia derivatives and had not adjusted their plant varieties accordingly.

Assessing the project using the four pillars model, this initiative lacked effectiveness in ensuring adequate access to finance and fostering coordination and collaboration among producers. The predominant outgrower model adopted by firms also struggled to develop more organized producer groups resulting in significant transaction costs and reduced competitiveness. Several export firms began experimenting with mechanized production to reduce reliance on the smallholder supply. On the other hand, the project focused on a very high demand product, which allows for continued small producer access to the market despite the increased mechanization of production.

10 Several natural substances can be derived from the stevia plant (scientifically known as steviol glycosides, which include glucose as part of their structure). One of the best-tasting and sweetest of all the steviol glycosides is high purity Rebaudioside-A, which can be up to 400 times sweeter than sugar. For more information regarding stevia, please see www.globalsteviainstitute.com. 


\section{Case 3. Conversion to organic cacao cultivation (Peru)}

This project involved the conversion from conventional cacao production to certified organic production of 200 members of the Naranjillo Agroindustry Cooperative in the province of Tocache, Peru, through the provision of technical assistance and training, strengthening of producer groups, and establishing a guaranteed sales channel. The project aimed to increase the quantity, quality and value of organic cacao production in a sustainable way consistent with market demand and by using technology improvements at the production level. Beneficiaries were small producers, with between 2 and 22 hectares of conventional cacao under production (several of whom had previously cultivated coca plants for the illicit cocaine trade). The project was implemented to increase product supply and to improve the livelihoods of the members of the cooperative.

Three years after the completion of the project, the beneficiaries continued to be among the most productive members of the cooperative. These beneficiaries, just $15 \%$ of COOPAIN producers, reportedly account for $35 \%$ of total organic production today and are considered important role models for recruiting new organic producers. In addition to converting producers to organic cultivation, the project also included a pilot initiative in organic chocolate production. Beneficiaries earned additional profits from the export of this higher value added product. Following the success of the project, COOPAIN changed its business model to focus entirely on organic cacao production, which is exported in a range of primary, intermediate and processed products (beans, paste, powder, liquor and chocolate) to destinations in Asia, Europe and the United States.

The project selected a product in which producers could be competitive in the global market and with an emphasis on upgrading. Incorporating producers into the cooperative helped them to achieve economies of scale, secured their access to the market, and spread the cost of certification over a broader base of producers. Technical assistance also improved the quality and quantity of the cocoa produced. Access to finance was limited, but nevertheless available through internal loans and savings programmes. Organic production has positive environmental sustainability outcomes, and by providing an alternative to coca production, this project helped improve the social conditions of the community. This initiative was able to cover the four pillars necessary for sustainable inclusion in the value chain.

\section{Case 4. Strengthening the competitiveness of organic fruit and vegetable producers in the Peruvian Andes}

This project focused on improving the competitiveness of organic ${ }^{11}$ fruit and vegetable producers in the Huánuco region of Peru. The project

11 For the purposes of this case study, the word "organic" is used to describe all produce that is cultivated and handled without the use of agrochemicals. 
consisted of four components: (1) improving the commercialization and supply of organic produce; (2) validating the Participatory Guarantee System (PGS), a regional, multi-stakeholder organic certification process, and developing manuals on the system for distribution in other regions; (3) improving the productive and business management skills of producers; and (4) strengthening collaborative and cooperative networks among producers. The project benefited 415 organic fruit and vegetables producers who were certified under the PGS; 100 of these producers also received organic certification granted by a third-party organization. These 100 producers were able to enter into the national value chain, selling a small amount of their produce in supermarkets in Lima. The remaining 315 producers participated in the local value chain selling their organic products at a local farmers' market and were able to charge higher prices thanks to the PGS certification. The 415 producers created a consortium to jointly market both fresh and processed organic products. As they did not yet have the relevant management skills to independently operate the consortium, the producers required ongoing support from the executing agency, the Development and Environment Institute (IDMA).

The intervention identified a product group (organic produce) in which the participants could compete at the national level and helped them to improve their productivity and horizontal coordination to achieve economies of scale. Strong producer associations were established with the potential to upgrade in the future. The product was environmentally friendly, and the project included women and children. According to the four pillars model, however, this initiative is less likely to be sustainable, as major constraints were not addressed through the project and the level of development of the beneficiaries was very low. By the end of the project, the key challenges to sustained inclusion lay in the lack of access to finance, managerial skills and direct access to buyers, meaning that producers continued to rely on the executing agency and were not yet ready to be independent. In addition, the certification system selected (PGS) was inappropriate since the national buyers required third-party organic certification.

\section{Case 5. Improving the competitiveness of micro and small rural apiculturists (Nicaragua and Honduras)}

This intervention focused on improving the competitiveness of micro and small honey producers in Honduras and Nicaragua by: (1) strengthening value chain actors and activities in each country; (2) enhancing technical capabilities; and (3) improving the supply chain environment by linking actors. The project benefited approximately 540 apiculturists in total: 412 in Nicaragua and 130 in Honduras. The beneficiaries were classified as micro (1-20 hives) and small (21-100 hives) producers. Beekeeping was a 
secondary occupation for the majority of producers. The project included a successful cascading training model that involved the successive transfer of knowledge from international experts to university graduates to sector leaders and ultimately to micro and small producers. The teaching format was modified according to the audience. The executing agency successfully partnered with several organizations working in the sector to create synergies and leverage limited resources. High demand for honey, particularly in Europe, facilitated sales and led beneficiaries to plan business expansions. However, growth was complicated by financing restraints in the sector.

The project selected organic honey as a product with strong international demand and which is particularly appreciated in European markets. Producers were able to sell all of their production, however, opportunities for expansion were constrained by lack of access to finance. The project provided technical assistance, facilitated access to markets and helped to coordinate the chain actors. The project did not include a finance component or help to build associations of producers. While the project led to an increase in income that has translated into better social conditions for the beneficiaries and their families, it is uncertain how the beneficiaries will sustain their participation within the chain without ongoing technical support and access to credit. Evaluating the project using the four pillars model, this intervention was moderately effective in providing access to technical training and linking producers with other stakeholders in the honey value chain. However, it did not promote access to finance, which is critical for industry sustainability, nor did it include activities relating to building cooperation and collaboration among the honey producers.

\section{Conclusions}

Despite their potential to play a competitive role in high-value agrifood value chains, small producers tend to remain excluded. This chapter proposed a holistic intervention model to sustainably include small and medium-sized producers in national and global value chains by mitigating key constraints that these producers face in developing countries. These constraints, relating to market access, knowledge and expertise, scale, financing and organization, must be overcome for producers to become competitive players in high-value agrifood chains. In order to provide producers with the instruments to participate and compete in value chains, the model proposes measures for addressing access to markets, access to training, access to finance and coordination and collaboration-building.

From an analysis of five IDB Multilateral Investment Fund projects, four key sets of lessons for future programming were identified. First, a market approach to intervention is essential. This requires a rigorous 
analysis of the market for the product, and an understanding of producers as productive agents rather than aid recipients. Second, not all small and medium-sized producers are the same. This has implications for programme design, such as intervention length and training content. Third, competitiveness bottlenecks must be overcome and interventions should ensure access to training, access to markets, access to finance and the building of coordination and collaboration among producers and with other actors in the chain. Fourth, agency requirements for implementation should be correctly assessed prior to embarking on the project. These lessons are described in greater detail below.

First, a market approach must be taken to any intervention. A clear market analysis must be conducted to ensure that the targeted product is commercially viable, that there is an adequate supply and that producers have sustainable market access. This calls for a thorough understanding of the product's characteristics, any certifications that are required and standards that must be met, and the market's growth prospects. In the project on stevia production, exporters opted to focus on a particular variety of the plant, despite signals of a market preference for a different variety. This left exporters and producers facing considerable uncertainty. In the organic fruits and vegetables project, the decision to adopt PGS certification was erroneous since it was recognized only at the local level and producers needed to obtain a third-party organic certification - not covered under the intervention - to be able to sell their produce to supermarkets in Lima. Furthermore, in order to cement the role of producers as productive agents in the value chain, a fundamental part of each intervention must be the development of an appropriate, feasible business plan for producers. Producers should be taught how to analyse and adapt different aspects of this business plan to the realities of the market through, for example, basic cost and price models. Training should also be provided on regular business challenges such as cash flow and human capital management.

Second, not all small and medium-sized producers are the same, which has implications for project design. Producers form a heterogeneous group from a range of socioeconomic and educational backgrounds and whose experience in both cultivation and commercialization differs significantly. These groups require different tools for integration into the value chain and have varied potential for participation. These differences must be taken into account in all stages of the project design, implementation and evaluation. For example, the organic fruit and vegetable producers in Peru took three years to set up their consortium and to produce organic crops of the quality required for sale in their proposed primary market, and were only just beginning to sell their produce in that market when the project came to an end, necessitating a 
second intervention. The length of the programme must be adapted to the beneficiaries' needs, with some requiring more initial assistance than others, depending on their level of development (which includes their education, experience and socioeconomic level). Certain interventions inevitably take longer to make an impact, for example, the transition to organic production takes three years for the European market. During this time, producers cannot market directly to their new clients. Project length should correlate with the time taken for producers to become economically sustainable participants in the value chain.

Third, in order to overcome competitiveness bottlenecks, interventions should address all four pillars of the model. Training must go beyond production techniques and include components to build entrepreneurial and interpersonal skills. This combination is vital to producing a quality product, fostering producer independence in relation to sales and promoting effective collaboration among producer groups. Access to markets is often limited by a lack of contacts and business prowess. Successful inclusive business projects would encourage influential actors, such as executing agencies of funding institutions, to engage with important buyers in the sector. Interventions would thus play a more active role in linking small and medium-sized producers with national and international buyers. For example, in the project on organic coffee production in Central America, although the cooperatives included in the project were already exporting their coffee, connecting the cooperatives with the international buyers at the outset allowed them to circumvent local intermediaries and earn higher returns. Developing and empowering producer associations and connecting them with other actors in the value chain is an important step towards achieving the economies of scale necessary for small producers to join national and international value chains. Individual small producers typically operate on less than 25 hectares and often lack the resources to take full advantage of their land, making their output insufficient to secure market access. Finally, access to credit is a necessary condition for value chain inclusion. Small producers do not have the resources to invest in new technologies and the infrastructure required to upgrade their operations to meet the standards of coordinated global value chains. Despite the importance of access to finance for beneficiaries to enter and sustain their participation in value chains, only one of the projects addressed that pillar of the model.

Fourth, the executing agency's requirements for implementation must be accurately assessed prior to embarking on the project. The success of projects depends to a large degree on the local experience and knowledge of the executing agency. It is often difficult to build trust among small producers who are disconnected from commercial chains or who have been taken advantage of by intermediaries in the past. In the stevia 
project, two years into implementation, firms still faced trust issues with their producers, who had been misled by intermediaries in the past. Where possible, alignment and synergies with other agencies working in the sector can allow limited project resources to be leveraged considerably in order to maximize the number of beneficiaries. For example, in the honey case, the project faced the task of establishing an entire industry with limited resources. In other cases, the principal funding institution may not be permitted to finance certain fundamental aspects of the project such as infrastructure development. By working with other agencies, projects can leverage access to a range of resources. This occurred in the case of the coffee project in Central America where project funds were matched by cooperative funds for the construction of new infrastructure for processing the coffee, thus facilitating functional upgrading. Finally, one of the challenges facing executing agencies is to ensure that smallholders are inserted sustainably in the chain when project resources are withdrawn. An exit strategy that ensures the development of competencies among producer groups is essential.

Finally, value chain inclusion interventions require a clear and standardized methodology. Interventions need a blueprint to guide design and implementation and evaluate impact. These five projects did not consider the value chain methodology and the four essential elements for inclusion in their design. As a result, they missed the opportunity to apply a market-oriented perspective with a view to improving producers' competitiveness. The value chain approach outlined in this chapter facilitates the identification of competitiveness bottlenecks faced by small producers, key value chain actors, national and international buyers and the certifications and standards required by the chain in order to improve chances for success. 


\section{Bibliography}

Bamber, P. (2012), "Paraguay Field Research: Stevia Sector", 23 February. (2011), "Honduras Field Research: Fruit \& Vegetables Sector", March.

Bamber, P. and K. Fernandez-Stark (2013), "Global value chains, economic upgrading and gender: the horticulture industry", Global Value Chains, Economic Upgrading and Gender: Case Studies of the Horticulture, Tourism, and Call Center Industries, C. Staritz and J.G. Reis (eds.), Washington, D.C., World Bank.

Berrios, E. (2012), "Nicaragua Field Research: Technoserve. Personal communication with K. Fernandez-Stark", 6 March.

Chilavert, F. (2012), "Paraguay Field Research. Personal communication with P. Bamber", 21 February.

Consorcio de Productores Orgánicos de Huánuco (2012), "Peru Field Research. Personal communication with P. Bamber and K. Fernandez-Stark", 20 February.

Coon, J., A. Campion and M. Wenner (2010), "Financing agriculture value chains in Central America", Technical Notes, No. IDB-TN-146, Washington, D.C., InterAmerican Development Bank, Institutional Capacity and Finance Sector, June.

Dávalos, E. (2012), "Paraguay Field Research: Steviapar. Personal communication with P. Bamber", 23 February.

Dolan, C. and J. Humphrey (2004), "Changing governance patterns in the trade in fresh vegetables between Africa and the United Kingdom", Environment and Planning A, vol. 36, No. 3, London, Pion.

FECOPROD (Federación de Cooperativas de Producción) (2012), "Paraguay Field Research: FECOPROD. Personal communication with P. Bamber", 23 February.

Fernández Maldonado and A. Figueroa (2012), "Peru Field Research. Personal communication with P. Bamber and K. Fernandez-Stark", 19 February.

Fernandez-Stark, K. and P. Bamber (2012), "Assessment of Five High-Value Agricultural Inclusive Business Projects Sponsored by the Inter-American Development Bank in Latin America", Durham, North Carolina, on Globalization, Governance \& Competitivenes, Duke University, May.

Fernandez-Stark, K., P. Bamber and G. Gereffi (2011), The Fruit and Vegetables Global Value Chain: Economic Upgrading and Workforce Development, Durham, North Carolina, Center for Globalization, Governance \& Competitiveness.

Gereffi, G. and others (2011), "Meeting the upgrading challenge: dynamic workforces for diversified economies", Skills for Upgrading: Workforce Development and Global Value Chains in Developing Countries, G. Gereffi, K. Fernandez-Stark and P. Psilos (eds.), Durham, North Carolina, Center on Globalization, Governance \& Competitiveness, Duke University.

Grievink, J-W. (2008), "New Business Services and Industry/Retail Relations", paper presented at the European Commision Conference "Competitiveness of the European Agro-food Industry: Focus on Innovation and Agro-food Logisitics", The Hague [online] http://ec.europa.eu/enterprise/sectors/food/ files/events/netherlands-2008/pres_27_nov/jan-willem_grievink_en.pdf.

Hazell, P. and others (2010), "The future of small farms: trajectories and policy priorities", World Development, vol. 38, No. 10, Amsterdam, Elsevier.

Henson, Spencer and others (2008), Linking African Smallholders to High-Value Markets: Practitioner Perspectives on Benefits, Constraints, and Interventions, Washington, D.C., World Bank. 
Humphrey, J. and L. Navas-Alemán (2010), Value Chains, Donor Interventions and Poverty Reduction: A Review of Donor Practice, Brighton, Institute of Development Studies.

Jaffee, S., S. Henson and L. Diaz Rios (2011), Making the Grade: Smallholder Farmers, Emerging Standards, and Development Assistance Programs in Africa, Washington, D.C., World Bank [online] http://siteresources.worldbank.org/INTARD/ Resources/Making_the_Grade_ePDF2.pdf.

Joshi, P.K. and others (2004), "Agriculture diversification in South Asia: patterns, determinants and policy implications", Economic and Political Weekly, vol. 39, No. 24.

Kolk, A. and R. van Tulder (2006), "Poverty alleviation as business strategy? Evaluating commitments of frontrunner multinational corporations", World Development, vol. 34, No. 5, Amsterdam, Elsevier.

Lee, J., G. Gereffi and J. Beauvais (2012), "Global value chains and agrifood standards: challenges and possibilities for smallholders in developing countries", Proceedings of the National Academy of Sciences, vol. 109, No. 31, Washington, D.C., National Academy of Sciences.

Maertens, M. (2009), "Horticulture exports, agro-industrialization, and farm-nonfarm linkages with the smallholder farm sector: evidence from Senegal", Agricultural Economics, vol. 40, No. 2, International Association of Agricultural Economists.

Maertens, M. and J.F.M. Swinnen (2009), “Trade, standards, and poverty: evidence from Senegal", World Development, vol. 37, No. 1, Amsterdam, Elsevier.

Maradiaga, C. and S. Galo (2011), "Honduras Field Research: FUNDER. Personal communication with P. Bamber", 21 March.

Markelova, H. and others (2009), "Collective action for smallholder market access", Food Policy, vol. 34, No. 1, Amsterdam, Elsevier.

Miyata, S., N. Minot and D. Hu (2009), "Impact of contract farming on income: linking small farmers, packers, and supermarkets in China", World Development, vol. 37, No. 11, Amsterdam, Elsevier.

Narrod, C. and others (2009), "Public-private partnerships and collective action in high value fruit and vegetable supply chains", Food Policy, vol. 34, No. 1, Amsterdam, Elsevier.

Neven, D. and others (2009), "Kenyan supermarkets, emerging middle-class horticultural farmers, and employment impacts on the rural poor", World Development, vol. 37, No. 11, Amsterdam, Elsevier.

Pingali, P., Y. Khwaja and M. Meijer (2005), “Commercializing small farms: reducing transaction costs", The Future of Small Farms: Proceedings of a Research Workshop. Washington, D.C., International Food Policy Research Institute.

Ravello, L. (2012), "Peru Field Research. Personal communication with P. Bamber and K. Fernandez-Stark", 20 February.

Reardon, T. and others (2009), "Agrifood industry transformation and small farmers in developing countries", World Development, vol. 37, No. 11, Amsterdam, Elsevier.

Van der Meer, C. (2006), "Exclusion of small scale farmers from coordinated supply chains: market failure, policy failure or just economies of scale", The Agrofood Chains and Networks for Development, R. Ruben, M. Slingerland and H. Nijhoff (eds.), Dordrecht, Springer.

Vargas, P. and D. Plata (2012), “Nicaragua Field Research: Apiculture Sector. 
Personal communication with K. Fernandez-Stark", 7 March.

VECO/Cordaid/IIED (VECO/Cordaid/International Institute for Environment and Development) (2008), "Inclusion of Small Producers in Value Chains: From Field Evidence to Action".

Velásquez, M. (2011), “Honduras Field Research: Fruit \& Vegetables Sector. Personal communication with P. Bamber", 17 March.

Weersink, A. and D. Herath (2009), "From plantations to smallholder production: the role of policy in the reorganization of the Sri Lankan tea sector", World Development, vol. 37, No. 11, Amsterdam, Elsevier.

Weinberger, K. and T.A. Lumpkin (2007), "Diversification into horticulture and poverty reduction: a research agenda", World Development, vol. 35, No. 8, Amsterdam, Elsevier.

World Bank (2008), World Development Report 2008. Agriculture for Development, Washington, D.C. 


\title{
Chapter V \\ Economic integration and value chains case study: Dairy products in Central America
}

\author{
Guillermo Zúñiga-Arias \\ Jorge Mario Martínez-Piva
}

\section{Introduction}

Central America has the oldest and deepest integration process in the Americas. It has evolved from a process of market integration into a broader process that includes a degree of social integration and some common political and judicial institutions. However, trade matters are still the core of the integration since this is the only arena in which there is agreement between all Central American countries. Since 1960, the region has been opening internal trade to most regional products, and today $95.7 \%$ of total goods are covered by a harmonized external tariff and can be freely traded within Central America.

Institutional differences between countries have stood in the way of their consolidation into a formal common market, and the integration process has taken a "variable geometry approach" (Martínez-Piva and Cordero, 2009). Since then the countries most interested in, or capable of, moving faster towards a common trade regime have been doing so, leaving the others behind. The variable geometry approach taken in the region has also enabled countries to develop their external trade agenda 
separately, thus postponing the creation of a common external tariff and an internal common market.

Progress made in trade integration, mostly focused on trade creation and trade facilitation, coupled with national institutional differences (such as the differing market structures, power relationships, levels of development and public policies in support of producers) have determined how productive chains interact in this region.

Regional value chains (RVCs) within the Central American integration process have chiefly been formed on the basis of trade and foreign direct investment (FDI) (mostly intraregional investment flows). This is seen as a way in which firms vertically and horizontally integrate separate economic activities located in different countries in order to capture a set of transactional benefits derived from placing these activities under common ownership (Dunning and Robson, 1987). This definition of the multinational firm as a coordinated and integrated unit of decisionmaking which engages in cross-border value-adding activities relies on a dimension that is new to this area, namely that of market failure. In Central America, although regional firms are small compared with multinationals from abroad, many have made regional investments to successfully integrate horizontally or vertically some of their activities. Most regional FDI is motivated by the quest for productive assets, since trade has enabled the creation of RVCs for most products across regional borders.

This paper analyses the creation of RVCs as a result of the regional integration process. Countries and regional institutional matters are identified so to understand the creation and specialization of countries that have similar characteristics.

\section{A. Problem}

Although the process of economic integration in Central America has been ongoing for more than 50 years, there are few research studies on how it has facilitated the creation of RVCs, whether by trade among neighbouring countries or by FDI.

The diverse institutional context in each country has determined how firms operate and how they interact with other local and regional firms. In Costa Rica and El Salvador, for example, local entrepreneurs have developed a national industry in sectors such as dairy products and are capable of trading large numbers of products and investing in neighbouring countries as part of an industrial strategy. In other countries in the region, such as Nicaragua and, to some extent, Panama, 
extraregional FDI plays an important role in the creation of national and regional value chains.

Providing analytical evidence of the interaction between the regional integration process and the RVCs in a region where little analysis has been made of these matters constitutes the main challenge of this paper.

\section{B. Objectives}

To determine conditions to enhance economic integration through RVC among developing small economies.

To determine the impact of vertical integration on economic integration.

To analyse the impact of trade and FDI on the development of different types of economic integration between the Central American Countries.

\section{Conceptual framework}

\section{Economic integration and international trade}

Balassa (1961) categorized different types of integration based on its level or deepening economic relations. From our point of view, the most suitable definition is the classical one, which considers five levels of economic integration -free trade, a customs union, a common market, an economic union and full economic integration - the last being the deepest, entailing the establishment of a single market with common institutions. In line with Balassa, Markevicius (2011) stresses that the first step in an integration process is to integrate economically, then, after a certain amount of trial and error, the countries can take steps forward to more complex integration levels until arriving at political integration.

Central American countries intend to establish a common market. Although this process has reached a level beyond a free trade area, it is not yet a perfect customs union since some external tariffs differ from country to country, and not all products are freely traded within it. However, 95.7\% of regional tariffs are harmonized and the region wishes to implement a customs union.

Regional economic integration is an important factor in shaping the global pattern of investment, production and trade (Dunning, 1998; Kumar, 1994) and Central America is no exception. International and regional trade is increasingly taking place in tightly coordinated systems, either as intrafirm trade or trade between legally independent firms in quasi-integrated 
value chains and production networks. The United Nations Conference on Trade and Development (UNCTAD) (UNCTC, 1990) estimates that multinational corporations account for about two-thirds of world trade: one-third is intra-firm trade, the other third is directly affected by TNC sourcing strategies. Simple spot-market transactions, where independent producers manufacture goods without knowing in advance who their customers will be and which product and process standards they expect them to comply with, are no longer the prevalent way of doing business. This is particularly relevant for integration processes since they facilitate trade, FDI and even the movement of people, and they often entail deep, complex integration processes.

According to a common classification, there are two types of multinational company: firstly, horizontal multinationals are firms that produce the same product in different countries and thus can be expected to be concentrated among countries that are similar in both size and in their stage of economic development (Markusen, 1984; Horstmann and Markusen, 1992; Brainard, 1993; Markusen and Venables, 1996). Secondly, vertical multinationals are firms that integrate production vertically across national borders to take advantage of factor price differences (Helpman, 1984; Markusen, 1984). The expectation of lower transaction costs is one of the main reasons for these multinationals to go abroad and it can therefore be expected that regional integration will create vertical multinationals and thus give rise to RVCs.

It is difficult to predict what effects integration and trade liberalization may have on competition -often imperfect- economies of scale and product differentiations; this is also a sensitive matter (Norman, 1990; Yamawaki, 2004). This difficulty permeates this work since Central American firms may locate headquarters activities such as administration and research and development at home, but establish procurement and production activities abroad, engaging intensively in intra-industry and intra-firm trade, thereby benefiting from regional differences (Gasiorek, Smith, and Venables, 1991) and facilitating vertical integration. This happens in the dairy industry and will be explained later.

\section{Foreign direct investment and economic integration}

FDI is seen as a way in which firms can vertically or horizontally integrate separate economic activities located in different countries in order to capture a set of transactional benefits derived from placing these activities under common ownership. This explanation of multinational firms as a coordinated and integrated unit of decision-making which engages in cross-border value-adding activities relies on market failures, since in a 
perfect competitive market there would be infinite access to resources and no companies would need to go abroad. The configuration of the relationship between cross-border agents is defined by market failures and the governance structure in place to oversee exchanges of goods (Dunning and Robson, 1987).

The practical links between economic integration and FDI flows have been described as "mutually reinforcing" (Dent, 1997) and the two processes are considered to be intertwined in that regional integration leads to greater preference for local production within the area (Buckley and others, 2001). Economic integration increases the location advantages of the markets inside the trading bloc, and firms from outside may exploit opportunities to service these markets through local production by means of FDI. The level of FDI may also rise as firms from outside attempt to avoid tariff or non-tariff barriers and to produce inside the region in order to defend their existing market share (Hoon Hyun, 2008).

It is commonly argued that, among other aspects of economic integration, customs unions may give rise to trade diversion since they may increase external tariffs in order to protect internal markets. In this case, multinationals take a defensive strategy in response to trade diversion by shifting production to the customs union (Hoon Hyun, 2008). Regional trade therefore becomes more attractive than extraregionaltrade, leading to a negative trade balance with the wider world (Viner, 1950). This is liable to lead to greater defensive investment in local affiliates, in the place of exports, and an increase in FDI inflows (Nielsen, Heinrich and Hansen, 1992; UNCTC, 1990). This was the case during the first years of the Central American integration process, when external tariffs were high under an industrialization policy based on an import-substitution strategy. However, Central America abandoned the import-substitution strategy more than 30 years ago and, therefore, FDI inflows currently respond to other variables unrelated to a protected internal market.

Traditional determinants of FDI location identified by corporate investment theory link the size and growth of the host market, factor prices and access to special resources to the static and dynamic effects of economic integration. A sizeable market without boundaries enables local firms to reach economies of scale, therefore enhancing efficiency and competitiveness within the region (Balassa, 1961; Corden, 1972; European Commission, 1997). In Central America it has enabled firms such as Dos Pinos to increase their production and efficiency and made it possible for Salvadoran producers to reach scarce means of production (land and herds) abroad, as shown later. For outsiders, market expansion, demandled growth, and technical progress lead to little or no increase in trade, 
while aggressive export-substituting investment in locally based affiliates increases cumulative FDI inflows (Nielsen, Heinrich and Hansen, 1992; UNCTC, 1990; Yannopoulos, 1990).

However, economic integration is relevant not only for large multinational firms but also for small and medium-sized enterprises (SMEs) since their production and input chains will find new partners within the region. SMEs can take advantage of cross-border activities, which provide opportunities not only for revenue growth but also for the exchange of knowledge and the enhancement of capabilities, thus strengthening the long-term competitiveness of the firm. Many SMEs have taken this path in Central America, as dairy firms from El Salvador and Nicaragua have shown.

The process of Central American integration can be said to be at a stage of "open regionalism" where integration deepens, facilitating trade and FDI, and tending to create or strengthen regional institutions while openly competing in global markets. This characteristic permits the coexistence of two types of FDI: one focused on the regional market (dairy producers investing in neighbouring countries so as to have access to important inputs, for example) and the other using the region as a platform for exports to countries in the wider world, generally the United States (most of these firms are integrated into global value chains and are specialized in particular parts of these chains).

\section{Value chain analysis and governance}

Before going into the concept of value chains and governance it is important to analyse the concepts of institutional arrangements and institutional environment. The institutional environment consists of the set of rules of the game (both formal and informal) which are established in a society within which institutional arrangements function. Institutional arrangements consist of a whole spectrum of concepts, ranging from markets at one end to central planning organizations at the other (Slagen, 2003; Zúñiga-Arias, 2007; 2011). Social scientists have taken a fresh view on value chains, conceptualizing them as governance systems, or arenas where firms with different degrees of power struggle to achieve monopolistic market power, erect trade barriers to protect innovation rents, and appropriate an increasing share of the overall gains of the value-adding process. International production sharing, where nations specialize in bits of the production processes in which they have the greatest comparative advantage, is central to many recent economic developments and experiences of industrialization. In East Asia especially, development typically takes place according to a set pattern whereby producers start with downstream intermediate exports and 
move towards upstream components thereafter (Sim, 2004). Commonly, a large developed country will then specialize in producing the upstream components while the downstream components will be produced by less developed small open economies (Sim, 2004). However, among countries of similar size and levels of development, such as those of Central America, RVCs tend to maximize efficiency among firms of a relatively common size and power by trading inputs or using resources from neighbouring countries, thus leading to greater coordination and production integration, both horizontally and vertically. The institutional environment in Central America is very diverse and firms have to deal with different sets of support policies, constraints, regulations and so on depending on the country in which they are located. The integration process has not been able to create a homogeneous business environment, which, along with income and cost differences, provides incentives to firms to diversify their investments, thereby creating RVCs.

The trend towards value chain governance has major implications for development, and outcomes vary considerably depending on the concrete patterns of governance. Moreover, these patterns tend to affect producer and consumer groups differently, to the benefit of some and the detriment of others.

For example, as large buyers press for lower purchasing prices, they drive their suppliers' efficiency up, but at the same time increase market concentration and raise entry barriers for small firms. Furthermore, the imposition of more stringent product and process standards puts additional demands on producers from developing countries and jeopardizes many weaker small-scale producers, while also opening up certain new opportunities for product differentiation. Support for lead firms may enhance the competitiveness of the whole chain, since in most cases suppliers are likely to gain indirectly from increasing market shares. In other cases, however, it may strengthen the lead firm's bargaining power and enable it to appropriate additional buyer rents at the expense of its suppliers.

\section{Methodology}

This study uses a case study to analyse RVCs. The main idea of a case study is to facilitate in-depth understanding of special interest issues. In this particular study the researchers focus in the dairy sector in Central America, particularly in El Salvador, Nicaragua, Costa Rica and Panama, in order to understand how regional integration has facilitated the creation of RVC. 
This document is based on a previous study undertaken by the Economic Commission for Latin America and the Caribbean (ECLAC) for which field work was undertaken in the countries referred to and a dairy chain for each country was drawn up. The study also shows the importance of small businesses in the region's dairy sector and the coordination mechanisms and power balances among different actors in the value chain.

This research entailed holding several meetings with strategic stakeholders in situ, and several statistical data sets were used to describe the different value chains.

In the case of Panama the authors base the description and analysis of the value chain and economic integration on secondary sources. Statistical data sets will also be used to better describe the process of economic integration and value chain.

\section{E. The dairy sector in Central America: an overview}

Zúñiga-Arias (2011) showed that the dairy sector in Costa Rica is specialized, with different production regions and different firms producing milk industrially. Dos Pinos (a cooperative) is the strongest actor in the chain, controlling around $80 \%$ of industrial milk production. Many small producers are members of the cooperative, which provides them with access to better niche markets and better prices.

Nicaragua has the largest herd of cattle in Central America, but its production system is not specialized, meaning that meat is produced alongside dairy products. Land use in the sector is extensive and the major challenges it faces include how to improve quality controls on milk and to open up access to consumer markets for smaller producers. The European multinational Parmalat is the biggest player in Nicaragua's dairy value chain.

In El Salvador the milk production sector is increasingly dominated by specialized herds farmed by cooperatives and small private firms. One characteristic of the Salvadoran dairy sector is that local companies are investing in Nicaragua to provide dairy inputs for their firms and set up local partnerships with small industries in Nicaragua for the production of El Salvador's national cheese, quesillo, for the nostalgic market among immigrants in the United States. This is a clear example of FDI within developing countries and Central American integration and shows how FDI and proximity have facilitated trade in dairy products and the related investment. 
Dairy tariffs among Central American countries vary greatly depending on the country and product in question. Tariffs on yoghurt are as low as $0 \%$ for some countries, but as high as $17 \%$ between Costa Rica and Nicaragua. Tariffs also reach $40 \%$ for different types of cheese imports from Nicaragua to El Salvador (this is considered to be a major reason for the amount of contraband). Average dairy import tariffs from Costa Rica to Panama are close to $17 \%$. Average tariffs on imports from Nicaragua to El Salvador are as high as 31\%, but Nicaragua imposes no tariffs on dairy imports from Central America. These two countries have specialized in the produce and materials they have in relative abundance, so Nicaragua produces raw milk for export to El Salvador, where it is made into cheese that is subsequently exported to the United States. Panama imposes a higher tariff on Costa Rican dairy products, the same one it applies on products from non-Central American countries.

There are few studies on the dairy chain in Panama, and no studies on the milk value chain could be found. Dairy markets in Panama are very dynamic, and firms from Latin America and abroad invest in and trade milk in that country. Nestlé and Dos Pinos are good examples of foreign firms investing in Panama. The Costa Rican firm Dos Pinos has invested at least US\$ 2 million in a cooperative in northern Panama, another example of FDI between developing countries. It can be argued that these investments are a strategic response to the aggressive development of dairy companies in the region. Costa Rica is the largest importer of milk from Panama and the largest exporter to Guatemala and Nicaragua. This situation stresses the intertwined nature of value chains in dairy products in Central America.

Table V.1

Yearly average exports and imports of dairy products in Central America, 1994-2011

(Tons)

\begin{tabular}{lrrrrrrr}
\hline & $\begin{array}{c}\text { Costa } \\
\text { Rica }\end{array}$ & $\begin{array}{c}\text { El } \\
\text { Salvador }\end{array}$ & Guatemala & Honduras & Nicaragua & Panama & Imports \\
\hline Costa Rica & & 0.06 & - & 0.33 & 1.11 & 7.39 & 8.89 \\
\hline El Salvador & 8.33 & & 1.72 & 7.78 & 22.22 & 1.17 & 41.22 \\
\hline Guatemala & 13.00 & 6.56 & & 2.56 & 7.39 & 2.78 & 32.28 \\
\hline Honduras & 4.17 & 4.61 & 1.11 & & 5.22 & 0.72 & 15.83 \\
\hline Nicaragua & 4.00 & 1.40 & 0.24 & 0.12 & & 2.11 & 7.86 \\
\hline Exports & 29.50 & 12.62 & 3.07 & 10.78 & 35.94 & 14.17 & \\
\hline
\end{tabular}

Source: Prepared by the authors on the basis of Food and Agriculture Organization of the United Nations (FAO), FAOSTAT [online] www.faostat.org. 
According to the United Nations Food and Agriculture Organization (FAO) Nicaragua imports the smallest amount of dairy products of any country in Central America (7.86 tons per year). There are two main reasons for this: firstly Nicaragua's low average GDP per capita and, secondly, the high production rate of local herds. El Salvador has the highest average imports of any country in Central America: 41.22 tons per year. This may be explained by its small production area and FDI flows into Nicaragua.

Nicaragua is the largest exporter in the region, followed by Costa Rica. Panama, though a small exporter, sends more than $50 \%$ of its milk exports to Costa Rica, stressing the degree of production integration between these two countries.

Table V.3 shows that FAO ranks the Central American countries around the middle of its list of 250 countries in terms of yield, herd number and dairy production. El Salvador has the highest yield rate in the region (it is in fiftieth place worldwide); Nicaragua has the largest herd in Central America and Costa Rica the highest production rate. Panama has the lowest output (see table V.2).

Table V.2

Main characteristics of the dairy industry in Central America

\begin{tabular}{|c|c|c|c|c|c|c|c|c|c|}
\hline & \multicolumn{3}{|c|}{$\begin{array}{l}\text { Animals } \\
\text { (head) }\end{array}$} & \multicolumn{3}{|c|}{$\begin{array}{c}\text { Yield } \\
\text { (hectograms per animal) }\end{array}$} & \multicolumn{3}{|c|}{$\begin{array}{l}\text { Production } \\
\quad \text { (tons) }\end{array}$} \\
\hline & 2008 & 2009 & 2010 & 2008 & 2009 & 2010 & 2008 & 2009 & 2010 \\
\hline Costa Rica & 643000 & 689074 & 702100 & 13841 & 13231 & 13541 & 889958 & 911743 & 950726 \\
\hline EI Salvador & 373068 & 391602 & 255675 & 13243 & 13831 & 21770 & 494071 & 541615 & 556594 \\
\hline Guatemala & 434957 & 435900 & 442700 & 7771 & 7800 & 8010 & 338000 & 340000 & 354600 \\
\hline Honduras & 513393 & 538131 & 558877 & 15515 & 13081 & 13229 & 796506 & 703902 & 739351 \\
\hline Nicaragua & 985000 & 1024000 & 1039900 & 7298 & 7303 & 7244 & 718882 & 747809 & 753281 \\
\hline Panama & 148900 & 159569 & 162600 & 12669 & 12100 & 12386 & 188635 & 193077 & 201400 \\
\hline
\end{tabular}

Source: Prepared by the authors on the basis of Food and Agriculture Organization of the United Nations (FAO), FAOSTAT [online] www.faostat.org. 
Table V. 3

Countries' position in terms of world dairy production

\begin{tabular}{lccc}
\hline & Yield & Herd & Production \\
\hline Costa Rica & 70 & 87 & 73 \\
\hline Nicaragua & 104 & 75 & 79 \\
\hline Honduras & 72 & 94 & 80 \\
\hline El Salvador & 50 & 123 & 90 \\
\hline Guatemala & 98 & 102 & 99 \\
\hline Panama & 75 & 131 & 113 \\
\hline
\end{tabular}

Source: Prepared by the authors on the basis of Food and Agriculture Organization of the United Nations (FAO), FAOSTAT [online] www.faostat.org.

\section{Nicaragua's dairy value chain}

Nicaragua has the most livestock of any country in Central America and is the region's largest exporter of dairy products. Dairy firms from Nicaragua are also engaged in processes of vertical integration with industries from El Salvador. The Nicaraguan State has launched several national programmes to promote and develop the cattle and dairy sector. There are three main issues of concern in the sector: its low degree of specialization, the low quality of milk and substandard quality controls on processes and the high production costs, due to the price of concentrates for livestock.

The problem of specialization is linked to that of quality. There are few specialized dairy farms and many producers therefore see dairy production as a subproduct of livestock farming. This attitude is not conducive to the production of quality milk and undermines relations with large dairy industries.

The production costs are related to the international prices of maize and soybeans and have become a major financial burden on small producers.

The Nicaraguan dairy chain is governed under two major institutional arrangements according to the size of producers: a vertical contract and incentives contract, the latter governing quality and volume. Large firms enter into contracts with cooperatives and large producers.

There is another group of producers linked to Salvadoran industries in both Nicaragua and El Salvador: small-scale producers that are isolated from the main markets in Nicaragua. The most suitable option open to them is therefore to sell their products to businesses in closer proximity to such markets. Such transactions tend to be governed by informal, verbal contracts and payment is generally made in cash after milk is delivered to the plant. 
Small producers isolated from markets can also process their milk and produce cheeses for sale to neighbours and at local rural markets.

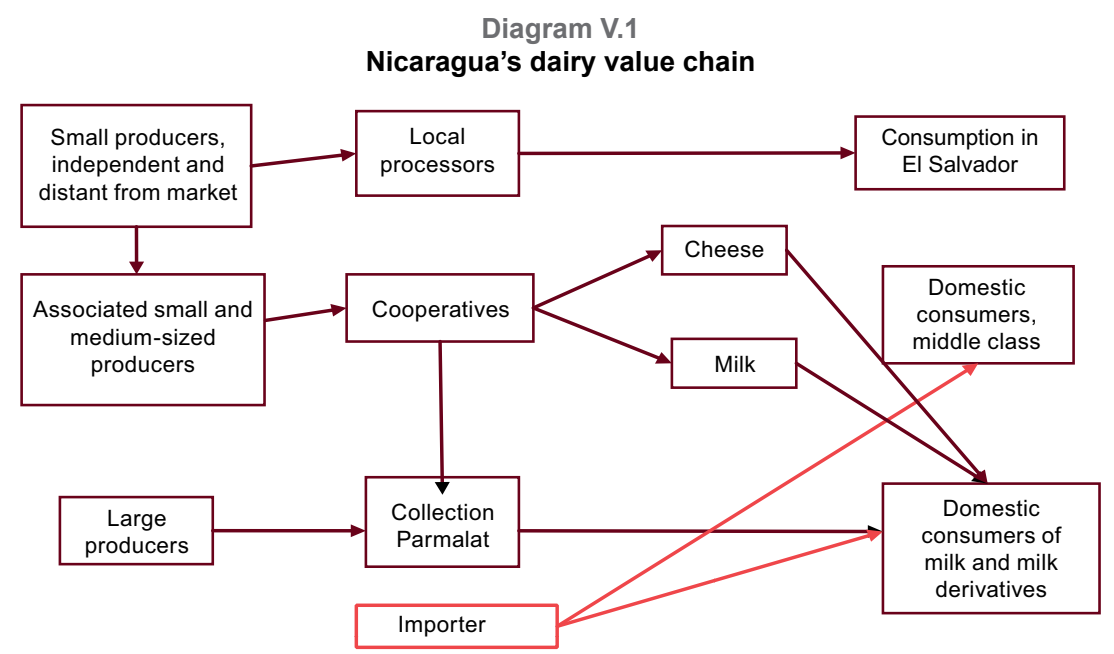

Source: G. Zúñiga-Arias, "El desarrollo de cadenas de valor agroindustriales en Costa Rica, El Salvador y Nicaragua. El caso de estudio de la agroindustria láctea", Estudios y Perspectivas series, No. 126 (LC/L.3332-P; LC/MEX/L.996.Rev.1), Mexico City, ECLAC subregional headquarters in Mexico, 2011.

\section{El Salvador's dairy value chain}

The nostalgic market in United States is a potent target market for Salvadoran industry. The main product exported to the nostalgic market is quesillo. El Salvador is not able to produce enough dairy products to cover either its local consumption requirements or the demand for its exports. Salvadoran firms therefore import milk from small Nicaraguan producers and actively invest in Nicaragua to secure the raw materials and intermediate products required for their industrialization. Direct investment made by El Salvador is mainly in infrastructure (processing plants, containers and distribution channels).

El Salvador has a highly developed industry that is able to produce high quality dairy products for local and export markets. However, owing to the lack of import controls and the growth in contraband it is possible to find low-quality quesillo in El Salvador's local markets. Price mechanisms are an important tool for assessing the quality of the product.

The governance structure of the dairy chain in El Salvador is controlled by several semi-industrialized companies producing for local and export markets. They purchase raw materials from small producers under verbal contracts, allowing the production system to be monitored 
in a fully vertically integrated manner. Another relevant agent is the cooperative sector, which has a large industry with its own supply of milk and has the capacity to enter local and export markets.

Contracts are generally verbal and payment for the milk is made on delivery. The degree of vertical integration is evident during quality controls.

\section{Diagram V.2}

The dairy value chain in El Salvador

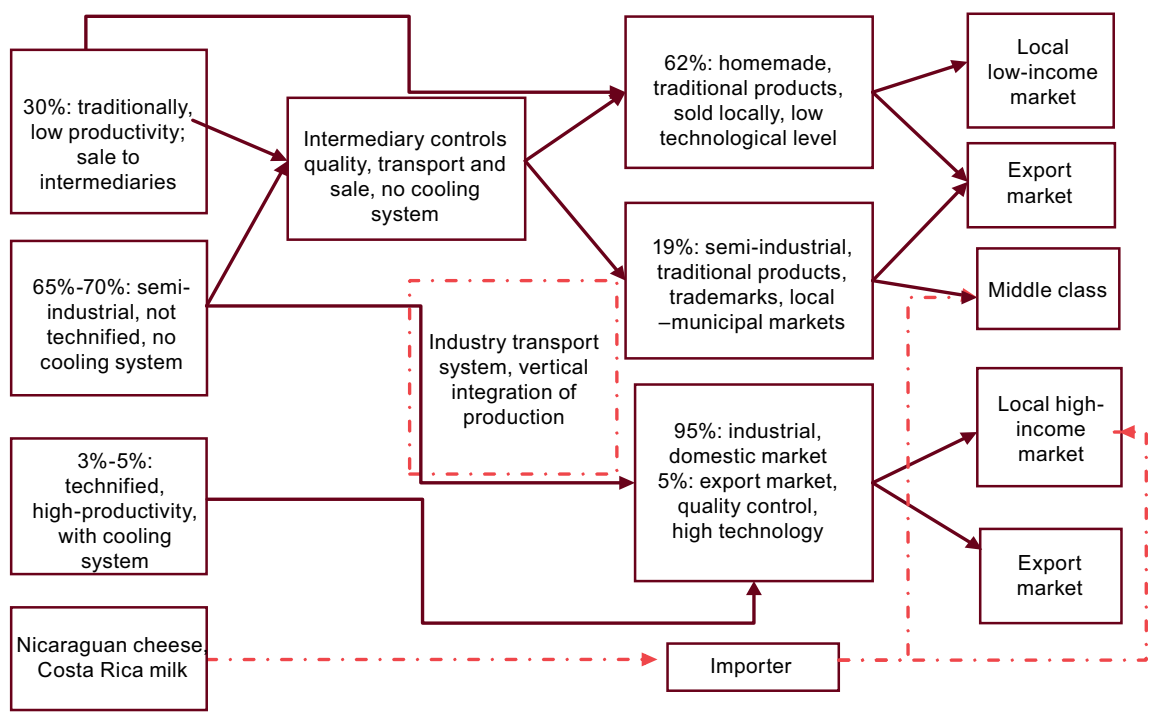

Source: G. Zúñiga-Arias, "El desarrollo de cadenas de valor agroindustriales en Costa Rica, El Salvador y Nicaragua. El caso de estudio de la agroindustria láctea", Estudios y Perspectivas series, No. 126 (LC/L.3332-P; LC/MEX/L.996.Rev.1), Mexico City, ECLAC subregional headquarters in Mexico, 2011.

\section{Costa Rica's dairy value chain}

The dairy sector in Costa Rica is well organized and comprises a wide range of stakeholders such as cooperatives, private companies and producers' associations. It has a history of being protected and supported by the State. It is specialized in that it produces only milk and its derivatives. Dairy products in Costa Rica are mainly industrialized, and the market is controlled by Dos Pinos, a cooperative formed by small producers accounting for over $80 \%$ of the market. This dominance has meant that it has been able to control the quality of products and to vertically integrate the small producers.

Small producers have designated quotas for their milk production, and if they deliver more raw milk than their quota the cooperative buys the 
excess production at half the market price. There are incentive contracts to promote product quality and several laboratory tests are performed during the processes between the farm and the production plant. Most of the milk delivered to the cooperative plant is refrigerated at the local farms, where production is mechanized.

In the case of Costa Rica, it is clear who the controller of the chain is, but there are also other agents in the market: two additional cooperatives, one private company and one international company. Producers' organizations have been very successful in lobbying politicians over the years and the price of the milk is now set by the State and high external tariffs are imposed on several dairy products (such as yoghurt).

Dos Pinos (the dominant player) has become a major exporter, and currently provides dairy products to Central America and the Caribbean countries. However, this firm is a net milk importer from Panama, where it has invested in industrial plants in order to increase its production capacity and has tried to buy or to build a processing plant.

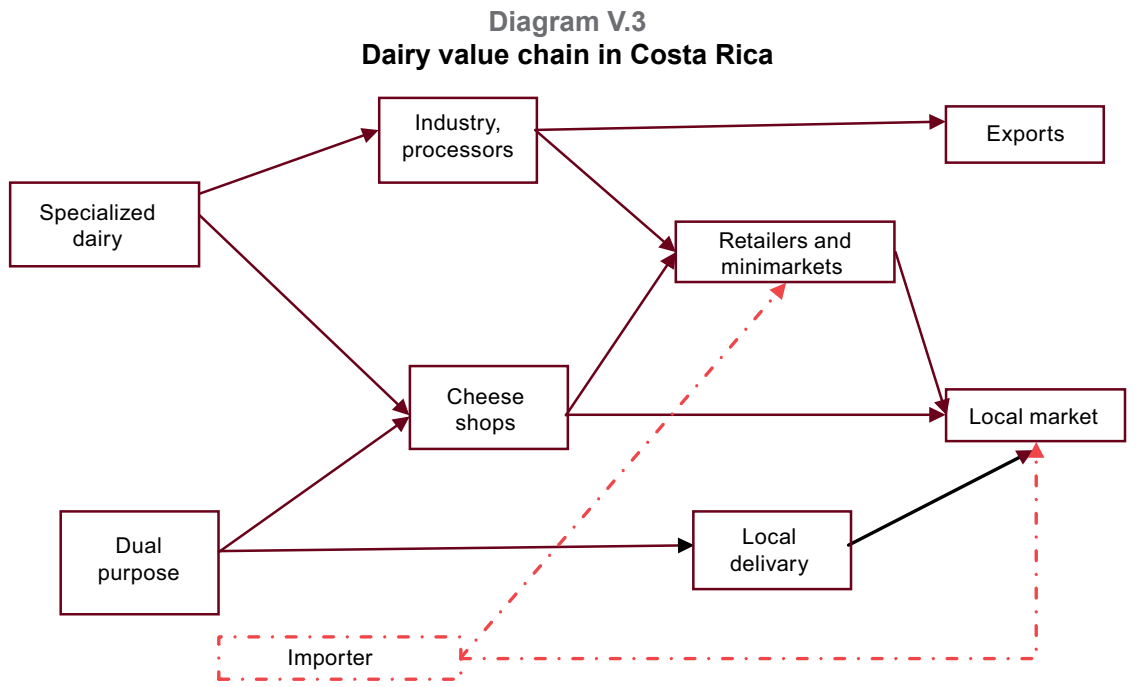

Source: G. Zúñiga-Arias, "El desarrollo de cadenas de valor agroindustriales en Costa Rica, El Salvador y Nicaragua. El caso de estudio de la agroindustria láctea", Estudios y Perspectivas series, No. 126 (LC/L.3332-P; LC/MEX/L.996.Rev.1), Mexico City, ECLAC subregional headquarters in Mexico, 2011.

\section{Panama's dairy value chain}

Panama is not seen as a main player in Central America's dairy supply chain, but has become a major exporter of milk to Costa Rica, the market for most of its exports. 
In recent years the Coca-Cola Company has shown an interest in acquiring a large-scale milk processing plant in Panama so as to control the local market and expand its export options. In March 2011 Coca-Cola FEMSA acquired the largest dairy producer in Panama (Estrella Azul), thus cementing its place in the regional market. Dos Pinos has also invested US\$ 2 million in vertically integrating a medium-sized Panamanian cooperative to secure the supply of milk it needs to increase production in Costa Rica. This movement is part of the strategy to keep its share in the Central American milk market.

Panamanian officials are currently working to improve quality controls and production systems. Several national programmes are being devised to improve and develop the dairy sector, such as the project of the Ministry of Agricultural Development (MIDA) and the International Institute for Cooperation on Agriculture (IICA) for a strategic plan for the Panamanian dairy sector ${ }^{1}$. The main problem this sector faces in Panama is its lack of organization. There is little research available on the dairy products value chain in the country. The Panamanian dairy sector is at an initial stage of expansion to the export market, and the State is currently promoting and supporting it. The market has few large companies and many small producers, and this is why Coca-Cola FEMSA and Dos Pinos are competing to coordinate or vertically integrate processes with the biggest agents in Panama's dairy value chain.

\section{Diagram V.4}

Structure of the dairy value chain in Panama

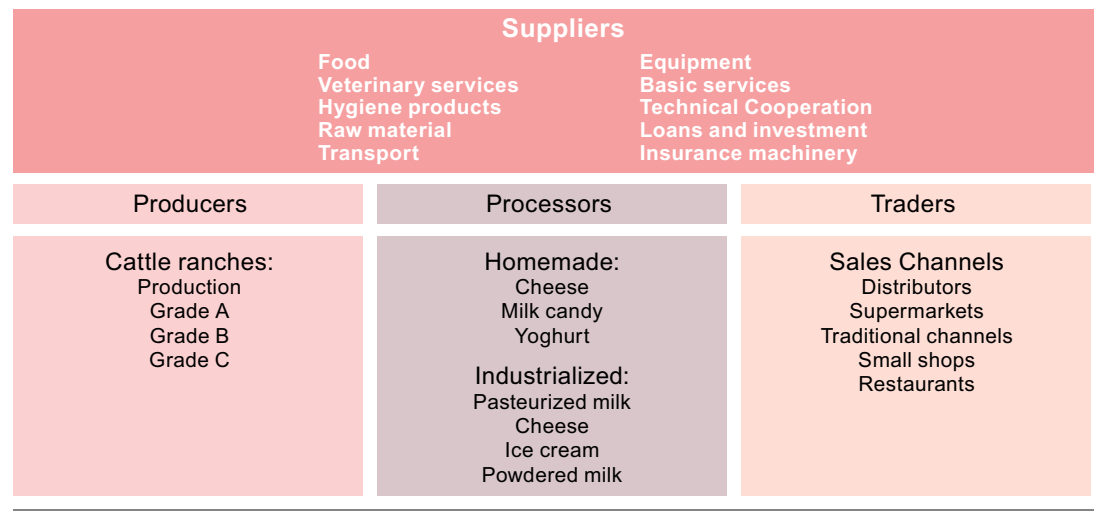

State support institutions

Source: Ministry of Trade and Industry, "Productos Lácteos San Antonio, S.A. (PROLACSA)", 2003 [online] http://www.mici.gob.pa/imagenes/pdf/caso_prolacsa_documento_final_.pdf .

The main objective of this plan is to enhance the productivity and competitiveness of the agrarian sector over the 2010-2014 period. The plan will develop four subprogrammes: a value chain analysis of specific sensitive products; an action plan for each value chain; a coordination mechanism for those particular chains and training processes within the value chains. 


\section{F. Economic integration through regional value chains}

Although efforts to promote economic integration need to take account of many different factors - trade, regional policy, trade agreements and FDI, for instance - the promotion and consolidation of RVCs may be considered a key element. This encompasses trade and FDI matters and institution-building; the effects include reinforcing regional trade, creating regional production culture and establishing standards. RVCs also have the potential to include an increasing number of regional partners.

The Central American internal market is very important for all Central American countries, but is particularly so for small and mediumsized producers. The region's internal market accounts for a quarter of its overall exports and for, respectively, 39\% and 55\% of El Salvador's and Guatemala's total exports.

Deepening Central American integration and promoting internal trade will have a direct impact on the creation of RVCs. This can be seen in the regional dairy industry as well as in RVCs in citrus products between Nicaragua and Costa Rica, maize and beans between Nicaragua and El Salvador and sugar cane between Guatemala and El Salvador.

Besides trade, there are two other important dimensions that have a direct and positive effect on regional integration: vertical and/or horizontal integration and FDI. Vertical integration and FDI are both present in the Central American dairy industry.

\section{Vertical Integration and Economic Integration}

Vertical integration (VI) can be explained simply as the integration of several chain activities under the control and monitoring of one particular agent. It may have several positive effects on economic integration, such as lower transaction costs and risks and closer relationships with consumers.

VI can reduce costs by bringing several activities along the chain under the umbrella of a single entity. Pineapples and bananas are good examples of how a single company is able to control and monitor all stages of production in the chain. Just as in the pineapple and banana sectors, in the dairy sector Parmalat, and Dos Pinos are completely vertically integrated and control both milk production and consumption.

The lower transaction costs also reduce the prevalence of opportunistic behaviours, the problem of moral hazard and the number 
of "free riders". VI also provides advantages in terms of monitoring, controlling and enforcement. All the above characteristics are examples of agency theory, whereby contracts or agreements are drafted in such a way as to maintain control before, during and after the signing of any agreements. This encourages the production plant to adopt certain specific production methods and standards, which tends to improve quality in the dairy sector and to facilitate the management of quota contracts. The dominant companies have total control over the production of milk.

Another issue is who is bearing the risk. It can be observed from the integration process in the dairy sector that milk producers bear the bulk of the risk. If the milk producer frees itself from the contract it will have to go and sell its product in an alternative market for a lower price or produce more traditional subproducts. VI also solves a problem of trust: in a concentrated market where most players know each other, it is very important for dominant companies to impose social controls on producers.

VI makes it easier to control relationships with consumers and therefore leads to the concentration of bargaining power. This ability to be close to the consumer allows vertically integrated companies to know what products consumers are interested in and willing to buy. This precious information gives them an advantage and enables them to promote high quality standards for raw materials, details that are commonly governed by a quality contract.

\section{FDI and integration of the Central American dairy industry}

As previously explained, there are at least two types of FDI strategy in the dairy industry in Central America. Firstly there is the case of FDI from El Salvador to Nicaragua, where evidence can be found of businesses from El Salvador acquiring companies in Nicaragua to produce quesillo under their supervision. This cheese is then exported to El Salvador and re-exported to nostalgic markets in the United States. These companies are located far from their main markets and the Salvadoran parent companies therefore have access to milk at better prices, with very low competition for raw materials from other agents in the chain. In other words, they accept the increased transaction costs inherent in negotiating and enforcing contracts in return for a constant supply of milk with little competition from other agents in the chain.

In the case of Costa Rica and Panama, FDI works differently because investment is made in cooperatives and companies that are already 
producing dairy products. However, in both cases the result is the vertical integration of production and processes.

Dos Pinos reduces transaction costs by signing a contract with cooperatives that passes the high transaction costs of controlling small producers on to them. Recent investments by Dos Pinos can be seen as a defensive strategy in respect of exports, since they were made in the knowledge of the Coca-Cola Company's interest in acquiring the largest producer of dairy products in Panama. Dos Pinos reacted by investing in a production plant in Panama, which had the additional benefit of providing Dos Pinos plants in Costa Rica with access to relevant inputs. With this investment Dos Pinos improved access to Panama's local market and secured an increase in the supply of milk to its plants in Costa Rica.

Salvadoran investments are made with a view to making more efficient use of resources. The scarcity of resources in El Salvador (especially land) acts as an incentive for the industrial sector to look for better access to land and herds for the supply of milk. Its strategy is not to enter the local market as a competitor but to produce quesillo in a cheaper production system, thereby benefiting from a larger margin when exporting to the United States.

These two examples show how large and medium-sized companies from open developing economies use the same strategies as large firms from developed countries. They also underline the importance of an integration process in creating the conditions for trade in dairy raw materials and thereby establishing an RVC. Local companies have benefited from these regional conditions and have, through FDI, extended their activities to neighbouring countries.

\section{G. Final remarks}

There is a lack of studies analysing economic integration within small economiesfrom developing countries that focus on the development of RVCs as a result of the integration process. Further research should be conducted to better understand the drivers for and impacts of FDI in such economies.

Case studies must be conducted to understand what motivates firms to move abroad and invest in other Central American countries and to determine the impact of such investments.

Further research will facilitate the design of solid public policies on FDI from and to open, small-scale developing economies. Policies for SMEs and regional trade will also benefit from further research. 
Further research on the relationship between Costa Rica and Panama in the dairy sector will show the rationale behind the RVC strategy of Dos Pinos in respect of recent investments from large multinationals on dairy products in the region. On the other hand, case studies on FDI and trade between El Salvador and Nicaragua will underline the strategic access that Salvadoran firms have to resources (land and livestock) in Nicaragua at competitive costs.

Case studies have shown that the rules in place are an important element in the development of different institutional arrangements. It is clear that participants in chains from countries with strong institutions have an advantage over agents producing in weaker institutional frameworks. This is why Costa Rican producers fare better in terms of incentives, access to credit, protection from competition and secure prices for production, for instance. This is reflected in the overall strength of the country's dairy sector. Nicaraguan producers, however, are either isolated firms that have difficulties bringing their products to their main markets, and therefore enter into arrangements with Salvadoran cheese producers, or producers located close to main markets that sign formal contracts with transnational plants.

Vertical integration is the most common governance structure found in the dairy industry in Central America. The depth of VI differs between agents and countries, ranging from complete VI, as in the trade relationship between El Salvador and Nicaragua, to partial VI, as in the case between Costa Rica and Panama. The main difference lies in whether participants decide to bear the risk themselves or to share it with other actors. The presence of major players with high bargaining power also is a factor affecting the make-up of the chain (as in Costa Rica). Another less important factor is the competitive market, where both cases can be observed. A better approach to the problem might be to study the development of the chain with due account for various cases of market failure and the strategic decisions taken by the different actors in the chain.

The regional integration process (and the better customs arrangements, lower tariffs and, business facilitation policies it has brought) has facilitated VI and FDI as RVCs have been formed in Central America. At the same time, the integration process has been reinforced by the regional integration of production in the private sector. 


\section{Bibliography}

Balassa, B. (1961), The Theory of Economic Integration, London, George Allen \& Unwin. Brainard, S.L. (1993), "A simple theory of multinational corporations and trade with a tradeoff between proximity and concentration", NBER Working Paper, No. 4269, Cambridge, Massachusetts, National Bureau of Economic Research, February.

Buckley, P. and others (2001), "Increasing the size of the "country": regional economic integration and foreign direct investment in a globalised world economy", Management International Review, vol. 41, No. 3, Springer.

Corden, W.M. (1972), "Economies of scale and customs union theory", Journal of Political Economy, vol. 80, No. 3, Chicago, University of Chicago Press.

Dent, C.M. (1997), The European Economy: The Global Context, London, Routledge.

Dunning, J.H. (1998), "The changing geography of foreign direct investments", Globalization, Foreign Direct Investment, and Technology Transfers: Impacts on and Prospects for Developing Countries, N. Kumar and others, London, Routledge.

Dunning, J.H. and P. Robson (1987), "Multinational corporate integration and regional economic integration", Journal of Common Market Studies, vol. 26, No. 2, John Wiley \& Sons, December.

European Commission(1997), The Single Market Review Series. Impacton Manufacturing: Motor Vehicles, Brussels, Commission of the European Communities (CEC).

Gasiorek, M., A. Smith and A.J. Venables (1991), "Completing the internal market in the EC: factor demands and comparative advantage", European Integration: Trade and Industry, L.A. Winters and A.J. Venables (eds.), New York, Cambridge University Press.

Helpman, E. (1984), "A simple theory of international trade with multinational corporations", Journal of Political Economy, vol. 92, No. 3, Chicago, University of Chicago Press, June.

Hoon Hyun, J. (2008), "How different are emerging multinationals' views of economic integration in Europe? A case study of Korean automobile manufacturers' strategic reactions", European Planning Studies, vol. 16, No. 6, Taylor \& Francis, July.

Horstmann, I.J. and J.R. Markusen (1992), "Endogenous market structures and the development of multinationals (naturafacitsaltum)", Journal of International Economics, vol. 32, No. 1-2, Amsterdam, Elsevier, February.

Kumar, N. (1994), "Regional trading blocs, industrial reorganization and foreign direct investment: the case of single European market", World Competition, vol. 18, No. 2.

Markevicius, N. (2011), "Optimisation of degree of economic integration between Lithuania and Belarus", Societal Studies, vol. 3, No. 1, Mykolas Romeris University.

Markusen, J.R. (1984), "Multinationals, multiplant economies, and the gains from trade", Journal of International Economics, vol. 16 (No. 3-4), Amsterdam, Elsevier, May.

Markusen, J.R. and A.J. Venables (1996), "The increased importance of multinationals in North American economic relationships: a convergence hypothesis", The New Transatlantic Economy, M.W. Canzoneri, W.J. Ethier and V. Grilli (eds.), London, Cambridge University Press. 
Martínez-Piva, J.M. and M. Cordero (2009), "Panamá y el proceso de integración centroamericana" (LC/MEX/L.946), Mexico City, ECLAC subregional headquartes in Mexico, December.

Nielsen, J., H. Heinrich and J. Hansen (1992), An Economic Analysis of the EC, New York, McGraw-Hill.

Norman, V. (1990), "Assessing trade and welfare effects of trade liberalization: a comparison of alternative approaches to CGE modeling with imperfect competition", European Economic Review, vol. 34, No. 1, Amsterdam, Elsevier.

Sim, N. (2004), "International production sharing and economic development: moving up the value-chain for a small-open economy", Applied Economic Letters, vol. 11, No. 14, Taylor \& Francis.

Slagen, L.H.G. (2003), New Institutional Economics and Economic Organization. Theory Reader, Wageningen, Agricultural Economics and Rural Policy Group, Wageningen University.

UNCTC (United Nations Centre on Transnational Corporations) (1990), Regional Economic Integration and Transnational Corporations in the 1990s: Europe 1992, North American, and Developing Countries (ST/CTC/SER.A/15), New York, United Nations. United Nations publication, Sales No. E.90.II.A.14.

Viner, J. (1950), The Customs Union Issue, London, Stevens and Sons.

World Bank (1991), World Development Report, Washington, D.C.

Yamawaki, H. (2004), "The determinants of geographic configuration of value chain activities: foreign multinational enterprises in Japanese manufacturing", International Economics and Economic Policy, vol. 1, No. 2-3, Springer.

Yannopoulos, G.N. (1990), "Foreign direct investment and European integration: the evidence from the formative years of the European Community", Journal of Common Market Studies, vol. 28, No. 3, Wiley.

Zúñiga-Arias, G. (2011), “El desarrollo de cadenas de valor agroindustriales en Costa Rica, El Salvador y Nicaragua. El caso de estudio de la agroindustria láctea", Estudios y perspectivas series, No. 126 (LC/MEX/L.996.Rev.1), Mexico City, ECLAC subregional headquarters in Mexico. United Nations publication, Sales No. S.11.II.G.50.

(2007), "Quality management and strategic alliances in the mango supply chain from Costa Rica. An interdisciplinary approach for analyzing coordination, incentives and governance", International Chains and Networks, vol. 3, Wageningen Academic Publishers.

\section{Web pages visited}

www.cnnexpansion.com/negocios/2011/10/17/cocacola-femsa-apunta-a-americalatina; 2011-10-17

www.iica.int/Esp/organizacion/DORI/Central/Documentos\%20Region\%20 Central/sector\%20lacteo.pdf; 2012-01-15

www.faostat.org; 2012-01-10

www.prolacsa.com; 2012-01-25 

Chapter VI

\section{Value chain development for cocoa smallholders in Ecuador}

Sonia Lehmann

Andreas Springer-Heinze

\section{A. The value chain approach to smallholder development in Ecuador adopted by the German Agency for International Cooperation (GIZ)}

The sustainable utilization of natural resources is a priority area of bilateral development cooperation between Ecuador and Germany. One important cooperation programme in this area is "Gestión Sostenible de los Recursos Naturales" - Sustainable Natural Resources Management (GESOREN) a 10-year programme started in 2004 and scheduled to come to a close at the end of 2013.

GESOREN pursues economic and environmental goals at the same time, based on the premise that improved incomes for poor rural families are a precondition for protecting the natural resource base. The living conditions of the rural population in Ecuador are still precarious and the poverty rate stands at $52 \%$ (INEC, 2010). 
Indigenous groups make up a large part of the Ecuadorian population and depend for their livelihood on agriculture, fisheries and, to some extent, hunting. Farms are small and generally rely on the manual labour of the entire family. The resulting low productivity not only contributes to poverty, but also places more intense pressure on resources -land, biodiversity and forests.

The poor rural population constitutes the target group of GIZ. The idea is to provide them with economic alternatives that can help them to put their land to more productive use. The resulting higher incomes are expected to relieve pressure on resources and mitigate poverty. However, achieving this task is a great challenge, as a wide range of interconnected economic and social factors have to be addressed. Moreover, the small scale of operations, and the uneven quality and quantity limit the marketability of rural produce. Access to services is a challenge, while there are few production incentives, since prices are low and sales outlets limited. Infrastructure and trade conditions put primary producers at a disadvantage, further discouraging investment. Marketing chains linking remote rural areas with domestic and export markets are often inefficient, resulting in losses not only in the rural areas but for the Ecuadorian economy as a whole.

To achieve the market integration of rural producers it is necessary to address these interlocking constraints simultaneously. One very effective and proven system concept for developing comprehensive solutions is the value chain.

Box VI.1

Definition of a value chain according to ValueLinks

A value chain is an economic system that can be described in three ways:

- The sequence of related business activities (functions) from the provision of specific inputs for a particular product to primary production, transformation, marketing and final consumption

- The set of enterprises that perform these functions, i.e. the producers, processors, traders and distributors of a particular product

- A business model for a particular commercial product using a particular technology and a particular way of coordinating production and marketing.

Fuente: German Agency of International Cooperation (GIZ), Value Links Manual.

GIZ has applied a value chain approach to rural development from the start-up of GESOREN, using the ValueLinks methodology of promotion as its strategy (see www.valuelinks.org). ValueLinks is the name of a concept, manual and training course developed by GIZ on the basis 
of experience with economic and rural development in many countries, in Latin America and other regions. This methodology structures the know-how of value chain development into twelve modules, organized according to the project cycle (see diagram VI.1). Modules in column 1,2 and 4 provide a framework that all projects adhere to. The first two modules in the left column address the design of projects and the selection of value chains for promotion. The analysis of the value chains and strategy formulation is presented in modules 2 to 4 in the second column. Module 11 on monitoring and managing for impact, the fourth column, closes the cycle.

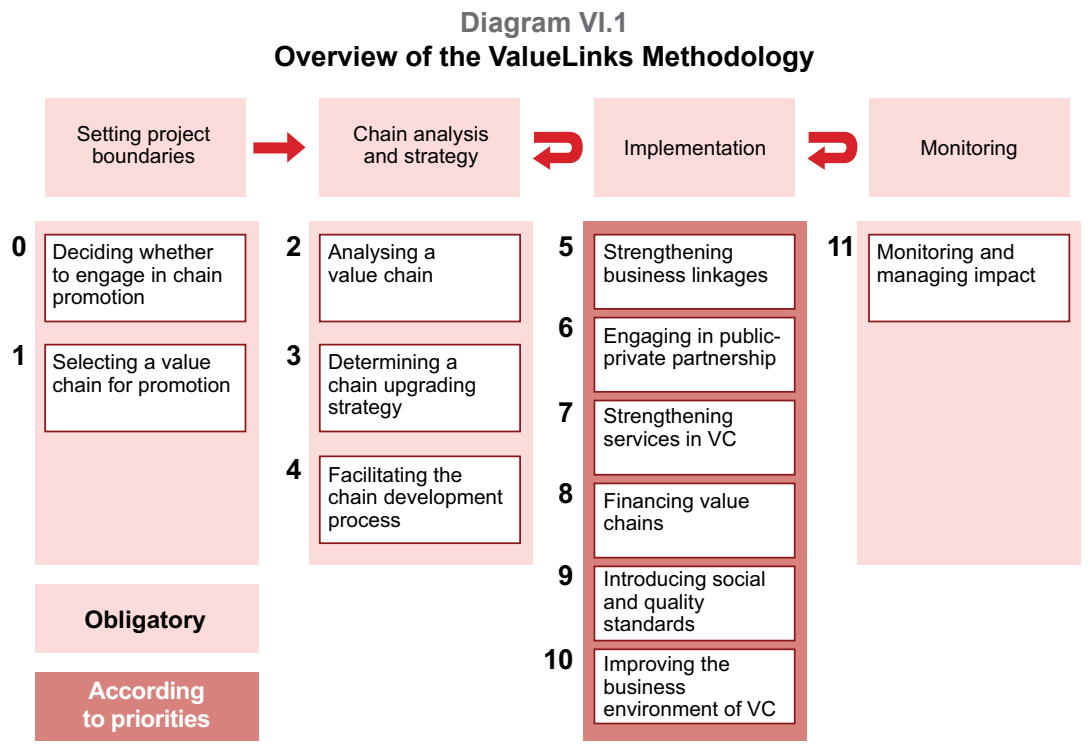

Source: German Agency for International Cooperation (GIZ), "ValueLinks Manual”.

Modules 5 to 10 contain know-how about different fields of chain upgrading, the relevance of which depends on the strategy for developing the value chain in question.

The approach is oriented towards a commercial potential that can be developed for the benefit of poor producers and the unemployed. It makes use of market forces to generate economic development that makes business sense and is sustainable and socially inclusive at the same time. The methodology is designed for public agencies as well as for the businesses in the chain. Essentially, the chain development project seeks to enable enterprises and providers of support services to work together to upgrade processes and arrive at optimal solutions. 
This chapter shows how GIZ has applied ValueLinks in Ecuador and describes the intervention strategy, the results obtained and the lessons learned. The article illustrates the conceptual and methodological elements of ValueLinks using the example of fine aromatic cocoa.

\title{
B. The selection of value chains for promotion
}

The intervention areas of GIZ in Ecuador are the provinces of Esmeraldas, Morona Santiago and Zamora Chinchipe, the Biosphere Reserve Sumaco in the Amazonia and the Ambato River basin in the Andean region.

\author{
Map VI.1 \\ Intervention areas of the GIZ-Programme for sustainable management \\ of natural resources in Ecuador
}

Source: German Agency for International Cooperation (GIZ), Ecuador.

Products and markets to be included in a value chain approach have to be carefully selected if they are to be effective. The first step is to establish a list of alternative options that hold out promise for rural development. GIZ used four main criteria to produce a preliminary list:

1. The products to be considered for selection had to be related to the use of the natural resources available within the GIZ intervention areas and to be part of the local production systems. The selection alternatives included agricultural products and products resulting from fishing and hunting activities, as well as timber products and products gathered in the wild. Products not produced or extracted in the region were excluded.

2. The commercial opportunity to be selected had to have productive potential or represent a competitive advantage for smallholders. This meant that it was necessary to verify that the beneficiaries would not be driven out of the value chain by bigger players after the support activities had ended. 
3. The beneficiary families had to demonstrate a minimal degree of organization, such as membership in a cooperative or an association as a starting position for ensuring marketable volumes.

4. The markets of the selected product had to demonstrate positive and stable growth, and pay prices high enough to cover the production cost of smallholders.

Table VI.1 shows some of the options that were identified and illustrates how the different criteria were evaluated. All are food products currently produced in the GIZ project regions. The broad commodity categories are presented in the top row of the table. In most cases, the choices were specified to represent particular market segments set out in the second row, as broad categories would not make it possible to discern channels of relevance to small producers. "Scoping" the options, that is, breaking them down into smaller categories, is also necessary for pragmatic reasons - making sure to align needs of value chain promotion with the project resources available.

Table VI.1

GIZ product and market evaluation matrix for promoting value chains, November 2002

\begin{tabular}{|c|c|c|c|c|c|c|}
\hline Subsector & Coffee & Cocoa & Bar & רanas & Cereals & Fruits \\
\hline Product & $\begin{array}{l}\text { High altitude/ } \\
\text { shadow grown } \\
\text { coffee }\end{array}$ & $\begin{array}{l}\text { National } \\
\text { cocoa (fine } \\
\text { aromatic) }\end{array}$ & Plantain & $\begin{array}{l}\text { Baby } \\
\text { banana }\end{array}$ & Quinoa & $\begin{array}{l}\text { Amazonian } \\
\text { fruits }\end{array}$ \\
\hline \multicolumn{7}{|l|}{ Criteria } \\
\hline $\begin{array}{l}\text { Activity relating to } \\
\text { the utilization of } \\
\text { natural resources }\end{array}$ & $\begin{array}{l}\text { Yes } \\
\text { Agriculture }\end{array}$ & $\begin{array}{l}\text { Yes } \\
\text { Agriculture }\end{array}$ & $\begin{array}{l}\text { Yes } \\
\text { Agriculture }\end{array}$ & $\begin{array}{l}\text { Yes } \\
\text { Agriculture }\end{array}$ & $\begin{array}{l}\text { Yes } \\
\text { Agriculture }\end{array}$ & $\begin{array}{l}\text { Yes } \\
\text { Agriculture }\end{array}$ \\
\hline $\begin{array}{l}\text { Comparative } \\
\text { advantage for } \\
\text { smallholders }\end{array}$ & $\begin{array}{l}\text { Yes } \\
\text { Labour- } \\
\text { intensive, } \\
\text { small scale } \\
\text { production }\end{array}$ & $\begin{array}{l}\text { Yes } \\
\text { Labour- } \\
\text { intensive, } \\
\text { small scale } \\
\text { production }\end{array}$ & No & $\begin{array}{l}\text { Yes } \\
\text { Production } \\
\text { by small- } \\
\text { holders } \\
\text { exclusively }\end{array}$ & $\begin{array}{l}\text { Yes } \\
\text { Production } \\
\text { by small- } \\
\text { holders } \\
\text { exclusively }\end{array}$ & No \\
\hline $\begin{array}{l}\text { Sustained } \\
\text { demand growth }\end{array}$ & $\begin{array}{l}\text { Yes } \\
\text { Speciality, } \\
\text { fair trade and } \\
\text { origin }\end{array}$ & $\begin{array}{l}\text { Yes } \\
\text { High- } \\
\text { quality } \\
\text { certified } \\
\text { markets }\end{array}$ & No & $\begin{array}{l}\text { Yes/No } \\
\text { Volatile } \\
\text { market } \\
\text { behaviour/ } \\
\text { possible } \\
\text { opportunity } \\
\text { in markets } \\
\text { for exotic } \\
\text { products }\end{array}$ & $\begin{array}{l}\text { Yes } \\
\text { Organic } \\
\text { markets }\end{array}$ & $\begin{array}{l}\text { Yes/No } \\
\text { Volatile } \\
\text { market } \\
\text { behaviour/ } \\
\text { possible } \\
\text { opportunity } \\
\text { in markets } \\
\text { for exotic } \\
\text { products }\end{array}$ \\
\hline $\begin{array}{l}\text { Producer engages } \\
\text { in cooperative } \\
\text { action }\end{array}$ & Yes & Yes & Yes & Yes & Yes & No \\
\hline $\begin{array}{l}\text { Value chain } \\
\text { selected for } \\
\text { promotion }\end{array}$ & Yes & Yes & No & Yes & Yes & No \\
\hline
\end{tabular}

Source: Prepared by the authors, on the basis of information provided by the German Agency for International Cooperation (GIZ). 
All the products found to comply with the criteria are relatively high value foods that are sold to speciality export market segments, primarily in Europe. This result follows a pattern: the increasing demand for exotic specialities in mature markets combines with small-scale production systems on the supply side. As long as these speciality products are not interesting enough for large-scale investors, smallholders have a chance to develop the markets for themselves. Moving from a conventional mass commodity (bananas) to a speciality product (organic baby bananas) is an example of "decommodification", which has been observed with several tropical products, most notably in the rise of speciality coffees. Ecuador is a case in point, producing "high altitude coffee", "bird-friendly" and other coffee varieties.

According to the American "Specialty Food Association" (n/d) speciality or gourmet food products tend to have superior characteristics such as exclusivity, exotic origin, special manufacturing methods (artisanal), ingredients (natural), design, limited supply, and a specific unusual use or application.

Of the different products retained for promotion, fine aromatic cocoa (or "cacao nacional") is a particularly interesting case and one that has received a great deal of attention. In the following, the major steps of ValueLinks are shown as applied to "fine aromatic" cocoa.

\section{Value chain analysis of a speciality product -the case of "fine aromatic cocoa"}

After selecting fine aromatic cocoa for promotion, GIZ collected additional information and quantitative data using the selection criterion as a starting point (see table VI.2, below). This serves to further pinpoint target markets and to set a baseline.

\section{Product and market characteristics}

Together with its partners, GIZ targeted the export market and value chain of high-value cocoa varieties. The Ecuadorian "national" cacao type is considered by the international chocolate industry as a unique speciality of Ecuador. These traditional types of cocoa serve the market segment of "fine aromatic cocoa" and are highly prized by chocolate producers who make high cocoa content chocolates specifying the variety and origin. 
Table VI.2

\section{Ecuador: basic data on export cocoa, May 2004}

\begin{tabular}{|c|c|}
\hline Criterion & Assessment \\
\hline $\begin{array}{l}\text { Sector/ Subsector } \\
\text { to be assessed }\end{array}$ & $\begin{array}{l}\text { Cacao (Theobroma cacao sp.), "national" type (also known in the chocolate } \\
\text { industry as arriba), fine and aroma cocoa, in fermented dry beans } \\
\text { for the export market. }\end{array}$ \\
\hline \multirow{4}{*}{$\begin{array}{l}\text { Activity relating to } \\
\text { the use of natural } \\
\text { resources }\end{array}$} & $\begin{array}{l}\text { Cacao is mostly grown in agro-forestry systems and traditional production } \\
\text { systems throughout the entire tropical region of the country. }\end{array}$ \\
\hline & It is estimated that there are 500,000 acres of cacao cultivated in the country. \\
\hline & $\begin{array}{l}\text { The planting surface is no less than } 5 \text { hectares per plantation/farm } \\
\text { (national average) }\end{array}$ \\
\hline & At least 5,560 hectares of cacao have organic certification. \\
\hline \multirow{3}{*}{$\begin{array}{l}\text { Comparative } \\
\text { advantage for } \\
\text { smallholders }\end{array}$} & $\begin{array}{l}90 \% \text { of the production of cacao in Ecuador comes from } 100,000 \text { small and } \\
\text { medium-sized producers. }\end{array}$ \\
\hline & $\begin{array}{l}\text { The market for common cacao does not have a comparative advantage for } \\
\text { smallholders. A long chain of (up to 10) intermediaries reduces } \\
\text { the benefits even more. }\end{array}$ \\
\hline & $\begin{array}{l}\text { Alternative or speciality markets offer opportunities for product differentiation; } \\
\text { they include the fair trade markets (which require that the production come } \\
\text { exclusively from small farmers) or gourmet markets (which emphasize the } \\
\text { origin of the product), and thus offer advantages for smallholders. }\end{array}$ \\
\hline \multirow[t]{5}{*}{$\begin{array}{l}\text { Sustained demand } \\
\text { growth }\end{array}$} & $\begin{array}{l}\text { Global candy markets have shown steady annual growth rates of around } \\
4 \% \text { from } 1996 \text { to } 2001 \text {. }\end{array}$ \\
\hline & $\begin{array}{l}\text { Between } 5 \% \text { and } 20 \% \text { of cacao imports in the largest markets are "fine and } \\
\text { aroma" cacao, used for the production of special chocolates. }\end{array}$ \\
\hline & The demand for "national" cacao is growing ( $+200,000$ metric tons per year). \\
\hline & $\begin{array}{l}\text { In Europe, the purchases of cacao with fair trade certification increased } \\
\text { by } 59.6 \% \text { between } 1997 \text { and } 2003 .\end{array}$ \\
\hline & $\begin{array}{l}\text { Estimates for the European market indicate an annual growth for the organic } \\
\text { food market of } 10.6 \% \text {. }\end{array}$ \\
\hline $\begin{array}{l}\text { Producers } \\
\text { experienced in } \\
\text { cooperative action }\end{array}$ & $\begin{array}{l}12 \text { (formal) associations of small cacao farmers have been identified. } \\
\text { These associations represent a total of } 4,400 \text { producers and } \\
12,500 \text { hectares of production. }\end{array}$ \\
\hline
\end{tabular}

Source: Prepared by the authors, on the basis of information provided by the German Agency for International Cooperation (GIZ).

PROECUADOR describes the product as "a type of cacao that is unique in the world, known for having a very short fermentation, and for resulting in smooth chocolate with good flavour and aroma, and therefore it is recognized globally with the fine aroma classification. Beginning in the nineteenth century, cocoa was grown near the upper basins of the Daule and Babahoyo tributaries, which form the Guayas River, along which it was transported to Guayaquil for export, and thus it was given the name "cacao arriba". It is planted at a maximum altitude of 1,200 metres above sea level, as established in the controlled designation of origin, awarded in order to obtain the "cacao arriba" - certification of origin by the Ecuadorian Institute of Intellectual Property. (PROECUADOR, 2011).

Ecuador is still by far the largest producer and exporter of aromatic cocoa worldwide, accounting for approximately $60 \%$ of the global volumes 
offered in this market segment. Other countries that supply this speciality cacao include Indonesia, Madagascar and Venezuela. This market can further be differentiated into smaller segments such as organic certified or fair trade cocoa.

When linking smallholders with speciality markets, it is important to understand that these types of value chains have different dynamics from those of products oriented toward traditional markets. The primary characteristics of speciality markets are as follows:

- The markets are made up of small and highly dynamic segments. Speciality segments are considerably smaller than conventional markets, offering opportunities only to a limited number of suppliers. Market segments evolve rapidly in a constant effort to adapt to emerging consumer preferences. While the total global food and drink market has recorded only modest growth, estimated at 3.2\% between 2010 and 2015, the market for organic products, which is only $1 \%$ of its size, had an average growth rate of $12 \%$ in the period 2001-2011 (FIBL/ IFOAM, 2011). The still smaller market for products with fair trade certification registered even more rapid growth, at an average rate of $36 \%$ in the period 2001-2011.

- Consumers pay higher prices for differentiated products. Participating in speciality markets implies a different and more costly production process than conventional techniques. As a result, these products include a premium above the normal market price, which reflects differentiation compared with conventional products, and the environmental and social benefits that these products have. Consumers are willing to pay for these "pluses".

- Quality requirements are translated into standards and certifications. Many of the speciality markets require compliance with quality protocols and procedural codes, which entail the implementation of control or verification mechanisms. They often involve an evaluation of the feasibility of meeting a specific standard, the certification as well as the coverage of additional costs such as of technical assistance, infrastructure adaptations and/or new equipment.

- Consumers react to stories and ethical messages. The marketing of speciality and exotic products requires more consumer information; moreover, sales benefit from the image created. Stories about cooperatives and the origin of the product illustrate the exclusivity of the product and connect consumers 
to producers. At the same time, they underpin the ethical side of the business. The way chocolate companies advertise is a case in point. For example, the German company Original Food advertises its "grand cru forest chocolate" bar "Río Napo" by showing tropical forest scenery and states that "the secret of this chocolate is the "national" cocoa from the Ecuadorian rain forest. It has been cultivated for generations by Quechua people in small gardens along the Napo River. Ancient, gnarled trees bear particularly aromatic fruits" (www.originalfood.de/ Produkt-Ordner/rionapo70g.html). Another example is the company Rausch, which tells a social story: "Cooperating with the government and other institutions active in the country, we support the cultivation of the unique fine-flavoured Ecuadorian cocoa: Arriba. ... Most cocoa farmers in Ecuador farm small plantations of 2 to 8 acres. We help cooperatives formed by smallholders in the areas of cultivation, fermenting, drying, storing and marketing" (www.rausch-schokolade. com/plantagen-schokolade/el-cuador.html).

\section{Value chain characteristics}

The market characteristics translate into specificities of the value chain structure:

- Direct and personal relationships to buyers: In a niche market there are few and rather small to medium-sized buyers seeking a direct and long-term relationship with producers so as to secure the supply and quality of the speciality product. There is hardly a role for large or numerous intermediaries.

- The chains are shorter and there is more coordination among participants: The efforts to differentiate a product require a high degree of specialization on the part of the operators along the chain, which often leads to vertical integration. The need to continuously adapt to market requirements, the exchange of information between the links, as well as communication with the consumer and the introduction of standards and certifications all require a closer relationship between suppliers, the industry and the consumer.

The value chain maps presented in diagrams VI.2 and VI.3, below, illustrate the difference in structure between the value chain of a conventional commodity and that of a speciality product produced by smallholders: 


\section{Diagram VI.2}

Ecuador: map of the conventional cocoa value chain

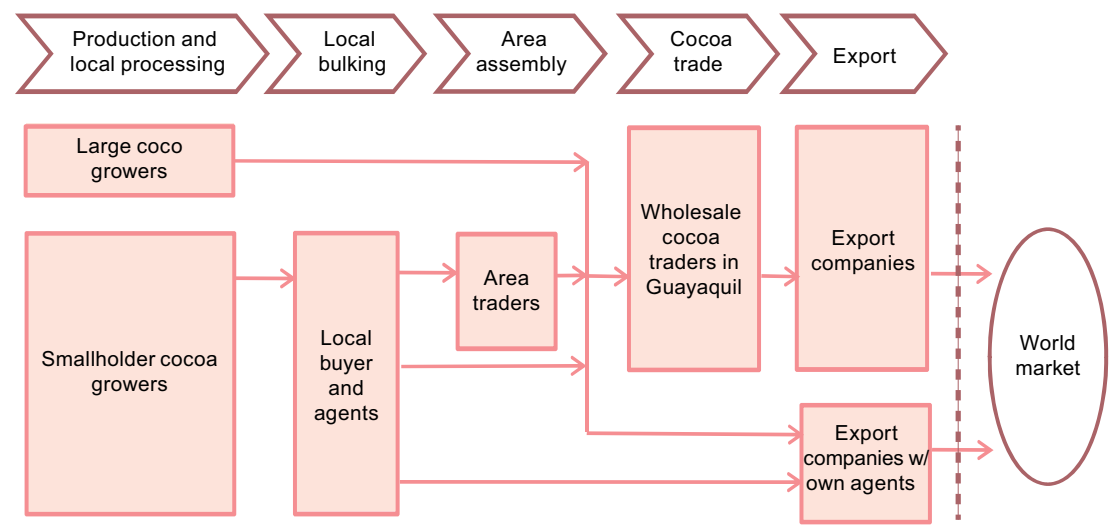

Source: Prepared by the authors.

Diagram VI.3

Ecuador: map of the speciality cocoa value chain
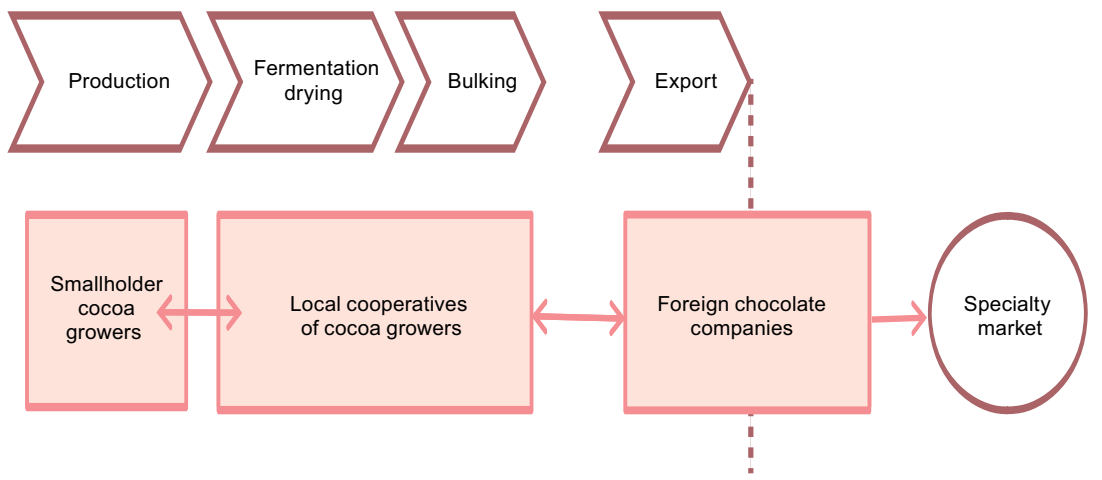

Source: Prepared by the authors.

- An important share of the value is generated locally: Cultivating high-value cocoa varieties requires more time but the value per weight ratio is higher than in conventional products. Both production and processing are suitable for small-scale units which invest less capital and more labour. Therefore, the share of smallholders in total value-added per unit is bigger.

- These value chains require specialized services: Factors such as quality control, clean technologies, the cold chain and traceability are only some of the issues involving personalized requirements when providing services to the chain. 


\section{Primary cocoa producers: characteristics and social aspects}

The most important part of the Ecuadorian cocoa production comes from smallholders with farms of less than five hectares. They normally grow cacao in combination with other products in agro-forestry systems using traditional farming practices. Families have a range of agricultural products allowing them to supplement their diet and earn income by selling the surplus. Product diversification protects the households against price fluctuations of commodities like coffee and cocoa. Table VI.3 presents a typical income structure.

Table VI.3

Ecuador: sources of income of the members of the KALLARI Association, located in the Sumaco Biosphere Reserve

\begin{tabular}{llrc}
\hline Sources of income & & Dollar/year & Percentage \\
\hline Agricultural Activities & Cocoa production & 885 & 49 \\
& Other agricultural crops & 344 & \\
& Fishing activities & 10 & \\
& Crops associated with cacao & 73 & \\
& Products for household & 760 & \\
& consumption & & \\
& Forest extraction & 1867 & 43 \\
\hline Non-agricultural activities & & 352 & 8 \\
\hline Transfers (BDH) given by the & & 4317 & 100 \\
government to vulnerable households & & & \\
\hline Total & & & \\
\hline
\end{tabular}

Source: German Agency for International Cooperation (GIZ), "Study on the impacts of value chain promotion on smallholder associations in Napo", KALLARI case study, 2011.

Most of the producers involved in speciality markets are grouped together in some way into associations or cooperatives. However, their business capacity is limited. Their social base and leaders are often weak and not very stable, especially if they do not yet have sufficient commercial experience.

One of the most common limitations for small-scale production is their inability to supply the right quality of product in time, which means that they are unable to take advantage of the existing market potential. Quality problems are related to the failure to incorporate market requirements into the production chain. This is a result of various factors. For example, producers located at the beginning of a long chain do not know enough about end-market requirements. Even if they receive information, they are often unable to understand it and take the necessary business decisions. A second reason is the inability to apply the quality criteria or requirements owing to lack of equipment, financing or the right technical assistance needed to achieve the required conditions. 


\section{Strategic analysis}

\section{Development objective and strategy for fine aromatic cocoa}

Cocoa is historically an important product in the Ecuadorian economy. It generates revenues for a significant part of the rural population, and also earns an important amount of foreign exchange. Over the past 15 years, annual cocoa production has averaged around 100,000 metric tons, with a notable increase in the last few years. Exports stood at 186,000 metric tons in 2011 and were approaching the 200,000 ton mark in 2012; the government is now looking at an export target of 300,000 tons per year ( $E l$ Telégrafo, 28 October 2012).

From the year 2000 onwards, the government identified the specific objective of revitalizing the production of aromatic cocoa. A consultative council of private associations and public agencies was formed and, with support from GIZ, held a series of meetings including annual cocoa forums in the following years. A decision was taken to specifically develop the value chain of fine aromatic cocoa in order to consolidate the market position of these entities and penetrate high-value cocoa markets. ${ }^{1} \mathrm{~A}$ national programme to promote the value chain was designed and agreed on by the participating actors (First National Cocoa Forum, 2004). This programme was to focus on the following lines of work:

- Quality improvement of the supply of cocoa beans

- Productivity increase in the plantations

- Image strengthening and promotion (cacao nacional)

- Organizational development at small-farmers' association level

- Development and improvement of services required by the value chain

- Strengthening the integration of all stakeholders (governance -institutional framework)

Following the general consensus to develop fine aromatic cocoa that GIZ had helped, the project took the development activities to the cocoa production areas. The objective and strategies were discussed in a series of round tables in the different cocoa-producing provinces (for example in Esmeraldas in the north of the coastal region and in the Amazon region). An important conclusion of these talks was that the value chain of fine aromatic cocoa had to be promoted by introducing business models that would link farmers directly to buyers of high-quality cocoa.

1 See First National Cocoa Forum (2004). 
The business model links (mostly) foreign chocolate-producing companies to farmer cooperatives. High-value chocolate-makers seek direct contacts with producers so as to ensure supplies and ascertain the origin. If the national objective of high-value market penetration is to be successful, it must be translated into a strategy developing the specific value chain shown in diagram VI.3. This is especially relevant in remote production areas far away from the port in Guayaquil. It is also high interest on the GIZ social and environmental agenda.

\section{Value chain problems, needs and opportunities}

ValueLinks advocates undertaking the strategic analysis of opportunities and objectives as the first step before moving on to the constraints analysis. The strategy for developing the value chain builds on the overall strategic objective, which has to be broken down into better solutions for the way business is done within the value chain in the fields of business linkages and procurement, horizontal cooperation of producers, service provision, value chain finance, quality assurance and the regulatory framework.

This objective is not only to overcome the current constraints of smallholders but also to consolidate and penetrate fine aromatic cocoa markets. The point is to identify all changes to be implemented in the value chain in order to enhance competitiveness. This includes the individual business contracts, described by Radi as business-to-business (b2b) arrangements (Radi, 2005); the regulatory framework that provides security to the partners (standards and the respective certification services) as well as the improvement of a wide range of technical and organizational issues that need to be resolved to get the value chain going. The analysis relates to the business models underpinning the value chain in diagram VI.3, which were just emerging when the programme was launched.

Several studies and meetings with stakeholders and (potential) business partners were necessary to conduct a profound situation analysis of small cocoa producers and their relation with market partners. They were summarized in a "SWOT" (Strengths, weaknesses, opportunities and threats) analysis.

Constraints exist on the side of buyers as well. Most chocolate companies did not have any experience buying from smallholder cooperatives (Radi, 2005, p.39 ff), and the conditions involved in contracting directly with farmers means a deviation from their normal routine. At the same time, communication problems had to be overcome as farmers do not understand international business language. Likewise, the requirements of new standards (origin, fair trade, organic) were unfamiliar to both the producers and buyers. The different needs, constraints and opportunities can be visualized within the value chain map. This has the advantage that their interconnectedness becomes clearer. 
Table VI.4

Ecuador: strengths, weaknesses, opportunities and threats of the aromatic cocoa chain

\begin{tabular}{|c|c|}
\hline Strengths & Opportunities \\
\hline \multirow{2}{*}{$\begin{array}{l}\text { Unique product at the global level (fine } \\
\text { aromatic cocoa), recognized by the industry } \\
\text { Cocoa associated with a history, culture and } \\
\text { biodiversity }\end{array}$} & $\begin{array}{l}\text { Growing demand in the chocolate industry } \\
\text { (both for the common product as well as for }\end{array}$ \\
\hline & $\begin{array}{l}\text { fine aromatic cocoa) } \\
\text { Fast-growing niche markets (for example }\end{array}$ \\
\hline $\begin{array}{l}\text { Good examples of direct associative } \\
\text { commercialization to speciality markets }\end{array}$ & $\begin{array}{l}\text { organic, origin, fair trade) } \\
\text { Feasibility of further differentiating the } \\
\text { cocoa product through certifications and its } \\
\text { productive, cultural and environmental qualities }\end{array}$ \\
\hline Weaknesses & Threats \\
\hline \multirow{2}{*}{$\begin{array}{l}\text { Insufficient orientation toward product quality } \\
\text { (lack of certifications, problems with mixing } \\
\text { varieties, non-uniform, post-harvest handling } \\
\text { and treatment) }\end{array}$} & $\begin{array}{l}\text { Competitor countries could replace the supply } \\
\text { that Ecuador cannot develop. }\end{array}$ \\
\hline & $\begin{array}{l}\text { The mix of cacao varieties could result in } \\
\text { penalties for the country. }\end{array}$ \\
\hline \multicolumn{2}{|l|}{ Low productivity on plantations } \\
\hline \multicolumn{2}{|l|}{$\begin{array}{l}\text { Mistrust and/or bad commercialization } \\
\text { experiences (contractual insecurity, } \\
\text { inadequate regulatory framework) }\end{array}$} \\
\hline \multicolumn{2}{|l|}{ Weak and insufficient associativity } \\
\hline Insufficient services & \\
\hline
\end{tabular}

Source: German Agency for International Cooperation (GIZ), Ecuador.

\section{E. Value chain development activities}

According to ValueLinks, the companies, farmer groups and cooperative associations have the primary responsibility for resolving the issues identified along the value chain. They are the entities that need to take action first. Public support agencies or development programmes support value chain upgrading by assisting the operators in mastering the constraints and making the necessary investments.

The main element in developing the fine aromatic cocoa value chain in Ecuador was the establishment of business linkages between farmer groups organized in cooperatives, on the one hand, and buyer companies, on the other. GIZ developed a series of support projects at the micro level, always combining one association with one buyer. The respective business model is the basis of the speciality cocoa value chain (see diagram VI.3). Table VI.5 presents the main commercial arrangements between farmers and buying companies that were promoted over the years -in the form of public-private partnerships (PPP). In fact, they account for the majority of these arrangements in the country. The projects were intended to foster concrete market access initiatives of individual companies thus improving the competitiveness of the whole chain. The table also shows the supporting players in addition to GIZ who helped to develop and consolidate the initiatives. 
The contractual arrangements were supported by different instruments such as direct technical assistance and training to farmers; in addition, advice was provided to both partners in the business linkage without entering into the contractual arrangements as such; further assistance was given with cooperative action, certification and quality control. By working with individual cooperatives and companies, the chain was gradually better able to take advantage of the opportunities in the speciality market based on the strengths that the product offered.

Table VI.5

\section{Ecuador: farmer-buyer contracts in the fine aromatic cocoa value chain}

\begin{tabular}{ll}
\hline Cocoa farmer association & B \\
\hline UNOCACE & Central southern coast- \\
based organization with 470 \\
members and an initial export \\
of 250 tons (2003)
\end{tabular}

\section{APROCANE}

430 associated producers in

the Esmeraldas province, with no market access (2003)

Buyer company
KAOKA
French chocolate
manufacturer, part of the
Cemoi-Group.

Max Felchlin AG High-end couverture chocolate producer in Switzerland; provides to speciality chocolatiers worldwide.
Support actors (besides GIZ)

Ministry of Agriculture and Livestock, National Autonomous Agricultural Research Institute (INIAP), Corporation for Export and Investment Promotion (CORPEI), InterAmerican Development Bank (IDB), GEFCAF Biocommerce Programme.

National Autonomous Agricultural Research Institute (INIAP), Corporation for Export and Investment Promotion (CORPEI), Inter-American Development Bank (IDB), Provincial Government of Esmeraldas, Fondo Ecuatoriano Populorum Progressio-(FEPP) (NGO).

KALLARI
590 Quechua families in
the Amazonia with cocoa
production but no market
access (2004)

Max Felchlin AG High-end couverture manufacturer in Switzerland; provides to speciality chocolatiers worldwide.

FEDECADE, AROMA AMAZÓNIO, CEFODI, SAN

CARLOS, UCOCS

3.000 farmers producing

Rainforest Alliance-RFAcertified cocoa with no market access (2005)

\section{Fortaleza del Valle}

700 families returning to cacao farming through an irrigation programme (2005)
Kraft Foods $\mathrm{GmbH}$ Multinational food industry. In this case the partner was the Germany- based firm.
Ministry of Agriculture and Livestock, Ministry of Economic and Social Inclusion, Provincial Government of Napo, Catholic Relief Services (CRS) (NGO), GEO Schützt den Regenwald Foundation (NGO).

Conservation and Development (NGO), the Association of Cacao Exporters of Ecuador (ANECACAO), COFINA (export company), Rainforest Alliance (RFA) (NGO).

\begin{tabular}{l} 
CIACPE \\
250 cacao producers without \\
access to markets (2007) \\
\hline FONMSOEAM \\
Afro-Ecuadorian organization \\
with 610 members without \\
market access(2008)
\end{tabular}

AGROXVEN

Cacao-exporting company representing 500 smallholders in the Ecuadorian coastal region (2009)

PRONATEC AG

Swiss importer of certified cocoa. Supplies small European processors.
National Autonomous Agricultural Research Institute (INIAP), Provincial Government of Manabi, Odebrecht (private company, through the Carrizal-Chone Consortium), UNOCACE (Farmer's association with exporting experience), RaboBank.

ICAM s.p.a.

Italian chocolate producer needing organic cocoa

\section{ETHIQUABLE Provincial Government of Esmeraldas,} French enterprise Fondo Ecuatoriano Populorum Progressio focused on special markets with organic and fair trade products FECD (NGO), Agronomos sin Fronteras (NGO), Great Wilderness Foundation (NGO).

Albrecht \& Dill GmbH National Autonomous Agricultural German cacao importer, Research Institute (INIAP), Solidaridad interested in cacao with (NGO). UTZ certification

Source: Prepared by the authors, on the basis of information provided by the German Agency for International Cooperation (GIZ). 
At the same time, the value chain upgrading strategy required the development of the value chain at higher levels as well, especially the development of new and better public services and adequate policies to support the sector. For this, GIZ promoted the development of spaces for coordinating and consensus-building among public and private stakeholders. Regional roundtables were organized to address pressing issues at the local level through research projects, encouraging associativity and facilitating access to financing. The policies were developed based on an intense exchange of information between public and private stakeholders, high-level political-trade missions, and participation in international forums such as the annual International Cocoa Organization (ICCO) conferences. Important allies of GIZ in this endeavour included the Ministry of Agriculture and Livestock, the National Autonomous Agricultural Research Institute (INIAP), the Corporation for Export and Investment Promotion (CORPEI), the Association of Cacao Exporters of Ecuador (ANECACAO) and a series of private cocoa-exporting companies and processors from abroad. The result was a policy that was not only recorded in planning documents, but rather a sector with participants who could coherently express a joint vision of the value chain and orient their actions towards a common forward-looking strategy.

Table VI.6 shows the combination and interplay between actions at the microeconomic and macroeconomic levels in the value chain.

\section{Table VI.6}

\section{Summary of the strategy for improving the fine aromatic cocoa value chain}

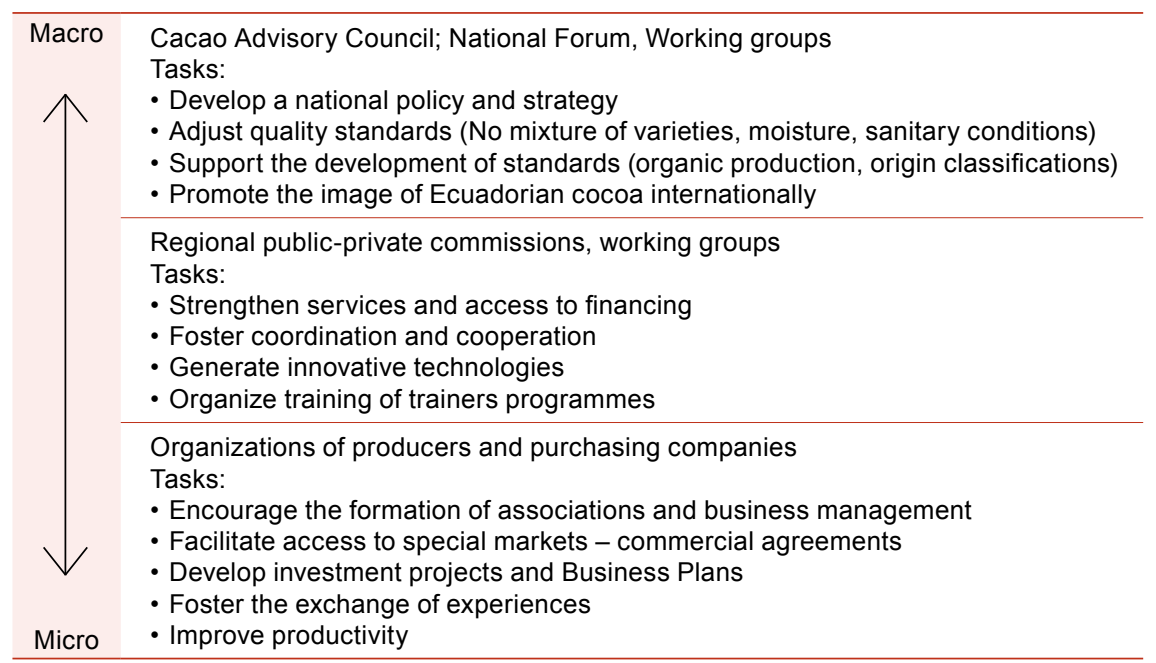

Source: Prepared by the authors, on the basis of information provided by the German Agency for International Cooperation (GIZ). 


\section{F. Impact and lessons learned}

\section{Impacts of value chain promotion}

One dimension of "pro-poor growth" is the aim to increase the total value generated by the value chain, that is, the total volume of business at the end point. At least a part of the additional value added must remain with the smallholders incorporated into the chain. The support measures implemented were aimed at achieving this impact. In order to verify this hypothesis, a results-based model was used, with a causal sequence. The actions and interventions carried out were intended to induce a change in the behaviour of the participants in the chain, who, in turn, would work to improve the functions of the chain, its relationships and the final points of sale in the market. This benefit would mean a more competitive value chain overall, and would translate into more value added and higher overall revenues. Depending on the number of smallholders and their participation in the chain, part of the additional revenues would go to that group as well.

Table VI.7

Results (impact) model designed by GIZ to promote value chains, including monitoring indicators, 2003

\begin{tabular}{|c|c|c|}
\hline Stages & Levels of impact & Indicators \\
\hline $\begin{array}{l}\text { Indirect } \\
\text { impact }\end{array}$ & - Poverty reduction & $\begin{array}{l}\text { Wealth/poverty status of smallholders } \\
\text { and the surrounding economic and } \\
\text { social conditions }\end{array}$ \\
\hline Impact & $\begin{array}{l}\text { - Additional income for operators } \\
\text { and smallholders } \\
\text { - Greater value added }\end{array}$ & $\begin{array}{l}\text { Modification in the incomes received } \\
\text { by smallholders }\end{array}$ \\
\hline Benefit & $\begin{array}{l}\text { - A more competitive value chain } \\
\text { - Improved technology, linkages, } \\
\text { horizontal cooperation, standards, } \\
\text { service agreements, etc. } \\
\text { - More producers integrated in the chain }\end{array}$ & Increase in business volume \\
\hline $\begin{array}{l}\text { Use of } \\
\text { services }\end{array}$ & $\begin{array}{l}\text { The operators within the chain are } \\
\text { taking steps to upgrade the } \\
\text { value chain }\end{array}$ & $\begin{array}{l}\text { Increased production volumes } \\
\text { Improved quality } \\
\text { Access to new markets } \\
\text { Product diversification }\end{array}$ \\
\hline Services & $\begin{array}{l}\text { - Promoting value chains by } \\
\text { implementing support projects }\end{array}$ & $\begin{array}{l}\text { Degree of fulfilment of GIZ plan } \\
\text { of action }\end{array}$ \\
\hline
\end{tabular}

Source: Prepared by the authors, on the basis of information provided by the German Agency for International Cooperation (GIZ).

The results model was complemented with a series of quantitative and qualitative indicators which could be measured easily and frequently by GIZ and its partners, so as to monitor changes along the value chain. The information on the development of each initiative was provided on a quarterly basis to GIZ. 
Table VI.8

Impacts on the competitiveness of the KALLARI value chain, 2006-2011

\begin{tabular}{ll}
\hline Indicator & Change observed \\
\hline Number of members & 2006: 1,214 members \\
& 2011: 2,150 members \\
\hline Sales volume & 2006: 27 metric tons \\
& 2011: 101 metric tons \\
\hline Export price & 2006: US $\$ 90$ per quintal of conventional cacao \\
& 2011: US\$ 195 per quintal of certified cacao \\
\hline Type and number of markets accessed & 2006: Export market for cocoa beans (1 customer) \\
Type and number of markets accessed & 2011: Export market for cocoa beans (3 customers) \\
\hline
\end{tabular}

Source: German Agency for International Cooperation (GIZ), "Study of the impacts of value chain promotion on associations of producers in Napo", KALLARI case study, 2011.

On the other hand GIZ monitored the national figures for the cocoa value chain. Between 2003 and 2012, Ecuador has managed to develop its sales to the international markets and almost duplicate the export volume to up to 190,000 metric tons in 2011, as shown in figure VI.1. With its policy towards the promotion of its high quality "cacao nacional", Ecuador has been able to expand its marketing strategy and benefit from the speciality markets.

Figure VI.1

Total cocoa exports, 2004-2011

(Metric tons)

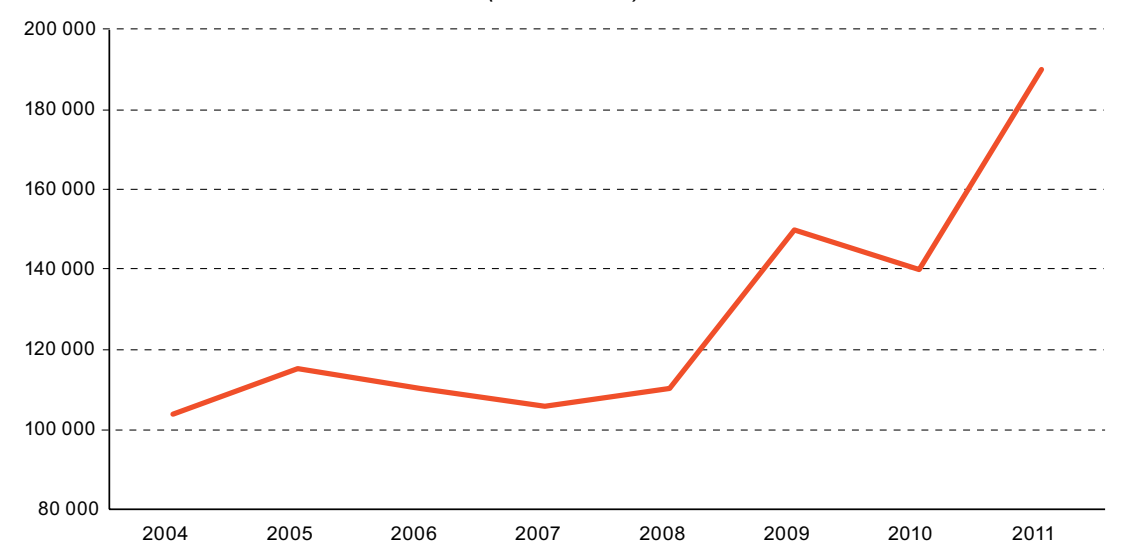

Source: Association of Cacao Exporters of Ecuador (ANECACAO), 2013, [on-line] http://www.anecacao.com.

The impact assessment has been complemented with case studies, which have also verified the fact that the smallholders participating in the GIZ support programmes have managed to stay integrated into the value chains over time, and that their commercial relationships, and consequently their options for placing their product on the market, had expanded. 
Table VI.9

Impacts of the promotion of the special cacao value chain, at the level of small cacao farmers, in selected cases

(Dollars)

\begin{tabular}{|c|c|c|c|}
\hline $\begin{array}{l}\text { Smallholder } \\
\text { association }\end{array}$ & Type of income & Participating producer & $\begin{array}{l}\text { Non-participating } \\
\text { producer }\end{array}$ \\
\hline \multirow[t]{2}{*}{ KALLARI } & Cocoa income & $\begin{array}{l}\text { 2006: US\$ 151/hectare } \\
\text { 2010: US\$ 473/hectare }\end{array}$ & 2010: US\$137/farm \\
\hline & Other agricultural income & US\$2,097/farm & US\$ 1,242/farm \\
\hline \multirow[t]{2}{*}{ APROCANE } & Cocoa income & $\begin{array}{l}\text { 2006: US\$ } 116 / \text { hectare } \\
\text { 2010: US\$ } 457 / \text { hectare }\end{array}$ & 2010: US\$33/farm \\
\hline & Other agricultural income & US\$ 3,696/farm & US $\$ 2,004 /$ farm \\
\hline \multirow[t]{2}{*}{ FONMSOEAM } & Cocoa income & $\begin{array}{l}\text { 2006: US\$ } 750 / \text { hectare } \\
\text { 2010: US\$ 499/ hectare }\end{array}$ & 2010: US\$344/ farm \\
\hline & Other agricultural income & US\$ 3,975/farm & US\$1,913/farm \\
\hline
\end{tabular}

Source: German Agency for International Cooperation (GIZ), "Study of the impacts of value chain promotion through associations of producers in Esmeraldas and Napo", 2011.

\section{Lessons learned}

Based on the GIZ experience in Ecuador, the following lessons learned have been developed. They can be used as recommendations and inputs for similar supportive processes in other regions or with other products:

- When value chains show insufficient competitiveness, which often happens when small holders are participating in them, an orientation to niche markets, can help to bridge the higher production costs. However, the orientation to "quality" also means new additional costs such as the implementation of new technologies or the acquisition of new equipment, as well as possible certifications of processes and product.

- The strategy of differentiating the product towards speciality markets, without a closed definition of the term "differentiation", has made it possible to learn along the way and take advantage of new opportunities emerging within the market itself. The constant key factor was quality, and the value chain took advantage of niches such as the market for certified products, but also certification of origin and linkages to unique and different forms of production.

- In order to ensure the sustainability of the process, sufficient attention must be paid to defining the characteristics to ensure a unique and original product. This task cannot be approached from the supply side only; actors who are close to the market should be incorporated in these activities. Parameters such as appearance, flavour or the final packaging of the product are 
taken into account by the consumer; however the proposed sales effort goes beyond those elements and involves presenting attributes such as the origin of the product, characteristics of the production area, production systems, and recognition of the population and/or related ethnicities.

- Identifying the product and the market requires a careful and detailed analysis. This analysis can establish the requirements that must be fulfilled further up the chain. Also, having a secured market access strategy motivates collaborating actors to implement the supportive measures.

- In short value chains, processors, importers or distributors are interested in direct relationships with suppliers. A buyer's interest may be whetted by a product's identified potential. Developing a chain based on a secure market will result in more efficient efforts and better decision-making about the interventions to be implemented along the chain. Also, buyers are often willing to support the investments necessary to facilitate market access.

- A market operation can be started with minimal volumes. Buyers are willing to work with the producers to develop a value chain. However, it must be clear for all participants once the market is secured that it will be necessary to increase volumes significantly, while maintaining product quality. This will often entail investments in equipment, infrastructure and technical personnel, which must be planned from the beginning of the project. Growth in sales volumes is essential for guaranteeing the sustainability of the business not only for the buyers but especially for the producers, who should be able to continue the process while covering production costs and ensuring that the commercial enterprise is profitable.

- The definition of clear roles and functions for the participants in the value chain and the participation of GIZ as a facilitator of the process helped the chain to operate "naturally" and to ensure the sustainability of the process and its results (impacts), and also allowed GIZ to exit without subsequent "gaps" caused by its absence.

- The incorporation of the private sector (through PPPs) allowed fast and visible results over the short term. These positive experiences made it possible to leverage long-term measures without losing the motivation and engagement of the participants. 


\section{Bibliography}

CORPEI/GIZ (Corporation for the Promotion of Exports and Investment/German Agency for International Cooperation) (2007), “Technical advance report: improvement of Ecuadorian national cocoa exports to Germany, through measures to assure quality", Quito.

Demenus, W. and P. Crespo (eds.) (2011), "Cadenas productivas y desarrollo económico rural en Latinoamérica", Quito, Ecuadorian Consortium of Provincial Councils (CONCOPE).

FIBL/IFOAM (Research Institute of Organic Agriculture/International Federation of Organic Agriculture Movements) (2011), The World of Organic Agriculture. Statistis and Emerging Trends, Bonn.

First National Cocoa Forum (2004), "Política y estrategia de competitividad de la cadena de cacao", unpublished.

GIZ (German Agency for International Cooperation) (2011a), “Fomento de la cadena de valor de cacao en organizaciones de pequeños productores de esmeraldas y napo. Análisis de impactos del programa GESOREN - GIZ", Serie Estudios de Impacto, Quito.

(2011b), "La mesa del cacao fino de aroma de la Reserva de Biosfera Sumaco. Análisis de impactos del Programa GESOREN - GIZ", Serie Estudios de Impacto, Quito. (2009), "ValueLinks Manual", Eschborn, Germany.

(2005), "Base de datos de organizaciones cacaoteras atendidas por GIZ", Quito. (2004), "La cadena de cacao orgánico en el Ecuador. Avances del proceso de desarrollo", PowerPoint presentation.

INEC (National Statistics and Census Institute) (2010) [online] www.inec.gob.ec.

Lehmann, S. and J. Flores (eds.) (2012), “Cooperación con el sector privado en el área prioritaria Protección del Medio Ambiente y los Recursos Naturales", Quito, Deutsche Gesellschaft für Internationale Zusammenarbeit (GIZ).

PROECUADOR (Institute for the Promotion of Exports and Investments) (2011), "Análisis sectorial de cacao y elaborados", Quito.

Quingaísa, E. (2007), "Estudio de caso: Denominación de origen "Cacao Arriba", Quito, United Nations Food and Agriculture Organization (FAO)/InterAmerican Institute for Cooperation on Agriculture (IICA).

Radi, C. (2005), "Estudio sobre los mercados de valor para el cacao nacional de origen y con certificaciones", German Agency for Technical Cooperation (GTZ)/Corporation for the Promotion of Exports and Investment (CORPEI).

Radi, C. and P. Ramírez (2005), "El abc para la comercialización directa de cacao especial y con certificación", German Agency for Technical Cooperation (GTZ)/ Corporation for the Promotion of Exports and Investment (CORPEI)/Northern Border Development Unit (UDENOR) / AMAZNOR.

Specialty Food Association (n/d) [online] https:/ /www.specialtyfood.com/.

Tropical Commodity Coalition (2010), "Sweetness follows. Guía para logar un sector de cacao sostenible".

\section{Weblinks}

http:/ / www.unocace.com/

http://www.gesoren.org.ec

http://www.anecacao.com. 

Chapter VII

\section{Brazilian production sharing and implications for production integration in South America}

Marco Kamiya

\section{Introduction}

Internationalization of production has been one of the main features of the global economy since the early 1990s, propelled by globalization of finance, better communication technologies and more efficient transport logistics. Production has evolved from an intra-firm activity to a crossborder process with different companies and countries involved. This trend has been particularly evident in East Asia and China in the past two decades with that region becoming one of the main hubs for global outsourcing and production networks in electronics, vehicles, and machinery industries, in which Japanese, European and American companies play a dominant role.

Global production networks, developed thanks to lower transport costs, advances in information technologies and communications, and improved infrastructure, which have reduced transaction costs worldwide, allow companies to arbitrage production and processes across countries and regions to margins allowed by distance over costs. Krugman (1995) defined four new aspects of modern world trade: the rise of intra-trade, or trade in similar products between countries; the emergence of super- 
trader countries with high trade-to-gross domestic product (GDP) ratios; the large exports of manufactured goods from low wage to high wage nations; and the slice-up of the value chain. The "slicing up of the value chain" is a remarkable feature and good news for developing countries, since the latter can be part of global value chains by choosing process and components and progressively becoming leaders of those segments, extending capacities through closer proximity of the process, and accelerating industrial upgrading and development.

The slicing up of the value chain occurs to different extents in all manufacturing sectors, but it is in the automotive industry and in electronics that vertical specialization is most evident. The automotive industry is made up of a network of suppliers dispersed among regional and worldwide producers with leading companies from the United States, Japan and Europe. Similarly, the electronics industry is organized by assemblers who manufacture goods by bringing together complex and simple components, most of which are stand-alone products. Both the automotive and the electronic industry are composed of parts and components that may be divided into production time frames and physical stages. As countries develop, the integration of developing countries into vertical specialized global value chains will continue in East Asia and China, Latin America and Africa, with the speed of integration defined by national strategies and firms' competitiveness. This study focuses on several practical developments in international production observed in Latin America and overseas: One of them is the extent of Brazil's involvement in production sharing. Brazilian companies are strengthening their position overseas, with multinational corporations competing in leading technologies and products, as is the case of Empresa Brasileira de Aeronáutica (Embraer) in the aircraft industry, Empresa Brasileira de Pesquisa Agropecuária (Embrapa) in agriculture processing businesses, Marco Polo in transport vehicles, as well as dozens of other major global players. However, Brazilian multinationals are not necessarily equivalent to more integration with global production networks, so one of the purposes of this study is to investigate the existence and magnitude of Brazil's production networks in South America and its contribution to industrialization and development. The second is the emergence of Brazilian multinationals, known as Multilatinas (Santiso, 2008; IDB, 2009). The ascent of competitive regional and global Latin American firms not only from Brazil but also from Mexico and other larger countries in the region sets the background for production integration and cooperation.

This chapter proceeds as follows: first, it discusses previous empirical work on quantification of production sharing, reviewing studies done on Brazil and describing the data available; second, trade in parts and components $(\mathrm{P} \& \mathrm{C})$ in the manufacturing industry is observed, with the 
focus on the electronics, automotive and aircraft industries; third it applies methodologies to quantify the magnitude and direction of Brazil-led production sharing using input-output matrix tables and trade statistics; and fourth, results and policy implications are presented.

\section{A. The state of theories and findings}

Production networks are variously described as systems whereby an industry transfers production processes of components overseas, imports back to the country or exports to a third-party country other than that in which the final good was assembled. Kimura and Ando (2005), Ng and Yeats (2005) and Nordas (2005) call this process production sharing; Feenstra and Hanson (1996) defined it as global production sharing; Hummels, Ishii and Yi (2001) refer to vertical integration.

These are similar ways of describing the phenomenon of global production process but with slight differences: a production network is defined as a system of production occurring in specific industries, such as vehicles or electronics, where the value chain is divided up between different countries on the basis of cost and efficiency. Production sharing is defined as the internationalization of production manufacturing with several countries participating in the different stages, producing parts and components of the final good based on comparative advantage. The term "production network" describes a value chain in an industrial sector and the concept is more related to industrial organization, as it deals with global value chains and global production networks, ${ }_{1}^{1}$ whereas vertical specialization and production sharing conjures up a macroeconomic framework. Other related definitions are 'fragmentation', denoting the dispersion of production processes as opposed to 'agglomeration', which evokes the physical proximity of different production processes. Industry arm's length outsourcing and offshoring are frequently used to describe production sharing, but there are some differences, since production sharing occurs between firms within developed countries or, to some extent, incorporates middle and emerging economies such as Brazil or China, but outsourcing is subcontracting of a service, which can be the design or production of a component, or other divisible task, to a third company which may be located within national borders, whereas offshoring is outsourcing the process overseas.

This apparently subtle difference between production sharing, outsourcing, and offshoring is extremely important from the perspective of a developing country. Production sharing occurs between firms in

See for example Yusuf, Anjum, Nabeshima (2004), Gereffi and M. Korzeniewics (1994) and Sturgeon (2006). 
developed or middle-income countries involving complex manufacturing such as machinery, electronics or vehicles, which are sectors that can be divided into processes, where each process produces a different component. Outsourcing can be done in simpler industries such as textiles, assembly of less complex goods such as personal computers or small home electronic appliances, furniture, or in services like phone assistance services, or even accounting. When outsourcing is done overseas, it is called offshoring.

As several authors have noted, production sharing and outsourcing are good news for developing countries, since specializing in a production niche or service enables them to integrate into international production networks without mastering the entire value chain of highly complex industries. Industrial leapfrogging, the progressive qualitative development of industrial capabilities, is also possible, as shown by Asian countries such as the Republic of Korea, Singapore, and Taiwan Province of China, or the most recent cases of China, Indonesia, Malaysia and Thailand. Although domestic market size is central, country size is not an overwhelming constraint to development since smaller countries or subnational regions and states can participate in international production networks by contributing to production sharing in specific components or services. For instance, a small but efficient country like Chile will find it difficult to develop a car industry overnight, but trade agreements and integration can make it attractive for local producers to specialize in components and services and, from that vantage point, it may become a major provider of specific industrial parts or inputs; later, Chilean companies may find it efficient to outsource processes to third-party neighbouring countries which may follow the same path.

The emergence of outsourcing in recent years, particularly in Asia, with the predominance of production of manufactured goods in China and East Asia and services in India, has changed the pattern of production and international trade. Several authors have found evidence of higher production sharing; for instance Hummels, Ishii and Yi (2001) estimate that production sharing accounted for more than one-third of world export growth between 1970 and 1995. Ng and Yeats (2005) reported that Asian exports increased more than fivefold between 1984 and 1996, with total exports tripling in the same period. Offshoring has grown in other regions; Mexico, for example, is a case in point with active manufacturing trade with the United States and Canada since the establishment of the North American Free Trade Agreement (NAFTA). In Latin America, special trade zones have been a major driver of outsourcing; Yeats (1998) states that "more than $40 \%$ of manufactured exports from the Dominican Republic, El Salvador, Haiti, Jamaica, and Mexico involve assembly operations using components manufactured abroad". 
These new developments in production networks and trade demand new theoretical frameworks. Suh states that with the accelerated growth of China and East Asia, the flying geese model, the classic Japanese model for regional cooperation and industrial development no longer seems appropriate for the new millennium (Suh, 2007, p. 247). Ando and Kimura go further, declaring that production fragmentation has outdated diverse theories: Ricardo's classic comparative advantage framework, the Heckscher-Ohlin model for North-South trade, the export platform argument, and the type of industrial promotion advocated by Japan's Ministry of Industry, Trade and Integration, as well as the flying geese pattern, of which it is stated: "the flying geese pattern argument cannot be applied anymore to recent international location patterns of manufacturing sectors in the sense that they are now dominated by more subtle production-process-location patterns, not by industry-by-industry location patterns" (Ando and Kimura, 2007, p. 3).

Recent efforts have been devoted to constructing new frameworks. See Jones and Kierzkowski (1990), ${ }^{2}$ followed by Arndt and Kierzkowski (2001), and Cheng and Kierzkowski (2001), which incorporate 'fragmentation' into the Heckscher-Ohlin model. In these models, increasing economies of scale determine the degree of division of labour with lower levels of production processes locally integrated in a physical way; then, when output increases, production is vertically fragmented and if gains in efficiency and productivity outweigh transport and logistics costs, production processes can be distributed according to productivity of labour with labour-intensive processes installed in lower-cost regions or countries, and capital-intensive segments in more advanced regions. ${ }^{3}$

Higher production sharing, fragmented vertical specialization and production networks that defy traditional trade models have implications that go further than theoretical discussions; although not the main aim of this paper, it is interesting to have a brief look at their repercussions on trade, growth and development. In terms of trade policies, if production sharing is widespread in a particular economy, tariff, monetary and trade policies are directly affected; for example, if a particular currency

For the diagram on costs and fragmentation, see Jones and Kierzkowski (1990). For application of Jones and Kierzkowski's framework to Singapore see Hoon and Ho (2001); for application to Brazil see appendix 5.

3 A related line of discussion is fragmentation versus agglomeration with a naturally created group of industries, suppliers and providers in one geographical setting. The original formulation was made by Alfred Marshall with his concept of "industrial districts", a phenomenon observed in Britain during the industrial revolution. Michael Porter extended the concept and applied it to management and microeconomic development with his definition of clusters, and in geography and economics, and the concept was expanded by Krugman, Venables, and others to describe agglomeration as a spatial concentration of economic and industrial activity. 
is devalued to promote exports, firms may decide to relocate overseas, or to increase production of components in the domestic market, ship them overseas and reimport them as finished products. As regards development policies, if the traditional flying geese, Japanese-type of development is no longer applicable, then an immediate effect of production sharing is to support those industries that are competitive and leaders in production of specific components; thus, depending on the country's particular industrial network, integration in a value chain will be prioritized over industry-wide supporting policies. With respect to investment policies, developing countries with relative strength in certain components may promote investment in related fields to allow domestic companies to build capacities in those niches instead of supporting a one-size-fits-all approach to foreign direct investment. These scenarios are examples of the implications of increasing production sharing and deserve further debate supported by empirical and theoretical studies.

Production networks highlight the need to focus on logistics and services rather than on tariff and non-tariff barriers as in the past. In this regard, Jones, Kierzkowski and Chen (2005) propose the concept of "service links" as the key component of international production sharing; they define fragmentation as the separation of "production blocks" through intermediate processes integrated by "service links", which are logistics, transport, communication technologies and others. This point is summarized as follows: "1. The optimal degree of fragmentation depends on the size of the market. Economic growth encourages fragmentation and trade in parts and components, and 2. Lowering of service-link costs promotes fragmentation and outsourcing of output" (Jones, Kierzkowski and Chen, 2005, p. 13). In the past, high costs of communications and logistics and limited numbers of service links constrained production processes predominantly within a nation, but today production is an international activity involving numerous different companies and countries made possible by the "service links", which lower costs and enhance availability.

Better service links are more obvious looking at East Asia and China, and are a necessary experience as a background for this study, where rapid economic integration combines production and distribution networks with several assembling and production centres, in contrast to simple outsourcing as in the maquilas ${ }^{4}$ between the United States and Mexico. Ando and Kimura (2007) propose a "two-dimensional fragmentation model" and highlight three elements that distinguish East Asia from other regions: its significance in each country in the region,

\footnotetext{
4 A maquila is a factory that imports components from a country and assembles or produces final goods for reexport.
} 
extensiveness, and production sophistication. In the two-dimensional fragmentation model proposed by the authors, the central elements are disintegration and distance, where production costs and service links influence the decision to outsource or fragment production on the basis of strong leading companies in the machinery industry, including, in this category, industries with multilayered production processes such as general machinery, electrical machinery, transport equipment and precision machinery. The machinery industry is highly dominated by Japanese companies, which have an integrated production hub in East Asia; thus, although the two dimensional model is descriptive, it highlights three important elements of production fragmentation: first, a group of companies with a clear competitive edge allowing demand and nurturing of a suppliers' network; second, the capacity to invest overseas; and third, proximity to integrated markets, in this case in East Asia.

The expansion of international production sharing is undeniable in East Asia and China but is not limited to that region. This demands new interpretation frameworks as global production processes become more complex and challenge traditional theories of trade and integration. With the lowering of tariffs, multiplication of trade agreements and fewer non-tariff barriers, trade is becoming more dependent on time and distance, so what clearly emerges is the importance of factor costs in the form of "service links" with technological innovation in communications, transport logistics and distribution, lowering transaction costs of production sharing and outsourcing, and geography becoming a more important factor of trade. From the perspective of developing countries, policies that improve the business climate are paramount, along with trade agreements and regional integration.

\section{B. Measuring production sharing}

Proper quantification of the magnitude of production sharing is essential to provide appropriate and relevant support for businesses in specific industries, since such policies depend on understanding the global value chain and its interaction with local production networks. Policies to promote foreign direct investment or exports also require an understanding of global production trends and the level of competiveness of local producers; indeed, production sharing has an immediate effect on macroeconomic and monetary policies, while the success of monetary policies in encouraging exports depends on the degree of production sharing or outsourcing which production centres of overseas companies can arbitrage between locations, thus avoiding a rise exchange rates. 
The measurement of vertical specialization is also critical because the impact of production sharing is not uniform across countries and industries. Production sharing is an unquestionable global trend as attested by several studies (Yi, 2003; and Yeats 2001), but the process is not homogeneous for all countries and manufacturing industries (Nordas, 2005), so there are several questions awaiting proper answers: What is the effect of production integration on small countries, on developing countries? Can countries specialized in primary products plan integration into global manufacturing networks? How is fragmentation affecting countries like Brazil, and how will what occurs with Brazil impact other countries in South America? The list is extensive and signals the need to understand production sharing and the importance of having reliable and accurate statistics.

An ideal set of indicators on production sharing should account for the following patterns; offshoring, vertical integration of firms, vertical specialization of countries, local and regional outsourcing by multinational companies, procurement of parts and components by foreign firms from locally based companies, supply of components from smaller companies to foreign affiliates and others. Measurement of production sharing should account for possible trade 'distortions', for example, parts imported by a country and exported with minimum or zero processing, separation between production integration and production sharing if the parts and components are simply being assembled rather than produced and built, and re-exported overseas. Two major sets of data are needed for an in-depth understanding of production and sharing. First a statistical database of imports and exports, highly disaggregated, indicating at each stage of disaggregation the goods' final use, further classified by exports, imports and re-exports; second, the international value chain of products, with value chains of machinery industries providing sufficient detail to explain the quantitative underpinning of the production processes. Unfortunately, those indicators are not available, and although this may become a quantitative research agenda, we have to rely on the information available.

Production sharing and production fragmentation in Brazil may be measured in two ways: by using input-output (IO) tables or by using tables with trade data. Input-output tables are limited in terms of periodicity and comparability, but in recent years, they have become more reliable and extensive. The Organization for Economic Cooperation and Development (OECD) produces IO tables for its 29 members, including Mexico, and 11 non-member countries, including Brazil and Argentina in Latin America, making it possible to compare across countries. In Brazil, the Brazilian Institute of Geography and Statistics (IBGE), also produces 
the basis of IO tables every three years and these tables, which cover 12 economic activities and 12 products, are currently available for 1995, 2000 and 2005.

Trade statistics are another source of information. The Standard International Trade Classification (SITC) is an official compilation offering disaggregated export/import data, including data on parts and components. The broad economic categories (BEC) classification is also available with products organized into primary and manufactured, distinguishing between capital, intermediate and consumer goods. Brazil is included in SITC, which is currently in Revision 4, but to make comparisons between Latin America countries or over periods of time, Rev 2 or Rev 3 must be used, since not all countries supply information to that level of disaggregation.

Several indices have been formulated to measure production fragmentation, and among the most commonly used are: Feenstra and Hanson (1996), who compute outsourcing and offshoring; Yeats (2001) for international production fragmentation, computing imported inputs over total imports; Grubel and Lloyd (1975), who measure balanced trade flows to total trade, which, despite criticism, is one of the most widely used in different variations to measure inter-industry trade; Campa and Goldberg (1997) estimate import and export exposure to determine the impact of exchange rates on employment, using IO tables instead of trade statistics, which is useful if complete IO tables are available. The different methodologies and refinements indicate the difficulties in definition and in obtaining data concerning the magnitude of production sharing. For an extensive assessment of methodologies and evolution, see Formentini and Iapadre (2008), who explain the different indicators with drawbacks and data requirements. ${ }^{5}$

In Latin America, including Brazil, recent studies have analysed production networks. Fung, Garcia-Herrero and Siu (2009) use trade data in parts and components $(\mathrm{P} \& \mathrm{C})$ to compare production sharing in East Asia and Latin America; they have found a dense network of P\&C between NAFTA agreement members of the United States, Mexico and Canada, with Brazil playing a part. Kimura and Ando

Comparative studies between Asia and Europe and Latin America are so far insufficient, but show different characteristics in Europe, where agglomeration is more common than fragmentation, Hayakawa, Ji and Obashi (2011) and Kimura, Takahashi and Hayakawa (2005). There are several studies focusing on production networks in Asia, in China and Japan. See Athukorala (2003), Athukorala and Yamashita (2006), Kimura and Obashi (2009) for a comparison of production networks in China and East Asia; Kimura, Takahashi and Hayakawa (2005) for analysis of the car industry in Asia; Ando and Kimura (2007) on trade and fragmentation in East Asia; Ando (2006) on vertical intra-industry production integration in East Asia; and Urata (2006) on evolving patterns of trade in East Asia. 
(2003) work with Japanese industrial surveys to analyse the behaviour of Japanese multinationals, comparing East Asia and Latin America, observing a well-developed machinery production network in East Asia in contrast with immature machinery networks in Latin America. Fragmentation and trade links in the motor industry in Brazil and Argentina are analysed by Calfat and others (2008), who find that Brazil has consolidated its presence in a few global value chains on a North-South trade pattern. Nordas (2005) includes Brazil in a group of major countries where the uneven nature of vertical specialization in the electronics and vehicle industries is observed. She concludes that Brazil's trend in vertical specialization has been uneven. Moreno and Posada (2007) refine standard indices to analyse the intra-industry trade of Colombia with neighbouring countries, finding that vertical intraindustrial trade is dominant and determined by levels of industrial development instead of proximity. Despite those initial efforts, research on production sharing and vertical specialization in Brazil and Latin America is still in a basic state, and more analysis and policy-oriented studies are needed.

Production sharing in Brazil is examined in the next section using available data taken from both trade statistics and input output tables. The possibilities and limitations will be assessed on the basis of a review of recent studies that measure vertical specialization in the region, after which some methodologies focusing on Brazil will be applied.

\section{Trade and production sharing}

This section aims to quantify production sharing in Brazil. This will be done for the machinery industry, defined as electronics, aircraft, vehicles, and light and complex manufacturing. Trade in parts and components (P\&C) will be observed in order to understand its magnitude in comparison with other regions and within South America. The following methodologies will be applied:

- Value of P\&C in imports and exports: This will provide insight into trade trends between Brazil and partners within and outside the region.

- The Campa and Goldberg index will be applied with inputoutput table data to identify similarities and differences.

- The revealed comparative advantage (RCA) will indicate the industries where Brazil has an advantage or disadvantage in assembly operations. 
The debate on the definition of production sharing and its different classifications and coverage is an on-going process, and fuzziness is reflected in the data and indices, so there are several studies focusing on small additions or changes in indicators, resulting in subtle, marginal differences in magnitude. In future studies, it will be much more important to focus on the parameters that affect production sharing and outsourcing, and this section seeks only to obtain an accurate magnitude of production sharing in Brazil with the data and traditional methods available, indicating their advantages and limitations.

\section{The context}

Brazil has been steadily growing by more than $5 \%$ over the past ten years, and the strong performance is explained by gains in trade and domestic investment, but the economy is not only based on primary products: services account for $65 \%$, industry for $28 \%$ and agriculture for $6.7 \%$. In manufacturing, Brazil possesses a wide range of industries, ranging from textiles, shoes, chemicals, cement, lumber, metals and steel, to machinery industries and equipment like aircraft, motor vehicles and parts, other machinery and equipment. Brazil has a strong automotive industry, which produces small passenger cars for the local market. Foreign producers play a prominent role since almost all the major car makers from the United States, Japan and Europe have assembly plants in Brazil and therefore foreign direct investment (FDI) in the automotive sector is significant, with almost a quarter of total FDI in manufacturing in the last ten years related to the vehicle industry. In the electronics industry, although production has slowed in the past decade, it is still one of the most dynamic, with leading multinationals established in the country; the electronics industry accounts for almost $10 \%$ of total FDI in manufacturing.

Brazilian trade has experienced marked growth attributable to gains in productivity and higher commodity prices. In 2008, Brazil's total exports were almost US\$ 190 billion, more than three times the US\$ 59 billion of 2000. Brazil's top exporting and importing countries are shown in table VII.1. The leading trading partners are the United States, Argentina and China, which account for almost $40 \%$ of total Brazilian export and import trade, whereas with most South American countries Brazilian exports exceed imports, as in the case of Argentina, Bolivarian Republic of Venezuela and Chile. Commodity prices have been rising steadily since 2003, when Lula da Silva was elected President, and the Brazilian real has appreciated more than $70 \%$ against the United States dollar, producing a trade surplus, which, although it has harmed exporters of manufactured goods, has not prevented exports of primary products from leading the trend. 
Table VII.1

Brazil: top import and export countries in 2008

\begin{tabular}{|c|c|c|c|c|c|c|c|}
\hline \multicolumn{4}{|c|}{ Brazil: trade with world } & \multicolumn{4}{|c|}{ Brazil: trade with Latin America $^{a}$} \\
\hline \multicolumn{2}{|c|}{ Exports } & \multicolumn{2}{|c|}{ Imports } & \multicolumn{2}{|c|}{ Exports } & \multicolumn{2}{|c|}{ Imports } \\
\hline $\begin{array}{l}\text { United States } \\
\text { of America }\end{array}$ & $14.0 \%$ & $\begin{array}{l}\text { United Stat } \\
\text { of America }\end{array}$ & $14.9 \%$ & Argentina & $8.9 \%$ & Argentina & $7.7 \%$ \\
\hline Argentina & $8.9 \%$ & China & $11.6 \%$ & $\begin{array}{l}\text { Venezuela } \\
\text { (Bolivarian } \\
\text { Republic of) }\end{array}$ & $2.6 \%$ & Chile & $2.4 \%$ \\
\hline China & $8.3 \%$ & Argentina & $7.7 \%$ & Chile & $2.4 \%$ & Bolivia & $1.7 \%$ \\
\hline Netherlands & $5.3 \%$ & Germany & $6.9 \%$ & Paraguay & $1.3 \%$ & Uruguay & $0.6 \%$ \\
\hline Germany & $4.5 \%$ & Japan & $3.9 \%$ & Peru & $1.2 \%$ & Peru & $0.6 \%$ \\
\hline Japan & $3.1 \%$ & Nigeria & $3.9 \%$ & Colombia & $1.2 \%$ & Colombia & $0.5 \%$ \\
\hline $\begin{array}{l}\text { Venezuela } \\
\text { (Bolivarian } \\
\text { Republic of) }\end{array}$ & $2.6 \%$ & $\begin{array}{l}\text { Republic } \\
\text { of Korea }\end{array}$ & $3.1 \%$ & Uruguay & $0.8 \%$ & Paraguay & $0.4 \%$ \\
\hline Chile & $2.4 \%$ & France & $2.7 \%$ & $\begin{array}{l}\text { Bolivia } \\
\text { (Plurinational } \\
\text { State of) }\end{array}$ & $0.6 \%$ & $\begin{array}{l}\text { Venezuela } \\
\text { (Bolivarian } \\
\text { Republic of) }\end{array}$ & $0.3 \%$ \\
\hline Italy & $2.4 \%$ & Italy & $2.7 \%$ & Ecuador & $0.4 \%$ & Ecuador & $<0.0 \%$ \\
\hline $\begin{array}{l}\text { Russian } \\
\text { Federation }\end{array}$ & $2.4 \%$ & Chile & $2.4 \%$ & & & & \\
\hline
\end{tabular}

Source: International Trade Centre (INTRACEN) http://www.intracen.org/.

a As percentage of the world total.

In Latin America, $8.9 \%$ of Brazilian exports are shipped to Argentina, followed by almost equal amounts to the Bolivarian Republic of Venezuela $(2.6 \%)$ and Chile $(2.4 \%)$. For imports, Brazil main partners in the region are Argentina with a significant $7.7 \%$ of total Brazilian imports, followed by Chile at $2.4 \%$ and the Plurinational State of Bolivia at $1.7 \%$. Overall, the United States is Brazil's main trading partner, and in South America, Argentina is the most important. Aggregate trade data must be analysed to examine trade in intermediate products that are used to produce final products; this is done in the following subsection.

\section{Trade in parts and components}

A straightforward way to estimate production sharing is to quantify imports and exports of parts and components (P\&C). The most recent Standard International Trade Classification (SITC), Revision 4 (Rev.4), approved by the United Nations in 2006 follows the previous revisions 2 and 3 in classification of goods, making it possible to distinguish between parts and components for broad sectors. In Rev.4, goods are classified into nine broad categories supplemented by two appendices that include gold and related items, each section being divided into groups, subgroups and basic headings, comprising a total of 2,970 products. Section 7 covers machinery and transport products, and 
Section 8 miscellaneous manufacturing articles; in both sections, the subgroups and headings include parts and components. The items labelled "parts" comprise approximately $10 \%$ of the total items and the information is far from perfect since other final products are components of larger items; however, this is the most organized data available and Rev. 4 is available for Brazil.

Table VII.2 lists the ten major products classified by share of $P \& C$ item over total $P \& C$ value for imports and exports. Brazilian trade in $\mathrm{P} \& \mathrm{C}$ is concentrated in a few goods, in terms of imported parts of telecommunications equipment (SITC 764.18) is $11.719 \%$, automobile P\&C (SITC 784.39, SITC 784.34, SITC 784.32, SITC 713.91) account for $10.334 \%$, whereas other electronics (SITC 764.93, SITC 759.97, SITC 751.97) constitute $18.751 \%$, and aircraft and helicopter parts (SITC 792.95) is 7.639\%. Therefore, the main imports of $\mathrm{P} \& \mathrm{C}$ are in telecommunications, motor vehicles, electronic equipment and aircraft/helicopter components.

Table VII.2

Brazil: imports of parts and components, 2008

\begin{tabular}{|c|c|c|}
\hline & SITC Rev. 4 & $\begin{array}{l}\text { Part/component item over } \\
\text { Part/component total } \\
\text { (percentages) }\end{array}$ \\
\hline 764.18 & $\begin{array}{l}\text { Parts of telecommunication equipment, accessories and } \\
\text { apparatus for voice, images or other data }\end{array}$ & 11719 \\
\hline 784.39 & $\begin{array}{l}\text { Other parts and accessories of tractors and motor vehicles } \\
\text { for the transport of people and goods }\end{array}$ & 9644 \\
\hline 764.93 & $\begin{array}{l}\text { Parts and accessories suitable for use solely/principally } \\
\text { with apparatus and equipment of monitors and projectors, } \\
\text { reception apparatus, transmission apparatus, radar and } \\
\text { video and digital camera equipment }\end{array}$ & 8440 \\
\hline 792.95 & Other aircraft/helicopter parts & 7639 \\
\hline 759.97 & $\begin{array}{l}\text { Parts and accessories for group office machines and } \\
\text { automatic data processing machines (other than covers, } \\
\text { carrying cases \& the like) }\end{array}$ & 6816 \\
\hline 784.34 & Gearboxes and parts thereof of motor vehicles & 5909 \\
\hline 784.32 & $\begin{array}{l}\text { Other parts and accessories of bodies (including cabs) of } \\
\text { motor vehicles }\end{array}$ & 5315 \\
\hline 714.91 & Parts for turbojets/turbo propellers & 4356 \\
\hline 713.91 & $\begin{array}{l}\text { Parts for the internal combustion piston engines, suitable for } \\
\text { use solely/principally with spark-ignition }\end{array}$ & 3781 \\
\hline 751.97 & $\begin{array}{l}\text { Parts and accessories of office machines (e.g., hectograph } \\
\text { or stencil-duplicating machines, addressing machines, } \\
\text { automatic banknote dispensers, coin-sorting machines, etc.); } \\
\text { other printers, copying machines and facsimile machines } \\
\text { whether or not combined }\end{array}$ & 3495 \\
\hline
\end{tabular}

Source: Prepared by the author, on the basis of the Standard International Trade Classification (SITC) Rev. 4 and data from the United Nations Commodity Trade Statistics Database (COMTRADE). 
Exports in P\&C from Brazil are predominantly automotive-related (SITC 784.39, SITC 713.91, SITC 784.32, SITC 784.33, SITC 784.34, SITC 784.35), accounting for almost $55.242 \%$, followed by other parts of aircraft and helicopters (SITC 792.95) and other electronics (SITC 716.9, SITC 723.99, SITC 728.39 ) $13.538 \%$. Thus, half of the exports in P\&C are automobilerelated, and this provides a first glimpse of Brazilian trade in P\&C.

Table VII.3

Brazil: exports of parts and components, 2008

\begin{tabular}{llc}
\hline & SITC Rev. 4 & $\begin{array}{c}\text { Part/component item over } \\
\text { Part/component total } \\
\text { (percentages) }\end{array}$ \\
\hline 784.39 & $\begin{array}{l}\text { Other parts and accessories of tractors and motor vehicles } \\
\text { for the transport of people and goods }\end{array}$ & 20692 \\
\hline 713.91 & $\begin{array}{l}\text { Parts for internal combustion piston engines, suitable for use } \\
\text { solely/principally with spark-ignition }\end{array}$ & 13886 \\
\hline 716.9 & Parts of rotating electric motors, AC motors, generators, etc. & 8357 \\
\hline 784.32 & $\begin{array}{l}\text { Other parts and accessories of bodies (including cabs) of } \\
\text { motor vehicles }\end{array}$ & 6769 \\
\hline 784.33 & Brakes and servo-brakes and parts thereof of motor vehicles \\
\hline 784.34 & Gearboxes and parts thereof of motor vehicles & 5298 \\
\hline 792.95 & Other parts of aircraft/helicopters & 4608 \\
\hline 784.35 & $\begin{array}{l}\text { Drive-axles with differential, whether or not provided with } \\
\text { other transmission components, and non-driving axles; parts } \\
\text { thereof of motor vehicles }\end{array}$ & 3989 \\
\hline 723.99 & Other parts for construction machinery & 3097 \\
\hline 728.39 & Parts for construction and mining machinery & 2084 \\
\hline
\end{tabular}

Source: Prepared by the author, on the basis of the Standard International Trade Classification (SITC) and data from the United Nations Commodity Trade Statistics Database (COMTRADE).

A number of conclusions can be drawn from these data:

(a) $P \& C$ import data indicate that the three most important manufacturing industries are telecommunication equipment, the automotive sector, electronic equipment and aircraft/ helicopters. This is an indicator of the main manufacturing industries in Brazil for final goods, for the export or local market.

(b) In the case of exports, products are highly concentrated in P\&C for the automotive industry; almost half of all P\&C exports are motor-related items. This may indicate that Brazil is not a leader in the production of final automotive products, but that it possesses a comparative advantage as a producer of $\mathrm{P} \& \mathrm{C}$, mainly in vehicles. 
(c) Product dispersion in imports, but product concentration in exports, meaning more different types of imported products than export goods, point to a diversified manufacturing industry in Brazil, with possible advantages in $P \& C$ items of global value chains, mainly in the automotive industry. The significant export share of other electronics (SITC 716.9, SITC 723.99, SITC 728.39), of over $10 \%$, also signals advantages in producing components for engines, construction and mining machinery.

These initial exercises generate further questions. Trade in $\mathrm{P} \& \mathrm{C}$ alone cannot quantify the ability of the Brazilian manufacturing sector in producing final products in the automotive and electronics sectors. Production and exports of $\mathrm{P} \& \mathrm{C}$ in the automotive industry are important and indicate participation of Brazil in global production networks. However, imports of $\mathrm{P} \& \mathrm{C}$ are not necessarily a sign of strength in the industries involved (electronics, automotive and other machinery equipment), since imports may only be due to obstacles to trade or rules on the domestic production content of components. In the following subsection, the estimates done on $\mathrm{P} \& \mathrm{C}$ are expanded with analysis of final products.

\section{Trade in final manufacturing products}

Exports of final products must be analysed in order to understand whether goods produced locally are for domestic consumption or for shipping overseas. An earlier methodology by Lall, Albaladejo and Zhang (2004), ${ }^{6}$ aimed at measuring competitiveness, is useful for our purposes and is used as a basis for classifying major manufacturing industries; the source of the data, SITC, and Lall, Albaladejo and Zhang (2004), mentioned a number of shortcomings in measuring fragmentation with those data, among them the difficulty in distinguishing "final products" from "parts and components"; P\&C are not separated by final products, so one part or component may be of use in two different industries, and the data do not show stages of production of a given product; moreover, $\mathrm{P} \& \mathrm{C}$ are used not only for fragmented production, but also for domestic-oriented industries or other non-integrated sectors. Most of these limitations still stand, but knowing the deficiencies of production sharing is still a good partial approach to measuring this trend.

The main purpose of Lall, Albaladejo and Zhang (2004) was to quantify competitiveness in manufacturing where the main sectors are electronics and the automotive sector. Although it is not the subject of this study, competitiveness is not constrained to manufacturing, but can also arise from processing of primary products, and this approach is important for Brazil, which is an important supplier of primary products. 
Used in several earlier studies, SITC rev 2 allows comparison between countries and years, since country reporting statistics go back more than 20 years. SITC Revisions 3 and 4 made a considerable effort to separate $\mathrm{P} \& \mathrm{C}$ for a larger range of industries, but results are not available for all countries. In the case of Brazil, SITC Rev 4 is available for year 2008 but not for previous years. Nonetheless, using SITC Rev. 4 for 2008 will help provide an updated snapshot of the manufacturing landscape of Brazil.

The new 'mapping' for the electronics and automotive industries is shown for electronics in table VII.4 and for automobiles and aircraft in table VII.5. Using SITC Rev. 4, the amendments are as follows: office machines and data-processing machines are coupled; household appliances become a separate sector; the column "finished products" is shown with more items and the column P\&C contains more categories. This new classification is consistent with developments in industry and in particular in Brazil, as shown by the data. Household appliances are also an important category in Latin America; electronic equipment in this category goes beyond televisions sets, and is different to telecommunications equipment, as was indirectly shown in SITC Rev.2. "Electrical machinery" deserves to be treated as a sector in its own right given its volume and significance, since it is a source industry composed of products that are key components of other electronic industries. Strictly speaking, electrical machinery as shown in table VII.4 is a P\&C sector and in the same way, "thermionic, cathode and semiconductors" also belong to a key industrial sector that produces components for final goods.

Most of the categories in the column of finished products are subdivided in SITC Rev 4, making it easier to identify components and subcomponents in comparison with previous SITC. P\&C description is also expanded in SITC Rev 4. For the automotive industry in Lall, Albaladejo and Zhang (2004), only automobiles and car engines are included, but in Brazil the rising importance of the aircraft industry needs to be considered and in addition, $\mathrm{P} \& \mathrm{C}$ produced or imported for final automotive products like cars, construction vehicles or motorcycles are also used for aircraft and helicopters. The P\&C listed in table VII.5 are used, directly or indirectly, by the automobile and aircraft industries, whereas car engines are components of automobiles and other similar vehicles. 
Table VII.4

Finished products and parts and components in the electronics industry

\begin{tabular}{|c|c|c|c|}
\hline Main sectors & Finishe & d products & $\begin{array}{c}\text { Parts and } \\
\text { components }\end{array}$ \\
\hline \multirow{9}{*}{$\begin{array}{l}\text { Office machines } \\
\text { and automatic } \\
\text { data-processing } \\
\text { machines }\end{array}$} & 751.1 & Typewriters, word-processing machines & \multirow{9}{*}{$\begin{array}{l}751.97 \\
759.8 \\
759.91 \\
759.93 \\
759.95 \\
759.97\end{array}$} \\
\hline & 751.2 & $\begin{array}{l}\text { Calculating machines, pocket-size data-recording, } \\
\text { accounting machines, cash registers }\end{array}$ & \\
\hline & 751.9 & Office machines & \\
\hline & 752.2 & Portable data-processing machines, n.e.s. & \\
\hline & 752.3 & Other data-processing machines & \\
\hline & 752.6 & Complete digital central processing units & \\
\hline & 752.7 & Storage units & \\
\hline & 752.8 & Other automatic data-processing machines & \\
\hline & 752.9 & Data-processing equipment & \\
\hline \multirow{13}{*}{$\begin{array}{l}\text { Television, } \\
\text { radio broadcast } \\
\text { receivers, sound } \\
\text { reproducing } \\
\text { devices, and } \\
\text { telecom equipment }\end{array}$} & 761.3 & Cathode-ray tube monitors & \multirow{13}{*}{$\begin{array}{l}764.18 \\
764.92 \\
764.93 \\
764.99\end{array}$} \\
\hline & 761.4 & Other monitors & \\
\hline & 761.5 & Projectors & \\
\hline & 761.6 & Reception apparatus for television & \\
\hline & 762.1 & Radio-broadcast receivers & \\
\hline & 762.2 & Radio-broadcast receivers, not needing external power & \\
\hline & 762.8 & Other radio broadcast receivers & \\
\hline & 763.3 & Sound recording or reproducing apparatus & \\
\hline & 763.8 & Video-recording or reproducing apparatus, & \\
\hline & 764.1 & Telephone sets & \\
\hline & 764.2 & Microphones, loudspeakers, headphones, and related & \\
\hline & 763.3 & Transmission apparatus & \\
\hline & 764.8 & Telecommunication equipment & \\
\hline \multirow{8}{*}{$\begin{array}{l}\text { Electrical } \\
\text { machinery }\end{array}$} & 771.1 & Transformers, electrical & \multirow{8}{*}{$\begin{array}{l}771.29 \\
772.38 \\
772.81 \\
772.82\end{array}$} \\
\hline & 772.2 & Printed circuits & \\
\hline & 772.3 & Electrical resistors & \\
\hline & 772.4 & Electrical apparatus for electrical circuits (lower) & \\
\hline & 772.5 & Electrical apparatus for electrical circuits (higher) & \\
\hline & 772.6 & Board, panel, etc. for electrical control of electricity & \\
\hline & 773 & Equipment for distributing electricity & \\
\hline & 774 & Electro-diagnostics apparatus for medical purposes & \\
\hline \multirow{7}{*}{$\begin{array}{l}\text { Household } \\
\text { appliances }\end{array}$} & 775.1 & Laundry machines & \multirow{7}{*}{$\begin{array}{l}775.49 \\
775.57 \\
775.79 \\
775.89 \\
775.98\end{array}$} \\
\hline & 775.2 & Refrigerators and food freezers & \\
\hline & 775.3 & Dishwashing machines & \\
\hline & 775.4 & Shavers and hair clippers & \\
\hline & 775.5 & Vacuum cleaners & \\
\hline & 775.7 & Other electromechanical domestic appliances & \\
\hline & 775.8 & Electrothermic appliances, n.e.s. & \\
\hline \multirow{4}{*}{$\begin{array}{l}\text { Thermionic, } \\
\text { cathode, } \\
\text { semiconductors, } \\
\text { etc. }\end{array}$} & 776.1 & Television picture tubes, cathode-ray & \multirow{4}{*}{$\begin{array}{l}776.29 \\
776.89\end{array}$} \\
\hline & 776.2 & Other electronic valves and tubes & \\
\hline & 776.3 & Diodes, transistors and similar semiconductor devices & \\
\hline & 776.4 & Electronic integrated circuits & \\
\hline
\end{tabular}

Source: Prepared by the author, on the basis of the Standard International Trade Classification (SITC) Rev.4 and data from the United Nations Commodity Trade Statistics Database (COMTRADE). 
Table VII.5

Finished products and parts and components in the automotive and aircraft industries

\begin{tabular}{|c|c|c|}
\hline Main sectors & Finished products & $\begin{array}{l}\text { Parts and } \\
\text { components }\end{array}$ \\
\hline \multirow[t]{7}{*}{ Automobiles } & 781.1 Vehicles for travelling on snow; golf cars & \multirow{7}{*}{$\begin{array}{l}784.31 \\
784.32 \\
784.33 \\
784.34 \\
784.35 \\
784.39 \\
785.35 \\
785.36 \\
785.37 \\
786.89\end{array}$} \\
\hline & 781.2 Motor vehicles for the transport of people, n.e.s. & \\
\hline & 782.1 Motor vehicles for the transport of goods & \\
\hline & 782.2 Special-purpose motor vehicles & \\
\hline & 783.1 Motor vehicles for the transport of ten or more people & \\
\hline & 783.2 Road tractors for semi-trailers & \\
\hline & 785.1 Motorcycles & \\
\hline \multirow[t]{6}{*}{ Aircraft } & 792.1 Helicopters & \multirow{6}{*}{$\begin{array}{l}792.91 \\
792.93 \\
792.95 \\
792.97\end{array}$} \\
\hline & 792.2 Aeroplanes and other aircraft, mechanically-propelled & \\
\hline & 792.3 Aeroplanes and other aircraft (medium size) & \\
\hline & 792.4 Aeroplanes and other aircraft (large) & \\
\hline & 792.5 Spacecraft (including satellites) and spacecraft launch vehicles & \\
\hline & 792.8 Aircraft, n.e.s. & \\
\hline \multirow[t]{2}{*}{ Car engines } & 713.1 Internal combustion piston engines for aircraft & \multirow[t]{2}{*}{713.19} \\
\hline & 713.2 Internal combustion piston engines for propelling vehicles & \\
\hline
\end{tabular}

Source: Prepared by the author, on the basis of the Standard International Trade Classification (SITC) Rev. 4 and data from the United Nations Commodity Trade Statistics Database (COMTRADE).

Exports of final electronic, automotive and aircraft products are shown in table VII.6 and table VII.7, following the above classification of industrial sectors. The data are presented in United States dollars and as a share of the world market. In the electronic sectors, one feature stands out: the rest of South America is an important export destination for Brazil. In the tables, LAS9 (the nine southern Latin American countries) consist of Brazil's main trading partner countries in South America: Argentina, Bolivarian Republic of Venezuela, Chile, Colombia, Ecuador, Paraguay, Peru, Plurinational State of Bolivia and Uruguay; thus, these nine countries provide a picture of trade with neighbouring countries in South America within Brazil's sphere of influence. Mexico is not included, since its trade is related with the United States and Canada, and following the same logic, Central American countries are not considered, but the United States is used to compare relative importance. 
Table VII.6

Brazil: exports of electronics, 2008

\begin{tabular}{|c|c|c|c|}
\hline Industrial sectors & $\begin{array}{l}\text { Destination } \\
\text { market }\end{array}$ & $\begin{array}{c}\text { Value } \\
\text { (millions of dollars) }\end{array}$ & $\begin{array}{l}\text { World market } \\
\text { share }\end{array}$ \\
\hline \multirow{3}{*}{$\begin{array}{l}\text { Office machines and automatic } \\
\text { data-processing machines }\end{array}$} & World & 353.64 & $100 \%$ \\
\hline & United States & 64.34 & $18 \%$ \\
\hline & LAS9 & 201.29 & $57 \%$ \\
\hline \multirow{3}{*}{$\begin{array}{l}\text { Television, radio broadcast } \\
\text { receivers, sound reproducing } \\
\text { devices, and telecom equipment }\end{array}$} & World & 2649.44 & $100 \%$ \\
\hline & United States & 254.07 & $10 \%$ \\
\hline & South America & 2095.74 & $79 \%$ \\
\hline \multirow{3}{*}{$\begin{array}{l}\text { Electrical machinery and household } \\
\text { appliances }\end{array}$} & World & 1378.15 & $100 \%$ \\
\hline & United States & 196.72 & $14 \%$ \\
\hline & LAS9 & 734.39 & $53 \%$ \\
\hline \multirow[t]{3}{*}{ Household appliances } & World & 399.64 & $100 \%$ \\
\hline & United States & 10.83 & $3 \%$ \\
\hline & South America & 273.88 & $69 \%$ \\
\hline \multirow{3}{*}{$\begin{array}{l}\text { Thermionic, cathode, } \\
\text { semiconductors, etc. }\end{array}$} & World & 78.87 & $100 \%$ \\
\hline & United States & 19.73 & $25 \%$ \\
\hline & LAS9 & 3.86 & $5 \%$ \\
\hline
\end{tabular}

Source: Prepared by the author, on the basis of the Standard International Trade Classification (SITC) Rev. 4 and data from the United Nations Commodity Trade Statistics Database (COMTRADE).

Table VII.7

Brazil: automotive/aircraft exports, 2008

\begin{tabular}{|c|c|c|c|}
\hline Industrial sectors & Destination market & $\begin{array}{c}\text { Value } \\
\text { (millions of dollars) }\end{array}$ & World market share \\
\hline \multirow[t]{3}{*}{ Automobiles } & World & 8786.88 & $100 \%$ \\
\hline & United States & 102.95 & $1 \%$ \\
\hline & South America & 5256.26 & $60 \%$ \\
\hline \multirow[t]{3}{*}{ Aircraft } & World & 5505.66 & $100 \%$ \\
\hline & United States & 2322.64 & $42 \%$ \\
\hline & South America & 195.44 & $4 \%$ \\
\hline \multirow[t]{3}{*}{ Car engines } & World & 1038.55 & $100 \%$ \\
\hline & United States & 137.53 & $13 \%$ \\
\hline & South America & 682.82 & $66 \%$ \\
\hline
\end{tabular}

Source: Prepared by the author, on the basis of the Standard International Trade Classification (SITC) Rev. 4 and data from the United Nations Commodity Trade Statistics Database (COMTRADE).

In electronics, the United States is an important market in all industrial sectors; it holds an $18 \%$ market share in office machines, $10 \%$ in television sets and similar items, $14 \%$ in electrical machinery and appliances, and $25 \%$ in thermionic, cathode and semiconductors. In household appliances, its share is relatively low: 3\%. Therefore, for Brazil the United States market represents an important destination 
notwithstanding the distance and the competition from electronic factories in Mexico, Central American export assembly plants, and Chinese manufacturers.

As final export destinations, South American countries are a key market for Brazil. The nine above-mentioned countries, LAS9, account for more than half of world market share in office machines (57\%); television sets and similar items (79\%); electrical machinery (53\%) and household appliances (69\%). All these products are manufactured by foreign affiliates established in Brazil for the South American market, and those products are weightier and large (these conditions do not apply to the Brazilian aircraft industry of which the main market is outside South America), so having a regional production centre is more efficient than shipping from outside the region. In addition, the domestic Brazilian market is substantial enough to warrant producing goods locally. For the thermionic, cathode and semiconductors sector, the United States market is more important than South America, and this is consistent with production structures, since that sector is actually a component for other products such as personal computers, networks, and other precision instruments, so those products are manufactured in Brazil by foreign affiliates and shipped back to them, with a small percentage $(5 \%)$ going to other South American countries. Also, since those products are shipped over smaller distances, weight is less important than other logistics services.

Table VII.7 shows the automobile, aircraft and engine sectors. A first feature is that the total value is considerable, with the three sectors totalling US\$ 15.3 billion, three times larger than electronics exports of US\$ 4.86 billion. Most automobile exports stay in South America (60\%), and only $1 \%$ goes to the United States, but in aircraft only $4 \%$ stays in South America, with the rest shipped outside the region. Car engines in this case go mainly to South America. In the case of automobiles, the industry is also made up of production centres of foreign companies, which supply the domestic market and neighbouring countries, and since weight and distance are key determining factors for this industry, regional production centres, such as the one in Brazil, which is one of the most important in Eastern South America are crucial. In the aircraft industry, which is composed of small and large airplanes and helicopters, Brazil is one of the main producers and its products are exported worldwide, with the exports of the aircraft sector alone exceeding exports of the five industries included in the electronics sector.

A comparison of exports of finished goods with trade in P\&C leads to a number of observations: most imports are parts of telecommunications equipment, accessories and devices for voice, images and others (SICT 
764.18). This confirms the fact that high precision components and devices are brought in from overseas. In addition, the other main imports in $\mathrm{P} \& \mathrm{C}$ are for the automobile industry, showing the degree of assembly of those sectors that import P\&C just to put them together locally for reexport or sale in the domestic market; but in order to know if the Brazilian manufacturing industry is not only importing components for assembly but also has some comparative advantages, we have to observe exports of $\mathrm{P} \& \mathrm{C}$, which are shown in table VII.3, indicating the importance of $\mathrm{P} \& \mathrm{C}$ exports in the automotive sector as well as in engines, car bodies, aircraft and machinery.

The analysis of final goods and P\&C leaves some pending questions:

- What is the place of Brazil in the main manufacturing industries, in office and light machines, household appliances, semiconductors, automotives, aircraft and engines? The response to this will shed light on the dynamics of production sharing in Brazil and the differences across industries; and,

- What is the state of production networks and vertical specialization and sharing in South America? The response to this is necessary to observe Brazil in a regional dimension. This paper focuses on Brazil, so those topics are not addressed here, but their importance is highlighted.

This subsection indicates the following facts: (i) the main exporting manufacturing industries in Brazil - the automotive industry and the aircraft industry - overshadow the electronics industry, which, for its part, encompasses a wide range of sectors ranging from office machines to semiconductors; (ii) P\&C imports and exports are indicative of the capacity to produce components that are necessary for larger value chains; (iii) The South American market for Brazilian manufactured products is considerable, accounting for as much as $79 \%$ of Brazil's total exports in the case of television sets and related items, and as much as $69 \%$ in the case of household appliances; total exports to other South American countries of automotive and car engines exceed $60 \%$.

\section{Magnitude of production sharing in Brazil}

The analysis of final products and $\mathrm{P} \& \mathrm{C}$ provides a rough landscape of the manufacturing industries in Brazil and their production sharing, but it is still necessary to determine whether Brazilian industry has comparative advantages in $\mathrm{P} \& \mathrm{C}$ in order to quantify production sharing. Three methods are applied in the following subsections: first, an analysis of P\&C 
based on input-output matrix data using the Campa \& Goldberg index, which is a proxy of trade in intermediate products; second, in contrast with the above-mentioned index, a measurement of vertical specialization using statistical trade data, defined as exports of intermediate products with the Hummels, Ishii and Yi index; and third, an estimation of the revealed comparative advantage (RCA), which indicates whether the main Brazilian manufacturing sector possesses advantages or disadvantages in assembly operations.

\section{Imported input share}

Different methods of measuring outsourcing have been used, but unfortunately, all are indirect indicators, since to measure the foreign content embodied in finished products, data of what exactly constitutes intermediate input are not available. One way to measure imported input share is by the Campa \& Goldberg index (Campa and Goldberg, 1997).

$$
C G_{j}^{i}=\frac{\sum\left(I M P_{j} / C O N_{j}\right) * I N P_{j}^{i}}{\sum\left(P Q^{i}+W^{i}\right)} * 100
$$

Where

IMP represents imports as share of consumption in industry $j$

$C O N$ represents consumption in industry $j$

$I N P$ represents purchase of input $j$ by industry $i$

$P Q$ represents total price $x$ quantities

$W$ represents total salaries

The imported input share (IIS) for four countries estimated by Campa \& Goldberg with the index indicated is shown in table VII.8. This reveals that the imported input share has been increasing in Canada, the United States and the United Kingdom, but not in Japan where IIS has decreased since the 1970s, indicating that Japanese industry is different in orientation and nature to those of the other countries because of the concentration of exports and the internal specialization of inputs. Canada and the United Kingdom also have rising levels of IIS over time, signalling an external orientation of the economy. According to Campa \& Goldberg, results taken from the input-output matrix are not comparable between countries, but the index can be constructed for Brazil from the IO matrix tables for 2000 and 2005. 
Table VII.8

Average imported input share in finished products, 1975-1995 (Percentages)

\begin{tabular}{lrrr}
\hline Country & $1970 \mathrm{~s}$ & $1980 \mathrm{~s}$ & $1990 \mathrm{~s}$ \\
\hline Canada & 15.8 & 14.4 & 20.2 \\
\hline United States & 4.1 & 6.2 & 8.2 \\
\hline United Kingdom & 13.4 & 19.0 & 21.5 \\
\hline Japan & 8.1 & 7.3 & 4.1 \\
\hline
\end{tabular}

Source: J. Campa and L. Goldberg, "The evolving external orientation of manufacturing: a profile of four countries", Economic Policy Review, New York, Federal Reserve Bank of New York, July 1997.

The input-output matrix available for Brazil ${ }^{7}$ includes a coefficient of imported input tables, indicating the level of imported inputs in final products of industrial sectors. These results are obtained by per unit cost structure where the imported share is indicated by a coefficient. Dividing the coefficient over the total production of each industrial sector gives a direct coefficient of imports. These sectors and coefficients are shown in table VII.9 for 2000 and 2005.

Table VII.9

Coefficient of imported inputs in industrial sectors, 2005

\begin{tabular}{rlrc}
\hline SIC & Industry & 2000 & 2005 \\
\hline 101 & Agriculture, hunting, forestry & 0.692 & 0.680 \\
\hline 102 & Fishing & 0.904 & 0.866 \\
\hline 201 & Oil and natural gas & 1.309 & 3.890 \\
\hline 202 & Mining and quarrying & 8.372 & 8.667 \\
\hline 203 & Other extractive products & 4.809 & 4.184 \\
\hline 301 & Food and beverages & 1.142 & 1.301 \\
\hline 302 & Tobacco & 5.121 & 4.901 \\
\hline 303 & Textiles & 6.274 & 5.158 \\
\hline 304 & Clothing and accessories & 0.904 & 0.787 \\
\hline 305 & Leather and footwear & 9.165 & 9.804 \\
\hline 306 & Wood products excluding furniture & 17.299 & 22.925 \\
\hline 307 & Pulp, paper, and paper products & 9.639 & 11.482 \\
\hline 308 & Magazines, printing products and CDs & 4.566 & 2.903 \\
\hline 309 & Coke, refined petroleum & 2.771 & 1.944 \\
\hline 310 & Alcohol & 0.530 & 0.098 \\
\hline 311 & Chemical products & 4.021 & 4.641 \\
\hline 312 & Resin and related & 4.190 & 4.368 \\
\hline 313 & Pharmaceuticals & 0.169 & 0.134 \\
\hline 314 & Agricultural products & 7.048 & 7.728 \\
\hline 315 & Perfume, hygiene and cleaning & 3.914 & 4.110 \\
\hline & & & \\
\hline
\end{tabular}

\footnotetext{
Input-output tables 2000-2005, Brazilian Geographical and Statistical Institute (IBGE), Brazil.
} 
Table VII.9 (concluded)

\begin{tabular}{rlrr}
\hline SIC & Industry & 2000 & 2005 \\
\hline 316 & Painting products & 0.528 & 0.440 \\
\hline 317 & Other chemical products & 2.711 & 1.567 \\
\hline 318 & Rubber and plastic products & 3.821 & 3.054 \\
\hline 319 & Cement & 2.998 & 3.407 \\
\hline 320 & Other non-metallic mineral products & 3.675 & 4.270 \\
\hline 321 & Iron and steel & 7.397 & 9.269 \\
\hline 322 & Non ferrous metals & 7.774 & 1.986 \\
\hline 323 & Metal products - except machinery and equipment & 4.663 & 6.194 \\
\hline 324 & Machinery and equipment, including maintenance and repair & 3.210 & 2.073 \\
\hline 325 & Household appliances & 3.071 & 2.636 \\
\hline 326 & Office, accounting \& computing machines & 2.046 & 0.176 \\
\hline 327 & Electrical machinery \& apparatus, n.e.c. & 8.510 & 9.016 \\
\hline 328 & Radio, television \& communication equipment & 6.434 & 5.399 \\
\hline 329 & Medical, precision \& optical instruments & 3.199 & 3.843 \\
\hline 330 & Motor vehicles, trailers \& semi-trailers & 2.004 & 3.549 \\
\hline 331 & Trucks and buses & 4.457 & 4.759 \\
\hline 332 & Parts and components for vehicles & 11.396 & 19.888 \\
\hline 333 & Other transport equipment & 5.444 & 20.354 \\
\hline 334 & Other manufacturing products & 1.875 & 1.070 \\
\hline
\end{tabular}

Source: Prepared by the author, on the basis of the Brazilian Geographical and Statistical Institute (IBGE), Input-output tables, 2000 and 2005.

The import coefficients yield some unexpected results. In the electronics sectors, higher coefficients are in electrical machinery (9.016 in 2005) and radio, television and communication equipment (5.399 in 2005); however, the coefficient for household appliances (2.636) is surprisingly low, considering the results based on statistical data. In the automotive industry, parts and components stood at 19.888 in 2005, up from 11.396 in 2000 and other transport equipment moves from 5.444 in 2000 to 20.354 in 2005 . These results should be seen in perspective; the implementation of MERCOSUR encouraged imports and integration of the automotive industry. Oliveira (2000) estimated the direct coefficient index for 1990 to 1995, finding that electronic equipment had the highest level of intermediate imports: 20.66 in 1995. Unfortunately results are not comparable since the IO tables by IBGE Brazil applied a different classification until 1999; however in the period from 1990 to 1995, Oliveira (2000) found that the coefficient changes frequently in all sectors and is far from stable, which is also seen when comparing the coefficient index for 2000 with 2005.

While remembering that the subject of this paper is to measure production sharing in the electronics and automotive/aircraft industry, we 
point out a particular feature that arises from the 2000 to 2005 data; import coefficients are over 20 for wood products, and 11.482 for paper and pulp products, and are noticeably higher for other products such as agriculture, thus showing that the study of production sharing in commodity industries in Brazil is clearly a pending assignment.

Applying the Campa \& Goldberg index to Brazil using the input-output matrix tables reveals the following: (i) From 2000 to 2005 the automotive sector seems to have expanded in IIS; 8 (ii) There is no consistent trend for production sharing, since marked fluctuations are the norm, but the automotive sector and electronic industry still have considerable levels of IIS; (iii) Agricultural, mining, and other processed commodities have an important level of IIS, and further studies on industrialization and regional production integration should be conducted. In addition, the input-output tables offer limited analysis due to different methodologies and comparison frameworks, so further work remains to be done in this regard.

\section{Degree of vertical specialization}

Hummels, Ishii and Yi (2001) (HIY) propose an alternative measure of production sharing. They define vertical specialization (VS) as the practice whereby a country uses imported intermediate parts to produce goods it later exports. This definition differentiates vertical specialization from outsourcing, which is considered a mere act of production relocation. VS is a production strategy involving FDI and trade in intermediate goods.

$$
V S_{k}^{i}=\frac{\sum(M I) * X}{\sum(G O)}
$$

Where:

$V S$ is country $\mathrm{k}$ and sector $\mathrm{i}$

$M I$ represents imports intermediates

$X$ represents total exports

and

$G O$ is gross output

The input-output table for Brazil for 2005 does not include the aircraft industry as a separate item. 
Based on this definition, the formula measures imported intermediate goods in products that are exported. The HIY index was one of the earlier attempts to measure the extent of production sharing and has been used for several countries. For example, Hummels, Rapoport and Yi (1998) found that total vertical trade may be as high as 50\% in smaller countries. Like the Campa and Goldberg (CG) index, the HIY uses input-output matrix data combined with trade data, but with an important distinction; the CG index measures intermediate goods versus final goods, whereas the HIY emphasizes foreign content in products that are subsequently exported.

As for the CG index, the availability of Brazil's IO matrix tables and trade data allows us to compute results. This is done for all sectors and for the electronics and automotive and aircraft sectors and results are shown in table VII.10. Results computed for Brazil indicate important trends: vertical specialization has increased for all sectors from 1995 to 2005, moving from 0.0634 to 0.1621 , but the pattern is mixed depending on the industry.

Table VII.10

Vertical specialization in the manufacturing sector in Brazil

\begin{tabular}{lccc}
\hline Industrial Sectors & 1995 & 2000 & 2005 \\
\hline Total all sectors & 0.0634 & 0.0846 & 0.1621 \\
\hline & & & \\
\hline $\begin{array}{l}\text { 15 Fabricated metal products, except machinery } \\
\text { and equipment }\end{array}$ & 0.0005 & 0.0005 & 0.0815 \\
\hline 16 Machinery and equipment, n.e.c. & 0.0030 & 0.0031 & 0.0058 \\
\hline 17 Office, accounting and computing machines & 0.0010 & 0.0014 & 0.0006 \\
\hline 18 Electrical machinery and apparatus, n.e.c. & 0.0018 & 0.0042 & 0.0021 \\
\hline 19 Radio, television and communication equipment & 0.0022 & 0.0050 & 0.0100 \\
\hline 20 Medical, precision and optical instruments & 0.0005 & 0.0013 & 0.0003 \\
\hline 21 Motor vehicles, trailers and semi-trailers & 0.0020 & 0.0054 & 0.0075 \\
\hline 22 Building and repairing of ships and boats & 0.0008 & 0.0003 & 0.0047 \\
\hline 23 Aircraft and spacecraft & 0.0156 & 0.0219 & $\ldots$ \\
\hline 24 Railroad equipment and transport equipment, n.e.c. & 0.0001 & 0.0001 & 0.0815 \\
\hline
\end{tabular}

Source: Prepared by the author, on the basis of the Brazilian Geographical and Statistical Institute (IBGE), Input-output tables, 2000 and 2005.

HIY applies the index using OECD IO tables, comparing an initial year to a later year (late 1960s, or early 1970s with late 1980s or early 1990s) for a number of countries: Australia, Canada, Denmark, France, Germany, Japan, Netherlands, United Kingdom and United States. Vertical specialization is found to have increased in all countries except Japan, where the index decreased, and Denmark, where it stayed flat. In Japan, the results are consistent with Campa and Goldberg (1997), who found a 
decrease in VS, as explained by the particular organization of Japanese industry, which has simultaneously transferred production overseas, and in the domestic market, has focused on production of specialized components that do not need imported parts and components.

Regarding the HIY, an observation is required. Measuring production sharing and vertical specialization is approximate and a conclusive index is not possible since goods are imported, re-exported, processed and re-imported. These movements are better captured by the IP matrix, which includes an import coefficient matrix and tracks intermediate imports used in each sector, but this option is still limited and in most cases the volume of VS may be underestimated. Several attempts to overcome data limitation have been debated; Koopman, Wang and Wei (2008) proposed a modified index using the HIY as a base but including a specification contained in Chinese customs declarations, in which products must be classified as being for final consumption or further processing, finding important differences with the HIY. Along the same lines, Dean, Fung and Wang (2008) discuss vertical specialization in Chinese trade, detecting evidence of VS underestimation in China. This debate is critical for obtaining an accurate index and measurement of vertical integration; in the case of Brazil, the data available do not allow the distinction as in Chinese imports, so the analysis is restricted to what is possible from the IO matrix tables and trade data, comparing different results to verify consistency.

Figure VII.1

Vertical specialization in manufacturing in Brazil, 1995, 2000 and 2005

A. Fabricated metal products, except machinery and equipment

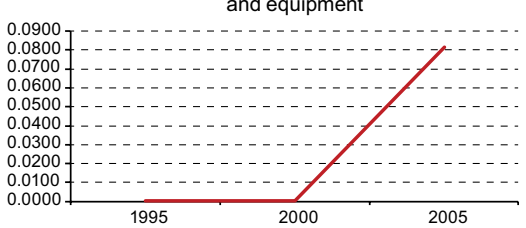

C. Office. accounting and computing machinery

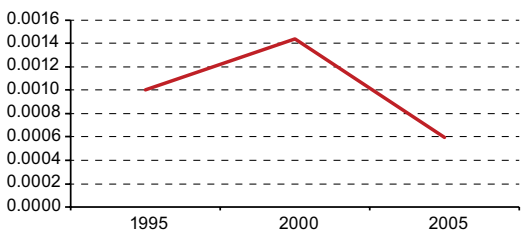

B. Machinery and equipment, n.e.c.

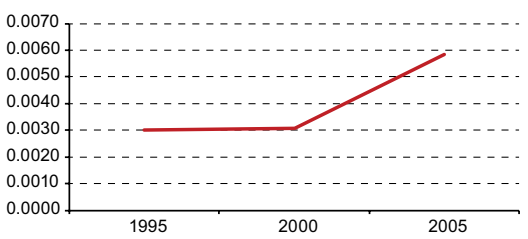

D. Electrical machinery and apparatus, n.e.c.

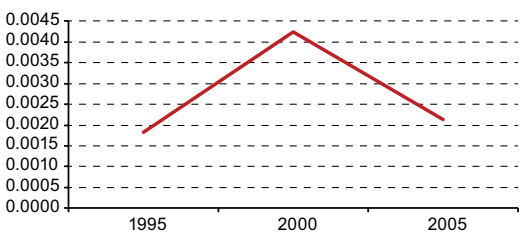


Figure VII.1 (concluded)
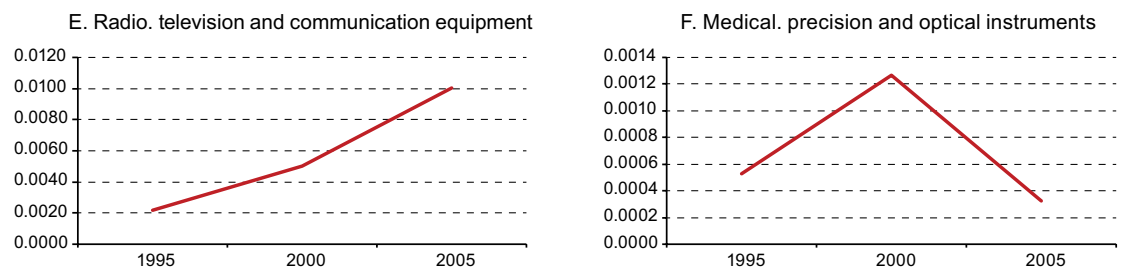

G. Motor vehicles, trailers and semi-trailers

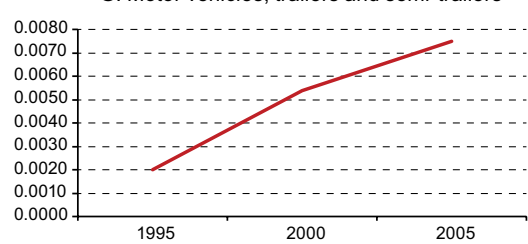

H. Building and repairing of ships and boats

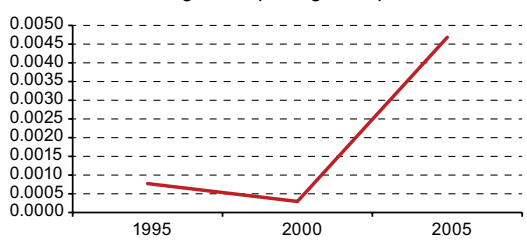

I. Aircraft and spacecraft

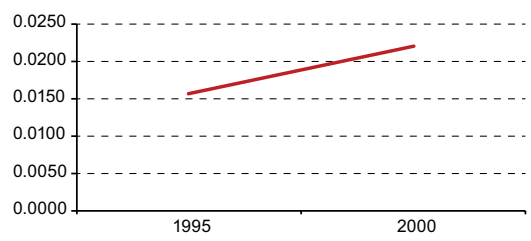

J. Railroad equipment and transport equip, n.e.c.

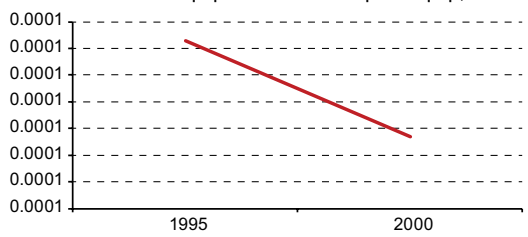

Source: Prepared by the author, on the basis of the Brazilian Geographical and Statistical Institute (IBGE), Input-output tables, 2000 and 2005.

The HIY for Brazil indicates that vertical specialization increased in metal products, machinery and equipment, radio television, motor industry and building and repairing, but decreased in office, accounting and computing machines; electrical machinery and apparatus; and medical, precision and optical instruments. In the aircraft industry and railroad equipment, the data relating to motor vehicle and semi-trailers are contained in the input-output matrix 2005, so results only show the period from 1995 to 2000. In general, a number of trends can be seen from the HIY for Brazil: (i) VS increased between 1995 and 2005, but the evolution is not upwards for all industries; (ii) Machinery and complex goods have higher VS though lighter manufacturing has lower VS, which implies that the Brazilian manufacturing industry has been developing and is able to supply basic components; (iii) The HIY index and the Campa \& Goldberg (CG) index, both of which are based on the input-output matrix table, are consistent. The CG index also shows similar patterns in VS, increasing markedly from 2000 to 2005. 


\section{Advantages in assembly operations}

The revealed comparative advantage (RCA) index is traditionally used to measure whether a country has a comparative advantage in a certain industry. In the index, $X$ represents exports, $\mathrm{i}=$ country, $\mathrm{j}=$ product, $\mathrm{t}=$ total export of product $\mathrm{j}$ by country $\mathrm{i}, \mathrm{w}=$ total world exports. Here a value less than 1 implies that the country has a relative disadvantage in production of the good or in the sector depending on the level of aggregation, and, vice versa, a value higher than 1 means the country has an advantage in the product or sector. This is an indicator of advantages given the endowments of the economy. Estimating the RCA for imports indicates the comparative advantage in assembly operations. ${ }^{9}$ However, in interpreting results, it must be considered that distortions are in place, subsidies or tariffs can make RCA for exports or imports increase or decrease, even if those policies are applied for neighbouring countries and are not part of Brazil in this case.

$$
R C A x=\left(\frac{x_{i j}}{X_{i t}}\right) *\left(\frac{x_{w j}}{X_{w t}}\right)
$$

Results computed for Brazil are shown in table VII.11. Brazil has an RCA higher than one in sectors $0,1,4$ and 6, prominently in sector 1 : Food and Live Animals, sector 2: Crude materials, except fuels, sector 4: Animal and vegetable oils, and sector 6: manufactured goods, and a disadvantage in the others. This does not mean that Brazil has no advantage in manufactured goods; raw materials and primary products also require processing and a complex production infrastructure depending on the goods. In the case of the manufacturing sectors $6,7,8$ and 9, only in 6 (manufacturing goods) does Brazil have an RCA higher than 1.0. For machinery and transport equipment the value is 0.60 and for miscellaneous manufacturing articles, it is 0.26 .

The RCA values in Brazil for primary products are not surprising; Brazil is a source of commodities and primary goods, and has a welldeveloped processing industry, which benefited over the past decade from increasing demand from China and East Asia. Lower RCA values in the manufacturing sector are, however, contrary to expectations since a considerable number of foreign companies produce in Brazil and exports are distributed across the regions. A closer analysis of the differences between the electronics industry, the automotive and the aircraft industries is made in table VII.12, where the RCA is shown for those sectors in parts and components for exports and imports.

See Ng and Yeats (2005). 
Table VII.11

Revealed comparative advantage

\begin{tabular}{cll}
\hline SITC & 2008 RCA & Brazil \\
\hline 0 & Food and live animals & 3.52 \\
\hline 1 & Beverages and tobacco & 1.88 \\
\hline 2 & Crude materials, inedible, except fuels & 5.48 \\
\hline 3 & Mineral fuels, lubricants and related materials & 0.67 \\
\hline 4 & Animal and vegetable oils, fats and waxes & 2.54 \\
\hline 5 & Chemicals and related products, n.e.s. & 0.59 \\
\hline 6 & Manufactured goods classified chiefly by material & 1.10 \\
\hline 7 & Machinery and transport equipment & 0.60 \\
\hline 8 & Miscellaneous manufactured articles & 0.26 \\
\hline 9 & Commodities and transactions n.e.s. & 0.62 \\
\hline
\end{tabular}

Source: Prepared by the author, on the basis of data from the United Nations Commodity Trade Statistics Database (COMTRADE).

Table VII.12

Revealed comparative advantages in Brazil: parts and components, electronics, automobiles and aircraft

\begin{tabular}{|c|c|c|}
\hline 2008 & $\begin{array}{c}\text { Revealed } \\
\text { comparative } \\
\text { advantages exports }\end{array}$ & $\begin{array}{c}\text { Revealed } \\
\text { comparative } \\
\text { advantages imports }\end{array}$ \\
\hline \multicolumn{3}{|l|}{ Electronics parts and components } \\
\hline 74149 Parts of refrigerating equipment & 0.6062 & 0.9418 \\
\hline 7429 Parts of the pumps for liquids & 0.7611 & 0.0000 \\
\hline 7439 Parts of centrifuges and filters & 0.2737 & 0.0000 \\
\hline 74419 Parts of fork-lift trucks & 0.0080 & 0.0000 \\
\hline 7449 Parts of lifting and loading machinery & 0.1149 & 0.0000 \\
\hline 74519 Parts of power hand tools & 0.2589 & 0.0000 \\
\hline 74523 Parts of packing machinery & 0.0494 & 0.0000 \\
\hline 7499 Parts of other non-electric machinery & 0.1074 & 0.0000 \\
\hline 759 Parts of office and adding machines & 0.0287 & 0.0000 \\
\hline 764 Parts of telecommunication equipment & 0.4521 & 0.0000 \\
\hline 77129 Parts of other electric power machinery & 0.1251 & 0.0000 \\
\hline 772 Parts of switchgear & 0.1693 & 0.0000 \\
\hline 77579 Parts of domestic electrical equipment & 0.0880 & 0.0000 \\
\hline 77589 Parts of electrothermic appliances & 0.0117 & 0.0000 \\
\hline 776 Parts of electronic components & 0.0222 & 0.0000 \\
\hline 77819 Parts of electronic accumulators & 0.4101 & 0.0000 \\
\hline 77829 Parts of electric lamps and bulbs & 0.1905 & 0.0000 \\
\hline 7783 Internal electric equipment for automotives & 0.8655 & 0.0000 \\
\hline 77889 Parts of other electrical machinery & 0.0043 & 0.0000 \\
\hline \multicolumn{3}{|l|}{ Vehicle parts and components } \\
\hline 784 Parts and motor vehicle accessories & 1.2215 & 0.0000 \\
\hline 625 Rubber tyres & 1.8097 & 0.0000 \\
\hline 78535 Parts of carriages and cycles & 0.2207 & 0.0000 \\
\hline 78689 Parts of trailers and non-motor vehicles & 0.3871 & 0.0000 \\
\hline 79199 Parts of railway vehicles and equipment & 1.1665 & 0.0000 \\
\hline \multicolumn{3}{|l|}{ Aircraft parts and components } \\
\hline 7929 Parts of aircraft and associated equipment & 0.5065 & 2.3487 \\
\hline
\end{tabular}

Source: Prepared by the author, on the basis of data from the United Nations Commodity Trade Statistics Database (COMTRADE). 
RCA for exports in P\&C reveals a distinctive feature; there is no single $\mathrm{P} \& \mathrm{C}$ in the electronic sector with an RCA above 1 . The highest values are 0.7783 for internal electric parts for automotives, 0.7924 for parts of pumps and liquids and 0.74149 for parts of refrigerating equipment. In the sector automotive $\mathrm{P} \& \mathrm{C}$ there are three sectors, including two key sectors in the production of P\&C (not tyres) with RCA higher than 1, whereas in the aircraft industry, the RCA is 0.50. This indicates that Brazil's P\&C industry has a comparative advantage in production of components for the automotive industry, but not in electronics or aircraft, although in the latter, if $\mathrm{P} \& \mathrm{C}$ for aircraft are manufactured for the domestic industry and not for export, the indicator is relative. In addition, in the automotive industry, higher relative RCA may be the result of market protection measures between MERCOSUR member countries, so trade with Argentina is not the result of competitiveness.

Contrasting RCA for imports complements the analysis of the manufacturing sectors. The RCA for imports is shown in (4), and it is similar to the RCA for exports, except that all variables are replaced by imports. In this case, an RCA of over 1 for $P \& C$ is a relative indicator of the advantages of the country in assembly operations, since in theory $\mathrm{P} \& \mathrm{C}$ are sent to locations where obtaining the final product is more efficient. In this case, we should also consider that several distortions might exist.

$$
R C A m=\left(\frac{m_{i j}}{M_{i t}}\right) *\left(\frac{m_{w j}}{M_{w t}}\right)
$$

In the electronic parts and component sector, the RCA for P\&C imports in table VII.12 is unexpected, at only 0.74149. Parts of refrigerating equipment have an RCA of 0.94 , close to, but still less than 1, with all other RCA values at 0.0000 . In the vehicle parts and components, no single product has an RCA higher than 0.0000; this should be expected to be higher considering the amount of trade and the size of the automotive industry in Brazil and its links, not only in South America, but also with the United States and Mexico. Only aircraft P\&C have a clear comparative advantage, with 0.7929 for aircraft parts and a value of 2.3487 for associated equipment.

The RCA analysis of imports and exports generates more questions than answers concerning the following facts: (i) Brazil has RCA in exports of $\mathrm{P} \& \mathrm{C}$ in the automotive sector, but not in the electronics or 
the aircraft sector, (ii) Brazil has no advantage in assembly operations in the manufacturing sector, except for a relatively high advantage (less than 1) in refrigerating equipment and in the aircraft sector. The estimates indicate that further study is needed on the determinants of the electronics, automotive and aircraft industries, their advantages and constraints. Further research is necessary to identify the policies implemented through MERCOSUR and to examine the tools relating to tariff and non-tariff trade that contribute to or affect production integration in the automotive sector.

\section{Results and policy implications}

The two main findings of this study are as follows: (i) first, production sharing in Brazil has been increasing in the past two decades, but the process is not a straight upward trend and the evolution depends on the industry; (ii) second, Brazil's trade in manufactured goods is significant; however, its strength may not be based on competitiveness, but rather on other factors resulting from domestic market size, membership of MERCOSUR, and production development policies targeting the electronic, automotive and aircraft industries.

Production sharing is an opportunity for developing countries to integrate into global value chains by building capacity in specific processes and components, and the Brazilian economy has expanded trade not only in primary products but also in manufactured goods, some of them highly sophisticated technological products. However, the trend towards more production integration or vertical specialization is not progressively determined and, in the case of Brazil, it seems that, despite trade growth, the trend is slowing and the industry is expanding but not building networks.

\section{(a) Results}

Trade data show that the main partners of Brazil are the United States, Argentina and China, with Argentina the most important trade partner in South America, followed by the Bolivarian Republic of Venezuela, Chile, Paraguay and Uruguay. In terms of trade in $\mathrm{P} \& \mathrm{C}$, the electronics industry and the automotive industry are the leaders; Brazil is also an essential provider of $P \& C$ in motor-related goods. In_finished products, the automotive industry is the most important sector in South America, whereas in the aircraft industry the market is overseas; weight and distance are significant variables determining trade flows for finished products. Production sharing in Brazil shows differences depending on the industry; although there was a general upward trend, 
it was reversed from 2000 to 2005, and it was not uniform across sectors. More research is needed on advantages for assembling. As indicated by RCA for imports, becoming assemblers offers few advantages, so advantages seems to be based on other variables, not necessarily arising from factor endowments.

\section{(b) Policy implications}

Implications for policy are at two levels; at a general level, Brazil should explore ways to strengthen its integration in global value chains by reducing link service costs. Trade with South American countries could enhance service links, reduce costs and increase regional efficiency. Brazil also needs to improve its efficiency and factor productivity in order to generate a sustainable advantage as a country with higher comparative advantages for exports and imports, which will revert positively in favour of Brazil's production sharing and production integration.

\section{(c) Research agenda}

Production fragmentation is an area which is still developing at a theoretical and practical level; in Brazil and the rest of Latin America, little has been done, despite the urgency of having data and analysis for public policies. This paper highlights some topics, mapping out a research agenda: (i) analysis of production networks in industries other than motor vehicles or electronic devices, for example, food and beverages, or chemicals; (ii) the nature of existing Brazilian links with advanced production networks outside Latin America, (iii) the analysis of determinants of imports and exports based on factor costs, and beyond fragmentation, the links between foreign direct investment and production integration by major manufacturing development countries such as Japan, Europe and the United States. 


\section{Bibliography}

Aminian, N., K.C. Fung and H. Iizaka (2007), "Foreign direct investment, intraregional trade and production sharing in East Asia", RIETI Discussion Paper Series, No. 07-E-064, Tokyo, Research Institute of Economy, Trade and Industry.

Ando, M. (2006), "Fragmentation and vertical intra-industry trade in East Asia", The North American Journal of Economics and Finance, vol. 17, No. 3, Amsterdam, Elsevier.

Ando, M. and F. Kimura (2007), "Fragmentation in East Asia: further evidence", Keio University, January, unpublished.

Arndt, S. (1997), "Globalization and the open economy", The North American Journal of Economics and Finance, vol. 8, No. 1, Amsterdam, Elsevier.

Arndt, S. and H. Kierzkowski (2001), Fragmentation: New Production Patterns in the World Economy, Oxford, Oxford University Press.

Athukorala, P. (2003), "Product fragmentation and trade patterns in East Asia", Departmental Working Papers, No. 2003/21, Canberra, Australian National University.

Athukorala, P. and N. Yamashita (2006), "Production fragmentation and trade integration: East Asia in a global context", The North American Journal of Economics and Finance, vol. 17, No. 3, Amsterdam, Elsevier, December.

Calfat, G. and others (2008), "Far from champions, close to midgets - International production sharing in Central and South America. The insertion of Mercosur into the world's fragmentation trade", IOB Working Paper, No. 2008.01, Antwerp, Institute of Development Policy and Management, University of Antwerp.

Campa, J. and L. Goldberg (1997), "The evolving external orientation of manufacturing: a profile of four countries", Economic Policy Review, New York, Federal Reserve Bank of New York, July.

Cheng, L. and H. Kierzkowski (2001), Global Production and Trade in East Asia, Boston, Massachusetts, Kluwer Academic Publishers.

Dean, J., K.C. Fung and Z. Wang (2008), "How vertically specialized is Chinese trade?", BOFIT Discussion Paper, No. 31/2008, Helsinki, Bank of Finland Institute for Economies in Transition (BOFIT).

Feenstra, R. (1998), "Integration of trade and disintegration of production in the global economy", Journal of Economic Perspectives, vol. 12, No. 4, Nashville, Tennessee, American Economic Association.

Feenstra, R. and G. Hanson (1996), "Globalization, outsourcing, and wage inequality", NBER Working Papers, No. 5424, Cambridge, Massachusetts, National Bureau of Economic Research.

Formentini, S. and L. Iapadre (2008), "Measuring international production fragmentation: where do we stand?", International Journal of Technological Learning, Innovation and Development, vol. 1, No. 3.

Fung, K.C., A. Garcia-Guerrero and A. Siu (2009), "Production sharing in Latin America and East Asia", Working Papers, No. 901, Economic Research Department, BBVA Bank.

Gereffi, G. and M. Korzeniewics (eds.) (1994), Commodity Chains and Global Capitalism. Westport, Greenwood Press. 
Grossman, G.M. and E. Helpman (2005), "Outsourcing in a global economy”, Review of Economic Studies, vol. 72, No. 1, Oxford, Oxford University Press. (2003), "Outsourcing versus FDI in industry equilibrium", Journal of the European Economic Association, vol. 1, No. 2-3, Wiley.

Grubel, H. and P. Lloyd (1975), Intra-Industry trade: The Theory and Measurement of International Trade in Differentiated Products, New York, Wiley.

Haddad, M. (2007), "Trade integration in East Asia: the role of China and production networks", Policy Research Working Paper Series, No. 4160, Washington, D.C., World Bank.

Hayakawa, K., Z. Ji and A. Obashi (2011), "Spatial distribution of industrial production: a comparison of East Asia and Europe", The Developing Economies, vol. $49, \mathrm{~N}^{\mathrm{o}} 4$.

Helpman, E. (2006), "Trade, FDI, and the organization of firms", Journal of Economic Literature, vol. 44, No. 3, Nashville, Tennessee, American Economic Association.

Hoon, H.T. and K.W. Ho (2001), "The changing pattern of production fragmentation in Singapore and its economic consequences", Global Production and Trade in East Asia, L. Cheng and H. Kierzkowski (eds.), Springer.

Hummels, D., J. Ishii and K.-M. Yi (2001), "The nature and growth of vertical specialization in world trade", Journal of International Economics, vol. 54, No 1 .

Hummels, D., D. Rapoport and K.-M. Yi (1998), "Vertical specialization and the changing nature of world trade", Economic Policy Review, New York, Federal Reserve Bank of New York, June.

Igawa, K. (eds.) (1997), Economic Relations and Developments in Asia and Pacific: Collected Papers of International Cooperation Studies, Research Institute for Economics and Business Administration, Kobe University.

IDB (Inter-American Development Bank) (2009), From Multilatinas to Global Latinas: The New Latin American Multinationals, Washington, D.C.

Ito, T. and A. Rose (eds.) (2005), International Trade in East Asia, Chicago, University of Chicago Press.

Jones, R. and H. Kierzkowski (2004a), "International trade and agglomeration: an alternative framework", IHEID Working Paper, No. 10-2004, Geneva, Graduate Institute of International Studies.

(2004b), "International fragmentation and the new economic geography", IHEID Working Paper, No. 11-2004, Geneva, Graduate Institute of International Studies. (1990), "The role of services in production and international trade", The Political Economy of International Trade, R. Jones and A. Krueger (eds.), Oxford, Basil Blackwell.

Jones, R. and A. Krueger (eds.) (1990), The Political Economy of International Trade, Oxford, Basil Blackwell.

Jones, R., H. Kierzkowski and Lurong Chen (2005), "What does evidence tell us about fragmentation and oursourcing?", International Review of Economics and Finance, vol.14.

Kim, J. and P-B. Ruffini (eds.) (2007), Corporate Strategies in the Age of Regional Integration, Cheltenham, Edward Elgar.

Kimura, F. and A. Obashi (2009), "International production networks: comparison between China and ASEAN", Working Papers, No. 01, Jakarta, Economic Research Institute for ASEAN and East Asia, January. 
Kimura, F. and M. Ando (2007), "Fragmentation in East Asia: Further Evidence", Hitotsubashi University/Keio University, unpublished.

(2005), "Two dimensional fragmentation in East Asia: conceptual framework and empirics", International Review of Economics and Finance, vol. 14, No. 3, Amsterdam, Elsevier.

(2003), "Fragmentation and agglomeration matter: Japanese multinationals in Latin America and East Asia", The North American Journal of Economics and Finance, vol. 14, No. 3, Amsterdam, Elsevier.

Kimura, F., Y. Takahashi and T. Hayakawa (2005), "Fragmentation and Parts and Components Trade: Comparison between East Asia and Europe", Tokyo, Faculty of Economics, Keio University, unpublished.

Koopman, Robert, Zhi Wang and Shang-jin Wei (2008), "How much of Chinese exports is really made in China? Assessing domestic value-added when processing trade is pervasive", NBER Working Paper, $\mathrm{N}^{\circ} 14109$.

Krugman, P. (1995), "Growing world trade: causes and consequences", Brookings Papers on Economic Activity, vol. 26, No. 1, 25 ${ }^{\text {th }}$ Anniversary Issue, Washington, D.C., Brookings Institution Press.

Lall, S., M. Albaladejo and J. Zhang (2004), "Mapping fragmentation: electronics and automobiles in East Asia and Latin America", QEH Working Papers, No. QEHWPS115, Oxford, University of Oxford.

Lee, S.-G. and P.-B. Ruffini (eds.) (1999), The Global Integration of Europe and East Asia: Studies of International Trade and Investment, Cheltenham, Edward Elgar.

Moreno, A.I. and M. Posada (2007), “Evolución del comercio intraindustrial entre las regiones colombianas y la Comunidad Andina, 1990-2004: Un análisis comparativo", Lecturas de Economía, No. 66, Medellin, University of Antioquia, Faculty of Economics.

$\mathrm{Ng}$, F. and A. Yeats (2005), "Production sharing in East Asia: who does what for whom and why", Policy Research Working Paper, No. 2197, Washington, D.C., World Bank.

Nordas, H.K. (2005), “International production sharing: a case for a coherent policy framework", WTO Discussion Paper, No. 11, Geneva, World Trade Organization.

Oliveira, M. de (2000), "A liberalização comercial brasileira e os coeficientes de importação 1990-1995", Texto para discussão, No. 703, Rio de Janeiro, Institute of Applied Economic Research (IPEA).

Santiso, J. (2008), "The emergence of Latin multinationals", CEPAL Review, No. 95 (LC/G.2382-P), Santiago, Chile, Economic Commission for Latin America and the Caribbean (ECLAC).

Sturgeon, T. (2006), “The Governance of Global Value Chains: Implications for Industrial Upgrading", paper presented at the Global Value Chains Workshop "Industrial Upgrading, Offshore Production, and Labor" (9-10 November), Social Science Research Institute, Duke University.

Suh, D.-C. (2007), "Economic power shift in East Asia and its political-economic implications", Corporate Strategies in the Age of Regional Integration, J. Kim and P-B. Ruffini (eds.), Cheltenham, Edward Elgar.

Terra, M.C. (2002), "Finance and changing trade patterns in Brazil", Finance and Competitiveness in Developing Countries, J.M. Fanelli and R. Mehdora (eds.), Ottawa, International Development Research Centre (IDRC). 
Urata, S. (2006), "The Changing Pattern of International Trade in East Asia", Graduate School of Asia-Pacific Studies (GSAPS), October.

Urata, S., C.S. Yue and F. Kimura (eds.) (2006), Multinationals and Economic growth in East Asia: Foreign Direct Investment, Corporate Strategies and National Economic Development, New York, Routledge.

Ventura, V. and J. Durán (2001), "Production sharing in Latin American trade: a research note", International Trade, No. 22 (LC/L.1693-P), Santiago, Chile, Economic Commission for Latin America and the Caribbean (ECLAC). United Nations publication, Sales No. E.01.II.G.221.

Yeats, A. (2001), "Just how big is global production sharing?", Fragmentation: New Production Patterns in the World Economy, S. Arndt and H. Kierzkowski Oxford, Oxford University Press.

Yi, K.-M. (2003), "Can vertical specialization explain the growth of world trade?", Journal of Political Economy, vol. 111, No. 1, Chicago, University of Chicago Press.

Yusuf, S., A. Anjum and K. Nabeshima (2004), Global Production Networking and Technological Change in East Asia, Washington, D.C., World Bank. 


\section{Annex}

\section{Vertical specialization in Brazil}

Vertical specialization in Brazil is estimated using the Hummels, Ishii and Yi (2001) (HIY) index, for Brazil for all production sectors, 1995, 2000 and 2005. The input-output matrix data were used for all years. For 2005, the aircraft and railroad sectors are included in category 21, motor vehicles, trailers and semi-trailers.

\section{Table VII.A.1}

Vertical specialization in Brazil

\begin{tabular}{lccc}
\hline Industry & 1995 & 2000 & 2005 \\
\hline 1 Agriculture, hunting, forestry and fishing & 0.0005 & 0.0009 & 0.0012 \\
\hline 2 Mining and quarrying (energy) & 0.0008 & 0.0007 & 0.0104 \\
\hline 3 Mining and quarrying (non-energy) & 0.0030 & 0.0035 & 0.0074 \\
\hline 4 Food products, beverages and tobacco & 0.0024 & 0.0015 & 0.0010 \\
\hline 5 Textiles, textile products, leather and footwear & 0.0036 & 0.0022 & 0.0009 \\
\hline 6 Wood and products of wood and cork & 0.0001 & 0.0002 & 0.0002 \\
\hline 7 Pulp, paper, paper products, printing and publishing & 0.0019 & 0.0014 & 0.0008 \\
\hline 8 Coke, refined petroleum products and nuclear fuel & 0.0014 & 0.0019 & 0.0033 \\
\hline 9 Chemicals excluding pharmaceuticals & 0.0069 & 0.0080 & 0.0095 \\
\hline 10 Pharmaceuticals & 0.0008 & 0.0003 & 0.0006 \\
\hline 11 Rubber \& plastics products & 0.0013 & 0.0015 & 0.0013 \\
\hline 12 Other non-metallic mineral products & 0.0004 & 0.0004 & 0.0006 \\
\hline 13 Iron \& steel & 0.0022 & 0.0021 & 0.0029 \\
\hline 14 Non-ferrous metals & 0.0042 & 0.0037 & 0.0051 \\
\hline 15 Fabricated metal products, except machinery and equipment & 0.0005 & 0.0005 & 0.0815 \\
\hline 16 Machinery and equipment, n.e.c. & 0.0030 & 0.0031 & 0.0058 \\
\hline 17 Office, accounting and computing machines & 0.0010 & 0.0014 & 0.0006 \\
\hline 18 Electrical machinery and apparatus, n.e.c. & 0.0018 & 0.0042 & 0.0021 \\
\hline 19 Radio, television and communication equipment & 0.0022 & 0.0050 & 0.0100 \\
\hline 20 Medical, precision and optical instruments & 0.0005 & 0.0013 & 0.0003 \\
\hline 21 Motor vehicles, trailers and semi-trailers & 0.0020 & 0.0054 & 0.0075 \\
\hline 22 Building and repairing of ships and boats & 0.0008 & 0.0003 & 0.0047 \\
\hline 23 Aircraft and spacecraft & 0.0156 & 0.0219 & 0.0000 \\
\hline 24 Railroad equipment and transport equipment n.e.c. & 0.0001 & 0.0001 & 0.0000 \\
\hline 25 Manufacturing, n.e.c.; recycling (include furniture) & 0.0001 & 0.0002 & 0.0002 \\
\hline So Prepad by the aut, on the basis of the Bazlan & & & \\
\hline
\end{tabular}

Source: Prepared by the author, on the basis of the Brazilian Geographical and Statistical Institute (IBGE), Input-output tables, 2000 and 2005. 
Chapter VIII

\title{
Value chains in Colombian exports to the European Union: How inclusive are they?
}

\author{
José Durán Lima \\ Sebastián Castresana
}

Nanno Mulder

\section{Introduction}

In recent years, Colombia has stepped up its efforts to internationalize its economy. Illustrations of this include the negotiation of a network of (partial) free trade agreements (FTAs) with countries in the region (such as Costa Rica in 2013, and Chile, Mexico and Peru in 2014) and with countries outside the region: Canada and the United States and, more recently (June 2012), the European Union. These agreements generate new opportunities in the Colombian economy, in particular in export-intensive sectors and other firms that sell inputs to these sectors. However, few studies have estimated how great these benefits may be.

In this chapter, the aim is to evaluate the benefits of the Association Agreement between the European Union and Colombia, in terms of domestic value chains, employment, poverty and inequality. We assess which export clusters have the strongest links with the rest of the economy, using the 2005 input-output table. Moreover, we analyse the direct and indirect employment associated with exports by destination market. Special emphasis is placed on the likely effects of the association agreement 
between Colombia and the European Union. We review earlier studies on these effects and look into the characteristics and dynamics of bilateral trade, the tariff structure existing before the signing of the agreement and the main outcomes of trade negotiations. Moreover, we describe the methodology for evaluating the social outcomes of two scenarios of the Association Agreement, while section E describes the main outcomes.

\section{A. Exports and value chains}

\section{Backward linkages of the export sector to the domestic economy}

Over the past two decades, production and international trade have been increasingly fragmented and organized around production networks and value chains, both in Colombia and worldwide. The degree to which these production linkages have evolved between the export sectors and the rest of the economy in Colombia can be assessed using the 2005 input-output table produced by the National Administrative Department of Statistics (DANE).

The selection of export sectors with strong backward linkages to the rest of the economy was done using the following criteria:

(a) Strength of backward linkages as shown by the RasmussenHirschman Index (RHI). ${ }^{1}$ All sectors with a value of the index above 1 are selected, which means that one extra unit of exports generates an additional demand to the rest of the economy which is higher than the average of all sectors;

(b) Share in total exports: those sectors that represent at least one percent of total exports;

(c) Depth of the value chain as approximated by the HirschmanHerfindahl Index (HHI). Using the domestic intermediate consumption matrix, we choose those sectors in which purchases of intermediate products from other sectors are most diversified (HHI index below 0.18). ${ }^{2}$

These criteria are used to split all sectors into two categories: those with relatively stronger backward linkages (fulfilling the first criterion) and the rest (see table VIII.1). The former category covers almost half (47\%) of total exports. Out of a total of 61 sectors, 28 have stronger domestic links with a weighted average of the RHI above 1 . Moreover, it turns out that this group's purchases of inputs from other sectors are more diversified $(0.16)$ than those of the second group (0.47).

For an explanation and calculation of this index, see Schuschny (2005), pp. 37-38.

For an explanation and calculation of this index, see Durán Lima and Alvarez (2011), pp. 78-79. 
Table VIII.1

Sectors with stronger and weaker backward linkages, 2005

\begin{tabular}{|c|c|c|c|}
\hline \multirow{2}{*}{ Number of sectors } & \multicolumn{3}{|c|}{ Selection criteria } \\
\hline & $\mathrm{XT}^{\mathrm{a}}$ & $\mathrm{RHI}^{\mathrm{b}}$ & $\mathrm{HHI}^{\mathrm{c}}$ \\
\hline \multicolumn{4}{|l|}{ Export sectors with stronger backward linkages ( 28 sectors) } \\
\hline $\begin{array}{l}\text { Coffee and related products, chemicals, agricultural products, } \\
\text { minerals, transport equipment, metallurgical products and some } \\
\text { services such as air transport. }\end{array}$ & $47 \%$ & 1.12 & 0.16 \\
\hline \multicolumn{4}{|l|}{ Export sectors with weaker backward linkages (33 sectors) } \\
\hline $\begin{array}{l}\text { Crude oil, coal, natural gas, refined oil products, other agricultural } \\
\text { products, distribution and many services such as public administration, } \\
\text { education, domestic servants, real-estate services } \\
\text { and water distribution. }\end{array}$ & $53 \%$ & 0.84 & 0.47 \\
\hline \multicolumn{4}{|c|}{$\begin{array}{l}\text { Source: Prepared by the authors on the basis of information from the National Administrative Department } \\
\text { of Statistics (DANE), "2005 Input-output table". Weighted indices using export values as weights. } \\
\text { a Share in total exports. } \\
\text { b Rasmussen-Hirschman Index: values above } 1 \text { indicate above average backward linkages. } \\
\text { c Herfindahl-Hirschman Index: values between } 0 \text { and } 0.10 \text { indicate high diversification, between } 0.10 \text { and } \\
0.18 \text {-moderate concentration and above } 0.18 \text { high concentration. }\end{array}$} \\
\hline
\end{tabular}

The 28 sectors with strong backward linkages include several types of manufactures, such as chemicals, metallurgical products, textiles, transport equipment, rubber and plastics, non-metallic minerals and machinery and equipment. These products account for a quarter of total exports (see table VIII.2). This category also includes some of the ten most exported products and services: coffee and related products (7\% of total exports) and air transport $(3 \%)$. The former has strong backward linkages, but its purchases of intermediate products are highly concentrated ( $\mathrm{IHH}=0.66)$. The list of 28 sectors also includes agricultural and agro-industrial products such as meat, fish, sugar and brown sugar, cacao, chocolate, skin and leather products. Each sector has an export share of $0.9 \%$ to $1.2 \%$. Of these sectors, only meat, fish, sugar and cinnamon present a concentrated purchasing pattern, notwithstanding the fact that their RHI is above 1.

Fourteen sectors have a share in total exports below $1 \%$, but show above average backward linkages. Their purchases of intermediate products are reasonably diversified, as shown by a higher number of backward linkages (36 on average), in particular in the goods-producing sector. In this group, products that stand out are starches and their by-products, wood products, cork, straw and related products, cacao, chocolate and confectionary products. Within services, auxiliary transport services, hotels and restaurants, and maintenance and repair services deserve attention. The first is strongly linked to the goods trade and the second to tourism. 
Table VIII.2

Ranking of products with significant backward linkages, 2005 (Indices and percentages)

\begin{tabular}{|c|c|c|c|c|}
\hline Sector & $\begin{array}{c}\text { Number of } \\
\text { backward linkages }\end{array}$ & $\mathrm{HH}^{\mathrm{a}}$ & $\mathrm{RH} \mathrm{I}^{\mathrm{b}}$ & $\begin{array}{l}\text { Share in } \\
\text { exports }\end{array}$ \\
\hline 1 Coffee and threshing & 24 & 0.66 & 1.28 & 7.2 \\
\hline 2 Chemicals and substances & 46 & 0.11 & 1.03 & 7.2 \\
\hline 3 Basic metallurgical products & 35 & 0.16 & 1.14 & 5.4 \\
\hline 4 Knitting and crochet; clothing & 37 & 0.16 & 1.15 & 4.1 \\
\hline 5 Transport equipment & 33 & 0.12 & 1.02 & 3.2 \\
\hline 6 Rubber and plastic products & 37 & 0.15 & 1.07 & 2.0 \\
\hline 7 Air transport & 25 & 0.13 & 1.02 & 2.0 \\
\hline 8 Non-metallic products & 33 & 0.08 & 1.06 & 1.9 \\
\hline 9 Other machinery and electrical supply & 31 & 0.09 & 1.03 & 1.7 \\
\hline 10 Machinery and equipment & 29 & 0.17 & 1.08 & 1.3 \\
\hline 11 Paper and cardboard products & 36 & 0.11 & 1.16 & 1.2 \\
\hline 12 Meat and fish & 35 & 0.51 & 1.45 & 1.2 \\
\hline 13 Sugar & 29 & 0.37 & 1.20 & 1.2 \\
\hline 14 Other food products & 38 & 0.06 & 1.17 & 1.0 \\
\hline 15 Cocoa, chocolate y confectionary products & 36 & 0.07 & 1.20 & 0.9 \\
\hline 16 Editing, printing and similar articles & 28 & 0.16 & 1.08 & 0.9 \\
\hline 17 Hide, leather products and footwear & 34 & 0.11 & 1.18 & 0.9 \\
\hline 18 Complementary transport services & 23 & 0.10 & 1.01 & 0.9 \\
\hline 19 Textiles & 31 & 0.11 & 1.04 & 0.7 \\
\hline 20 Milling products, starches and their products & 45 & 0.14 & 1.15 & 0.5 \\
\hline 21 Natural textile fibre, thread and yarn & 30 & 0.16 & 1.10 & 0.5 \\
\hline 22 Other manufactured goods & 36 & 0.08 & 1.01 & 0.5 \\
\hline 23 Furniture & 33 & 0.09 & 1.18 & 0.4 \\
\hline 24 Beverages & 34 & 0.07 & 1.08 & 0.2 \\
\hline 25 Wood, cork, straw and braiding material products & 37 & 0.11 & 1.16 & 0.1 \\
\hline 26 Hotels and restaurants & 38 & 0.07 & 1.17 & 0.0 \\
\hline 27 Construction of building and repair & 28 & 0.14 & 1.06 & 0.0 \\
\hline 28 Large construction works & 26 & 0.12 & 1.06 & 0.0 \\
\hline Total 28 sectors (averages) & 33 & 0.16 & 1.12 & 47.1 \\
\hline
\end{tabular}

Source: Prepared by the authors on the basis of information from the 2005 input-output table and other official data.

a Herfindahl-Hirschman Index: values between 0 and 0.10 indicate high diversification, between 0.10 and 0.18 -moderate concentration and above 0.18 high concentration.

b Rasmussen-Hirschman Index: values above 1 indicate above average backward linkages. 


\section{Domestic value chains related to exports to the European Union}

The same procedures were applied to Colombian exports to the European Union (see table VIII.3). Out of the ten predominant sectors in exports to the European Union (accounting for 90\% of the total in 2005), seven showed above average backward linkages: coffee and threshed coffee products (representing $21 \%$ of exports to the European Union), basic metals (12\%), meat and fish $(2 \%)$, leather and footwear $(1 \%)$, textiles and clothing and nonmetallic mineral products. Using 2010 data, we estimated that $38 \%$ of exports to the European Union had above average backward linkages. Two sectors have below average backward linkages: coal and other agricultural products. These two categories accounted for the largest shares in total exports to the European Union: 36\% and 15\% of the total, respectively, in 2005 .

Table VIII.3

Colombia: export sectors to the European Union with strongest backward linkages, 2005

(Indices and percentages)

\begin{tabular}{|c|c|c|c|c|c|c|}
\hline \multirow{3}{*}{$\begin{array}{l}\text { Sectors (percentage } \\
\text { of total exports to the } \\
\text { European Union) }\end{array}$} & \multicolumn{6}{|c|}{ Indicators } \\
\hline & \multicolumn{3}{|c|}{$\begin{array}{l}\text { Proxy indicators } \\
\text { of the depth of } \\
\text { backward linkages }\end{array}$} & \multicolumn{3}{|c|}{$\begin{array}{c}\text { Share of destination } \\
\text { market in total exports } \\
\text { of sector }\end{array}$} \\
\hline & $\begin{array}{l}\text { Number of } \\
\text { linkages }\end{array}$ & $\mathrm{HHI}^{\mathrm{b}}$ & $\mathrm{RHI}^{\mathrm{c}}$ & $\begin{array}{l}\text { European } \\
\text { Union }\end{array}$ & $\begin{array}{l}\text { United } \\
\text { States }\end{array}$ & $\begin{array}{c}\text { European } \\
\text { Union and } \\
\text { United } \\
\text { States }\end{array}$ \\
\hline Coal $(36.2 \%)$ & 19 & 0.09 & 0.8 & 42.0 & 34.5 & 76.5 \\
\hline $\begin{array}{l}\text { Coffee and its preparations } \\
(20.9 \%)\end{array}$ & 24 & 0.66 & 1.3 & 36.3 & 35.1 & 71.4 \\
\hline $\begin{array}{l}\text { Other agricultural products } \\
(14.9 \%)\end{array}$ & 34 & 0.12 & 0.8 & 27.9 & 62.5 & 90.4 \\
\hline $\begin{array}{l}\text { Basic metallurgical products } \\
(11.6 \%)\end{array}$ & 35 & 0.16 & 1.1 & 16.5 & 39.0 & 55.5 \\
\hline Meat and fish (2.4\%) & 35 & 0.51 & 1.4 & 33.1 & 12.7 & 45.8 \\
\hline $\begin{array}{l}\text { Leather products and } \\
\text { footwear }(1.4 \%)\end{array}$ & 34 & 0.11 & 1.2 & 19.8 & 25.6 & 45.4 \\
\hline Metallic minerals $(1.2 \%)$ & 25 & 0.07 & 0.9 & 73.1 & 19.3 & 92.4 \\
\hline Clothing (knitting) (0.9\%) & 37 & 0.16 & 1.2 & 2.6 & 49.9 & 52.6 \\
\hline Other textiles $(0.5 \%)$ & 31 & 0.11 & 1.0 & 9.0 & 24.5 & 33.6 \\
\hline $\begin{array}{l}\text { Non-metallic mineral } \\
\text { products }(0.4 \%)\end{array}$ & 33 & 0.08 & 1.1 & 2.7 & 50.3 & 53.0 \\
\hline All ten sectors $(90.4 \%)$ & 23 & 0.22 & 0.9 & 23.7 & 41.3 & 68.1 \\
\hline
\end{tabular}

Source: Prepared by the authors on the basis of information from the 2005 input-output table and the United Nations Commodity Trade Statistics Database (COMTRADE).

a Includes banana, fruits, vegetables and fresh flowers as main export sectors.

b Herfindahl-Hirschman Index, Values between 0 and 0.10 indicate high diversification, between 0.10 and 0.18 -moderate concentration and above 0.18 high concentration.

c Rasmussen-Hirschman Index, Values above 1 indicate above average backward linkages. 
As a complement to the previous analysis, this section describes the organization and governance of the four main domestic value chains in exports to the European Union. These categories are coal, coffee, metallurgical products, leather and footwear.

\section{(a) Coal}

The mining sector in Colombia is of vital importance, representing the third largest export sector. Together with the strong expansion in coal extraction over the past twenty years, government and mining companies have tried to improve working and environmental conditions and increase benefits for local communities. Most (70\%) extracted coal is exported, while $30 \%$ is used domestically for household consumption and in different sectors such as textile and cement factories, electricity power stations.

The coal sector's main domestic backward linkages are to the following sectors: (i) exploration of coal deposits in terms of volumes and quality; (ii) exploitation services, which cover design and building of access routes, preparation of the mine in terms of delimitation of areas within the deposits and coal extraction through different methods; (iii) coal processing, using chemicals to obtain end products, such as coke and gas; and (iv) domestic and international transport. Although its backward linkages are the weakest of all 10 sectors analysed, this sector accounts for $36 \%$ of total exports, of which $42 \%$ are sold to the European Union.

The "inclusive" character of coal mining depends not only on the creation of direct and indirect employment but also on its payments of royalties for sustainable development. In 2010, three funds were created from these collected royalties: one for science and technology, another for regional development and a third for regional compensation. By law, mining companies are also obliged to create decent jobs, promote sustainable development, protect the environment and improve the infrastructure of local schools (Law 1382, 2010). Some mining companies also carry out projects to improve the working conditions of workers and social conditions for themselves and their families.

\section{(b) Coffee and its preparations}

The value chain of coffee and its preparations is probably the most inclusive export product in Colombia. This production chain includes different stages. First, there are the agricultural activities on the plantation - such as sowing, harvesting and drying. Dried coffee is transported to threshing plants, where it is peeled to turn it into green coffee (without roasting). The final production stages are coffee roasting, grinding and packaging of its different types (caffeinated, decaffeinated, or mixed). 
Coffee is also used as an input in other industries to produce for example candies and pharmaceuticals.

In 1927, a large group of small coffee farmers established the National Federation of Coffee Growers (FNC). To date, it is the main trading entity of the coffee sector. This private, non-profit Federation brings together over 500,000 families in all rural areas where coffee is produced. The FNC represents the Colombian coffee sector at the national and international level, exporting US\$ 2.21 billion in 2010. FNC participates in the entire coffee value chain.

This Federation has three main goals: to promote a sustainable business; to strengthen social networks in coffee-growing communities; and to advertise Colombian coffee abroad as one of the best in the world. At the centre of the Federation are the coffee producer and his or her family. Its organization is highly democratic (with 15 departmental boards and 356 subsidiary municipal committees), the aim being to make decisions that represent the views of the coffee producers and their families.

The Federation's main role is to purchase coffee from its small producers at a guaranteed price. This helps to avoid large buyers dictating unfair prices and purchase conditions on small coffee growers. The reference price is fixed on a daily basis using different criteria. The Federation has a network of 511 purchase points and 36 cooperative businesses. In 2008, FNC accounted for $27 \%$ of total Colombian coffee exports. Its coffee brand "Juan Valdés" has become internationally renowned. From 2005 onwards, the Government of Colombia granted its coffee a certificate of origin. In 2007, the European Union recognized this product under its Protected Geographical Indication (PGI). The quality recognition by consumers was instrumental in increasing the coffee price and improving the sustainable long-term development of the industry. In addition to exporting directly, the company Juan Valdés opened stores and cafés in Colombia and other countries in Latin America, as well as in Spain and the United States.

The Foundation also provides other types of support to small coffeegrowers. This includes technical assistance to increase productivity and quality of coffee, credit, agricultural research, environmental protection, social assistance and community infrastructure. With this support, FNC looks to maintain its country's coffee culture together with its capital, social and strategic character.

More than one third of total coffee exports go to the European Union, accounting for $20 \%$ of total exports to that grouping. Given its characteristics and large participation in exports to the European Union, the coffee chain seems the most inclusive. 


\section{(c) Iron and steel}

The iron and steel value chains are not very inclusive in terms of participation by small and medium-sized enterprises (SMEs). This is because of high fixed costs, economies of scale and great capital intensity. Basic metal industries consist of different production stages starting from iron and steel extraction to different production lines. Iron and steel products are inputs to many sectors and exported mainly to the United States, European Union and neighbouring countries, especially the Bolivarian Republic of Venezuela, Ecuador and Peru. The European Union absorbs $16 \%$ of total exports (see table VIII.3). This sector shows comparatively stronger domestic backward production linkages than other sectors, but its penetration of European Union value chains is small in contrast to Latin American value chains.

\section{(d) Hides, leather products and footwear}

The typical leather value chain includes cattle ranching, slaughter houses, tannery, production of footwear and other leather products, and sale on the local or foreign market. Small producers are most present in skin processing and production of leather products, working often with outdated, inefficient and contaminating technologies. Only a small share of production is exported by a few large firms.

To improve inclusiveness of this value chain in terms of SME participation and their export intensity, it is necessary to improve their competitiveness. This can be done by reducing informality, improving productivity by working with modern technology, better design, logistics and distribution. To share the cost of these investments, business owners must be encouraged to join forces and cooperate.

\section{Direct and indirect employment in sectors exporting to the European Union}

This section aims to evaluate the inclusiveness of the export value chains to the European Union in terms of the generation of (direct and indirect) employment. Moreover, we give some examples of governance and organization of the value chain, which, in turn, determines who in the value chain absorbs most of the value added.

Employment in the export sector is estimated using the following sources: (a) intermediate use table at basic prices. The value of production and exports are taken from the 2005 input-output table (IOT); (b) Employment data by sector according to the IOT are from DANE and based on their 2005 Continuous Household Survey; (c) Exports by destination are from the United Nations COMTRADE database using the 
2002 Harmonized System. These data are adapted to the classification of the IOT using a DANE correspondence table.

We estimate the employment required for US\$ 1 million of production in each sector. This number is obtained using the employment coefficient of the 2005 IOT. In that year, an average of 131 persons was needed to produce US\$ 1 million of output. The sectors with the highest employment requirements are in services, agriculture and fishing (see table VIII.4). ${ }^{3}$

\section{Table VIII.4}

\section{Employment requirements per US\$1 million of production in sectors} which export predominantly to the European Union, 2005

(Thousands of workers)

\begin{tabular}{lcccc}
\hline Sectors & $\begin{array}{c}\text { Direct } \\
\text { employment }\end{array}$ & $\begin{array}{c}\text { Indirect } \\
\text { employment }\end{array}$ & $\begin{array}{c}\text { Total } \\
\text { employment }\end{array}$ & $\begin{array}{c}\text { Degree of } \\
\text { linkages }\end{array}$ \\
\hline Coal & 18 & 30 & 49 & Weak \\
\hline Coffee and derived products & 13 & 325 & 338 & Strong \\
\hline Other agricultural products & 241 & 15 & 256 & Weak \\
\hline Basic metal products & 24 & 38 & 62 & Strong \\
\hline Meat and fish & 13 & 112 & 124 & Strong \\
\hline $\begin{array}{l}\text { Leather products and footwear } \\
\text { (including hides) }\end{array}$ & 108 & 40 & 149 & Strong \\
\hline Metallic minerals & 45 & 30 & 75 & Weak \\
\hline Knitwear and crochet; clothing & 90 & 38 & 128 & Strong \\
\hline Textile products except clothing & 53 & 33 & 85 & Medium \\
\hline Non-metallic mineral products & 36 & 30 & 66 & Medium \\
\hline $\begin{array}{l}\text { Other manufactured goods, not } \\
\text { specified elsewhere }\end{array}$ & 76 & 25 & 101 & Medium \\
\hline Other machinery and electrical supply & 28 & 27 & 55 & Medium \\
\hline Food products, not specified elsewhere & 27 & 57 & 84 & Medium \\
\hline Furniture & 101 & 49 & 150 & Medium \\
\hline $\begin{array}{l}\text { Wood products, cork, straw and } \\
\text { braiding material }\end{array}$ & 111 & 55 & 166 & Medium \\
\hline Total & 90 & 40 & 131 & \\
\hline Sour: & & & & \\
\hline
\end{tabular}

Source: Prepared by the authors on the basis of information from the National Administrative Department of Statistics (DANE), "2005 Input-output table".

Note: Weak linkages= $\mathrm{RHI}$ index below 1.0; Strong $=\mathrm{RHI}>1$; $\mathrm{IHH}<0.18$; Medium $=\mathrm{RHI}>1$, but $\mathrm{IHH}>$ 0.18 , or alternatively, the proportion exported to the European Union is below $1 \%$. See table VIII.2 for explanations of $\mathrm{HHI}$ and $\mathrm{RHI}$, and table VIII.3 for the weights of the sectors in total exports to the European Union.

The most employment-intensive sectors in services are cultural services, sports and other non-market services, sewage and other waste treatment services, sanitation and other environmental protection services, water, infrastructure construction, and rental and leasing services. 
The coffee cluster has the highest employment contents of all export sectors: 338 jobs for every US\$ 1 million worth of production. This sector's indirect employment requirement is noticeably larger than the direct employment needs. The coffee value chain includes threshing, drying, packaging, transportation, etc (see diagram VIII.1). This cluster belongs primarily to the agricultural sector, which provides the largest part of its inputs. It is also connected to other sectors such as distribution, business services, chemicals, metal products, and transport. Compared with other export sectors, coffee is the one that generates most indirect employment (567,000 jobs).

\section{Diagram VIII.1 \\ Backward linkages of the coffee sector, 2005}

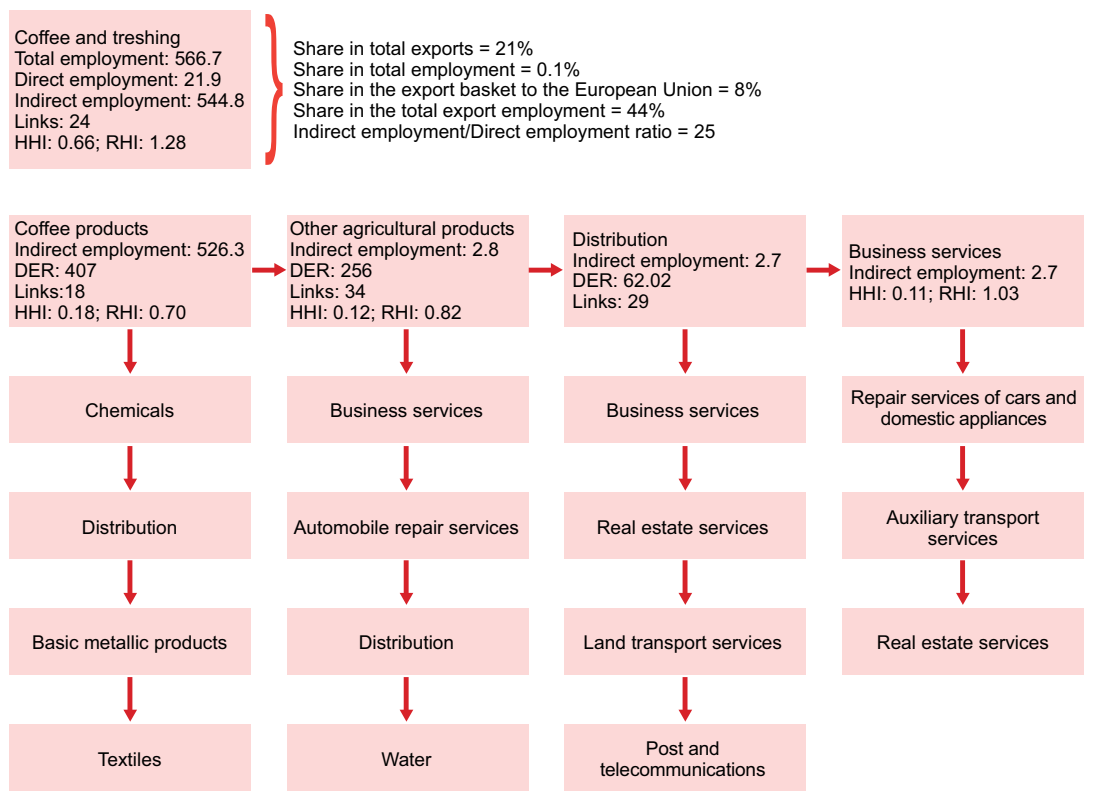

Source: Prepared by the authors on the basis of information from the National Administrative Department of Statistics (DANE), "2005 Input-output table".

Note: $\mathrm{DER}=$ direct employment requirements; $\mathrm{RHI}=$ Rasmussen-Hirschman Index: values above 1 indicate above average backward linkages; $\mathrm{HHI}=$ Herfindahl-Hirschman Index: values between 0 and 0.10 indicate high diversification, between 0.10 and 0.18 -moderate concentration and above 0.18 high concentration.

The other agricultural products sector has a total employment requirement of 256 people for every US\$ 1 million, especially in terms of direct employment. This primary sector is highly labour-intensive.

The employment associated with exports to all destinations was estimated using the labour coefficients and export vector at the sectoral 
level. Table VIII.5 presents the results in terms of gross output, exports, export-related employment and total employment in $2005 .^{4}$ The oil and mining sector accounted for one third of total goods exports, was labour-intensive and had high export intensity (63\% of gross output). The second-largest and third-largest export sectors were chemistry and pharmaceuticals, and food, drink and tobacco, respectively. The latter sector exported less than oil and mining, but its gross output was almost twice that of oil and mining. In terms of export employment, food, drink and tobacco constituted the largest sector, followed by agriculture, forestry, hunting and fishing. In 2005, total exports generated a little over 2,035,000 jobs, predominantly in the food, beverage and tobacco, agriculture, forestry, hunting and fishing, and oil and mining sectors (see table VIII.5).

\section{Table VIII.5}

Output, exports and total and export-related production and employment, 2005

\begin{tabular}{|c|c|c|c|c|c|c|}
\hline & $\begin{array}{l}\text { Gross output } \\
\text { (billions of } \\
\text { pesos) } \\
\text { (A) }\end{array}$ & $\begin{array}{l}\text { Exports } \\
\text { (billions of } \\
\text { pesos) } \\
\text { (B) }\end{array}$ & $\begin{array}{l}\text { Export } \\
\text { share } \\
(\mathrm{C})=\mathrm{B} / \mathrm{A}\end{array}$ & $\begin{array}{c}\text { Total } \\
\text { employment } \\
\text { (thousands) } \\
\text { (D) }\end{array}$ & $\begin{array}{l}\text { Employment } \\
\text { in export } \\
\text { sector } \\
\text { (thousands) } \\
\text { (E) }\end{array}$ & $\begin{array}{l}\text { Percentage } \\
\text { of total } \\
(F)=E / D\end{array}$ \\
\hline $\begin{array}{l}\text { Agriculture, forestry, } \\
\text { hunting and fishing }\end{array}$ & 16668 & 1718 & 10.3 & 3156 & 415 & 13.1 \\
\hline Oil and mining & 11907 & 7439 & 62.5 & 202 & 230 & 113.7 \\
\hline $\begin{array}{l}\text { Food, beverages } \\
\text { and tobacco }\end{array}$ & 21290 & 3056 & 14.4 & 534 & 723 & 135.5 \\
\hline $\begin{array}{l}\text { Textiles, clothing } \\
\text { and footwear }\end{array}$ & 7450 & 1441 & 19.3 & 523 & 177 & 33.8 \\
\hline $\begin{array}{l}\text { Wood, cellulose and } \\
\text { paper }\end{array}$ & 5381 & 527 & 9.8 & 201 & 36 & 18.1 \\
\hline $\begin{array}{l}\text { Chemical and } \\
\text { pharmaceutical } \\
\text { products }\end{array}$ & 13831 & 3664 & 26.5 & 102 & 85 & 83.3 \\
\hline Rubber and plastics & 3011 & 469 & 15.6 & 78 & 26 & 32.9 \\
\hline $\begin{array}{l}\text { Non-metallic } \\
\text { minerals }\end{array}$ & 3693 & 445 & 12.0 & 123 & 29 & 23.9 \\
\hline $\begin{array}{l}\text { Metals and by- } \\
\text { products, machinery } \\
\text { and equipment }\end{array}$ & 7999 & 1941 & 24.3 & 171 & 115 & 67.0 \\
\hline $\begin{array}{l}\text { Automobiles and } \\
\text { their parts and } \\
\text { pieces }\end{array}$ & 2659 & 753 & 28.3 & 34 & 31 & 90.2 \\
\hline Other manufactures & 2258 & 322 & 14.3 & 228 & 25 & 11.0 \\
\hline Other activities & 156745 & 1519 & 1.0 & 10718 & 143 & 1.3 \\
\hline Total & 252893 & 23293 & 9.2 & 16071 & 2035 & 12.7 \\
\hline
\end{tabular}

Source: Prepared by the authors on the basis of information from the National Administrative Department of Statistics (DANE), "2005 Input-output table"

4 Due to space constraints, the 61 sectors of the input-output table were condensed into 12 sectors. 
In $2005,12.7 \%$ of total employment was related directly or indirectly to exports. ${ }^{5}$ Within the goods-producing sector, export-related employment was much higher (35.3\%). Oil and mining, and food, drink and tobacco are the sectors with a higher than average share of export-related employment. The non-tourism services sector has a very low share $(1.3 \%)$ of employment linked to exports.

Employment linked to exports can be split into two parts: direct and indirect employment. The first is the number of persons employed by the firms that are directly engaged in exporting activities, while the second are workers in upstream industries that supply inputs to these firms. In 2005 , indirect employment was $20 \%$ greater than direct employment. That is, every single worker in the export sector generates 1.2 indirect jobs. The coffee and threshed products sector is the one that not only creates most exports-linked employment, but also generates most indirect employment (almost 25 indirect jobs for each direct job) (see table VIII.6).

Table VIII.6

Total employment in sectors linked to exports to the European Union, 2005 (Thousands of workers)

\begin{tabular}{|c|c|c|c|c|}
\hline Sectors & $\begin{array}{c}\text { Direct } \\
\text { employment } \\
(D E)\end{array}$ & $\begin{array}{l}\text { Indirect } \\
\text { employment } \\
\text { (IE) }\end{array}$ & $\begin{array}{c}\text { Total } \\
\text { employment } \\
\text { (TE) }\end{array}$ & $\begin{array}{l}\text { Ratio of IE } \\
\text { to } \mathrm{DE}\end{array}$ \\
\hline Coal & 46.5 & 77.0 & 123.5 & 1.7 \\
\hline Coffee and threshed products & 22.0 & 544.8 & 566.8 & 24.8 \\
\hline Other agricultural products & 362.0 & 22.9 & 384.9 & 0.1 \\
\hline Basic metallurgical products & 29.9 & 47.6 & 77.5 & 1.6 \\
\hline Meat and fish & 3.4 & 30.1 & 33.6 & 8.8 \\
\hline Leather and footwear products (including hides) & 22.0 & 8.2 & 30.1 & 0.4 \\
\hline Metallic minerals & 35.5 & 23.1 & 58.6 & 0.7 \\
\hline Knitting and crochet; clothing & 86.6 & 37.0 & 123.6 & 0.4 \\
\hline Textiles excluding clothing & 8.0 & 5.0 & 13.0 & 0.6 \\
\hline Non-metallic mineral products & 16.1 & 13.2 & 29.3 & 0.8 \\
\hline Other manufactured goods & 8.5 & 2.8 & 11.3 & 0.3 \\
\hline Other machinery and electrical supply & 10.8 & 10.6 & 21.4 & 1.0 \\
\hline Other food products & 6.1 & 12.8 & 18.9 & 2.1 \\
\hline Furniture & 9.3 & 4.4 & 13.7 & 0.5 \\
\hline Wood, cork and straw products & 3.4 & 1.7 & 5.1 & 0.5 \\
\hline Fifteen main sectors & 670.0 & 841.1 & 1511.1 & 1.3 \\
\hline Other products & 244.8 & 279.2 & 524.0 & 1.1 \\
\hline Total & 914.8 & 1120.3 & 2035.1 & 1,2 \\
\hline Fifteen main total products as a share of total & 73.2 & 75.1 & 74.3 & \\
\hline
\end{tabular}

Source: Prepared by the authors on the basis of information from the National Administrative Department of Statistics (DANE), "2005 Input-output table"

5 From 1997 to 2005, export linked employments grew at a lower average annual rate (1.1\%) than total employment (3.4\%). As a consequence, the share of export-related employment fell from $15 \%$ to $13 \%$ over this period. 
The employment embodied in exports varies by destination market (see figure VIII.1). This is because of differences not only in the dollar values exported to each market, but also in the composition of the export basket to each market and associated job requirements. Employment related to exports to the European Union account for $24 \%$ of total embodied employment in exports, whereas this destination accounts for only $15 \%$ of the total value of exports. This can be explained by the concentration of European Union exports in sectors with high employment requirements per dollar of output.

\section{Figure VIII.1 \\ Participation of sectors in export value and employment embodied in exports by trading partner, 2005}

(Percentages)

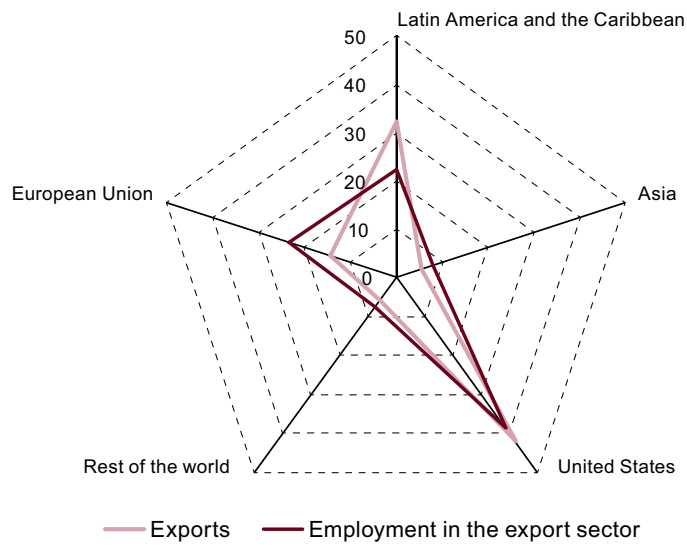

Source: Prepared by the authors on the basis of information from the National Administrative Department of Statistics (DANE), "2005 Input-output table" and the United Nations Commodity Trade Statistics Database (COMTRADE).

After Asia, the European Union is the destination market that creates proportionally most indirect jobs. Exports to the European Union create two indirect jobs for each direct job (see table VIII.7). This is double the indirect to direct employment ratio of exports to the United States. This means that exports to the European Union create comparatively more employment than exports to the United States. Another characteristic of jobs embodied in European Union exports is their low share of female employment (33\%), which is less than that of exports to Latin America and the Caribbean (39\%). 
Figure VIII.2

Participation of sectors in export value and employment embodied in exports to the European Union, 2005

(Percentages)

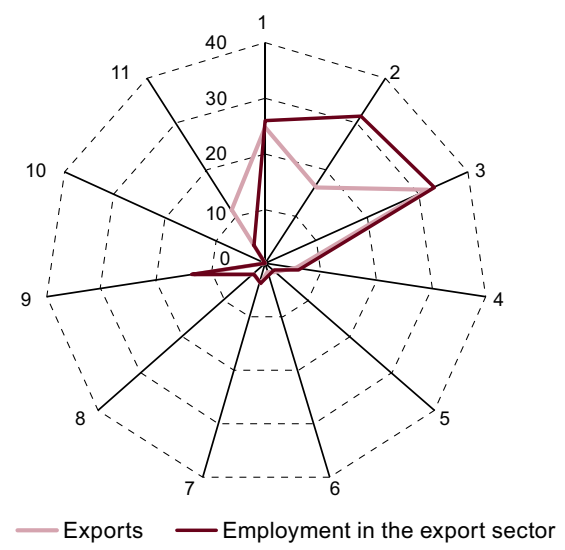

Source: Prepared by the authors on the basis of information from the National Administrative Department of Statistics (DANE), "2005 Input-output table" and the United Nations Commodity Trade Statistics Database (COMTRADE).

Note: $\quad 1=$ agricultural, forestry, hunting and fishing; $2=$ Oil and mining; $3=$ Food, beverages and tobacco; $4=$ Textiles, clothing and footwear; $5=$ Wood products, cellulose and paper; $6=$ Chemical and pharmaceutical products; $7=$ Rubber and plastics; $8=$ Non-metallic minerals; $9=$ Metal products, machinery and equipment; $10=$ Motor vehicles and parts; and $11=$ Other manufactures.

Table VIII. 7

Direct and indirect exports employment by destination market, 2005

(Thousands of workers and percentages)

\begin{tabular}{lcccccc}
\hline Destination market & $\begin{array}{c}\text { Indirect } \\
\text { employment } \\
\text { (IE) }\end{array}$ & $\begin{array}{c}\text { Direct } \\
\text { employment } \\
\text { (DE) }\end{array}$ & $\begin{array}{c}\text { Total } \\
\text { employment }\end{array}$ & IE/DE & Men & Women \\
\hline $\begin{array}{l}\text { Latin America and } \\
\text { the Caribbean }\end{array}$ & 192.0 & 226.7 & 418.8 & 1.2 & 60.8 & 39.2 \\
\hline Asia & 31.4 & 121.4 & 152.8 & 3.9 & 63.8 & 36.2 \\
\hline United States & 375.8 & 351.2 & 727.0 & 0.9 & 69.3 & 30.7 \\
\hline European Union & 160.6 & 283.0 & 443.6 & 2.0 & 67.4 & 32.6 \\
\hline Rest of the world & 155.0 & 137.9 & 292.9 & 1.3 & 63.9 & 36.1 \\
\hline $\begin{array}{l}\text { Total export } \\
\text { employment }\end{array}$ & 914.8 & 1120.3 & 2035.1 & 1.2 & 66.1 & 33.9 \\
\hline
\end{tabular}

Source: Prepared by the authors on the basis of information from the National Administrative Department of Statistics (DANE), "2005 Input-output table" and the "Continuous Household Survey", 2005. 


\section{B. Background to the Association Agreement between Colombia and the European Union}

The characteristics of bilateral trade between Colombia and the European Union will largely determine the economic and social effects of the Free Trade Agreement between the two parties. These will be reviewed in this section, together with the main conclusions from other evaluation reports, keeping in mind that this study focuses on outcomes in terms of GDP, employment, linkages, poverty and income distribution.

\section{Bilateral trade}

Bilateral trade between Colombia and the European Union is mostly interindustrial. Colombian exports to the European Union consist mainly of mining and farming products and these represent over $60 \%$ of the total. For its part, the European Union sells mostly heavy manufactures to Colombia. It should be noted that Colombia sells proportionally more agricultural products to the European Union than to other countries. The main farm products exported to the European Union are bananas, roasted coffee (decaffeinated and normal), fresh flowers, oil extracts and concentrates, as well as some fishing and livestock products. For some of these products, such as bananas, flowers and fruits, the European Union is the main export market (see figure VIII.3). In contrast, for the European Union, the Colombian market is very small and represents only $0.09 \%$ of total exports. Nevertheless, Colombia is a strategic partner for the European Union, and in particular Spain, within the Andean sub-region and within South America in terms of foreign direct investment.

Figure VIII.3

Colombia and the European Union: composition of export basket by product and destination market, 2010

(Percentages)

A.1 By product

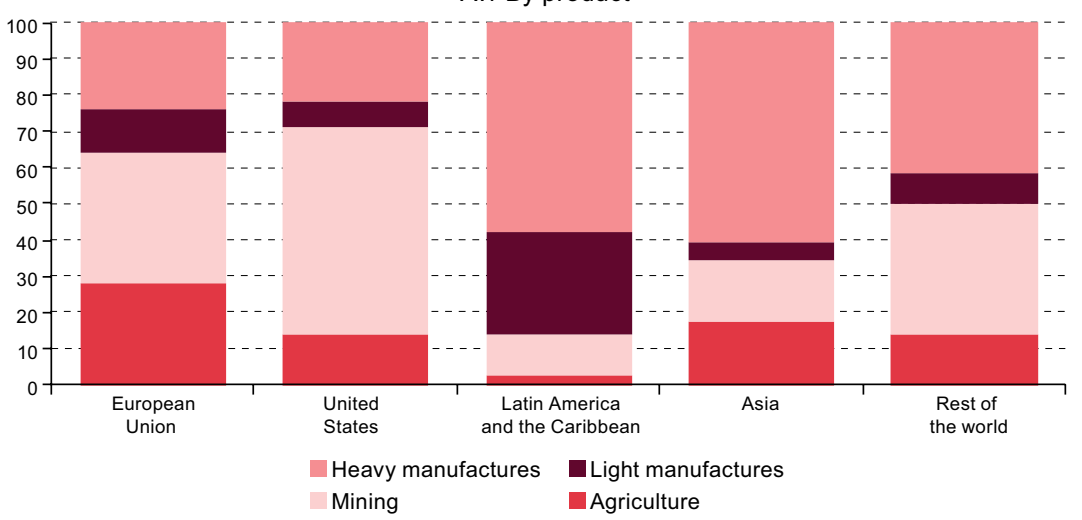


Figure VIII.3 (concluded)

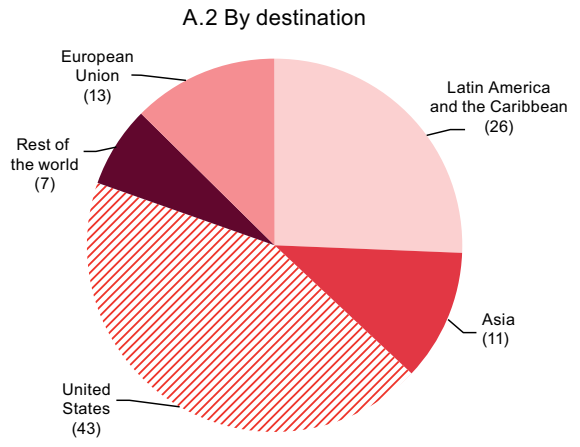

B.1 By product

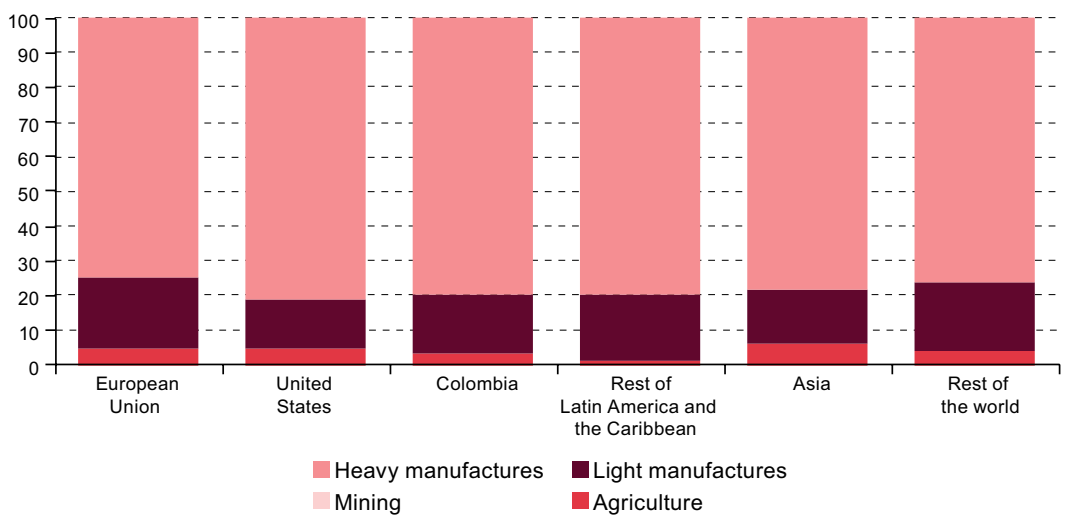

B.2 By destination

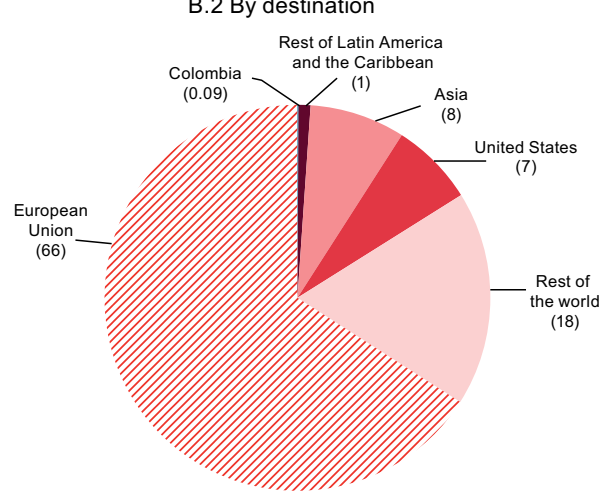

Source: Prepared by the authors on the basis of information from the Global Trade Analysis Project (GTAP) database and the National Administrative Department of Statistics (DANE). 
Although the average tariff charged by the European Union on Colombian products $(1.2 \%)$ is lower than the corresponding tariff charged by Colombia (11.7\%), this does not necessarily mean that the former market is more open. This is because the European Union applies high tariffs to particular subsectors such as fruits and vegetables, dairy products, sugar and other cereals. These products represent $18 \%$ of total Colombian exports to the European Union. Although Colombian exports to the European Union benefit from the Generalized System of Preferences (GSP), several products, including coffee, bananas, biofuel, oil, fruits, vegetables, and fish products suffer from high most favoured nation (MFN) duties (see table VIII.8).

Table VIII. 8

European Union: tariffs applied to imports from Colombia, February 2012 (In ad valorem percentages and specific duties)

\begin{tabular}{lccc}
\hline Product & $\begin{array}{c}\text { Duty heading } \\
\text { SA }\end{array}$ & $\begin{array}{c}\text { GSP+ } \\
\text { (percentages) }\end{array}$ & $\begin{array}{c}\text { MFN duty } \\
\text { (percentages) }\end{array}$ \\
\hline Coking coal & 27011210 & 0.0 & 0.0 \\
\hline Other coal & 27011290 & 0.0 & 0.0 \\
\hline Fresh bananas & 08031010 & 0.0 & 16.0 \\
\hline Dry bananas & 08031090 & 0.0 & 16.0 \\
\hline Other bananas & 08039010 & 0.0 & 176 euros \\
\hline Unroasted coffee (without decaffeination) & 09011100 & 0.0 & 0.0 \\
\hline Unroasted Coffee (decaffeinated) & 09011200 & 0.0 & 8.3 \\
\hline Coffee by-products that contain coffee & 09019090 & 0.0 & 11.5 \\
\hline Ferronickel & 72026000 & 0.0 & 0.0 \\
\hline Ferromolybdenum & 07202700 & 0.0 & 2.7 \\
\hline Coke and semi-coke of coal & 27040000 & 0.0 & 0.0 \\
\hline Coffee extracts, essences and concentrates & 21011100 & 0.0 & 9.0 \\
\hline Pigments for the fabrication of paint & 32129000 & 0.0 & 6.5 \\
\hline Pomegranate & 08109020 & 0.0 & 8.8 \\
\hline Figs and medlars & 08109075 & 0.0 & 8.8 \\
\hline Copper waste & 74040000 & 0.0 & 0.0 \\
\hline Smoked and peeled shrimp & 03061610 & 0.0 & 20.0 \\
\hline Prawns & 03061792 & 0.0 & 12.0 \\
\hline Crude animal oil & 15132110 & 0.0 & 3.2 \\
\hline Packaged animal oil (<1 kilo) & 15132130 & 0.0 & 12.8 \\
\hline Source Prear & & & 0.0 \\
\hline
\end{tabular}

Source: Prepared by the authors on the basis of official information from the Integrated Tariff of the European Communities (TARIC) database [online] http://ec.europa.eu/taxation_customs/ dds2/taric/.

In the other direction, European Union exporters of light and heavy manufactures face high tariffs when selling to customers in the Colombian market. 


\section{Outcomes of the Association Agreement}

The Association Agreement () between Colombia and the European Union consists of three pillars: political dialogue, cooperation and free trade. This chapter assesses only the impact of part of the third pillar approximated by tariff cuts. It does not measure the outcome of reductions of other trade barriers such as of rules of origin; customs and trade facilitation measures, technical obstacles, sanitary and phytosanitary measures, trade remedy measures, services, establishment and movement of capital, public procurement, intellectual property, competition, trade disputes, horizontal and institutional measures, sustainable trade and development, technical assistance and capacity building.

Colombia's main purpose in negotiating the Association Agreement was to consolidate its privileges under GSP+ and improve its access to the European Union market for its main agricultural exports, such as coffee, banana, meat and sugar. Table VIII.9 presents the bilateral tariff structure before the Association Agreement. It also shows some of the European Union's concessions to Colombia, for example the tariff cut of bananas from 176 euros to 114 euros per ton, which will be further reduced to 75 euros in 2020. Other tariff cuts apply to meat and sugar within the agreed quotas for sugar and sugar products (62,000 tons and 20,000 tons, respectively) and fine cut beef (5,600 tons) (see table VIII.9).

Colombia succeeded in excluding from import liberalization some sensitive products of its export basket, belonging to the Andean PriceBand System. They include chicken, corn, oilseeds, pork meat, poultry products and rice. In this last case, Colombia will liberalize the fixed component over a period of ten years and will maintain a variable tariff, which will be modified in accordance with fluctuations in international prices. ${ }^{6}$ In the dairy sector, tariff reduction will be carried out over a longer period (15 years) and specific products, such as powdered milk and whey, will be protected by a special safeguard if imports exceed $120 \%$ of the agreed quota.

Regarding coffee, one of Colombia's main export products, the European Union tariff was cut to zero for roasted coffee and coffee preparations. Also, a rule of origin was agreed which considers all whole bean and roasted coffee as native if they have been harvested and cultivated in member countries of the agreement (including Peru).

The Andean Price-Band System (SAFP) has two components: a fixed tariff and a variable tariff that fluctuates with international prices. When the latter are low, and likely to have a negative impact on domestic production, a tariff surcharge is levied. When international prices are high, the tariff is reduced. 
Table VIII. 9

Tariff protection structure at the product group level, baseline of the Global Trade Analysis Project (GTAP)

(Percentages)

\begin{tabular}{|c|c|c|c|c|c|c|}
\hline \multirow[b]{2}{*}{ Sectors } & \multicolumn{3}{|c|}{ Colombia to European Union } & \multicolumn{3}{|c|}{ European Union to Colombia } \\
\hline & $\begin{array}{l}\text { Sensitive } \\
\text { products }\end{array}$ & $\begin{array}{l}\text { Duty } \\
\text { charged } \\
\text { to the } \\
\text { European } \\
\text { Union }\end{array}$ & $\begin{array}{c}\text { Share of } \\
\text { European } \\
\text { Union } \\
\text { exports to } \\
\text { Colombia }\end{array}$ & $\begin{array}{l}\text { Sensitive } \\
\text { products }\end{array}$ & $\begin{array}{l}\text { Duty } \\
\text { charged to } \\
\text { Colombia }\end{array}$ & $\begin{array}{l}\text { Share of } \\
\text { Colombian } \\
\text { exports to } \\
\text { the European } \\
\text { Union }\end{array}$ \\
\hline Rice & $\mathrm{x}$ & 0.0 & 0.0 & & 0.0 & 0.0 \\
\hline Wheat & $\mathrm{x}$ & 0.0 & 0.0 & & 0.0 & 0.0 \\
\hline Other cereals & $x$ & 11.2 & 0.0 & & 1.6 & 0.0 \\
\hline Fruits and vegetables & & 13.9 & 0.1 & $X(-35.2 \%)$ & 9.0 & 10.8 \\
\hline Seeds & $\mathrm{x}$ & 9.9 & 0.0 & & 0.0 & 0.0 \\
\hline Other crops & $x$ & 6.4 & 0.4 & & 0.0 & 18.3 \\
\hline Vegetable fibre & & 1.9 & 0.0 & & 0.0 & 0.0 \\
\hline Livestock & & 7.3 & 0.1 & & 0.1 & 0.1 \\
\hline Forestry & & 4.7 & 0.0 & & 0.0 & 0.1 \\
\hline Fishing & & 4.6 & 0.0 & & 0.0 & 0.1 \\
\hline Energy extraction & & 0.0 & 0.0 & & 0.0 & 35.8 \\
\hline Mining & & 5.0 & 0.5 & & 0.0 & 0.2 \\
\hline Meat & $\mathrm{x}$ & 13.6 & 0.1 & $x$ & 0.7 & 0.1 \\
\hline Vegetable oil & & 19.6 & 0.3 & & 0.0 & 3.5 \\
\hline Dairy & $\mathrm{x}$ & 15.8 & 0.2 & $\mathrm{X}$ & 4.8 & 0.1 \\
\hline Other foods & & 17.5 & 1.8 & $X(-17.3)$ & 1.9 & 5.8 \\
\hline Sugar & $x$ & 9.6 & 0.0 & $X(-82.5)$ & 126.5 & 0.1 \\
\hline $\begin{array}{l}\text { Beverages and } \\
\text { tobacco }\end{array}$ & & 19.6 & 1.5 & $x$ & 9.1 & 0.2 \\
\hline Textiles & $x$ & 17.0 & 2.4 & & 0.0 & 0.4 \\
\hline Clothing & $x$ & 19.6 & 0.8 & & 0.0 & 1.0 \\
\hline Leather and footwear & & 16.6 & 0.3 & & 0.1 & 1.2 \\
\hline Wood & & 14.6 & 0.9 & & 0.0 & 0.1 \\
\hline Paper & & 13.0 & 5.4 & & 0.0 & 0.3 \\
\hline Oil by-products & & 9.5 & 0.3 & & 0.0 & 2.5 \\
\hline Chemicals & & 8.6 & 27.6 & & 0.0 & 2.2 \\
\hline Mineral products & & 14.0 & 1.5 & & 0.0 & 0.4 \\
\hline Metals & & 7.7 & 4.1 & & 0.0 & 14.9 \\
\hline Metal products & & 13.6 & 2.0 & & 0.0 & 0.3 \\
\hline Car parts & & 25.7 & 9.0 & & 0.0 & 0.1 \\
\hline Transport equipment & $x$ & 4.9 & 1.2 & & 0.0 & 0.1 \\
\hline Other manufactures & & 8.3 & 5.6 & & 0.0 & 0.9 \\
\hline $\begin{array}{l}\text { Machinery and } \\
\text { equipment }\end{array}$ & & 8.3 & 33.8 & & 0.1 & 0.7 \\
\hline Services & & 0.0 & 0.0 & & 0.0 & 0.0 \\
\hline Simple average & & 10.7 & $\ldots$ & & 4.8 & $\ldots$ \\
\hline Weighted average & & 11.1 & $\ldots$ & & 1.2 & $\ldots$ \\
\hline
\end{tabular}

Source: Prepared by authors on the basis of information from the Global Trade Analysis Project (GTAP) database and the Association Agreement. 
Colombia also lowered various tariff peaks on European Union imports. However, bilateral tariff liberalization was asymmetrical and mostly favoured Colombian exports.

With respect to industrial products, the European Union liberalized $99.9 \%$ of the sectors of interest to Colombia. For its part, Colombia will reduce tariffs gradually: $65 \%$ of all tariff lines will be zero when the Association Agreement takes effect, $20 \%$ of the tariff lines will be cut over a period of 5 years, and the remaining $5 \%$ of the tariff lines from 7 to 10 years. For example, in the case of cars and trucks, the tariff reduction schedule will take 7 years.

\section{Survey of previous studies}

Several studies evaluated the likely impacts of an Association Agreement between Colombia and the European Union or described the characteristics of bilateral trade. Buitrago (2007) estimated the employment embodied in Colombian exports and imports using direct employment coefficients from the 2004 supply and use table of DANE, trade statistics and household surveys. He concluded that employment embodied in exports and imports accounted for $12 \%$ and $18 \%$ of total employment, respectively. Most workers in the trade sector (63\%) had a medium (between 8 and 11 years of schooling) or higher (12 years of more) level of education. Employment embodied in exports to the European Union accounted for $10.5 \%$ of all employment generated by the export sector.

The National Planning Department (DNP, without date) estimated possible impacts of the Association Agreement on consumption, trade and GDP, using a country model calibrating the production structure of the Colombian economy. Results of these simulations show that as a result of the Association Agreement, real GDP would increase by $0.46 \%$, consumption by $0.26 \%$, exports by $0.71 \%$, imports by $1.73 \%$, labour income of low-skilled labour by $0.53 \%$, and the income of medium- and highskilled workers by $0.25 \%$.

Reina and Oviedo (2011) estimate the potential of Colombian exports to the European Union using indices on European Union import intensity and Colombian revealed comparative advantages. In the agricultural and food sector, Colombia has a comparative advantage and the European Union a high import demand for the following products: cacao, coffee, fruits, herbs and spices, honey, meat products, raw animal products and vegetable products, sugar and derivatives and tea. Within the other manufacturing industries, the products with export potential are paper, cardboard, perfumes, toiletries, cleaning products, plastic products, leather and leather products. These authors also stress that Colombia's lower 
import tariffs resulting from the Association Agreement will reduce the costs of intermediate inputs and capital goods from the European Union and enhance the competitiveness of Colombia's firms. Examples of these products are chemicals, industrial equipment, machines, pharmaceuticals and vehicles.

\section{Modelling the effects of the Association Agreement on Colombia}

This section extends the analysis of the above papers with an evaluation of the impact of trade liberalization resulting from the Association Agreement on Colombia, in terms of gains and losses of individual sectors and workers. This is done using the computable general equilibrium (CGE) model and database of the Global Trade Analysis Project (GTAP, version 8.0). In addition, the job market is modelled through microsimulations to estimate the effects of the Association Agreement on poverty and income distribution. The methods used for modelling are described below.

\section{Computable general equilibrium model}

The GTAP is a CGE model with multiple countries and products which maintains a database with trade flows, a global transportation sector, which monitors the difference between the CIF and FOB values of all shipped goods, and a global banking sector, which intermediates between global savings and investment. This model simulates the demand for consumption goods by households and that for intermediate goods by firms and government. The latter two also demand production factors capital, labour, land and natural resources (Hertel, 1997; Hertel and Tsigas, 1997).

The model simulations are done using the GTAP 8.0 database and General Equilibrium Modelling Package (GEMPACK). This software was developed by the Centre of Political Studies at Monash University (Harrison and Pearson, 1996). Goods are identified by country of origin. Consumers choose between domestic and imported goods from different geographic origins (Armington, 1969). The Armington hypothesis can model trade in a single good in two directions, meaning that the same good can be exported and imported simultaneously as domestic goods and are assumed to be imperfect substitutes of imported products.

Households sell qualified and non-qualified labour, capital, land and natural resources to firms, and receive an income in return. Consumer 
preferences are modelled using a constant difference of elasticities (CDE) utility function, with parameters depending on income and price elasticities. Following a decision tree, consumers decide on the quantity they will buy, and in turn how much they buy at home and import from different countries. To model these choices, a constant elasticity of substitution (CES) Armington function is incorporated into the CDE function. The maximization of this combined function gives the quantities consumed of goods of domestic origin and the quantities of goods imported from abroad.

Firm behaviour can also be modelled using a multi-stage technology tree. This tree shows the firm's demand for primary production factors (capital, qualified and non-qualified labour, land and natural resources) and intermediate inputs of domestic origin or imported from different countries. The separability assumption in the production process allows for simultaneous decisions on the consumption and inputs and each level, purchase without considering changes in these variables at other levels.

The acquisition of production factors and intermediate inputs in the production process is modelled using Leontief functions with fixed proportions. ${ }^{7}$ The separation between the two means that the optimal mix of factors does not change with the price of intermediate inputs, and they cannot be substituted for each other. Production factors are mobile across sectors within a country (albeit imperfectly) but not across countries. The quantity of each production factor used is determined by the minimization of costs using CES production functions integrated in the Leontief function.

The CES functions fix the demand for domestic and imported inputs from different geographic origins (see figure 1). The firm's decision on how much it will sell on the domestic market and how much it will export is modelled using the constant elasticity of transformation (CET) function, which is similar to a CES function.

One of the main parameters in models with an Armington type of preferences is the elasticities of substitution between domestic and imported goods. Their value will affect the outcomes of the model, in particular when modelling the effects of tariff cuts. Recent studies show that these elasticities are relatively high. The substitution elasticity between imports of different origins is double those of domestic and imported goods. This helps to avoid the complementarity effects. The GTAP models assume the same substitution elasticities in all countries.

7 This equals a CES function with substitution elasticities converging to zero. 
The closure of this model, meaning determining which variables are defined as exogenous or endogenous, was done in various steps according to the design of the simulations. Additional assumptions include the existence of unemployment in Colombia and an annual growth rate of real GDP in the European Union of $-0.3 \%$.

\section{Micro simulation methodology}

For the analysis of the impact of the Association Agreement on unemployment, poverty and inequality at the micro-level, we combined the aggregate results for the labour market obtained from the CGE model with a micro simulation model based on data from the large integrated household survey (2010). This macro-micro simulation approach follows that of Bourguignon, Robilliard and Robinson. (2008). ${ }^{8}$

The two models are linked sequentially using the following macro variables of the labour market: unemployment rate by labour category, employment structure by sector and occupational category (employed or not employed), and relative and average wages. In this context, microsimulation is based on the principle that changes in the labour market at the macro-level can be simulated with the random selection process, and that the labour market is segmented. The workers that move within the labour market are chosen randomly, depending on the macro conditions of the CGE model. The sum of the movements between labour market segments resemble the changes in labour markets estimated using the CGE model. The counterfactual household incomes are calculated from the new labour and non-labour incomes. ${ }^{9}$

The model for the labour market allows us to estimate employment levels by sector. These are used in combination with a logit model to estimate who will be employed next in each sector. Subsequently, we selected those workers who have the highest probability to be hired. Table VIII.10 shows the results of the logit model for each demographic cohort. All estimated variables are significant with the expected sign. The higher unemployment rate in urban compared to rural areas can explain the sign of the variable "urban population".

8 Other studies use similar methodologies for other Latin American countries. Wong and Kulmer (2008) estimated the impact of fiscal policies and trade opening for Ecuador for 2005 and 2006. Berrettoni and Cicowiez (2005) evaluated the effect of an agreement between the Andean Community and Mercosur, with the focus on the impact on poverty, unemployment and inequality.

9 As this process is random, the simulation is repeated several times using a Monte Carlo procedure to generate confidence intervals. 
Table VIII.10

Estimation results on the probability of employment

\begin{tabular}{|c|c|c|c|}
\hline \multirow{2}{*}{ Variables } & (1) & $(2)$ & (3) \\
\hline & Head of household & Spouse & Others \\
\hline \multirow[t]{2}{*}{$\operatorname{Sex}(1=\operatorname{man})$} & $0.641^{* * *}$ & $0.302^{* * *}$ & $0.218^{* * *}$ \\
\hline & $(25.29)$ & $(7.938)$ & $(14.54)$ \\
\hline \multirow[t]{2}{*}{ Man } & $0.0493^{* * *}$ & $0.0651^{* * *}$ & $0.0223^{* * *}$ \\
\hline & $(12.39)$ & $(10.71)$ & $(6.413)$ \\
\hline \multirow[t]{2}{*}{ Man2 } & $-0.000494^{* * *}$ & $-0.000372^{* * *}$ & $1.20 \mathrm{e}-05$ \\
\hline & $(-11.64)$ & $(-4.949)$ & $(0.246)$ \\
\hline \multirow[t]{2}{*}{ Civil status $(1=$ married $)$} & $-0.0958^{* * *}$ & 0.0992 & $0.212^{* * *}$ \\
\hline & $(-3.708)$ & $(0.412)$ & (10.10) \\
\hline \multirow[t]{2}{*}{ Qualification (1= qualified) } & $0.124^{* * *}$ & $0.193^{* * *}$ & $-0.0665^{* * *}$ \\
\hline & $(5.023)$ & $(6.781)$ & $(-3.975)$ \\
\hline \multirow[t]{2}{*}{ Urban (1= urban population) } & $-0.872^{* * *}$ & -0.0400 & $-0.491^{* * *}$ \\
\hline & $(-14.37)$ & $(-0.768)$ & $(-10.74)$ \\
\hline \multirow[t]{2}{*}{ Children below the age of 18} & $0.0164^{* *}$ & $-0.0186^{*}$ & $0.0531^{* * *}$ \\
\hline & $(1.980)$ & $(-1.946)$ & (7.821) \\
\hline \multirow[t]{2}{*}{ Socioeconomic class } & $0.0488^{* * *}$ & $0.0537^{* * *}$ & $0.0248^{* * *}$ \\
\hline & $(7.412)$ & $(6.620)$ & $(4.871)$ \\
\hline \multirow[t]{2}{*}{ Remittances } & $-0.904^{* * *}$ & $-0.403^{* * *}$ & $-0.682^{* * *}$ \\
\hline & $(-15.50)$ & $(-3.420)$ & $(-9.907)$ \\
\hline \multirow[t]{2}{*}{ Constant } & $-2.738^{* * *}$ & $-6.350^{* * *}$ & $-5.146^{* * *}$ \\
\hline & $(-15.96)$ & $(-14.90)$ & $(-30.97)$ \\
\hline Observations & 178614 & 75143 & 143808 \\
\hline
\end{tabular}

Source: Prepared by authors.

Note: Robust $z$-statistics are shown in parentheses. Significance levels: ${ }^{\star \star \star} p<0,01,{ }^{\star \star} p<0,05,{ }^{\star} p<0,1$.

The wages of these newly hired workers must be estimated, as they cannot be observed directly. For this purpose, we estimated a wage equation, based on Mincer (1973). The data on the wages of those people who actually work cannot be used directly because of a selection bias in the sample. To solve this problem, a two-stage estimation procedure based on Heckman (1979) is applied.

\section{Two scenarios}

The starting point for the two scenarios is 2011 when Colombia and the European Union began to apply bilateral tariffs. As the GTAP 8.0 database levels of protection are for 2007, these are updated to 2011 using the database of the Latin American Integration Association (LAIA) for tariffs for Colombia and the TARIC database for those of the European Union. From here, two counterfactual scenarios were defined: 
Scenario 1: Association Agreement between Colombia and the European Union. This scenario simulates the effects of the complete removal of bilateral tariffs between Colombia and the European Union, except for import sensitive products for both countries, such as dairy products, fruits, sugar and vegetables in the case of the European Union (see table VIII.9). In the latter case, the tariff cuts equal the most favourable treatment to be given to these products in the future. For example, for fruits and vegetables, we supposed a 35\% tariff cut, equal to the tariff reduction from 176 to 114 euros per ton in 2014.

Scenario 2: Scenario 1 plus free trade agreements between Colombia and the United States and Peru and the United States. This scenario adds tariff cuts between Colombia and the United States and between Peru and the United States, except for import-sensitive products for these two Andean countries (rice, wheat, other cereals, oilseeds, other crops, meat, dairy products, textiles, clothing and transport equipment).

In addition to the zero tariff, we considered three special cases in which we calculate the tariff equivalent of specific duties and quotas: fruits and vegetables (with a European Union tariff cut from 9\% to 5.8\%), beef and sugar (reductions from $0.7 \%$ to $0.5 \%$ and $175 \%$ to $31 \%$, respectively).

\section{Macroeconomic and social outcomes of the Association Agreement with the European Union}

In this section, we present simulation results of the two scenarios in three domains: macroeconomics, international trade and social areas. These results help answer the question of how inclusive the Association Agreement between Colombia and the European Union really is, for example in terms of employment.

\section{Macroeconomic outcomes}

The Association Agreement with the European Union seems to have a limited static impact on Colombia's economy, which varies from $0.04 \%$ to $1.26 \%$ of GDP depending on whether the FTA between Colombia and the United States is also considered (see table VIII.11). The static impact on all other macroeconomic variables is also greater (exceeding $1 \%$ ) under scenario 2 . The greatest differences in outcomes between scenarios 1 and 2 are in exports and imports: both increase by 4 percentage points more when Colombia bilaterally opens markets with the European Union and the United States rather than only with the European Union. 
Table VIII.11

Colombia: outcomes of simulations of an association agreement with the European Union

(Changes in relation to the baseline)

\begin{tabular}{lcccccc}
\hline Scenarios & $\mathrm{C}$ & $\mathrm{I}$ & $\mathrm{G}$ & $\mathrm{X}$ & $\mathrm{M}$ & $\mathrm{GDP}$ \\
\hline 1. Complete liberalization (only European Union) & 0.05 & 0.13 & 0.05 & 1.26 & 1.32 & 0.04 \\
\hline $\begin{array}{l}\text { 2. Likely liberalization (sensitive products } \\
\text { European Union + United States) }\end{array}$ & 1.21 & 1.49 & 1.39 & 5.44 & 5.33 & 1.26 \\
\hline
\end{tabular}

Source: Prepared by authors on the basis of calculations with the GTAP 8.0 database.

Note: $\quad \mathrm{C}=$ private consumption; $\mathrm{I}=$ gross fixed capital formation; $\mathrm{G}=$ government expenditure; $\mathrm{X}=$ exports; $\mathrm{M}=$ imports and $\mathrm{GDP}=$ gross domestic product.

One reason for the increase in GDP and other macroeconomic variables is the lower price of imported inputs following the implementation of both agreements. Under scenario 2, the lower tariffs on imported inputs from the United States will favour Colombian exports to the European Union. The latter will increase much more under scenario 2 than under scenario 1 (see next section).

\section{Effects on international trade}

As predicted, scenario 2 is comparatively more advantageous for Colombia than scenario 1. Under scenario 2, market access for Colombian exports will improve not only to the European Union market, but also to the United States market. Both destinations account for more than half of Colombia's exports. In quantitative terms, the impact on both exports and imports is four times as great under scenario 2 (implementation of trade agreements with both the European Union and the United States) (5.3-5.4\%) than under scenario 1 (Association Agreement with the European Union only) (1.3\%).

Exports of all products increase under both scenarios, with the exception of mining products. The largest increases in foreign sales from scenario 1 to 2 are observed for light and heavy manufactures. Exports increase in the first case from $1.4 \%$ to $14.5 \%$ and in the second from $2.3 \%$ to $8.1 \%$. In the case of imports, the most significant growth takes place in the case of farming products and light manufactures. This latter sector represents $9 \%$ of total Colombian imports (see table VIII.12).

Exports from Colombia to the European Union expand by $1.9 \%$ and $4 \%$ under scenarios 1 and 2, respectively. The largest increases in exports will occur in sugar (over 200\%), and fruits and vegetables (over 10\%). The substantial increase in sugar shipments to the European Union has little impact on total exports, since this product accounts for only $0.1 \%$ of the total. In contrast, the increase in fruit and vegetable exports (including bananas) has a greater impact on total foreign sales as this category accounts for $7.3 \%$ of total exports. The exports of other crops will not increase under either 
scenario, but exporters of these products will have more regulatory stability in a context where they will likely lose the SGP+ treatment. The exports of meat, vegetable oil, dairy and other food products (which include coffee) may increase by $1.9 \%$ under scenario 1 and by $5 \%$ under scenario 2 . The largest increases in the exports of manufactures are expected for textiles and clothing, chemicals, metal products, transport equipment, and machinery.

Table VIII.12

Colombia: impact of scenarios 1 and 2 on international trade by broad sector (Changes in relation to the baseline)

\begin{tabular}{|c|c|c|c|c|c|c|}
\hline \multirow[t]{2}{*}{ Sectors } & \multicolumn{2}{|c|}{$\begin{array}{c}\text { Composition of } \\
\text { goods and services } \\
\text { (percentage of total) }\end{array}$} & \multicolumn{2}{|c|}{$\begin{array}{c}\text { Scenario } 1 \\
\text { Association } \\
\text { Agreement Colombia- } \\
\text { European Union-27 }\end{array}$} & \multicolumn{2}{|c|}{$\begin{array}{c}\text { Scenario } 2 \\
\text { Association } \\
\text { Agreement Colombia- } \\
\text { European Union 27; } \\
\text { FTA Colombia- } \\
\text { United States }\end{array}$} \\
\hline & Exports & Imports & Exports & Imports & Exports & Imports \\
\hline Goods & 89.4 & 87.0 & 1.3 & 1.6 & 5.6 & 6.1 \\
\hline Farming & 10.8 & 5.1 & 1.2 & 0.7 & 1.8 & 10.0 \\
\hline Mining and extraction & 29.2 & 0.6 & 0.0 & 0.9 & -0.1 & 3.9 \\
\hline Light manufactures & 14.1 & 8.7 & 1.4 & 1.0 & 14.5 & 6.0 \\
\hline Heavy manufactures & 35.2 & 72.6 & 2.3 & 1.7 & 8.1 & 5.9 \\
\hline Services & 10.6 & 13.0 & 1.3 & -0.3 & 4.6 & 0.2 \\
\hline Goods and services & 100.0 & 100.0 & 1.3 & 1.3 & 5.5 & 5.4 \\
\hline
\end{tabular}

Source: Prepared by authors, on the basis of calculations with the Global Trade Analysis Project (GTAP) multisector model and updated database.

a Data of the baseline year are for 2007, which is the reference year of the GTAP database version 8.0 and the main data source for the model.

Exports of mining products stagnate under both scenarios. This sector accounts for $48 \%$ of Colombia's exports to the European Union in 2011. As the implementation of the Association Agreement will cut tariffs for many products of interest to Colombian exports to the European Union, it is likely that the structure of the export basket will change in favour of agricultural products, such as coffee and its derivatives, whose share fell from $21 \%$ to $10 \%$ between 2005 and 2011 according to data from the United Nations Commodity Trade Statistics Database (COMTRADE).

Colombian imports from the European Union increase by 35\% and $27 \%$ under scenarios 1 and 2, respectively. In other words, imports from the European Union will increase less when Colombia also negotiates a free trade deal with the United States, which would allow it to buy cheaper imports from this market. The sectors that stand to benefit most from the simultaneous opening-up of the market to the European Union and the United States are transport equipment, metal products, other manufactures, chemicals, and machinery and equipment. These categories represent more than half of total imports of Colombian goods and services. 
Colombian imports of European Union services, which account for one third of total imports of goods and services, tend to stagnate under both scenarios. For their part, imports of agricultural and mining products increase over two digits, but their impact on total imports is small as their weight in total imports is below $1 \%$.

\section{Social impacts}

The impact of the two trade liberalization scenarios on poverty and income distribution depends on various factors. A first element is the dynamics of the export sectors linked to the European Union and the United States. A second factor is the sectoral employment structure and qualification of the workforce in each sector. A third element is the degree of backward linkages, as estimated by the employment requirements per million dollars of production.

The employment structure by industry shows that the services sector is the main employer, accounting for more than two thirds of total employment. The second and third largest employers are agriculture $(12 \%)$ and light manufacturing $(11 \%)$. It is no coincidence that these sectors are also those that have the highest employment requirements: in agriculture, US\$ 1 million of production generates 293 jobs (see table VIII.13). The next two sectors with the highest employment requirement are light manufacturing and services. The analysis on the social impact of trade liberalization therefore needs to focus on these three sectors.

Table VIII.13

Employment by industry in Colombia: persons employed, level of qualification and employment content of production, 2010

(Number of workers and percentages)

\begin{tabular}{lrrrrr}
\hline & $\begin{array}{c}\text { Workers } \\
\text { (thousands) }\end{array}$ & $\begin{array}{c}\text { Share of } \\
\text { non-qualified }\end{array}$ & $\begin{array}{c}\text { Share of } \\
\text { qualified }\end{array}$ & Participation & $\begin{array}{c}\text { Number of workers } \\
\text { per million dollars } \\
\text { of production } \\
\text { (2005) }\end{array}$ \\
\hline Goods & 6229 & 89.8 & 10.2 & 32.4 & 141 \\
\hline Agriculture & 2311 & 97.0 & 3.0 & 12.0 & 293 \\
\hline Mining and extraction & 931 & 94.5 & 5.5 & 4.8 & 32 \\
\hline Light manufacturing & 2112 & 86.2 & 13.8 & 11.0 & 127 \\
\hline Heavy manufacturing & 875 & 74.5 & 25.5 & 4.6 & 54 \\
\hline Services & 12978 & 71.7 & 28.3 & 67.6 & 98 \\
\hline Goods and services & 19207 & 77.6 & 22.4 & 100.0 & 131 \\
\hline
\end{tabular}

Source: Prepared by authors on the basis of information from the National Administrative Department of Statistics (DANE), 2010 Household Survey and 2005 Input-output table. 
At the product level, the largest employment impact of trade liberalization is on fruits and vegetables. This latter group includes the coffee value chain, which has strong backward linkages as it generates 25 indirect jobs for every direct job in this activity. Most of the coffee value chain and indirect jobs are within the agricultural sector, including sowing, recollection, drying, threshing, selection, roasting, grinding and packaging. Further down the value chain is the processing part, such as the production of instant coffee or decaffeinated coffee, which also creates employment. Lastly, processed coffee is used as an input in food industries (such as candy and drinks) and pharmaceutical products. Other products that concentrate employment in the export sector are food products, textiles, metal products and mining.

Goods exports to the European Union accounted for the employment of 444,000 workers in 2005 and 530,000 in 2011. The Association Agreement with the European Union should boost export-related employment to 556 thousand people. This means that from 2005 to 2011, employment associated with exports to the European Union grew by $11 \%$ per year. Moreover, the simulation of scenario 2 shows that employment should increase by $5 \%$ compared with the 2011 baseline.

The microsimulations of the social impacts of scenario 2, based on the assumption of an Association Agreement with the European Union and an FTA with the United States show interesting results (see table VIII.14). First, the unemployment rate falls by 2.6 percentage points to $9.2 \%$. Second, the trade agreements have a pro-poor outcome, as the poverty rate declines by $1.7 \%$. Third, inequality diminishes marginally as indicated by the GINI index, which goes down from 0.540 to 0.528 (see table VIII.14). Similar calculations for sectors that dominate exports to the European Union (food and other crops, textiles, metal products and mining) indicate that this pro-poor outcome is generalized. The Association Agreement with the European Union and the FTA with the United States boost employment and family income, and in turn reduce poverty and inequality.

Table VIII.14

Colombia: microsimulation results

(Percentages)

\begin{tabular}{lccc}
\hline & $\begin{array}{c}\text { Baseline } \\
(\mathrm{A})\end{array}$ & $\begin{array}{c}\text { Scenario 2 } \\
\text { (B) }\end{array}$ & $\begin{array}{c}\text { Change in percentage points } \\
\text { C= A-B }\end{array}$ \\
\hline Total poverty & 30.4 & 28.7 & -1.7 \\
\hline - Extreme poverty (US\$ 2 per day) & 16.8 & 15.4 & -1.4 \\
\hline - Extreme poverty (US\$ 1 per day) & 5.4 & 4.6 & -0.8 \\
\hline Unemployment rate & 11.8 & 9.2 & -2.6 \\
\hline Gini coefficient & 0.540 & 0.528 & -2.3
\end{tabular}

Source: Prepared by authors on the basis of the microsimulation model. 


\section{E. Conclusions}

This chapter assesses the backward linkages and inclusive character of predominant sectors in Colombian exports to the European Union. This was done using data from the DANE 2005 input-output table and 2005 employment matrix, and an evaluation of the employment and other social effects of the Association Agreement with the European Union, using a computable general equilibrium and a microsimulations model.

The degree of domestic backward linkages of Colombian exports to the European Union is evaluated using the Rasmussen Hirschman index, the Herfindahl-Hirschman index and the share in total exports at the industry level. Results show that out of ten main predominant sectors in exports to the European Union, seven have backward linkages that are above the average of the economy: coffee and threshing, basic metals, meat and fish, leather and footwear, textiles and clothing and metal products. These sectors with above average linkages represent $38 \%$ of Colombian exports to the European Union.

Sectors with above average linkages are also those that require more employment per one million United States dollars' worth of production and exports. Among those that are most important in European Union exports are coffee and threshing (338 workers per US\$ 1 million of production), meat and fish (124), leather and footwear (149) and textiles and clothing (128).

The coffee cluster is an interesting case of an export sector with extensive backward linkages. Every direct job in this sector requires 25 indirect jobs in industries selling inputs to the coffee cluster. These supplying industries include agricultural activities (sowing, harvesting, drying, threshing, grinding), services (business services, distribution, real-estate services, transport, water and telecommunication) and manufacturing (chemicals, metal products, food and textiles).

The export sector accounted for the employment of up to 2 million people, or $13 \%$ of total employment in 2005. Exports to the European Union represent one quarter of total employment in the export sector, while only $15 \%$ of total exports are sold to the region. Exports to the United States embody $42 \%$ of export-related employment, but represent $39 \%$ of total exports. This comparison shows that exports to the European Union are of "better quality" than exports to the United States, as the former has deeper backward linkages and creates more indirect employment.

For the evaluation of the economic and social impacts of the trade agreements with the European Union and the United States, a multi-sector and multi-product computable general equilibrium model is calibrated for two possible scenarios. The first is an Association Agreement with the European Union, and the second an Association Agreement with the European Union plus a free trade agreement with the United States. In both cases, Colombia's 
sensitivities were taken into account for agricultural products (dairy products, cereals, wheat and rice) and textiles and clothing. Moreover, in the simulation it is assumed that Peru and Central American countries had also concluded free trade agreements with both partners. The CGE calculations are complemented with a microsimulations model to estimate the effects of the trade agreements on poverty and income distribution.

The most positive outcomes are produced under scenario 2, in which Colombia implements trade agreements with both the European Union and the United States. This scenario is also highly plausible as both parties have approved the agreement, which in turn has been ratified by the European Parliament and Colombian Congress. The macroeconomic simulation results show that, as a result of scenario 2, Colombian GDP would increase by $1.3 \%$, exports by $5.3 \%$, while private consumption, investment and government expenditure would also rise.

It is shown that the coffee value chain promotes the inclusion of SMEs. In the case of the meat and fish sectors, the agreement with the European Union offers new opportunities to expand the chain. In this case, the challenge for the Government of Colombia and private sector is to fully exploit the expanded quotas negotiated as part of the trade agreement. The coal sector will benefit little from the trade agreement, as it already accounts for $48 \%$ of total exports to the European Union in 2011. Moreover, the coal sector has few backward linkages and generates little indirect employment (1.7 indirect jobs for every direct one). The coal sector has a dual character in terms of large businesses coexisting with small and informal firms, which have few linkages.

The pending challenges are to increase exports by those sectors with strong domestic backward linkages and high employment requirements (especially indirect employment). This is the case of exports of light manufactures (vegetable oil, food, drinks and tobacco, textiles, clothing and footwear). These sectors have an average employment requirement of 127 workers per one million dollars' worth of production.

The microsimulations model shows that the free trade agreements with the European Union and the United States have favourable social outcomes. They reduce unemployment by 2.1 percentage points and poverty by 1.7 percentage points. Moreover, both agreements slightly reduce inequality, as measured by the reduction of the GINI coefficient.

It should be kept in mind that the results presented in this chapter are of a static nature. They do not consider, for example, the dynamic second round effects that arise from an increase in investment. The economic and social effects of the trade agreements are therefore probably larger than estimated here, in particular for those sectors with strong backward linkages with the rest of the economy. 


\section{Bibliography}

Armington, P.S. (1969), "A theory of demand for products distinguished by place of production", Staff Papers, vol. 16, No. 1, Washington, D.C., International Monetary Fund.

Berrettoni, D. y M. Cicowiez (2005), "El acuerdo de libre comercio MERCOSURComunidad Andina de Naciones: Una evaluación cuantitativa", Estudios estadísticos series, No. 33 (LC/L.2310-P), Santiago, Chile, Economic Commission for Latin America and the Caribbean (ECLAC). United Nations publication, Sales No. S.05.II.G.59.

Bourguignon, F., A.-S. Robilliard and S. Robinson (2008), "Examining the social impact of the Indonesian financial crisis using a macro-micro model", Paris, Paris Dauphine University.

Buitrago, L.M. (2007), Colombia: Contenido de trabajo de las exportaciones e importaciones, International Gender and Trade Network, Latin American Chapter.

Durán Lima, J.E. y M. Alvarez (2011), “Manual de comercio exterior y política comercial: nociones básicas, clasificaciones e indicadores de posición y dinamismo", Documento de proyecto, ECLAC, Santiago.

Greene, W.H. (2003), Econometric Analysis, Upper-Saddle River, Prentice Hall.

Harrison, W.J. and K.R. Pearson (1996), "Computing solutions for large general equilibrium models using GEMPACK", Computational Economics, vol. 9, No. 2, Society for Computational Economics, August.

Heckman, J.J. (1979), "Sample selection bias as a specification error", Econometrica, vol. 47, No. 1, New York, The Econometric Society.

Hertel, T. (ed.) (1997), Global Trade Analysis: Modeling and Applications, New York, Cambridge University Press.

Hertel, T. and M. Tsigas (1997), "Structure of GTAP", unpublished [online] https:/ / www.gtap.agecon.purdue.edu/ resources/res_display.asp?RecordID $=413$.

Mincer, J.A. (1973), Schooling, Experience and Earnings, New York, National Bureau of Economic Research.

Reina, M. and S. Oviedo (2011), "Colombia y el TLC con la Unión Europea”, Policy Paper, No. 4, Bogota, Friedrich Ebert Stiftung.

Schuschny, A. (2005), “Tópicos sobre el Modelo de Insumo-Producto: teoría y aplicaciones", Serie estudios estadísticos y prospectivos, No. 37, CEPAL, Santiago.

Schuschny, A., J. Durán and C. de Miguel (2007), “El modelo GTAP y las preferencias arancelarias en América Latina y el Caribe: Reconciliando su año base con la evolución reciente de la agenda de liberación regional", Manuales series, No. 53 (LC/L.2679-P), Santiago, Chile, February. United Nations publication, Sales No. S.07.II.G.29.

Wong, S. and V. Kulmer (2008), "Integración comercial con la Unión Europea e impactos sobre la pobreza en el Ecuador", Projects document, No. 357 (LC/W.357), Santiago, Chile, Economic Commission for Latin America and the Caribbean (ECLAC). 


\section{Publicaciones recientes de la CEPAL ECLAC recent publications}

\section{www.cepal.org/publicaciones}

\section{Informes periódicos institucionales / Annual reports}

También disponibles para años anteriores / Issues for previous years also available

- Anuario Estadístico de América Latina y el Caribe 2013 / Statistical Yearbook for Latin America and the Caribbean 2013, 226 p.

- Balance Preliminar de las Economías de América Latina y el Caribe 2013, 92 p. Preliminary Overview of the Economies of Latin America and the Caribbean 2013, 92 p.

- Panorama Social de América Latina, 2013, 226 p. Social Panorama of Latin America, 2013, 220 p.

- Panorama de la Inserción Internacional de América Latina y el Caribe 2013, 128 p. Latin America and the Caribbean in the World Economy 2013, 122 p.

- Estudio Económico de América Latina y el Caribe 2013, 220 p. Economic Survey of Latin America and the Caribbean 2013, 210 p.

- La Inversión Extranjera Directa en América Latina y el Caribe 2012, 152 p. Foreign Direct Investment in Latin America and the Caribbean 2012, 142 p.

\section{Libros y documentos institucionales} Institutional books and documents

- Pactos para la igualdad: hacia un futuro sostenible, 2014, 340 p. Covenants for Equality: Towards a sustainable future, 2014, 330 p.

- Integración regional: hacia una estrategia de cadenas de valor inclusivas, 2014, 226 p. Regional Integration: Towards an inclusive value chain strategy, 2014, 218 p. Integração regional: por uma estratégia de cadeias de valor inclusivas, 2014, 226 p.

- Prospectiva y desarrollo: el clima de la igualdad en América Latina y el Caribe a 2020, 2013, 72 p.

- Comercio internacional y desarrollo inclusivo: construyendo sinergias, 2013, 210 p.

- Cambio estructural para la igualdad: una visión integrada del desarrollo, 2012, 330 p. Structural Change for Equality: an integrated approach to development, 2012, 308 p.

- La hora de la igualdad: brechas por cerrar, caminos por abrir, 2010, $290 \mathrm{p}$. Time for Equality: closing gaps, opening trails, 2010, 270 p. A Hora da lgualdade: Brechas por fechar, caminhos por abrir, 2010, 268 p.

\section{Libros de la CEPAL / ECLAC books}

126 Planificación, prospectiva y gestión pública: reflexiones para la agenda del desarrollo, Jorge Máttar, Daniel E. Perrotti (eds.), 2014, 250 p.

125 La crisis latinoamericana de la deuda desde la perspectiva histórica, José Antonio Ocampo, Barbara Stallings, Inés Bustillo, Helvia Velloso, Roberto Frenkel, 2014, 174 p. 
124 La integración de las tecnologías digitales en las escuelas de América Latina y el Caribe: una mirada multidimensional, Guillermo Sunkel, Daniela Trucco, Andrés Espejo, 2014, 170 p.

123 Fortalecimiento de las cadenas de valor como instrumento de la política industrial: metodología y experiencia de la CEPAL en Centroamérica, Ramón Padilla Pérez (ed.), 2014, 390 p.

122 Cambio estructural y crecimiento en Centroamérica y la República Dominicana: un balance de dos décadas, 1990-2011, Hugo E. Beteta y Juan Carlos Moreno-Brid, 2014, 398 p.

\section{Copublicaciones / Co-publications}

- Decentralization and Reform in Latin America: Improving Intergovernmental Relations, Giorgio Brosio and Juan Pablo Jiménez (eds.), ECLAC / Edward Elgar Publishing, United Kingdom, 2012, 450 p.

- Sentido de pertenencia en sociedades fragmentadas: América Latina desde una perspectiva global, Martín Hopenhayn y Ana Sojo (comps.), CEPAL / Siglo Veintiuno, Argentina, 2011, 350 p.

- Las clases medias en América Latina: retrospectiva y nuevas tendencias, Rolando Franco, Martín Hopenhayn y Arturo León (eds.), CEPAL / Siglo XXI, México, 2010, 412 p.

- Innovation and Economic Development: The Impact of Information and Communication Technologies in Latin America, Mario Cimoli, André Hofman and Nanno Mulder, ECLAC / Edward Elgar Publishing, United Kingdom, 2010, 472 p.

\section{Coediciones / Co-editions}

- Perspectivas de la agricultura y del desarrollo rural en las Américas: una mirada hacia América Latina y el Caribe 2014, CEPAL / FAO / IICA, 2013, 220 p.

- Perspectivas económicas de América Latina 2014: logística y competitividad para el desarrollo, CEPAL/OCDE, 2013, $170 \mathrm{p}$.

Latin American Economic Outlook 2014: Logistics and Competitiveness for Development, ECLAC/ OECD, 2013, $164 p$.

- Juventud y bono demográfico en Iberoamérica, Paulo Saad, Tim Miller, Ciro Martínez y Mauricio Holz, CEPAL/OIJ/UNFPA, 2012, $96 \mathrm{p}$.

- Perspectivas económicas de América Latina 2013: políticas de pymes para el cambio estructural, OCDE/ CEPAL, 2012, 192 p.

Latin American Economic Outlook 2013: SME Policies For Structural Change, OECD / ECLAC, 2012, 186 p.

\section{Cuadernos de la CEPAL}

101 Redistribuir el cuidado: el desafío de las políticas, Coral Calderón Magaña (coord.), 2013, 460 p.

101 Redistributing care: the policy challenge, Coral Calderón Magaña (coord.), 2013, 420 p.

100 Construyendo autonomía: compromiso e indicadores de género, Karina Batthyáni Dighiero, 2012, $338 \mathrm{p}$.

99 Si no se cuenta, no cuenta, Diane Alméras y Coral Calderón Magaña (coordinadoras), 2012, 394 p.

98 Macroeconomic cooperation for uncertain times: The REDIMA experience, Rodrigo Cárcamo-Díaz, $2012,164 p$.

97 El financiamiento de la infraestructura: propuestas para el desarrollo sostenible de una política sectorial, Patricio Rozas Balbontín, José Luis Bonifaz y Gustavo Guerra-García, 2012, 414 p.

\section{Documentos de proyecto / Project documents}

- La economía del cambio climático en la Argentina: primera aproximación, 2014, 240 p.

- La economía del cambio climático en el Ecuador 2012, 2012, 206 p. 
- Economía digital para el cambio estructural y la igualdad, 2013,130 p

The digital economy for structural change and equality, 2014, $128 \mathrm{p}$.

- Estrategias de desarrollo bajo en carbono en megaciudades de América Latina, Joseluis Samaniego y Ricardo Jordán (comps.), María Teresa Ruiz-Tagle (ed.), 2013, 184 p.

- La cooperación entre América Latina y la Unión Europea: una asociación para el desarrollo, José E. Durán Lima, Ricardo Herrera, Pierre Lebret y Myriam Echeverría, 2013, 157 p.

\section{Cuadernos estadísticos de la CEPAL}

41 Los cuadros de oferta y utilización, las matrices de insumo-producto y las matrices de empleo. Solo disponible en CD, 2013.

40 América Latina y el Caribe: Índices de precios al consumidor. Serie enero de 1995 a junio de 2012. Solo disponible en CD, 2012.

\section{Series de la CEPAL / ECLAC Series}

Asuntos de Género / Comercio Internacional / Desarrollo Productivo / Desarrollo Territorial / Estudios Estadísticos / Estudios y Perspectivas (Bogotá, Brasilia, Buenos Aires, México, Montevideo) / Studies and Perspectives (The Caribbean, Washington) / Financiamiento del Desarrollo / Gestión Pública / Informes y Estudios Especiales / Macroeconomía del Desarrollo / Manuales / Medio Ambiente y Desarrollo / Población y Desarrollo / Política Fiscal / Políticas Sociales / Recursos Naturales e Infraestructura / Reformas Económicas / Seminarios y Conferencias.

\section{Revista CEPAL / CEPAL Review}

La Revista se inició en 1976, con el propósito de contribuir al examen de los problemas del desarrollo socioeconómico de la región. La Revista CEPAL se publica en español e inglés tres veces por año.

CEPAL Review first appeared in 1976, its aim being to make a contribution to the study of the economic and social development problems of the region. CEPAL Review is published in Spanish and English versions three times a year.

\section{Observatorio demográfico / Demographic Observatory}

Edición bilingüe (español e inglés) que proporciona información estadística actualizada, referente a estimaciones y proyecciones de población de los países de América Latina y el Caribe. Desde 2013 el Observatorio aparece una vez al año.

Bilingual publication (Spanish and English) proving up-to-date estimates and projections of the populations of the Latin American and Caribbean countries. Since 2013, the Observatory appears once a year.

\section{Notas de población}

Revista especializada que publica artículos e informes acerca de las investigaciones más recientes sobre la dinámica demográfica en la región. También incluye información sobre actividades científicas y profesionales en el campo de población.

La revista se publica desde 1973 y aparece dos veces al año, en junio y diciembre.

Specialized journal which publishes articles and reports on recent studies of demographic dynamics in the region. Also includes information on scientific and professional activities in the field of population.

Published since 1973, the journal appears twice a year in June and December. 
Las publicaciones de la CEPAL están disponibles en:

ECLAC Publications are available in:

\section{www.cepal.org/publicaciones}

También se pueden adquirir a través de:

They can also be ordered through:

$$
\text { www.un.org/publications }
$$

United Nations Publications

PO Box 960

Herndon, VA 20172

USA

Tel. (1-888)254-4286

Fax (1-800)338-4550

Contacto / Contact. publications@un.org

Pedidos / Orders: order@un.org 


\section{Global value chains and world trade}

Prospects and challenges for Latin America

RENÉ A. HERNÁNDEZ JORGE MARIO MARTINEZ-PIVA NANNO MULDER

Editors
Scant empirical evidence is available on how the Latin American and Caribbean region participates in global value chains (GVCs) and what

drives this process. Frequent questions in this connection are: How has the spread of information and communications technologies and free trade agreements facilitated the region's participation in GVCs? To what extent do small firms participate in GVCs? What learning mechanisms and production and technological feedbacks operate in different types of GVCs? How can countries and firms take advantage of upgrading processes in GVCs? What role do policies play to influence these processes?

To address some of these questions, four international organizations (the Economic Commission for Latin America and the Caribbean (ECLAC), the Inter-American Development Bank (IADB), the Organization for Economic Cooperation and Development (OECD) and the World Bank), in partnership with Colegio de México, organized a joint conference in 2012 on Latin America's prospects for upgrading in global value chains. This volume contains a selection of the original research presented at that meeting. The evidence shows that the participation of the region in GVCs remains small but has increased since the 2008 economic crisis, and that the benefits of the participation in these chains largely depend on the region's position and the GVC governance structure. Another key element of potential gains is the endogenous efforts of governments and firms to deliberately create or strengthen technological capabilities, learning trajectories, innovation, knowledge diffusion and workforce development.

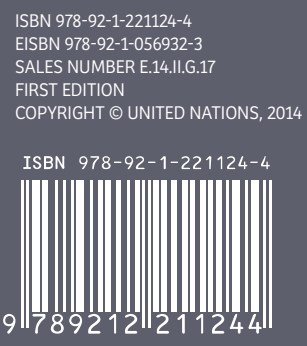

